\title{
Ischemia and reperfusion-induced damage of the isolated mouse heart : involvement of type IIA secretory phospholipase A2
}

Citation for published version (APA):

de Windt, L. J. (1999). Ischemia and reperfusion-induced damage of the isolated mouse heart: involvement of type IIA secretory phospholipase A2. [Doctoral Thesis, Maastricht University]. Universiteit Maastricht. https://doi.org/10.26481/dis.19991222lw

Document status and date:

Published: 01/01/1999

DOI:

10.26481/dis.19991222lw

Document Version:

Publisher's PDF, also known as Version of record

Please check the document version of this publication:

- A submitted manuscript is the version of the article upon submission and before peer-review. There can be important differences between the submitted version and the official published version of record.

People interested in the research are advised to contact the author for the final version of the publication, or visit the DOI to the publisher's website.

- The final author version and the galley proof are versions of the publication after peer review.

- The final published version features the final layout of the paper including the volume, issue and page numbers.

Link to publication

\footnotetext{
General rights rights.

- You may freely distribute the URL identifying the publication in the public portal. please follow below link for the End User Agreement:

www.umlib.nl/taverne-license

Take down policy

If you believe that this document breaches copyright please contact us at:

repository@maastrichtuniversity.nl

providing details and we will investigate your claim.
}

Copyright and moral rights for the publications made accessible in the public portal are retained by the authors and/or other copyright owners and it is a condition of accessing publications that users recognise and abide by the legal requirements associated with these

- Users may download and print one copy of any publication from the public portal for the purpose of private study or research.

- You may not further distribute the material or use it for any profit-making activity or commercial gain

If the publication is distributed under the terms of Article $25 \mathrm{fa}$ of the Dutch Copyright Act, indicated by the "Taverne" license above, 


\section{Ischemia and reperfusion-induced damage of the isolated mouse heart Involvement of type IIA secretory phospholipase $\mathrm{A}_{2}$}

\section{Proefschrift}

ter verkrijging van de graad van doctor aan de Universiteit Maastricht, op gezag van de Rector Magnificus, Prof. Dr. A.C. Nieuwenhuijzen Kruseman, volgens het besluit van het College van Dekanen, in het openbaar te verdedigen op woensdag 22 december 1999 om 14.00

$$
\text { door }
$$

Leon Johannes de Windt Geboren te Willemstad, Curacao, op 24 januari 1970 


\section{Promotores:}

Prof. dr. R.S. Reneman

Prof. dr. G.J. van der Vusse

\section{Co-promotor:}

dr. M. van Bilsen

\section{Beoordelingscommissie:}

Prof. dr. M.J.A.P. Daemen

Prof. dr. M. Borgers

Prof. dr. A. van der Laarse (Universiteit Leiden)

dr. C.P. Reutelingsperger

Prof. dr. J.F.M. Smits 
Opgedragen aan mijn ouders Lucio Guillermo de Windt en Jacoba de Windt-de Wit 



\section{Table of Contents}

Chapter 1 Introduction

Chapter 2 Phospholipase $\mathrm{A}_{2}$-mediated hydrolysis

of cardiac phospholipids: a review of literature.

Chapter 3 Cloning and cellular distribution of type IIA secretory phospholipase $A_{2}$ expressed in the heart.

Chapter 4 Immunological determination of type IIA secretory phospholipase $\mathrm{A}_{2}$.

Chapter 5 Functional and metabolic evaluation of an improved isolated, left ventricular ejecting murine heart model.

Chapter 6 Functional recovery, energy metabolism and lipid homeostasis in the ischemic-reperfused mouse heart.

Chapter 7 Reduced ischemia tolerance of hearts from mice with targeted deletion of the insulin-like growth factor-1 gene.

Chapter 8 Type IIA secretory phospholipase $\mathrm{A}_{2}$-deficiency fails to attenuate decline in mechanical function, cellular viability and accumulation of fatty acids in the ischemic-reperfused mouse heart.

Chapter 9 Prelimenary results on the generation of transgenic mice with a cardiac-specific overexpression of type IIA secretory phospholipase $\mathrm{A}_{2}$.

Chapter 10 General Discussion

Samenvatting 180

Summary

Dankwoord

Curriculum Vitae 

Chapter 1

\section{Introduction}


Clinical relevance of ischemia/reperfusion induced myocardial injury

Coronary heart disease is a wide-spread disorder in the western industrialized world. Although a downward trend is observed in mortality rates due to coronary heart disease, it remains the most important cause of death (O Rourke et al. 1993, Uemura et al., 1988, Widdershoven et al., 1997). The most common clinical manifestations of the disorder include myocardial ischemia, unstable angina pectoris, cardiac arrhythmias and sudden cardiac arrest. Myocardial ischemia is often caused by an atherosclerotic stenosis of coronary arteries, while sudden cardiac syndromes such as acute myocardial infarction generally results from a thrombotic occlusion of the coronary vessel. Prolonging myocardial ischemia will eventually result in myocardial cell death by necrotic and apoptotic processes or a combination thereof (Schaper et al., 1988, MacLellan et al., 1997). Currently, clinical treatment mainly consists of techniques to re-open the thrombotic occlusion of a coronary vessel (reperfusion) by intracoronary thrombolysis and percutaneous transluminal coronary angioplasty. Although reperfusion is a prerequisite to prevent inevitable death of the flow-deprived cardiac muscle cells, indications exist that reperfusion itself may induce additional myocardial cell damage (Piper et al., 1990, Fox et al., 1992). In spite of intensive research over the past 3 decades, knowledge of the mechanisms of ischemia and reperfusion-induced cardiac cell injury is still limited and an expansion of our understanding of the causal events behind this particular disorder may have substantial therapeutic potentials.

\section{Ischemia and reperfusion-induced cell damage}

Impaired blood supply to cardiac tissue leads to a range of functional, biochemical and ultrastructural changes in cardiomyocytes (Jennings et al., 1978, Schaper et al., 1979, Reimer et al., 1983, Post et al., 1985, Van der Vusse et al., 1992). Interruption of blood flow will immediately result in a lack of oxygen supply to the cardiac muscle cell. As a result mitochondrial respiration ceases and ATP generation by oxidative phosphorylation is hampered. Glycolysis, the conversion of glucose to lactate, will subsequently become the major process by which the cardiac cell can generate ATP. A negative sideeffect of acceleration of anaerobic glycolysis is acidification of the oxygen deprived cells. Since ATP generation through glycolysis is insufficient to cover myocardial energy demand (Jennings et al., 1978), the tissue content of phosphocreatine and ATP will decline, despite the fact that contractile activity is slowed or even stopped (Ganote et al., 1975).

Cellular energy depletion will manifest itself in impaired cellular ion homeostasis, which leads to a rise in intracellular $\mathrm{Na}^{+}$, through activation of the $\mathrm{Na}^{+} / \mathrm{H}^{+}$exchanger. To compensate for the intracellular increase in $\mathrm{Na}^{+}$, the $\mathrm{Na}^{+} / \mathrm{Ca}^{2+}$ exchanger is then activated, resulting in intracellular $\mathrm{Ca}^{2+}$ accumulation (Peng et al,. 1980, Li et al., 1988, Allshire et al., 1989). The increase in intracellular $\mathrm{Ca}^{2+}$ most likely results in activation of $\mathrm{Ca}^{2+}$-dependent proteases that degrade the cytoskeleton and cytoskeletal membrane connections (Schwartz et al., 1984). Furthermore, activation of $\mathrm{Ca}^{2+}$-dependent phospholipases might result in accumulation of membrane-destabilizing factors like lysophospholipids and fatty acids. Collectively, these processes will weaken the (intracellular) membranes of the sarcolemma, sarcoplasmatic reticulum and 
mitochondria (Van der Vusse et al., 1982, Chien et al., 1984, Van Bilsen et al., 1989). Loss of lysosomal integrity during ischemia will result in the release of lysosomal proteases and phospholipases, which will also contribute to the degradation of cellular structures (Decker et al., 1990).

Prolongation of the ischemic duration eventually leads to cardiac cell death by a combination of the above mentioned processes. If restoration of blood flow takes place soon after oxygen deprivation, complete structural and functional recovery of the cardiac muscle cell is possible. If the duration of the ischemic episode is extended beyond a certain point, ischemic injury becomes irreversible and will lead to cell death (Schaper et al., 1988, MacLellan et al., 1997). Although restoration of flow to the weakened myocardium is necessary to alleviate the detrimental impact of ischemia, reperfusion itself may induce additional microvascular and cellular damage (the so-called reperfusion-injury; Piper et al., 1990, Fox et al., 1992). Whether reperfusion per se inflicts cellular damage or that the reperfusion phenomenon is merely a manifestation of ongoing destruction of the cardiac muscle cell already started during the preceding ischemic interval, is still matter of continuous debate (Miura et al., 1990, Fox et al., 1992).

Restoration of blood flow to the ischemic region of the heart results in enhanced supply of, among others, water, oxygen calcium ions and oxidizable substrates to the previously weakened cardiomyocytes. Due to the accumulation of low-molecular weight substanses, such as lactate, degradation products of adenine nucleotides and inorganic phosphate, reperfused cells readily take up water from the microvascular compartment during the initial reperfusion phase, which imposes an osmotic load on the affected cardiac muscle cell (Steenbergen et al., 1985). Moreover, the continuing increase in intracellular $\mathrm{Ca}^{2+}$ may result in substantial accumulation of these ions in cardiac muscle cells (Peng et al., 1980, Schwartz et al., 1984, Allshire et al., 1989). The increase in supply of $\mathrm{O}_{2}$ and oxidizable substrates will result in enhanced production of oxygen free radicals by mitochondria, which may be partially damaged during the preceding period of flow deprivation (Ceconi et al., 1982). Moreover, the decline in activity of a set of enzymes involved in oxygen free radical scavaging may add to the damaging effect of oxygen free radicals (Ferrari et al., 1988).

The nature of the relationship between increased osmotic load, elevated intracellular $\mathrm{Ca}^{2+}$ levels and enhanced production of oxygen free radicals on the one hand, and loss of cellular viability on the other, is most likely complex. For example, the weakening of membranes by physical forces and the hydrolytic activity of $\mathrm{Ca}^{2+}$-dependent proteases and $\mathrm{Ca}^{2+}$-dependent phospholipases (membrane phospholipids damaged by oxygen free radicals are more vulnerable for hydrolysis; Weglicki et al., 1973, Dan et al., 1996) may contribute to the loss of cardiac cell integrity during the initial reperfusion phase.

\section{Role of phospholipase $A_{2}$ in phospholipid degradation during ischemia and reperfusion}

A variety of studies suggest that membrane phospholipid degradation is a critical event in the development of irreversible myocyte injury in flow-deprived cardiac tissue (Van der Vusse et al., 1982, Chien et al., 1984, Van Bilsen et al., 1989, Van der Vusse et al., 1992). Net degradation of phospholipids under 
pathophysiological conditions is thought to destabilize cardiac membranes and to result in loss of function of the semi-permeable barrier as evidenced by the release of macromolecules into the extracellular environment (Van Bilsen et al., 1989). The mechanism behind ischemia-induced phospholipid degradation is unclear, but may be due to the enhanced activity of endogenous phospholipase $A_{2}$ in the heart (Van der Vusse et al., 1989, Van Bilsen et al., 1995), alone or in combination with impaired resynthesis of phospholipid molecules (Van Bilsen et al., 1989). The observation that arachidonic acid, which under normoxic conditions is predominantly esterified in the cardiac phospholipid pool (Van der Vusse et al., 1992), readily accumulates during ischemia suggest degradation of membrane phospholipids (Van der Vusse et al., 1982, Chien et al., 1984, Van Bilsen et al., 1989). Interestingly, accumulation of arachidonic acid proceeds even faster following restoration of flow to the previously ischemic myocardium (Van Bilsen et al., 1989).

Experimental data suggest that especially cardiac type IIA phospholipase $A_{2}$, a low molecular mass member of the phospholipase $A_{2}$ family, is a likely candidate to be involved in ischemia-induced degradation of membrane phospholipids and subsequent cellular damage (Van der Vusse et al., 1989, Van Bilsen et al., 1995). The observation that in addition to arachidonic acid a whole set of long-chain fatty acids accumulate during prolonged myocardial ischemia and reperfusion of the isolated rat heart strongly suggests a predominant role of the aspecific type IIA phospholipase $A_{2}$ (Van Bilsen et al., 1995). The notion that reperfusion is accompanied by a calcium overload of the ischemic cardiac muscle cell supports a predominant role of the calcium-dependent type IIA phospholipase $\mathrm{A}_{2}$ (Van der Vusse et al., 1992, Van Bilsen et al., 1995). Finally, in a number of ischemia/reperfusion and anoxia/reoxygenation studies membrane phospholipid degradation and release of cytoplasmic proteins into the extracellular milieu could be efficiently blocked by pharmacological inhibition phospholipase $\mathrm{A}_{2}$ and by antibodies raised against type IIA related phospholipases $\mathrm{A}_{2}$ (Van Bilsen et al., 1990, Prasad et al., 1991, KikuchiYanoshita et al., 1993).

\section{Aims of the present study}

The present study specifically focusses on the hypothesis that hydrolytic activity of type IIA secretory phospholipase $\mathrm{A}_{2}$ is involved in ischemia/reperfusion-induced phospholipid degradation. Testing of this hypothesis required an integration of molecular biological, biochemical and physiological techniques. Accordingly, the first aim was to establish the presence, abundance and cellular localization of type IIA secretory phospholipase $\mathrm{A}_{2}$ in cardiac muscle by means of molecular biological and immunochemical techniques. The second aim was to develop and characterize an ex vivo, antegradely perfused mouse heart model, which allows detailed analysis of the functional and metabolic changes, with special emphasis on changes in phospholipid metabolism, during cardiac ischemia and reperfusion. Such an ex vivo model system would be helpful for the evaluation of cardiac function in genetically modified mice. The third and final aim of this thesis was to determine the role of type IIA secretory phospholipase $\mathrm{A}_{2}$ in ischemia/reperfusion induced cellular damage by means of mutant inbred mouse 
strains that lack functional type IIA secretory phospholipase $A_{2}$ and by creating transgenic mice that overexpress this phospholipase isoform in a cardiacspecific manner.

\section{General outline of the thesis}

The theoretical aspects of cardiac phospholipid homeostasis under (patho)physiological conditions are described in Chapter 2. In addition, an overview is given of the currently described mammalian phospholipase $A_{2}$ types that may play a role in myocardial ischemia and reperfusion-induced cellular injury. Chapter 3 describes the cloning of the full length cDNA and molecular characterization of rat heart type IIA secretory phospholipase $A_{2}$. In Chapter 4 the expression and purification of recombinant rat heart type IIA phospholipase $A_{2}$ is described. In addition, the ability of a polyclonal antisera raised in the rabbit against this purified recombinant enzyme was compared with several antitype IIA secretory phospholipase $\mathrm{A}_{2}$ antibodies to detect type IIA secretory phospholipase $\mathrm{A}_{2}$ at the protein level. In Chapter 5, the development and characterization of the isolated, left ventricular ejecting mouse heart model is described. The stability of the mouse heart in this experimental model under normoxic conditions was characterized in terms of functional and metabolic performance. In Chapter 6 the ischemia tolerance of the antegradely perfused wildtype mouse heart was determined by investigating functional and metabolic recovery following various periods of ischemia and subsequent reperfusion. In Chapter 7 the ischemia tolerance of hearts derived from heterozygous IGF-1 knockout mice is compared to their wildtype littermates. In addition, the functional recovery and extent of irreversible cell injury following global ischemia and reperfusion is related to the tissue content of arachidonic acid in the reperfused ventricles. The study on heterozygous IGF-1 knockout mice was included to test the sensitivity of the isolated working mouse heart preparation to detect small differences in ischemia/reperfusion-induced cardiac injury. In Chapter 8 this isolated murine heart model is applied to determine the role of type IIA secretory phospholipase $\mathrm{A}_{2}$ in ischemia/reperfusion damage in more detail by making use of genetically closely related inbred mouse strains, one of which is wildtype and the other contains two mutated type IIA secretory phospholipase $\mathrm{A}_{2}$ alleles, resulting in a non-functional protein product. In Chapter 9, prelimenary results are given about generation of transgenic mice with a cardiac-specific overexpression of type IIA secretory phospholipase $\mathrm{A}_{2}$. In the general discussion (Chapter 10) the data obtained in this thesis are discussed in a broader spectrum and future directions for research are delineated. The thesis is preceded by an Introduction.

\section{References}

1. Allshire AP, Cobbold PH. Cytosolic $\mathrm{Ca}^{2+}$ in hypoxic cardiomyocytes. In: Piper HM, Isenberg G (eds). Isolated adult cardiomyocytes. CRC Press, Boca Raton, Florida 1989;1:287-308.

2. Ceconi C, Curello S, Albertini A, Ferrari R. Effect of lipid peroxidation on heart metabolism. In: Caldera CM, Harris P (eds). Advances in studies in heart metabolism. Bologna, CLUEB 1982:424-431. 
3. Chien KR, Han A, Sen A, Buja LM, Willerson JT: Accumulation of unesterified arachidonic acid in ischemic canine myocardium. Relationship to a phosphatidyl deacylationreacylation cycle and the depletion of membrane phospholipids. Circ Res 1984;54:313-322.

4. Dan P, Ntzan DW, Dagan A, Ginsburg I, Yedgar S: $\mathrm{H}_{2} \mathrm{O}_{2}$ renders cells accesible to lysis by exogenous phospholipase $\mathrm{A}_{2}$ : a novel mechanism for cell damage in inflammatory processes. FEBS Lett 1996;383:75-78.

5. Decker RS, Decker ML. Lysosomal integrity in ischemic, hypoxic and recovering heart. In: Piper HM (ed). Pathophysiology of severe ischemic myocardial injury. Kluwer Academic Publishers, Dordrecht 1990;104:115-145.

6. Ferrari R, Curello S, Ceconi C, Cargoni A, Condorelli E, Albertini A. Alterations of glutathione status during myocardial ischemia and reperfusion. In: Singel PK (ed). Oxygen Radicals in the Pathophysiology of Heart Disease, Kluwer Academic Publishers, Dordrecht $1988 ; 145-160$.

7. Fox AA. Reperfusion injury: laboratory phenomenon or clinical reality ? Cardiovasc Res 1992;26:656-659.

8. Ganote CE, Seabra-Gomes R, Nayler WG, Jennings RB.Irreversible injury in anoxic perfused rat hearts. Am J Pathol 1975;81:179-198.

9. Jennings RB, Hawkins HK, Lowe JE, Hill ML, Klotman S, Reimer KA. Relation between high energy phosphate and lethal injury in myocardial ischemia in the dog. Am J Pathol 1978;92:187-214.

10. Kennedy BP, Payette P, Mudgett J, Vadas P, Pruzanski W, Kwan M, Tang C, Rancourt DE, Cromlish W. A natural disruption of the secretory group II phospholipase $\mathrm{A}_{2}$ gene in inbred mouse strains. J Biol Chem 270;22378-22385, 1995.

11. Kikuchi-Yanoshita R, Yanoshita R, Kudo I, Arai, H, Takamura T, Nokomoto K, Inoue K. Preferential hydrolysis of phosphatidylethanolamine in rat ischemic heart homogenates during in vitro incubation. $J$ Biochem 1993;114:33-38.

12. Li Q, Altschuld RA, Stokes BT. Myocyte deenergization and intracellular free calcium dynamics. Am J Physiol 1988;255:C162-C168.

13. Li Q, Li, B, Wang X, Leri A, Jana KP, Liu Y, Kajstura J, Baserga R, Anversa P. Overexpression of insulin-like growth factor-1 in mice protects from myocyte death after infarction, attenuating ventricular dilatation, wall stress, and cardiac hypertrophy. J Clin Invest 1997;100:1991-1999.

14. MacLellan WR, Schneider MD. Death by design. Programmed cell death in cardiovascular biology and disease. Circ Res 1997;81:137-144.

15. MacPhee M, Chepenik KP, Lidell RA, Nelson KK, Stracusa LD, Buchberg AM. The secretory phospholipase $\mathrm{A}_{2}$ gene is a candidate for the $\mathrm{Moml}$ locus, a major modifier of $A P C^{M}$-induced intestinal neoplasia. Cell 1995;81:957-966.

16. Miura T. Does reperfusion induce myocardial necrosis ? Circulation 1990;82:1070-1072.

17. O Rourke RA. Overview of trends in heart disease. Changing prognosis after myocardial infarction. Ann Epidemiol 1993;3:541-546.

18. Peng CF, Kane JJ, Straub KD, Murphy ML. Improvement of mitochondrial energy production in ischemic myocardium by in vivo infusion of ruthenium red. $J$ Cardiovasc Pharmacol 1980;2:45-54.

19. Piper HM. Irreversible ischemic injury - definition of the problem. In: Piper HM (ed) Pathophysiology of severe ischemic myocardial injury. Kluwer Academic Publishers, Dordrecht, The Netherlands 1990:3-14.

20. Post JA, Leunissen-Bijvelt J, Rijgrok TJC, Verkleij AJ. Ultrastructural changes of sarcolemma and mitochondria in the isolated rabbit heart during ischemia and reperfusion. Biochem Biophys Acta 1985;845:119-123.

21. Prasad MR, Lawrentiu MP, Moraru II, Liu X, Maity S, Engelman RM, Das DK: Role of phospholipase $\mathrm{A}_{2}$ and $\mathrm{C}$ in myocardial ischemic reperfusion injury. Am $\mathrm{J}$ Physiol 1991;260:H873-H877.

22. Prinzen FW, Van der Vusse GJ, Willemsen PHM, Coumans WA, Roemen THM, Reneman RS. Accumulation of nonesterified fatty acids in ischemic canine myocardium. Am J Physiol 1983;247:H264-H272.

23. Prinzen FW, Van der Vusse GJ, Willemsen PHM, Coumans WA, Roemen THM, Reneman RS. Accumulation of nonesterified fatty acids in ischemic canine myocardium. Am J Physiol $1983 ; 247 ; \mathrm{H} 264-\mathrm{H} 272$. 
24. Reimer KA, Jennings RB, Tatum AH. Pathobiology of acute myocardial ischemia: metabolic, functional and ultrastructural changes. Am J Cardiol 1983;52:72A-81 A.

25. Schaper J, Herlein F, Schlepper M, Thiedeman K-U. Ultrastructural, functional and biochemical criteria for estimation of reversibility of ischemic injury: a study on the effects of global ischemia on the isolated dog heart. $J$ Mol Cell Cardiol 1979;11:521-541.

26. Schaper J, Schaper W. Time course of myocardial necrosis. Cardiovasc Drugs Ther 1988;2:17-25.

27. Schwartz P, Piper HM, Spahr R, Spiekermann PG. Ultrastructure of adult myocardial cells during anoxia and reoxygenation. Am J Pathol 1984;115:349-361.

28. Steenbergen $\mathrm{C} \mathrm{Jr}$., Hill ML, Jennings RB. Volume regulation and plasma membrane injury in aerobic, anaerobic and ischemic myocardium in vitro: effect of osmotic swelling on plasma membrane integrity. Circ Res 1985;57:864-875.

29. Uemura K, Pisa Z Trends in cardiovascular disease mortality in industrialized countries since 1950. World Helath Stat $Q$ 1988;41:155-178.

30. Van Bilsen M, Van der Vusse GJ, Willemsen PHM, Coumans WA, Reneman RS. Lipid alterations in isolated working rat hearts during ischemia and reperfusion: its relation to myocardial damage. Circ Res 1989;64:304-314.

31. Van Bilsen M, Van der Vusse GJ, Willemsen PHM, Coumans WA, Roemen THM, Reneman RS. Effect of nicotinic acid and mepacrine on fatty acid accumulation and myocardial damage during ischemia and reperfusion. $J$ Mol Cell Cardiol 1990;22:155-163.

32. Van Bilsen M, Van der Vusse GJ. Phospholipase $A_{2}$-dependent signalling in the heart. Cardiovasc Res 1995;30:518-529.

33. Van der Vusse GJ, Glatz JFC, Stam HCG, Reneman RS: Fatty acid homeostasis in the normoxic and ischemic heart. Physiol Rev 1992;72:881-940.

34. Van der Vusse GJ, Reneman RS, Van Bilsen M. Accumulation of arachidonic acid in ischemic/reperfused cardiac tissue: possible causes and consequences. Prostaglandins Leukot Essent Fatty Acids 1997;57:85-93.

35. Van der Vusse GJ, Van Bilsen M, Reneman RS. Is phopholipid degradation a critical event in ischemia- and reperfusion-induced damage. NIPS 1989;4:49-53.

36. Weglicki WB, Owens K, Urschel CW, Serur JR, Sonnenblick EH. Hydrolysis of myocardial lipids during acidosis and ischemia. Recent Adv Stud Card Struct Metab 1973;781-793.

37. Widdershoven JW, Gorgels AP, Vermeer F, Dijkman LW, Verstraaten GM, Dassen WR, Wellens HJ. Changing characteristcs and in-hospital outcome of patients admitted with acute myocardial infarction. Observations from 1982-1994. Eur Heart $J$ 1997;18:10731080 . 
Chapter I 


\section{Chapter 2}

\section{Phospholipase $\mathrm{A}_{2}$-mediated hydrolysis of cardiac phospholipids: a review of literature.}

Published as:

LJ De Windt, RS Reneman, GJ Van der Vusse, M Van Bilsen. Phospholipase $\mathrm{A}_{2}$-mediated hydrolysis of cardiac phospholipids: the use of molecular and transgenic techniques. Mol Cell Biochem 1998;180:65-73. 


\begin{abstract}
Under pathophysiological conditions, like myocardial ischemia and reperfusion, cardiac phospholipid homeostasis is severely disturbed, resulting in a net degradation of phospholipids and the accumulation of degradation products, such as lysophospholipids and (non-esterified) fatty acids. The derangements in phospholipid metabolism are thought to be involved in the sequence of events leading to irreversible myocardial injury. The net degradation of phospholipids as observed during myocardial ischemia may result from increased hydrolysis and/or reduced resynthesis, while during reperfusion hydrolysis is likely to prevail in this net degradation. Several studies indicate that the activation of phospholipases $A_{2}$ plays an important role in the hydrolysis of phospholipids. In this review current knowledge regarding the potential role of the different types of phospholipases $A_{2}$ in ischemia and reperfusion-induced damage is being evaluated. Furthermore, it is indicated how recent advances in molecular biological techniques could be helpful in determining whether disturbances in phospholipid metabolism indeed play a crucial role in the transition from reversible to irreversible myocardial ischemia and reperfusioninduced injury, the knowledge of which could be of great therapeutic relevance.
\end{abstract}




\section{Introduction}

All living cells are surrounded by membranes, consisting of phospholipids, cholesterol and proteins. The cell membrane (plasmalemma) serves as a selective barrier to create and maintain an internal environment to allow the cell to fulfil its specific functions. In addition to its function as physical barrier, the plasmalemma is also an important source of phospholipid-derived bioactive lipids, like lysophospholipids and fatty acids, such as arachidonic acid (Van der Vusse et al., 1992). Arachidonic acid can subsequently serve as a substrate for the production of auto/paracrine factors, including prostaglandins and thromboxanes (Karmazyn et al., 1989, Engels et al., 1990).

The integrity of the membrane is a prerequisite for proper functioning of the cell. Therefore, the major constituents of the plasmalemma, the phospholipids, are subjected to a continuous turnover process to enable the cell to synthesize any required phospholipid and to regulate the fatty acyl composition of the phospholipids (Van der Vusse et al., 1992). In this way, the cellular membrane adjusts its physico-chemical properties in response to changes in the extracellular environment. The turnover of phospholipids requires the liberation of fatty acids from phospholipids (deacylation), as well as the reincorporation of fatty acyl moieties into the phospholipid pool (reacylation). These phospholipid turnover cycles are also operative in cardiomyocytes (Van der Vusse et al., 1992).

During myocardial ischemia/reperfusion a net phospholipid degradation has been observed, either caused by increased activity of phospholipid hydrolyzing enzymes, such as phospholipase $A_{2}$, or caused by an impairment of the resynthesis of phospholipids (Van Bilsen et al., 1989, Van der Vusse et al., 1990, Van der Vusse et al., 1992, Van Bilsen et al., 1995). Therefore, detailed knowledge of cardiac phospholipid homeostasis and derangements therein under pathophysiological conditions can be of great therapeutic value, as ischemic heart diseases as a result of the occlusion of a coronary artery are still by far the most common cause of death in western industrialized countries.

In this review we will focus on cardiac phospholipase $A_{2}$-mediated phospholipid hydrolysis and its possible role in the derangements in phospholipid homeostasis as a crucial event in the transition from reversible to irreversible cell damage as a result of myocardial ischemia and reperfusion. Although not the subject of this review, it is important to note that derangements in the resynthesis of phospholipids may also be involved, especially under energy-deprived conditions like ischemia. In addition, the usefulness of sophisticated molecular biological techniques in combination with an appropriate murine heart model in the assessment of the role of phospholipases $A_{2}$ during myocardial ischemia and reperfusion will be discussed.

\section{Cardiac phospholipids}

Myocardial membranes consist of a variety of phospholipid species, differing in chemical composition of the hydrophylic alcoholic headgroup, or of the hydrophobic tail that is composed of two long-chain fatty acyl residues connected to 
the glycerol backbone. The phospholipid subtypes are classified by their hydrophylic alcohol headgroup. The hydrophylic alcohol is attached to the third (sn3 ) carbon atom of the glycerol moiety via an inorganic phosphate (Figure 1). The hydrophobic part of phospholipids is formed by the fatty acyl chains bound to the first $(s n-l)$ and second $(s n-2)$ carbon atom of the glycerol backbone (Figure 1). The $s n-I$ and $s n-2$ fatty acyl residues are generally a saturated and (poly-)unsatured fatty acid, respectively. The number of carbon atoms of the long-chain fatty acyl residues commonly ranges from 14 to 24 . The number of unsaturated bonds of the $s n-2$ fatty acyl chain may vary between zero and six (Van der Vusse et al., 1992).

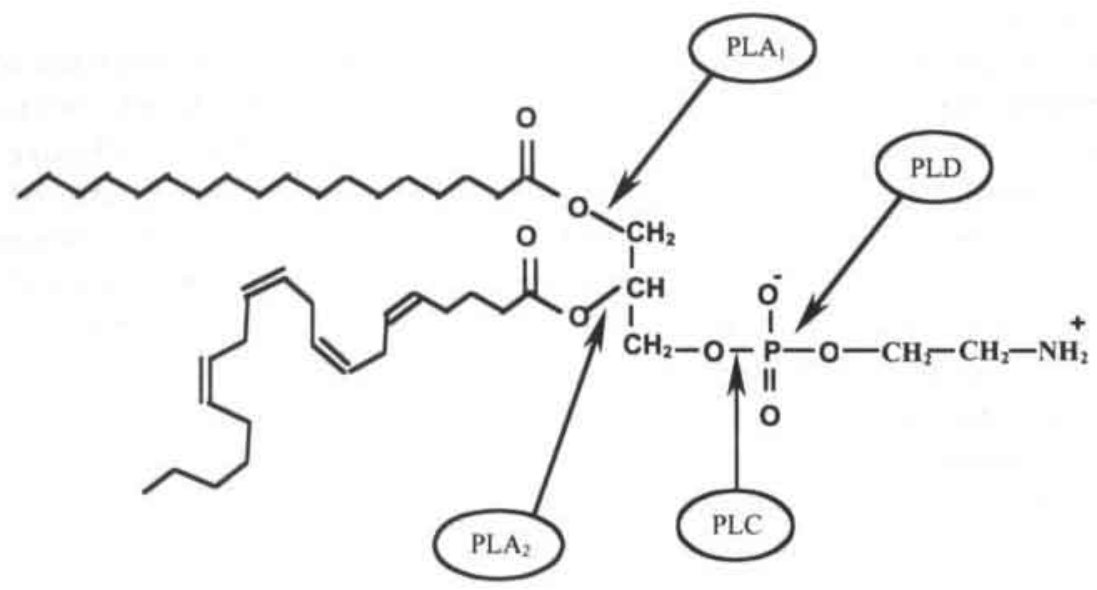

Figure 1. Chemical structure of 1-palmitoyl, 2-arachidonoyl phosphatidylethanolamine and the cleavage site of different phospholipases. The arrows point to the covalent bond hydrolyzed by phospholipase $A_{1}\left(P L A_{1}\right)$, phospholipase $\mathrm{A}_{2}\left(\mathrm{PLA}_{2}\right)$, phospholipase $\mathrm{C}$ (PLC) and phospholipase D (PLD).

The fatty acyl residues at the $s n-1$ and $s n-2$ position are generally O-acyl-residues, i.e., they are connected to the glycerol backbone via an ester linkage. In membrane phospholipids, however, a certain proportion of the fatty acyl residues at the $s n-1$ position is connected to the $s n-1$ carbon atom of glycerol via a vinyl ether linkage (O-[1-alkenyl]-residues). These phospholipids are commonly referred to as plasmalogens. The plasmalogen content in membranes is tissue-dependent and varies between cardiac membranes of different animal species, ranging from $\sim 5 \%$ in the rat heart to $\sim 40 \%$ in the rabbit heart (Hatch et al., 1989).

Because of their shape and amphipathic nature, phospholipids readily form lipid bilayers in an aqueous environment. In case of the sarcolemma, the hydrophilic headgroups of the inner leaflet point towards the intracellular space and those of the outer leaflet towards the extracellular space. The fatty acids tails are burried in the inner part of the bilayer.

The various phospholipid classes in the sarcolemmal bilayer are asymmetrically distributed. The outer leaflet is relatively enriched with phosphatidylcholine and sphingomyelin, while the negatively charged 
phosphatidylserine, phosphatidylethanolamine and phosphatidylinositol are located almost exclusively in the cytoplasmic leaflet. This phenomenon results in a more negatively charged inner leaflet as compared to the outer sarcolemmal leaflet. To compensate for differences in fluidity between the leaflets, the cholesterol/phospholipid ratio is higher in the outer leaflet of the sarcolemma (Post et al., 1988).

\section{Phospholipid homeostasis in the normoxic situation}

Under normoxic conditions the amount of intracellular (non-esterified) fatty acids is very small, indicating that the pool size of these fatty acids is well controlled (Van der Vusse et al., 1992). Apparently a strict balance exists between the activity of enzymes that control the liberation of fatty acyl moieties from phospholipid molecules and that of enzymes that control the rate of incorporation of fatty acyl residues into the phospholipid pool.

The cardiomyocyte is equipped with a set of enzymes required for the resynthesizing part of phospholipid turnover as well as for the hydrolytic part of the phospholipid turnover cycle. De novo synthesis of phospholipids takes place in the sarcoplasmic reticulum. Newly synthesized phospholipids are transported to the sarcolemma through the cytosol (Van der Vusse et al., 1992). For de novo synthesis of phoshatidylcholine the condensation of 1,2-diacylglycerol and CDP-choline is achieved by the action of choline-phosphotransferase. When the substrate is a lysophoshatidylcholine, the incorporation of the second fatty acyl moiety is dependent on the activity of the enzymes acyl-CoA synthetase and lysophosphatidylcholine acyltransferase (Figure 2).

Among the enzymes involved in the hydrolytic part of the phospholipid turnover process are phospholipase $\mathrm{A}_{1}\left(\mathrm{PLA}_{1}\right)$ and phospholipase $\mathrm{A}_{2}\left(\mathrm{PLA}_{2}\right)$, which hydrolyze the ester bond between the fatty acyl unit at the $s n-1$ and $s n-2$ carbon atom of glycerol, respectively. In case of a plasmalogen, a plasmalogen-specific type $\mathrm{PLA}_{2}$ is present in the cardiomyocyte to remove fatty acyl chains from the $s n-2$ position (Hazen et al., 1991). The vinyl ether bond at the $s n-l$ position is hydrolyzed by a specific plasmalogenase (Arthur et al., 1985). Phospholipase C (PLC) breaks the covalent bond between the polar headgroup and the carbon atom at the $s n-3$ position of glycerol and phospholipase D (PLD) the bond between phosphate and the alcohol unit that together form the polar headgroup (Figure 1). The final products of phospholipase $A_{1}$ and $A_{2}$ activity are lysophospholipids and fatty acids. In turn, the remaining fatty acyl chain of lysophospholipids can be removed by lysophospholipase. It has been hypothesized that in cardiac cells the balance between the activities of lysophospholipid acyltransferase and phospholipase $A_{2}$ determines the actual level of unesterified arachidonic acid (Irvine, 1982, Van der Vusse et al., 1992). 

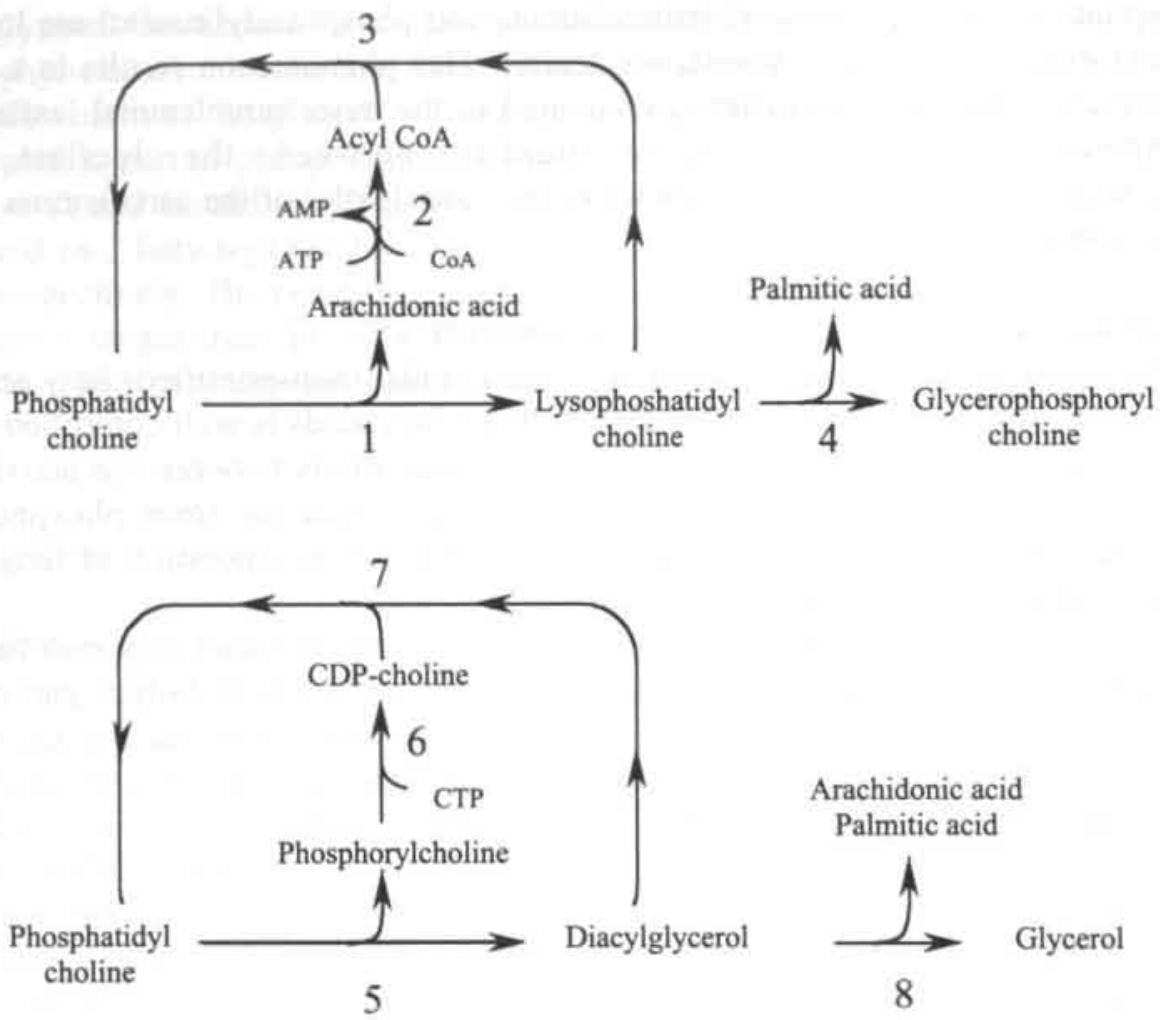

Figure 2: Synthesis and degradation of 1-palmitoyl, 2-arachidonoyl phosphatidylcholine. Pathway I (upper panel) describes the deacylation-reacylation pathway for this phospholipid. Pathway II depicts the turnover of the hydrophylic headgroup of phsphatidylcholine. Numbers refer to the enzymes involved in the pathways: (1) phospholipase $A_{2}$, (2) fatty acyl-CoA synthetase, (3) lysophosphatidylcholine acyltransferase, (4) lysophospholipase, (5) phospholipase C, (6) CTP:phosphocholine cytidyltransferase, (7) phosphocholine transferase, (8) diacylglycerol + monoacylglycerol lipases. [Reprinted with permission from Van der Vusee of al 19071

Studies with radiolabeled substrates show that the cardiomyocyte is able to change the polar headgroup as well as the fatty acyl units of the membrane phospholipids (Van der Vusse et al., 1992). Detailed knowledge about phospholipid turnover rate in cardiomyocytes, however, is still lacking. In vitro measurements revealed a maximal myocardial total phospholipase activity of about $3 \mu \mathrm{mol}$ phosholipid. $\mathrm{h}^{-1} \cdot \mathrm{g}^{-1}$ tissue in rat heart (Termin et al., 1987). Based on the presence of approximately $30 \mu \mathrm{mol}$ total phospholipid . $\mathrm{g}^{-1}$ tissue and assuming that degradation of phospholipids keeps pace with resynthesis, complete turnover of all sarcolemmal phospholipids could be accomplished in about 10 hours. However, it cannot be excluded that phospholipid species in different subcellular compartments are subjected to different turnover rates (Miyazaki et al., 1987, Miyazaki et al., 1990). 
The heart contains at least three different types of phospholipases $A_{2}$. Recently, a member of type IIA secretory PLA 2 (type IIA sPLA $A_{2}$ ) was cloned in our laboratory (De Windt et al., 1996). All mammalian type II PLA 2 s are small molecular weight acylhydrolases of about $14 \mathrm{kD}$ with a slight preference for phosphatidylserine and phosphatidylethanolamine over phosphatidylcholine, but they have no specificity for the type of fatty acyl moiety at the $s n-2$ position. Type IIA sPLA ${ }_{2} \mathrm{~S}$ have been found to be associated with membranes like the plasmalemma of guinea pig spermatozoa (Garcia et al., 1991), the outer contact sites and the inner membrane of mitochondria (Levrat et al., 1992), or the matrix of $\alpha$-granules in platelets (Aarsman et al., 1989). Furthermore, type IIA sPLA 2 can be secreted from rat platelets upon stimulation, due to the presence of a putative eukaryotic signal sequence for secretion at the $\mathrm{N}$-terminal end of the enzyme (Horigome et al., 1987). Whether in cardiomyocytes type IIA sPLA $\mathrm{A}_{2}$ is present in a membrane-associated form or can be secreted remains to be elucidated. Circumstantial evidence for a membrane-associated localization of type IIA sPLA 2 in cardiomyocytes was provided by a cytochemical study by Kriegsmann and coworkers, in which they showed that a monoclonal antibody against bee venom type II sPLA $A_{2}$ bound to antigens at the level of the sarcolemma (Kriegsman et al., 1993).

The knowledge of mechanisms involved in the regulation of type IIA sPLA 2 activity is gradually increasing; mechanisms of short-term regulation of the enzyme activity and those involved in long-term regulation of enzyme content can be distinguished (Van Bilsen et al., 1995). Short-term regulation is based on the requirement of (sub)millimolar calcium concentrations for maximal activity of the enzyme. This raises questions about the probability of its intracellular activity under normoxic conditions, as in the cardiomyocyte the overall intracellular calcium concentration oscillates from $0.15 \mu \mathrm{M}$ during diastole to $2.0 \mu \mathrm{M}$ during systole. However, Langer and colleagues have demonstrated that in specific regions close to the sarcolemma calcium concentrations up to $600 \mu \mathrm{M}$ may be reached during systole, postulating the existence of multiple compartments with different calcium concentrations within the cytosol (Langer, 1994). Accordingly, the calcium concentration in the subsarcolemmal space might be sufficient to allow intracellular activity of type IIA sPLA $\mathrm{A}_{2}$ under physiological conditions.

As far as the short-term regulation of extracellular activity is concerned evidence has been provided that type IIA sPLA $\mathrm{A}_{2}$ activity can be modulated by the association of the enzyme via its putative C-terminal heparin-binding domain to the proteoglycans of the extracellular matrix. The association of type IIA sPLA 2 with the sulfated polysaccharides results in changes of enzyme activity on membrane phospholipids (Sartipy et al., 1996). This mechanism of regulation could be of importance for the heart, if cardiac type IIA sPLA $\mathrm{A}_{2}$ is associated to the extracellular part of the sarcolemma, where calcium concentrations are no longer a limiting factor for the activity of the enzyme. Finally, it appears that type IIA sPLA 2 activity can be modulated by accessory proteins, like phospholipase $\mathrm{A}_{2}$-activating protein (PLAP) which has a stimulatory effect, or uteroglobins and annexins which are putative inhibitors of type IIA $s \mathrm{PLA}_{2}$ activity. The exact mechanism of action and 
the physiological significance of these accessory proteins on type IIA $\mathrm{SPLA}_{2}$ activity are still a matter of debate (Van Bilsen et al., 1995, Jans et al., 1995).

Long-term regulation of type IIA $s \mathrm{PLA}_{2}$ activity is accomplished by adjusting the level of gene transcription. In several cell types type IIA sPLA ${ }_{2}$ expression is induced by inflammatory cytokines like interleukin-1 (IL-1), interleukin-6 (IL-6), and tumor necrosis factor $\alpha$ (TNF $\alpha$ ), or by cAMP-elevating substances like forskolin (Schalkwijk et al., 1992, Pfeilschifter et al., 1993, Konieczkowski et al., 1993). These observations were substantiated by the demonstration of the presence of cAMP and cytokine responsive elements in the 5 flanking region of the type IIA sPLA 2 gene (Ohara et al., 1990). In contrast, the expression of this enzyme is downregulated by a variety of substances like glucocorticoids, transforming growth factor $\beta$ (TGF $\beta$ ), aspirin, and tetranactin (Schalkwijk et al., 1992, Van den Bosch et al., 1992, Vervooldeldonk et al., 1996, Walker et al., 1996). Recently it was shown that activation of the nuclear transcription factor NF- $\mathrm{KB}$ is an essential component of the cytokine signalling pathway responsible for type IIA sPLA 2 gene regulation (Vervoordeldonk et al., 1996). That this mechanism of regulation is also operative in cardiac cells is supported by the observation that type IIA sPLA ${ }_{2}$ mRNA levels increase in cultured rat neonatal cardiomyocytes upon stimulation with TNF $\alpha$ (De Windt et al., 1996).

The recent discovery of a high-molecular mass phospholipase $A_{2}$ (85-110 kD) or type IV cytosolic PLA 2 (type IV cPLA $_{2}$ ) led to a different view of the activation of $s n-2$ acylhydrolysis through receptor mediated signal transduction (Scharp et al., 1993). This enzyme selectively cleaves arachidonoyl residues at the $s n-2$ position of membrane phospholipids. Type IV $\mathrm{cPLA}_{2}$ is equally active against ethanolamine- and choline containing phospholipids, and hydrolyzes both 1-acyl-2arachidonoyl phospholipids, and 1-alkenyl-2-arachidonoyl phospholipids. Type IV $\mathrm{CPLA}_{2}$ has a predominantly cytosolic localization and requires $\mathrm{Ca}^{2+}$ in the micromolar range for translocation to its site of action, the phospholipid bilayer. Because of these features, the high molecular mass cytosolic phospholipase $A_{2}$ is a likely candidate for the acute liberation of arachidonic acid from membrane phospholipids in cardiac cells under physiological conditions, e.g. by alterations in the cellular $\mathrm{Ca}^{2+}$ concentration as a result of ligand-receptor interactions. This notion is substantiated by the observation that type IV $\mathrm{CPLA}_{2}$ itself is a substrate for mitogen-activated protein kinases (MAPK), which serve as important mediators for a variety of receptor-mediated signal transduction pathways (Lin et al., 1993).

The third type of phospholipase $A_{2}$ present in the myocardium was first reported in 1985 by Gross and coworkers (Wolf et al., 1985). It has a molecular mass of $\sim 40 \mathrm{kD}$ and was shown to be $\mathrm{Ca}^{2+}$-independent for its activity. Although it has a preference for $s n$-2-arachidonoyl plasmalogens, it is also capable of hydrolyzing diacyl-phospholipids or plasmalogens with other fatty acids at the $s n-2$ position, albeit at lower rate (Diez et al., 1994). $\mathrm{Ca}^{2+}$-independent, plasmalogen specific type $\mathrm{V}$ phospholipase $\mathrm{A}_{2}$ (type $\mathrm{V}$ iPLA $\mathrm{A}_{2}$ ) is localized in the cytosol and can translocate to the cell membrane by interacting with the glycolytic enzyme phosphofructokinase (PFK), forming a large $400 \mathrm{kD}$ protein complex, indirectly regulating the activity of type $\mathrm{V}$ iPLA $_{2}$ via allosteric modulation of PFK by cytosolic ATP levels (Hazen et al., 1993). Recently a novel regulatory mechanism 
was identified whereby the $\mathrm{Ca}^{2+}$-independent type $\mathrm{V}$ iPLA${ }_{2}$ is modulated indirectly by calcium ions, i.e., through alterations in the interaction of the phospholipase complex with calmodulin (Wolf et al., 1996).

To summarize, at least three different types of phospholipase $A_{2}$ activities have been identified in the heart: a $14 \mathrm{kD} \mathrm{Ca}^{2+}$-dependent type IIA sPLA , type $\mathrm{V}$ ${ }_{i P L A}$ and type IV cPLA $_{2}$. Recently, Chen and colleagues cloned another low molecular mass $\mathrm{Ca}^{2+}$-dependent phospholipase $\mathrm{A}_{2}$ from rat heart that showed only limited homology to type IIA sPLA 2 (Chen et al., 1994). Dennis and coworkers demonstrated that type IIA sPLA $A_{2}$, type IV $\mathrm{CPLA}_{2}$ and type V iPLA $_{2}$ were involved in the release of arachidonic acid following stimulation of $\mathrm{P}_{388 \mathrm{D}_{1}}$ macrophages (Balsinde et al., 1996). Interestingly, type IIA sPLA ${ }_{2}$ was accountable for $60-70 \%$ of the AA release in this particular model system. As far as cardiomyocytes are concerned the contribution of the different phospholipase $A_{2}$ types in the ligandreceptor-induced hydrolysis of phospholipids remains to be established.

\section{Effect of ischemia and reperfusion on cardiac phospholipids}

Ischemic heart diseases are predominantly caused by impaired coronary perfusion. If the ischemic period has a limited duration, structural and functional recovery of the myocardium is possible by timely restoration of blood flow. If the ischemic period is prolonged, however, injury becomes irreversible, eventually leading to cell death and cardiac dysfunction. During myocardial ischemia phospholipid homeostasis is disturbed. The net degradation of phospholipids results in an increase of their degradation products, mainly fatty acids and lysophospholipids (Weglicki et al., 1973, Van der Vusse et al., 1982, Chien et al., 1984, Van Bilsen et al., 1989). The sarcolemma appears to be the primary target for accelerated phospholipid degradation in oxygen and energy-depleted cardiomyocytes (Van der Vusse et al., 1992). Although timely restoration of blood flow is required to save the myocardium from irreversible damage, an even more dramatic rise in the tissue levels of lysophospholipids and fatty acids has been observed during the reperfusion phase. Whether this reperfusion-induced injury is a manifestation of cell damage which was already present during ischemia or is a caused by the re-introduction of blood flow per se to the previously ischemic myocardium, is still a matter of debate (Van der Vusse et al., 1989, Van der Vusse et al., 1994).

Currently there are two hypotheses concerning the mechanism involved in the increased phospholipid degradation of the sarcolemma during ischemia and reperfusion (Van der Vusse et al., 1989, Van der Vusse et al., 1994). The first hypothesis implies that the integrity of the sarcolemma is lost due to physical forces, before the phospholipids are hydrolysed. Mechanical stress will be imposed on the sarcolemma of energy-deprived cells by adjacent non-ischemic, contracting myocytes or by hypercontracture of the ischemic cells themselves. In addition, lowmolecular weight substances such as lactate, protons and inorganic phosphate, will accumulate inside ischemic myocytes. This will lead to a shift of water from the extracellular to the intracellular space, imposing an increased osmotic force on the cell membrane. Together with weakening of the anchoring of the cytoskeleton to the sarcolemma, this might result in enhanced membrane fragility. When the 
sarcolemma is unable to withstand the physical forces anymore the sarcolemma will rupture, after which intracellular structures will become accessible to the extracellular fluid. This will lead to the activation of, amongst others, $\mathrm{Ca}^{2+}$ dependent proteases and phospholipases, which will start to digest cellullar components. According to the physical forces hypothesis, degradation of phospholipids is merely an epiphenomenon, reflecting post-mortem autolysis of cardiac cells (Van der Vusse et al., 1989, Buja et al., 1991).

In the second hypothesis, the loss of integrity is explained, among others, by a imbalance between hydrolysis and resynthesis of the membrane phospholipids. As indicated before, this may result from increased activity of hydrolyzing enzymes, like phospholipases, or impaired resynthesis due to loss of catalytic activity of the enzymes involved. Acyl-CoA synthetase, an enzyme involved in phospholipid resynthesis, requires ATP as cofactor and is inhibited by AMP and adenosine. Therefore, the ischemia-induced decrease in cellular ATP and elevated levels of AMP and adenosine might lead to impairment of resynthesis (Van Bilsen et al., 1989). In this light it is also of interest to note that the activity of lysophosphatidyl acyltransferase was found to be compromized in the ischemic pig heart (Das et al., 1986) while in several studies PLA 2 activity was found to be increased in the ischemic and reperfused heart (Van der Vusse et al., 1992). The latter hypothesis implies that the increased degradation of membrane phospholipids plays a pivotal role in the transition to irreversible injury of cardiomyocytes during myocardial ischemia (Buja et al., 1991, Van der Vusse et al., 1992).

\section{Role of $P L A_{2}$ in ischemia/reperfusion induced phospholipid hydrolysis}


role in the transition from reversible to irreversible ischemic myocardial injury. First, in ischemic myocardium various phospholipid degradation products accumulate, including arachidonic acid and lysophospholipids. As arachidonic acid is predominantly ( $99 \%$ ) located in the esterified form at the $s n-2$ position in phospholipids, its liberation is conceivably due to PLA $A_{2}$ activity (Van der Vusse $e t$ al., 1992). Second, chemical inhibitors of $\mathrm{PLA}_{2}$ have been reported to protect the cardiomyocytes against ischemia, anoxia, or energy-deprivation (Van Bilsen et al., 1990, Atsma, 1996).

Earlier attempts to identify the PLA $\mathrm{A}_{2}$ type involved in the enhanced phospholipid hydrolysis during myocardial ischemia and reperfusion have focussed on the plasmalogen-specific, $\mathrm{Ca}^{2+}$-independent type $\mathrm{V}$ iPLA 2 . Hazen and coworkers reported that in the rabbit heart the activity of type $\mathrm{V}$ iPLA $\mathrm{A}_{2}$ is greatly enhanced already $2 \mathrm{~min}$ after the onset of ischemia (Hazen et al., 1991). Moreover, halo-enollactone suicide substrate (HELSS), a specific inhibitor of type V iPLA ${ }_{2}$ was found to reduce cell death in cultured neonatal cardiomyocytes exposed to chemical anoxia (Atsma et al., 1996). However, several other observations raise questions as to whether cardiac type $\mathrm{V}$ iPLA $\mathrm{P}_{2}$ plays an important role in the ischemia/reperfusion-induced phospholipid degradation. First, in cardiac homogenates the diacyl-form of phosphatidylethanolamine is hydrolyzed rather than the plasmalogen-form of phosphatidylethanolamine (Kikuchi-Yanoshita et al., 
1993). In line with the latter finding Davies and coworkers observed that the levels of lysoplasmenylcholine and lysoplasmenylethanolamine did not significantly increase in isolated rat hearts subjected to ischemia (Davies et al., 1992). Secondly, the time course of arachidonic acid accumulation during reperfusion does not coincide with that of type $\mathrm{V}$ iPLA ${ }_{2}$ activation. The enzyme activity quickly goes down to normal levels after ischemia, whereas arachidonic acid continues to accumulate (Hazen et al., 1991, Van der Vusse et al., 1992). Thirdly, Vesterqvist and colleagues reported a marked decrease in the activity of type V iPLA 2 in isolated rabbit hearts subjected to a prolonged period of global ischemia (Vesterqvist et al., 1996). In their study they used intact isolated sarcolemmal membranes as substrate to measure enzyme activity, while Hazen and colleagues used exogenously added phospholipid substrates (Hazen et al., 1991).

In our opinion type IIA sPLA 2 is a likely candidate to be involved in ischemia/reperfusion-induced degradation of membrane phospholipids, because not only arachidonic acid, but also other (un)satured fatty acids accumulate during prolonged myocardial ischemia (Figure 3). This argues in favor of the involvement of an aspecific PLA $\mathrm{P}_{2}$ rather than an arachidonoyl-, plasmalogen-specific PLA (Buja, 1991, Van der Vusse et al., 1994). Secondly, the observation that cardiac fatty acid levels, including arachidonic acid, continue to rise in the reperfusion phase points toward a role for type IIA sPLA 2 in the process. Reperfusion is known to be accompanied by a substantial increase in intracellular calcium concentration, so that the activation of calcium-dependent phospholipases can be anticipated. Furthermore, during reperfusion peroxidation of membrane phospholipids, as a result of enhanced oxygen free radical production, has been demonstrated (Van der Vusse et al., 1992). It is of interest to note that peroxidation-damaged phospholipids are more vulnerable for type IIA sPLA ${ }_{2}$ attack (Dan et al., 1996). Furthermore, in a study by Prasad and colleagues it was shown that pretreatment of isolated hearts with antibodies raised against a snake venom type II sPLA $\mathrm{A}_{2}$ effectively blocked the degradation of membrane phospholipids and mitigated the release of cytoplasmic proteins in the acute reperfusion phase (Prasad et al., 1991). Anti-type IIA sPLA 2 antibodies were also found to decrease the phospholipid degradation in homogenates of rat hearts that had been previously subjected to a period of hypoxia and reoxygenation (Kikuchi-Yanoshita et al., 1993). Finally, increased expression levels of type IIA sPLA ${ }_{2}$ have been found in rat brain after severe forebrain ischemia (Lauritzen et al., 1994) and in rat small intestinal mucosa after ischemia and revascularization (Otamiri et al., 1987). On the basis of the above, it is tempting

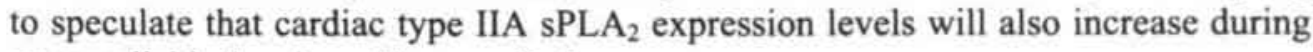
myocardial ischemia and/or reperfusion.

Alternatively, the observation that type II PLA $\mathrm{PL}_{2}$ activity can be greatly enhanced by members of the inflammatory cytokine family, might be of relevance to the process of ischemic injury. First of all it has been shown that serum levels of inflammatory cytokines, like IL-1, IL- 6 and TNF $\alpha$, are increased in various pathophysiological conditions, including myocardial ischemia (Maury et al., 1989, Guill n et al ., 1995). 
(nmol/g dry weight)

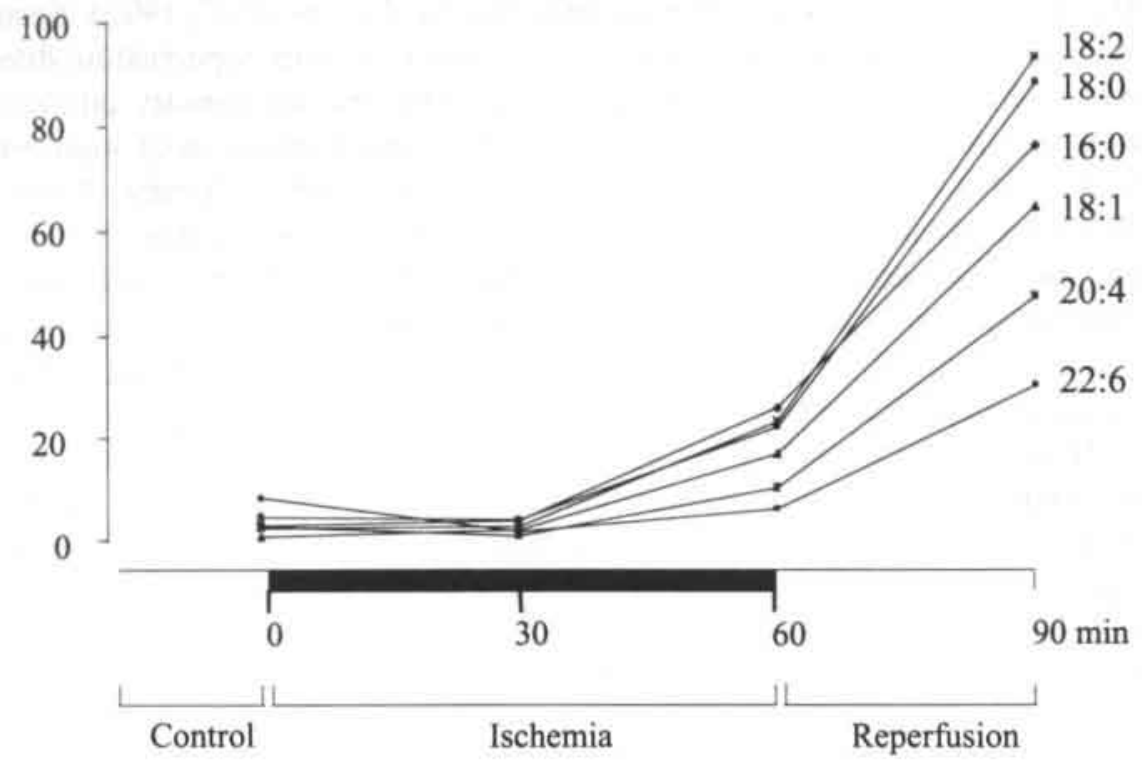

Figure 3: Effects of ischemia and reperfusion of isolated rat hearts on the tissue content of individual fatty acid species. Values are give in nmol.g ${ }^{-1}$ dry weight and represent the mean of 6-10 experiments. 16:0 refers to palmitic acid, 18:0 to stearic acid, 18:1 to oleic acid, 18:2 to linoleic acid, 20:4 to arachidonic acid, and 22:6 to docosahexaenoic acid. [Adapted from Van Bilsen, thesis 1989].

Moreover, for other cell types it has been shown that cytokine stimulation caused a very rapid (within 5 minutes) increase of type IIA sPLA ${ }_{2}$ activity (Bomalski et al., 1992). Finally, it has been demonstrated that cardiomyocytes can produce TNF $\alpha$ under hypoxic stress (Yamauchi-Takihara et al., 1995), and that stimulation of cultured rat neonatal cardiomyocytes with TNF $\alpha$ resulted in increased type IIA sPLA $_{2}$ mRNA levels (De Windt et al., 1996). Therefore, it can be hypothesized that cytokines secreted by cardiomyocytes could indirectly influence sarcolemmal stability, by increasing the cellular level of type IIA sPLA ${ }_{2}$ in an autocrine manner.

\section{Future directions: the use of molecular and transgenic techniques}

As indicated above, no definitive proof has been provided that enhanced phospholipid hydrolysis and the induction of irreversible cell damage are causally related. It is also uncertain which type of $\mathrm{PLA}_{2}$ would be accountable for the ischemia and reperfusion-induced hydrolysis of membrane phospholipids. Studies performed with phospholipase inhibitors lack specificity, which hampers an unequivocal interpretation of the results obtained. For example, in an isolated rat heart preparation subjected to a period of global ischemia followed by reperfusion, the phospholipase inhibitor mepacrine was able to reduce the phospholipid degradation, but also was shown to exert a negative inotropic effect (Van Bilsen et $a l ., 1989$ ) and to interfere with transsarcolemmal calcium fluxes (Philpson et al., 1985). Accordingly, current conventional pharmacological and/or physiological 
approaches do not provide conclusive answers as to the role of PLA 2 in ischemia/reperfusion injury.

The advent of molecular biological techniques and transgenic technology allows the generation of mice with either an overexpression (gain of function ) or the absence ( loss of function ) of specific genes. By using transgene technology it has been possible to study the role of a specific gene of interest and to dissect complex cardiovascular phenotypes involving several gene products. This approach has been demonstrated to be effective in creating murine models resembling human myocardial diseases, such as cardiac hypertrophy/failure, congenital heart diseases, and hypertension, just to mention a few (see reviews by Field, 1993 and Chien, 1994). The transgene technology has also been successfully applied in studies related to ischemia and reperfusion damage. For example, the contribution of oxygen free radical to ischemia/reperfusion damage was confirmed by the subjecting the hearts of transgenic mice overexpressing superoxide dismutase to transient ischemia (Chen et al., 1996). In addition, transgenic mice overexpressing HSP70 were found to be less vulnerable against ischemic injury, clearly indicating the protective effect of HSP70 in this setting (Plumier et al., 1995, Marber et al., 1995).

In our laboratories we are currently applying transgene technology in order to modulate type IIA sPLA 2 activity in the heart. With this approach mechanisms underlying disturbances in phospholipid homeostasis as a result of cardiac ischemia and reperfusion will be studied. To achieve this, transgenic mice have been generated that harbor the recently cloned cDNA of rat heart type IIA sPLA downstream to the proximal fragment $(250 \mathrm{bp})$ of the promoter of the myosin light chain-2 (MLC-2) gene. Recent studies indicate that this part of the promoter is sufficient to mediate cardiac-specific expression (Lee et al., 1992). In this way, several lines of transgenic mice, differing in copy number and, hence, in the level of cardiac type IIA sPLA ${ }_{2}$ activity, will become available for analysis.

The hearts of transgenic and control mice will be subjected to ischemia and reperfusion ex vivo to assess the causal relationship, if any, between the level of type IIA sPLA $\mathrm{A}_{2}$ and the extent of phospholipid hydrolysis on the one hand and cellular damage and functional recovery on the other. We are currently scaling down the technique of isolated rat heart perfusion (Neely et al., 1967), according to "the assisted mode perfusion", to the level of the mouse. This model will allows us to study functional recovery by parameters like the recovery of left ventricular developed pressure and cardiac output. The development of this isolated left ventricular ejecting mouse heart model will not only be of interest for this particular problem, but will be of great value for future studies to evaluate cardiac function of transgenic mice, whatever the transgene they are harboring.

\section{References}

1. Aarsman AJ, Leunissen-Bijvelt J, van den Koedijk CD, Neys FW, Verkleij AJ, Van den Bosch H. Phospholipase $A_{2}$ activity in platelets. Immunopurification and localization of the enzyme in rat platelets. Lipids Mediat 1989;1:49-61.

2. Arthur G, Mock T, Zaborniak C, Choy PC. Plasmalogenase in hamster heart. Biochim Biophys Acta 1985;833:189-195. 
3. Atsma DE. Mechanisms of cell death in energy depleted cardiomyocytes. Role of calcium overload, calpain and phospholipase. Thesis, Rijksuniversiteit Leiden, The Netherlands; 1996.

4. Balsinde J, Dennis EA. Distinct roles in signal transduction for each of the phospholipase $A_{2}$ enzymes present in P388D 1 macrophages. $J$ Biol Chem 1996;271:6758-6765.

5. Bomalski JS, Steiner MR, Simon PL, Clark MA. IL-1 increases phospholipase $A_{2}$ activity, expression of phospholipase $\mathrm{A}_{2}$-activating protein, and release of linoleic acid from the murine $\mathrm{T}$ helper cell line EL-4. J Immunol 1992;148:155-160.

6. Buja LM. Lipid abnormalities in myocardial cell injury. Trends Cardiovas Med 1991;1:40-45.

7. Ceconi C, Curello S, Albertini A, Ferrari R. Effect of lipid peroxidation on heart metabolsim. In: Caldera CM, Harris P (eds). Advances in studies in heart metabolism. Bologna, CLUEB 1982:424-431.

8. Chen EP, Bittner HB, Davis D, Folz RJ, Van Trigt P. Extracellular superoxide dismutase transgene overexpression preserves postischemic myocardial function in isolated murine hearts. Circulation 1996;92:412-417.

9. Chen J, Engle SJ, Seilhamer JJ, Tischfield JA. Cloning and recombinant expression of a novel human low molecular weight $\mathrm{Ca}^{2+}$-dependent phospholipase $\mathrm{A}_{2}$. J Biol Chem 1994;269:23652368.

10. Chien KR, Han A, Sen A, Buja LM, Willerson JT. Accumulation of unesterified arachidonic acid in ischemic canine myocardium. Relationship to a phosphatidyl deacylation-reacylation cycle and the depletion of membrane phospholipids. Circ Res 1984;54:313-322.

11. Chien KR. Genes and physiology: molecular physiology in genetically engineered animals. J Clin Invest 1996;97:901-909.

12. Dan $\mathrm{P}$, Ntzan DW, Dagan A, Ginsburg I, Yedgar $\mathrm{S} . \mathrm{H}_{2} \mathrm{O}_{2}$ renders cells accesible to lysis by exogenous phospholipase $\mathrm{A}_{2}$ : a novel mechanism for cell damage in inflammatory processes. FEBS Lett 1996;383:75-78.

13. Das DK, Engelman RM, Rousou JA, Breyer RH, Otani H, Lemeshow S. Role of membrane phospholipids in myocardial injury induced by ischemia and reperfusion. Am $J$ Physiol 1986;251:H71-H79.

14. Davies NJ, Schultz R, Olley PM, Strydnadka KD, Panas DL, Lopaschuk GD. Lysoplasmenylethanolamine accumulation in ischemic/reperfused isolated fatty acids perfused hearts. Circ Res 1992;70:1161-1168

15. De Windt LJ, Van Bilsen M, Van der Vusse GJ, Reneman RS. Cloning and cellular distribution of a group II phospholipase $A_{2}$ expressed in the heart. J Mol Cell Cardiol 1997;29:2093-2106.

16. Diez E, Chilton FH, Stroup G, Mayer RJ, Winkler JD, Fonteh AN. Fatty acid and phospholipid selectivity of different phospholipase $A_{2}$ enzymes studied by using a mammalian membrane as substrate. Biochem J 1994;310:721-726.

17. Engels W, Van Bilsen M, De Groot MJM, Reneman RS, Van der Vusse GJ. Ischemia and reperfusion induced formation of eicosanoids in isolated rat hearts. Am J Physiol 1990;258:H1865-H1871.

18. Ferrari R, Curello S, Ceconi C, Cargoni A, Condorelli E, Albertini A. Alterations of gluthatione status during myocardial ischemia and reperfusion. In: Singel PK (ed). Oxygen Radicals in the Pathophysiology of Heart Disease, Dordrecht 1990;104:115-145.

19. Field LJ. Transgenic mice in cardiovascular research. Annu Rev Physiol 1993;55:97-114.

20. Garcia R, Martines R, Rabago M, Hernandez-perez O, Reyes A, Rosado A. Subcellular distribution of phospholipase $\mathrm{A}_{2}$ and ATPases during capacitation and acrosome reaction in guinea pig spermatozoa. Arch Androl 1991;26:93-105.

21. Guill n I, Blanes M, G mez-Lech n MJ, Castell JV. Cytokine signaling during myocardial infarction: sequential appearance of IL-1 and IL-6. Am J Physiol 1995;269:R229-R235.

22. Hatch GM, Choy KO, Choy PC. Regulation of phosphatidylcholine metabolism in mammalian hearts. Biochem Cell Biol 1989;67:67-77.

23. Hazen SL, Gross RW. The specific association of a phosphofructokinase isoform with myocardial calcium-independent phospholipiase $\mathrm{A}_{2}$ - implication for the coordinated regulation of phospholipolysis and glycolysis. J Biol Chem 1993;268:9892-9900.

24. Hazen SL, Ford DA, Gross W. Activation of a membrane associated phospholipase $A_{2}$ during rabbit myocardial ischemia which is highly selective for plasmalogen substrate. $J$ Biol Chem 1991:266:5629-5633. 
25. Horigome K, Hayakawa M, Inoue K, Nojima S. Selective release of phospholipase $A_{2}$ and lysophosphatidylserine-specific lysophospholipase from rat platelets. $J$ Biochem 1987;101:625631.

26. Irvine RI. How is the level of free arachidonic acid controlled in mammalian cells? Biochem $J$ 1982;204:204-209.

27. Jans SWS, Van Bilsen M, Reutelingsperger CPM, Borgers M, De Jong YF, Van der Vusse GJ. Annexin V in the adult rat heart: isolation, localization and quantitation. $J \mathrm{Mol}$ Cell Cardiol 1995;27:335-348.

28. Karmazyn M, Dhalla NS. Physiological and pathophysiological aspacts of cardiac prostaglandines. Can J Physiol Pharmacol 1989;61:912-921.

29. Kikuchi-Yanoshita R, Yanoshita R, Kudo I, Arai, H, Takamura T, Nokomoto K, Inoue K. Preferential hydrolysis of phosphatidylethanolamine in rat ischemic heart homogenates during in vitro incubation. J Biochem 1993;114:33-38.

30. Konieczkowski M, Sedor JR. Cell-specific regulation of group II phospholipase $A_{2}$ expression in rat mesangial cells. J Clin Invest 1993;92:2524-2532.

31. Kriegsmann J, Muller WD, Richter W, Wunderlich J, Wallukat G. Demonstration of membraneassociated phospholipase $\mathrm{A}_{2}$ in cultivated heart muscle cells by immunogold-technique in surface replicas. Acta Histochem 1993;95:61-66.

32. Langer GA. Myocardial calcium compartimentation. Trends Cardiovas Med 1994;4:103-109.

33. Lauritzen I, Heurtaux C, Lazdunski M. Expression of group II PLA $\mathrm{P}_{2}$ in rat brain after severe forebrain ischemia and in endotoxin shock. Brain Res 1994;651:353-356.

34. Lee KJ, Ross RS, Rockman HA, Harris AN, O Brien TX, Van Bilsen M, Shubeita HE, Kandolf R, Brem G, Price J, Evans SM, Zhu H, Franz WM, Chien KR. Myosin light chain-2 luciferase transgenic mice reveal distinct regulatory programs for cardiac and skeletal muscle specific expression of a single contractile protein gene. J Biol Chem 1992;267:15875-15885.

35. Levrat $C$, Louisot P. Dual localization of the mitochondrial phospholipase $A_{2}$ : outer membrane contact sites and inner membrane. Biochem Biophys Res Co 1992;183:719-724.

36. Lin LL, Wartmann M, Lin AY, Knopf JL, Seth A, Davis RJ. cPLA 2 is phosphorylated and activated by MAP kinase. Cell 1993;72:269-278.

37. Marber MS, Mestril R, Chi SH, Sayen R, Yellon DM, Dillmann WH. Overexpression of the rat inducible $70-\mathrm{kD}$ heat stress protein in a transgenic mouse increases the resistance of the heart to ischemic injury. J Clin Invest 1995;95:1446-1456.

38. Maury CPJ, Teppo AM. Circulating tumor necrosis factor alpha (cachetin) in myocardial infarction. J Intern Med 1989;225:333-336.

39. Miyazaki Y, Gross RW, Sobel BE. Biochemical and subcellular distribution of arachidonic acid in rat myocardium. Am J Physiol 1987;253:C846-C853.

40. Miyazaki Y, Gross W, Sobel BE, Saffitz JE. Selective turnover of sarcolemmal phospholipids with lethal cardiac myocyte injury. Am J Physiol 1990;259:C325-C331.

41. Neely JR, Leibermeister H, Battersby EJ, Morgan HE. Effect of pressure development on oxygen consumption by isolated rat heart. Am J Physiol 1967;212:804-814.

42. Ohara O, Ishizaki J, Nakano T, Arita H, Tereoka H. A simple and sensitive method for determining transcription initiation site: identification of two transcription initiation sites in rat Type II phospholipase A 2 gene. Nucleic Acids Res 1990;18:6997-7002.

43. Otamiri T, Franzen L, Lindmark D, Tageson C. Increased phospholipase $A_{2}$ and decreased lysophospholipase activity in the small intestinal mucosa after ischemia and revasculariation. Gut 1987;28:1445-1453.

44. Pfeilschifter J, Schalkwijk C, Briner VA, Van den Bosch H. Cytokine-stimulated secretion of Type II phospholipase $A_{2}$ by rat mesangial cells. J Clin Invest 1993;92:2516-2523.

45. Philipson KD, Langer GA, Rich TL. Charged amphiphiles regulate heart contractility and sarcolemma-Ca ${ }^{2+}$ interactions. Am J Physiol 1985;248:H147-H150.

46. Plumier, JCL, Ross BM, Currie RW, Angelidis CE, Kazlaris H, Kollias G, Pagoulatos GN. Transgenic mice expressing the human heat shock protein 70 have improved post-ischemic myocardial recovery. J Clin Invest 1995;95:1854-1860.

47. Post JA, Langer GA, Op den Kamp JAF, Verkleij AJ. Phospholipid asymmetry in cardiac sarcolemma. Analysis of intact cells and gas dissected membranes. Biochim Biophys Acta 1988;943:256-266. 
48. Prasad MR, Lawrentiu MP, Moraru II, Liu X, Maity S, Engelman RM, Das DK. Role of phospholipase $A_{2}$ and $C$ in myocardial ischemic reperfusion injury. Am J Physiol 1991;260:H873H877.

49. Sartipy P, Johansen B, Camejo G, Rosengren B, Bondjers G, Hurt-Camejo E. Binding of human phospholipase $\mathrm{A}_{2}$ Type II to proteoglycans. J Biol Chem 1996;271:26307-26314.

50. Schalkwijk C, Pfeilschifter J, Marki F, Van den Bosch H. Interleukin-1- $\beta$ and forskolin-induced synthesis and secretion of group II phospholipase $\mathrm{A}_{2}$ and prostaglandin E2 in rat mesangial cells is prevented by transforming growth factor- $\beta 2$. J Biol Chem 1992;67:8846-8851.

51. Sharp JD, White DL. Cytosolic phospholipase $A_{2}$ mRNA levels and potential for transcriptional regulation. J Lip Med 1993;8:183-189.

52. Termin E, Leonardi J, Lafont H, Nalbone G. Intracellular phospholipase activity in rat heart: comparison between endogenous and exogenous substrates. Biochimie 1987;69:245-248.

53. Van Bilsen $M$ and Van der Vusse GJ. Phospholipase $A_{2}$-dependent signalling in the heart. Cardiovasc Res 1995;30:518-529.

54. Van Bilsen M, Van der Vusse GJ, Willemsen PHM, Coumans CA, Roemen THM, Reneman RS. Effect of nicotinic acid and mepacrine on fatty acid accumulation and myocardial damage during ischemia and reperfusion. $J$ Mol Cell Cardiol 1990;22:155-163.

55. Van Bilsen M, Van der Vusse GJ, Willemsen PHM, Coumans WA, Roemen ThHM, Reneman RS. Lipid alterations in isolated working rat hearts during ischemia and reperfusion: its relation to myocardial damage. Circ Res 1989;64:304-314.

56. Van Bilsen M. The significance of myocardial non-esterified fatty acid accumulation during ischemia and reperfusion. Thesis, Maastricht University, The Netherlands: 1989

57. Van den Bosch H, Schalkwijk C, Pfeilschifter J, Marki F. The induction of cellular group II phospholipase $\mathrm{A}_{2}$ by cytokines and its prevention by dexamethasone. Adv Exp Med Biol 1992:318:1-10.

58. Van der Vusse GJ, Glatz JFC, Stam HCG, Reneman RS. Fatty acid homeostasis in the normoxic and ischemic heart. Physiol Rev 1992;72:881-940.

59. Van der Vusse GJ, Roemen THM, Prinzen FW, Coumans WA, Reneman RS. Uptake and tissue content of fatty acids in dog myocardium under normoxic and ischemic conditions. Circ Res 1982;50:538-546.

60. Van der Vusse GJ, Van Bilsen M, Reneman RS. Is phopholipid degradation a critical event in ischemia- and reperfusion-induced damage. NIPS 1989;4:49-53.

61. Van der Vusse GJ, Van Bilsen M, Reneman RS. Ischemia and reperfusion induced alterations in membrane phospholipids: an overview. Ann NY Acad Sci 1994;723,1-14.

62. Van der Vusse GJ, Van Bilsen M, Sonderkamp T, Reneman RS: Hydrolysis of phospholipids and cellular integrity. In: HM Piper (ed). Pathophysiology of severe ischemic myocardial injury. Kluwer Academic Publishers, Dordrecht, The Netherlands, 1990:167-193.

63. Vervoordeldonk MJBM, Pineda-Torra IM, Aarsman AJ, Van den Bosch H. Aspirin inhibits expression of the interleukin-1 $\beta$-inducible group II phospholipase $A_{2}$. FEBS Lett 1996;397;108112.

64. Vesterqvist O, Sargent CA, Grover GJ, Ogletree ML. Myocardial calcium-independent phospholipase $\mathrm{A}_{2}$ activity during global ischemia in isolated rabbit hearts. Cardiovas Res 1996;31:932-940.

65. Walker G, Kunz D, Pignat W, Wiesenberg I, Van den Bosch H, Pfeilschifter J. Tetranactin inhibits interleukin $1 \mathrm{~B}$ and cAMP induction of group II phospholipase $A_{2}$ in rat renal mesangial cells. Eur J Pharm 1996;306:265-270.

66. Weglicki WB, Owens K, Urschel CW, Serur JR, Sonnenblick EH. Hydrolysis of myocardial lipids during acidosis and ischemia. Recent Adv Stud Card Struct Metab 1973;3:781-793.

67. Wolf MJ, Gross RW. The calcium-dependent association and functional coupling of calmodulin with myocardial phospholipase $A_{2}$. J Biol Chem 1996;271:20989-20992.

68. Wolf RA, Gross RW. Identification of neutral active phospholipase $\mathrm{C}$ which hydrolyzes choline glycerophospholipids and plasmalogen selective phospholipase $\mathrm{A}_{2}$ in canine myocardium. $J$ Biol Chem 1985;260:7259-7303.

69. Yamauchi-Takihara K, Ihara Y, Ogata A, Yoshizaki K, Azuma J, Kishimoto T. Hypoxic stress induces cardiac myocyte-derived interleukin-6. Circulation 1995;91:1520-1524. 


\section{Chapter 3}

\section{Cloning and cellular distribution of type IIA secretory phospholipase $\mathrm{A}_{2}$ expressed in the heart.}

Published as:

LJ de Windt, PHM Willemsen, S P pping, GJ Van der Vusse, RS Reneman, M Van Bilsen. Cloning and cellular distrubution of a group II phospholipase $\mathrm{A}_{2}$ expressed in the heart. J Mol Cell Cardiol 1997;29:2093-2106. 


\begin{abstract}
Phospholipase $A_{2}$ has been considered to play a role in physiological membrane turnover in cardiac tissue and in the degradation of membrane lipids under pathophysiological conditions, such as ischemia and reperfusion. We report the cloning of a cDNA encoding a member of the $\mathrm{Ca}^{2+}$-dependent, low molecular mass type IIA secretory phospholipase $\mathrm{A}_{2}$ (type IIA sPLA ${ }_{2}$ ) present in rat heart. The cDNA predicts a mature protein of 146 amino acid residues including a 21 amino acid sequence at the N-terminal end, which has the features characteristic of eukaryotic secretory signal peptides. The deduced amino acid sequence constitutes an enzyme of the type II class of sPLA $\mathrm{P}_{2} \mathrm{~S}$, and resembles type IIA sPLA $\mathrm{S}_{2} \mathrm{~S}$ from other mammalian sources. A Northern blot analysis performed to determine the tissue distribution showed that rat ileum contains the largest amount of the type IIA sPLA $\mathrm{P}_{2}$ transcript among the tissues examined, a weaker signal was present in heart, spleen, and soleus muscle, and no signal could be detected in EDL muscle, stomach, liver, kidney, brain, and lung. Northern blot analysis and RT-PCR techniques indicate the presence of this enzyme in neonatal and adult rat cardiomyocytes and in a cultured rat cardiac fibroblast-like cell line, but not in rat cardiac-derived endothelial cell lines. Transcription levels of rat heart type IIA $\mathrm{SPA}_{2}$ in isolated neonatal rat cardiomyocytes were found to increase after stimulating the cells with tumor necrosis factor- $\alpha$ or the $\alpha_{1}$-adrenergic agonist phenylephrine.
\end{abstract}




\section{Introduction}

Phospholipases $\mathrm{A}_{2}\left(\mathrm{PLA}_{2} \mathrm{~s}\right)$ (phosphatide 2-acylhydrolase; EC 3.1.1.4) hydrolize the $s n-2$ fatty acyl ester bond of phospholipids giving yield to fatty acids and lysophospholipids. PLA $\mathrm{P}_{2} \mathrm{~S}$ have been implicated in such diverse activities as membrane turnover, signal transduction, and inflammation (Van Bilsen and Van der Vusse, 1995). Furthermore, myocardial ischemia and reperfusion are associated with disturbances in phospholipid homeostasis. The net loss of membrane phospholipids and the concomitant accumulation of lysophospholipids and fatty acids are likely to compromise cellular integrity (Van der Vusse et al., 1992). Several lines of evidence support the notion that the degradation of phospholipids during ischemia/reperfusion is due to the activation of myocardial PLA $\mathrm{P}_{2}$.

In mammalian cells three types of $\mathrm{PLA}_{2} \mathrm{~S}$ have been distinguished, i.e., an ubiquitously expressed high molecular mass $(85 \mathrm{kDa}) \mathrm{PLA}_{2}$ with a high specificity for arachidonic acid-containing phospholipids (Sharp et al., 1991), a $40 \mathrm{kDa} \mathrm{Ca}{ }^{2+}$ independent enzyme that prefers $s n-2$ arachidonoyl plasmalogens as substrate (Hazen et al.,1990, Clark et al., 1991), and the low molecular mass (13-15 kDa), $\mathrm{Ca}^{2+}$-dependent $\mathrm{PLA}_{2} \mathrm{~S}$ (Van Schaick et al., 1993, Komada et al., 1989, Ishizaki et al., 1989).

At present, it is unclear which type(s) of $\mathrm{PLA}_{2}$ is (are) involved in the degradation of phospholipids during ischemia and reperfusion. The findings in a number of studies indicate that a calcium-dependent non-specific PLA $A_{2}$ may play an essential role in the hydrolysis of myocardial phospholipids under these conditions. This notion is substantiated by the finding that antibodies raised against a snake venom type II sPLA $\mathrm{A}_{2}$ were able to inhibit phospholipase activities in the isolated rat heart after an ischemic insult (Prasad et al., 1991). Further indications for the presence of a membrane-associated type IIA $\mathrm{SPLA}_{2}$ in rat heart myocytes were provided by a histochemical study of Kriegsmann and colleagues (1993) using a monoclonal antibody against bee venom PLA .

To allow a more specific analysis of the (patho)physiological role of type IIA sPLA ${ }_{2}$ within the heart, the availability of its cDNA would be very helpful. Because of the presence of marked differences in subcellular localization and subtle differences in DNA sequence between type IIA $\mathrm{SPLA}_{2} \mathrm{~s}$ that were cloned from various rat tissues (Van Schaick et al., 1991, Komada et al., 1989, Ishizaki et al., 1989), we have chosen for a strategy with conventional cloning techniques to identify the cDNA of type IIA sPLA ${ }_{2}$ that might be present in the heart. In addition, we wanted to determine the tissue distribution of this $\mathrm{PLA}_{2}$ and its cellular distribution within the heart. Furthermore, it was investigated whether in cardiomyocytes the transcription level of this $\mathrm{PLA}_{2}$ is subject to regulation by cytokines similar to what has been found in other cell types, like rat vascular smooth cells (Nakano et al., 1990), rat hepatoma cells (Crowl et al., 1991), and rat mesangial cells (Pfeilschifter et al., 1989). 


\section{Materials and Methods}

\section{Isolation of adult and neonatal cardiomyocytes}

Adult cardiomyocytes (CMC) were isolated from the ventricles of rats (Wistar-Kyoto) as described previously by Linssen et al. (1993). Briefly, after perfusion of the isolated heart with a collagenase solution, the ventricles were chopped and incubated in Modified Krebs Ringer buffer containing $2.5 \mathrm{mM} \mathrm{CaCl}_{2}, 0.06 \%$ collagenase type I (Gibco BRL, Breda, the Netherlands) and $1 \%$ bovine serum albumin (BSA). Cells were centrifuged at $25 \times \mathrm{g}$ for $90 \mathrm{~s}$. The cells were plated on tissue culture dishes in CMC culture medium (i.e., M199, $2 \mathrm{mM}$ L-glutamine, $13 \mathrm{mM} \mathrm{NaHCO}$, $10 \mathrm{mM}$ HEPES, $100 \mathrm{U} / \mathrm{ml}$ penicillin, $100 \mu \mathrm{g} / \mathrm{ml}$ streptomycin, $4 \%$ fetal calf serum). The immortal cardiac-derived endothelial cell lines RHEC-50 and RHEC-116, and the cardiac-derived fibroblast-like cell line CFLC-122 (cell lines described by Linssen $e t$ al., 1990 and 1993) were cultured in DMEM (Gibco 42430) supplemented with 10\% fetal calf serum (Gibco BRL).

Neonatal ventricular myocytes were isolated as described by Iwaki $e$ t al. (1990) with slight modifications. Briefly, hearts were removed from decapitated 1 to 3 days old Wistar-Kyoto rats. Atria were trimmed off and ventricular tissue was cut into pieces, transferred to a spinner flask and digested to single cells with collagenase type I (Gibco BRL) and pancreatin (Gibco BRL) in Ads-buffer ( $\mathrm{pH} 7.35$ ), consisting of 116 $\mathrm{mM} \mathrm{NaCl}, 20 \mathrm{mM}$ HEPES, $0.9 \mathrm{mM} \mathrm{NaH}_{2} \mathrm{PO}_{4}, 5 \mathrm{mM}$ glucose, $5.4 \mathrm{mM} \mathrm{MgSO}_{4}$. The cell suspension was loaded on a discontinuous gradient of Percoll (Sigma Chemical Co., St. Louis, USA) with two different densities (1.059 and $1.082 \mathrm{~g} / \mathrm{ml}$, respectively) to separate the cardiomyocytes from non-myocytes, mainly fibroblasts and endothelial cells. The cardiomyocytes were allowed to adhere to tissue culture dishes coated with $1 \%$ gelatin type B (Sigma G-9382) in a 4:1 mixture of DMEM (Gibco 42430) and M199 (Gibco 31153), supplemented with 10\% horse serum (Gibco 16050), 5\% newborn calf serum (Sera-Lab, Sussex, UK), and antibiotics (pennicilin $100 \mathrm{U} / \mathrm{ml}$, streptomycin $100 \mu \mathrm{g} / \mathrm{ml}, \mathrm{P} / \mathrm{S}$, Gibco BRL).

\section{$R T-P C R$}

Total RNA from adult rat heart (Lewis strain), isolated myocytes, and the above described cardiac-derived cell lines, was prepared using TRIzol Reagent (Gibco BRL). Reverse transcription (RT) was performed with Superscript ${ }^{\mathrm{TM}}$-II RNAse $\mathrm{H}$ reverse transcriptase (Gibco BRL) according to the instructions of the supplier. Polymerase chain reaction (PCR) was performed on a DNA thermal cycler (Perkin Elmer Co., Norwark, USA) using Thermus Aquaticus (Taq) polymerase (Gibco BRL). After an initial incubation of $5 \mathrm{~min}$ at $95^{\circ} \mathrm{C}$, the reactions were cycled 30 times between $55^{\circ} \mathrm{C}$, $72{ }^{\circ} \mathrm{C}$, and $95{ }^{\circ} \mathrm{C}$, all for $1 \mathrm{~min}$. An additional extension reaction at $72{ }^{\circ} \mathrm{C}$ for $10 \mathrm{~min}$ was included after cycle 30 . Samples were size-fractionated by agarose gel electrophoresis and visualized after staining with ethidium bromide. RT-PCR and PCR reactions were performed with combinations of primers designated PLA-F1 [5'GAGTTTGGGCAAATGATTC-3], PLA-R1 [5'-CAGCTTTATCGCACTGGCA-3'], and PLA-R2 [5'-AGTCCTGGTTTGTAGAGCAG-3'] (all purchased from Pharmacia, Uppsala, Sweden). PLA-F1 and PLA-R1 correspond to bp 73-91 and bp 328-346 of

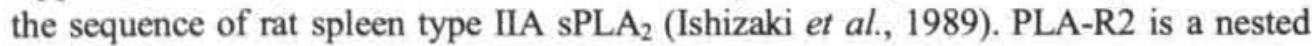


primer in the rat heart PLA 2 cDNA sequence corresponding to bp 291-311 in Figure 2. The subsequently found 273 bp RT-PCR product was subcloned in a pBluescript vector. The fragment was excised as a Xho I/Pst I fragment and radioactively labeled using $\left[{ }^{32} \mathrm{P}\right]-\mathrm{dCTP}(3000 \mathrm{Ci} / \mathrm{mmol}$, NEN DuPont, Dordrecht, the Netherlands) by random priming using a commercial kit (rediprime ${ }^{\mathrm{M} M}$, Amersham, Buckinghamshire, UK). The probe was designated PLA-probe.

\section{Figure 1}

PCR amplification of RT-RNA from adult rat myocytes. The PCR products generated with primers PLA-F1 and PLA-R1 on RT-RNA from adult rat cardiomyocytes were resolved by gel electrophoresis and stained with ethidium bromide. Control refers to PCR reaction to which $\mathrm{H}_{2} \mathrm{O}$ was added instead of template (negative control). An 1 $\mathrm{kb}$ ladder (Gibco BRL) was used as molecular weight marker.

\section{RACE-RT-PCR}



5'-RACE-RT-PCR (rapid amplification of cDNA-ends-reverse transcription polymerase chain reaction) was applied to generate the full length cDNA from adult rat cardiomyocyte total RNA, using a kit from Gibco BRL. Primer PLA-R1 was used for first round amplification, while the supplied anchor primer and the nested primer PLAR2 were used for the second round of amplification, according to the supplier's instructions.

\section{Library screening}

$1.2 \times 10^{6}$ clones from an adult rat heart UNI-ZAP ${ }^{\mathrm{TM}}$ XR-cDNA library (Stratagene, La Jolla, California, USA) were lifted in duplicate onto nylon filters. The filters were denatured, baked at $80^{\circ} \mathrm{C}$ for $1 \mathrm{~h}$, prehybridized for $2 \mathrm{~h}$ in $6 \times$ SSPE, $1 \times$ Denhardt's solution, $0.5 \%$ sodium dodecyl sulfate (SDS), $100 \mu \mathrm{g} / \mathrm{ml}$ salmon sperm DNA at $58{ }^{\circ} \mathrm{C}$, and hybridized overnight in the same solution with $10^{6} \mathrm{cpm} / \mathrm{ml}$ of ${ }^{32} \mathrm{P}$-labeled PLAprobe. Final washing conditions were $0.1 \times \mathrm{SSC}$ at $60^{\circ} \mathrm{C}$ for $15 \mathrm{~min}$.

Filters were exposed to X-ray film for $24 \mathrm{~h}$. After three subsequent rounds of duplicate filter lifting in order to obtain a purified clone, 12 potential positive clones were found and subjected to an In Vivo Excision reaction of the insert, using the ExAssist/SolR system (Stratagene), thereby directly cloning the insert into a 
pBluescript vector. Candidate clones were subjected to restriction enzyme digest analysis and sequence reactions using the $\mathrm{T} 7$ sequence kit (Pharmacia).

Northern blot analysis

Total RNA from various rat tissues and cells was isolated using TRIzol Reagent (Gibco BRL) and the RNA (10 $\mu \mathrm{g})$ was size-fractionated on a $1 \%$ agarose, $18 \%$ formaldehyde gel according to the method described in Sambrook et al. (1989). The RNA was transferred to a nylon filter (Hybond-N, Amersham) by capillary transfer overnight. After UV crosslinking and baking at $80{ }^{\circ} \mathrm{C}$ for $2 \mathrm{~h}$, the filters were prehybridized for $2 \mathrm{~h}$ in $6 \times \mathrm{SSPE}, 1 \times$ Denhardt s solution, $0.5 \%$ sodium dodecyl sulfate (SDS), $100 \mu \mathrm{g} / \mathrm{ml}$ salmon sperm DNA at $58^{\circ} \mathrm{C}$ and hybridized in the same solution with $10^{6} \mathrm{cpm} / \mathrm{ml}$ of ${ }^{32} \mathrm{P}$-labeled PLA- probe. Final washing conditions were $1 \times \mathrm{SSC}$ with $0.1 \% \mathrm{SDS}$ at $50{ }^{\circ} \mathrm{C}$ for $30 \mathrm{~min}$. To correct for possible differences in loading and transfer, the filters were also hybridized with an ${ }^{32} \mathrm{P}$-labeled $18 \mathrm{~S}$ probe. Filters were exposed to X-ray film with two intensifying screens.

\section{Stimulation of neonatal cardiomyocytes}

For these experiments, after isolation from the hearts, $2 \times 10^{6}$ neonatal rat cardiomyocytes were allowed to adhere to $10 \mathrm{~cm}$ tissue culture dishes coated with $1 \%$ gelatin type B in a 4:1 mixture of DMEM (Gibco 42430) and M199 (Gibco 31153), supplemented with $10 \%$ horse serum (Gibco 16150 ), $5 \%$ newborn calf serum, and $\mathrm{P} / \mathrm{S}$. After $24 \mathrm{~h}$ the cells were rinsed twice with sterile PBS and serum free medium was added (a 4:1 mixture of DMEM and M199 with P/S). After $24 \mathrm{~h}$ tumor necrosis factor$\alpha(\mathrm{TNF}-\alpha$, final concentration $1 \mathrm{nM})$ or phenylephrine (PE, final concentration 10 $\mu \mathrm{M})$ were added to the cells. After a $16 \mathrm{~h}$ incubation unstimulated cells, TNF- $\alpha$ stimulated, and PE-stimulated cells were harvested for RNA isolation using TRIzol reagent (Gibco). The RNA was subjected to Northern blot analysis according to the method described above. The Northern blots were exposed to storage phosphor screens and subsequently scanned and quantified using a PhosphorImager and the ImageQuant software (Molecular Dynamics, Sunnyvale, CA, USA).

\section{Results}

\section{$R T$-PCR on isolated myocytes}

In order to investigate the presence of type IIA sPLA $\mathrm{P}_{2}$ in cardiac myocytes, two primers, designated PLA-F1 and PLA-R1, were generated corresponding to bp 73-91 and bp 328-346 of the sequence of rat spleen type IIA sPLA (Ishizaki et al., 1989). PCR amplification using these primers on reverse transcribed (RT) RNA from isolated adult rat heart myocytes, produced several bands among which one prominent band of the expected size of $273 \mathrm{bp}$ (Figure 1). These fragments were subcloned into the pBluescript vector and sequenced in both directions. Sequence comparison was performed using the GenBank data base. This confirmed only the 273 bp PCR-product to be part of a type IIA sPLA2 cDNA. The $273 \mathrm{bp}$ fragment was found to be nearly identical to the corresponding part of rat spleen and platelet type IIA sPLA $\mathrm{P}_{2}$. Only at one position (bp 126 in Figure 2/Figure 3, Panel A) a thymidine residue in the 
spleen/platelet type was found to be be replaced by a cytidine residue in the heart cDNA.

The 273 bp PCR-product was subcloned in the pBluescript vector and isolated as a Xho I/Pst I fragment and labeled with $\left[{ }^{32} \mathrm{P}\right]-\mathrm{dCTP}$. The fragment was designated PLA-probe and used as a probe for the screening of a cDNA library and in RNA blot analysis.

\section{Screening of rat heart cDNA library.}

In order to obtain the full length cDNA of the PLA $A_{2}, 1.2 \times 10^{6}$ clones of an adult rat heart cDNA library were screened, using the radioactively labeled PCR-fragment as a probe. Twelve potential candidates were identified after three sequential rounds of plaque purification. After using the ExAssist/SolR system supplied with the cDNA library to allow efficient excision of the pBluescript phagemid, the candidates were subjected to restriction analysis and Southern blot analysis. Based on these analyses, only one of the twelve candidates proved to contain a part of a type IIA sPLA $\mathrm{PDNA}_{2}$. This was affirmed after sequencing the pBluescript plasmid containing the fragment of approximately $600 \mathrm{bp}$. This revealed that the clone contained a large part of the coding region, starting from basepair 104, and the complete 3 untranslated region ending in a poly(A) tail (Fig. 2). However, the 5 end of the coding region was missing.

\section{5'-RACE-PCR}

In order to procure the missing part of the coding region, the 5'rapid amplification of cDNA ends-PCR technique was applied. Total RNA from adult rat heart myocytes was isolated, and a first round PCR amplification was performed, using primer PLA$\mathrm{R} 1$ to produce a crude 5 '-rat heart PLA $\mathrm{A}_{2}$-cDNA sample. This product was tailed with a supplied anchor primer at its 5' end and amplified using a supplied complementary anchor primer and the nested PLA 2 primer, designated PLA-R2. The product obtained was electrophorized on an agarose gel and visualized after staining with ethidium bromide. A very faint PCR-fragment of approximately $400 \mathrm{bp}$ was isolated from the gel via the Qiaex gel extraction procedure (Qiagen $\mathrm{GmbH}$, Hilden, Germany), and reamplified with the last set of primers that was applied in the 5'RACE-PCR reaction. This product was cloned into a PCR-II vector of the TA cloning kit (InVitrogen Corp., San Diego, USA). Sequencing reactions using the primers PLA-F1 and PLA-R2 revealed the product as being a part of a type $\Pi \mathrm{A}$ sPLA 2 cDNA and containing the missing 5 end of the rat heart type IIA sPLA $\mathrm{CDNA}_{2}$.

\section{Cloning of full length $P L A_{2}$}

The first 404 basepairs of the PLA 2 5-RACE-PCR fragment and the clone isolated by screening the cDNA library were combined, using internal BamHI sites at bp 164 and bp 610 in de cDNA sequence of type IIA sPLA ${ }_{2}$ and an EcoRI site in de anchor primer used in the 5 RACE-PCR reaction, which resulted in the full length PLA ${ }_{2}$ cDNA in pBluescript. In this sequence an open reading frame (438 basepairs) was found, predicting a protein of 146 amino acids, containing a short sequence composed of 21 amino acid residues at the $\mathrm{N}$-terminal end, which has the features characteristic of eukaryotic secretory signal peptides. Furthermore, the enzyme contains a carboxylterminal extension of six amino acids (KGKTPSC) and misses the elapid loop present 
in type I sPLA $A_{2}$, both features being characteristic for type II sPLA $A_{2}$ enzymes (Davidson et al., 1990, Figure 2/Figure 3, Panel A).

Met Lys Val Leu Leu Leu Leu Ala Val Val Ile Met Val phe Gly Ser Ile Gln Val Gln

Gly Ser Leu Leu Glu phe Gly Gln Met Ile Leu phe Lys Thr Gly Lys Arg Ala Asp Val 61 GGG AGC CTT CTG GAG TIT GQG CAA ATG ATT CTG TTT AAG ACA GGA AAG AGA GCT GAT GTT

Thr Asp Trp Cys Cys Val Thr His Asp Cys Cys Tyr Asn Arg Leu Glu Lys Arg Gly Cys

181 ACA GAT TGG TGC TGT GTG ACT CAT GAC TGT TGT TAC AAC CGT CTG GAG AAA CGT GGA TGT

Gly Thr Lys Phe Leu Thr Tyr Lys Phe Ser Tyr Arg Gly Gly Gin Ile Ser Cys Ser Thr 241 GGC ACA AAG TIT CTG ACC TAC AAG TTC TCC TAC CGA GGG GGC CAA ATC TCC TGC TCT ACA

Asn Gin Asp Ser Cys Arg Lys Gin Leu Cys Gin Cys Asp Lys Ala Ala Ala Glu Cys Phe 301 AAC CAG GAC TCC TGC CGG AAA CAG CTG TGC CAG TGC GAT AAA GCT GCC GCT GAA TGT TIT

Ala Arg Asn Lys Lys Ser Tyr Ser Leu Lys Tyr Gln Phe Tyr Pro Asn Ly's Phe Cys Lys

361 GCC CGG AAC AAG AAA AGC TAC AGT TTA AAG TAC CAG TTC TAC CCC AAC AAG TTT TGC AAA

Gly Lys The Pro Ser Cys

421 GGG AAG ACG CCC AGT TGC IGAAMAGACATCTTCTGAAACATCCAGACATCCTCTAACACCTCTCCTAGCCCA

\section{Figure 2}

Nucleotide sequence of the cDNA of rat heart type IIA secretory phospholipase $\mathrm{A}_{2}$ (type IIA $\left.\mathrm{sPLA}_{2}\right)$.The cloned nucleotide sequence and deduced amino acid sequence of the largest found open reading frame (ORF) of rat heart type IIA $s P L A_{2}$ is shown. The start codon (position +1 ) and stopcodon are indicated in bold. The putative polyadenylation signal in the 3 -untranslated region is indicated in bold. The first 21 amino acids residues that form the eukaryotic signal peptide for protein secretion are indicated in bold. The respective position of the primers PLA-F1, PLA-R1 and PLA-R1 are underlined, and the predicted cleavage site for signal peptidase $(\downarrow)$ is indicated. 
At the DNA level the differences with the sequence isolated from spleen by Ishizaki et al. (1989), and from platelets by Komada et al. (1989) are minimal. Within the coding region at bp 126 a thymidine residue in the spleen and platelet type has been replaced by a cytidine residue in the heart cDNA. This replacement has no consequences for the amino acid sequence. In the 3 untranslated region at bp 457 a guanidine residue is present in the platelet type, while in the heart and spleen type a thymidine residue is present. Furthermore, the platelet cDNA contains a short insertion of two adenine and three cytidine residues at bp 531 and at bp 676 a guanidine residue in the spleen and platelet type is substituted by a cytidine residue in the heart sequence. However, more differences in the coding region can be observed between the PLA $\mathrm{A}_{2}$ cDNAs cloned from rat heart and rat liver (Van Schaick et al., 1989). In addition to the basepair difference in the coding region (bp 126), the rat liver cDNA shows a cytidine residue at bp 344 and a guanidine residue at bp 345, resulting in an arginine at position 115 in the amino acid sequence, whereas an alanine residue is found in the heart, spleen, and platelet type IIA sPLA 2 (Figure 3, Panel A and B).

\section{Tissue and cellular distribution}

Northern blot analysis showed this $\mathrm{PLA}_{2}$ transcript to be present in a number of rat tissues and to correspond to a $0.9 \mathrm{~kb}$ signal (Figure 4). In rat ileum a very strong signal was found, and a relatively weaker signal in heart, spleen, and soleus muscle. No signal could be detected in rat EDL muscle, stomach, kidney, brain and lung tissue (Figure 4).

In addition it was investigated whether the type IIA sPLA $\mathrm{A}_{2}$ was present in isolated adult cardiomyocytes and several cardiac-derived cell lines (Figure 5). A positive signal was observed in adult rat ventricular myocytes and in the cardiacderived fibroblast-like cell line CFLC-122. No hybridization signal was found in the cardiac-derived endothelial cell lines RHEC-50 and RHEC-116 (Linssen et al.,1993b), not even after prolonged exposure of the film. Relative to the signal obtained in total heart $(100 \%)$ the signals in the cardiomyocytes and cardiac-derived fibroblast-like cell line amounted to $105 \%$ and $130 \%$, respectively (Figure 5).

To check whether type IIA sPLA $\mathrm{P}_{2}$ was indeed absent in the endothelial cell lines, RT-PCR was applied because of the greater sensitivity levels that are intrinsic to this technique. RT-PCR was performed on total RNA isolated from rat ileum, total heart, isolated adult cardiomyocytes and from the two cardiac-derived endothelial cell lines and the cardiac-derived fibroblast-like cell line, using PLA-F1 and PLA-R1 as primers (Figure 6). As expected, PCR-fragments of expected size (273 bp) were found in ileum and total heart. Furthermore, a similar signal was obtained in isolated adult cardiomyocytes and the cardiac-derived fibroblast-like cell line. In contrast, no signal was detected in either one of the cardiac-derived endothelial cell lines, thereby validating the Northern blot data shown above. 
Rat heart

Rat spleen

Rat platelet

Rat. liver

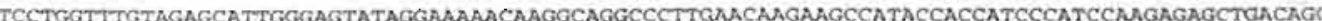



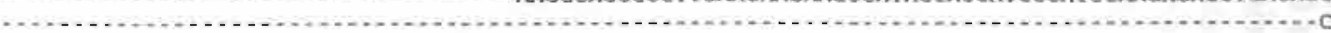
-

60

so

100

TGAAGGTCCTCCTGTTGCTAGCAGTTGTGATCATGGCCTTGGCTCAATTCAGGTCCAGGGGAGCCTTCTGGAGTTTGGGCAMATGATTCTGTTTAAGACAGGAAACAGAGCTGATGT ATGAAGGTCCTCCTGTTGCTAGCAGTTGTGATCATGGCCTTTGGCTCAATTCAGGTCCAGGGGAGCCTTCTGGAGTTIGGGCAAATGATTCTGTTTAAGACAGGAAAGAGAGCTOATGTI ATGNAGGTCCTCCTGTTGCTAGCAGTTGTGATCATGGCCTTTGGCTCAATTCAGGTCCAGGGGAGCCTTCTGGAGTTTGGGCNANTAATTCTGTTTAAGACAGGMAGAGAGCTGATGTP A.

240

260

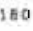

220

240

AGCTACGGCTTCTACGGTTGCCATTGTGGTGTGGGTGGCAGÄGGATCCCCCAAGGATGCCACAGATTGGTGCTGTGTGACTCATGACTGTTACTGTAACCGTCTGGAGAACGTGGATGT AGCTATGGCTTCTACGGTTGCCATTGTGGTGTGGGTOGCAGAGGATCCCCCAAGGATGCCACAGATTGGTGCTGTGTGACTCATGACTGTTICTGTAACCGTCTJGAGAAACGTGGATGT AGCTATGGCTTCTACGGTTGCCATTGTGGTGTGGGTGGCAGAGGATCCCCCAAGGATGCCACAGATTGGTGCTGTGTGACTCATGACTGTTACTGTAACCGTCTGGAGAAACGTGGATGT AGCTATGGCTTCTACGGTTGCCATTGTGGTGTGGGTGGCAGAGGATCCCCCNGGATGCCACAGATTGGTGCTGTGTGACTCATGACTGTTGTTACAACCGTCTGGAGAAACGTGGATGT

260

280

300

320

310

360

GGCACARAGTTTCTGACCTACAAGTTCTCCTACCGAGGGGGCCAAATCTCCTGCTCTACAAACCAGGACTCCTGCCGGAAACAGCTGTGCCAGTGCGATAAAGCTGCCGCTGAATGTTTTT GGCACARAGTTTCTGACCTACAAGTTCTCCTACCGAGGGGGCCAAATCTCCTGCTCTACAAACCAGGACTCCTGCCGGAAACAGCTGTGCCAGTGCGATSAMGCTGCCGCTGAATGTTTT GGCACAAAGTTTCTGACCTACAAGTTCTCCTACCGAGGGGGCCAAATCTCCTGCTCTACAAACCAGGACTCCTGCCGGAAACAGCTGTGCCAGTGCGATALAGCTGCCGCTGAATGTTTT GGCACARAGTTTCTGACCTACAAGTTCTCCTACCGAGGGGCCNAATETCCTGCTCTACARACCAGGACTCCTGCCGGAN.CAGCTGTGCCAGTGCGATANCOTGCCGCTGAATGTTTT

GCCCGGAACAAGAAAAGCTACAGTTTAAAGTACCAGTTCTACCCCAACAAGTTTTGCAMGGGMGACGCCCAGTTGCTGAAGAGACATCTTCTGMACATCCAGACATCCTCTAACAC GCCCGGAACAAGAAAAGCTACAGTTTANAGTACCAGTTCTACCCCANCAAGTTTGCAAAGGGAGACGCCCAGTTGCTGAAGAGACATCTTCTGAMACATCCAGACATCCTCTAACAC GCCCGGAACAAGALAAGCTACAGTTTAAAGTACCAGTTCTACCCCAACAGTTTTGCAAAGGGAAGACGCCCAGTTGCTEAAAGAGACATCTTCOGALACATCCAGACATCCTCTAACAC



CСTCTCCTAGCCCANCCAATTCCCCAGTGATCAMGAMACACCCCTCTCC -.... TAGAAGCAGGCGGGCCCTTCTGTCTTCACCCAGAAGGAGCCGCTGAAGCCTGATCTTTCCCCA. CCTCTCCTAGCCCAACCAAGTTCCCC RGTGATCAAGNARACACCCCTCTCC - . . - TAGAAGCAGGCGGGCCCTTCTGTCTTCACCCAGAAGGAGCCGCTGMAGCCTGATCTTTCCCCAA

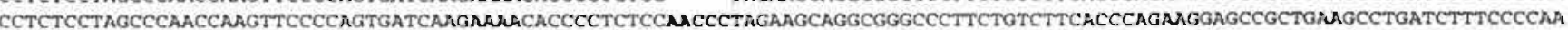
C. 
(b)

$+1$

10

20

30

40

Heart MKVLLLLAVVIMAFGSIQVQGSLLEFGQMILFKTGKRADVSYGFYGCHCG Spleen MKVLLLLAVVIMAFGSIQVQGSLLEFGQMILFKTGKRADVSYGFYGCHCG Platelet MKVLLLLAVVIMAFGSIQVQGSLLEFGQMILFKTGKRADVSYGFYGCHCG Liver SLLEFGQMILFKTGKRADVSYGFYGCHCG

VGGRGSPKDATDWCCVTHDCCYNRLEKRGCGTKFLTYKFSYRGGQISCST VGGRGSPKDATDWCCVTHDCCYNRLEKRGCGTKFLTYKFSYRGGQISCST VGGRGSPKDATDWCCVTHDCCYNRLEKRGCGTKFLTYKFSYRGGQISCST VGGRGSPKDATDWCCVTHDCCYNRLEKRGCGTKFLTYKFSYRGGQISCST

$\begin{array}{cccc}110 & 120 & 130 & 140 \\ \text { NQDSCRKQLCQCDKAAAECFARNKKSYSLKYQFYPNKFCKGKTPSC } & \cdot \dot{*} \text { NQDSCRKQLCQCDKAAAECFARNKKSYSLKYQFYPNKFCKGKTPSC } \\ \text { NQDSCRKQLCQCDKAAAECFARNKKSYSLKYQFYPNKFCKGKTPSC } \\ \text { NQDSCRKQLCQCDKRAAECFARNKKSYSLKYQFYPNKFCKGKTPSC }\end{array}$

\section{Figure 3}

Comparison of type IIA sPLA 2 primary structures. $A$, The cDNA sequences of type IIA sPLA from $_{2}$ rat heart, spleen, platelet and liver are depicted. Alignment is based on maximizing homology using Clustal W 1.60 Multiple sequence alignment software. The start codon (position +1 ) and stop codon are underlined. Differences between the cDNA sequences are given in bold and are depicted within boxes. $B$, the amino acid sequences of rat heart, spleen, platelet and liver type IIA sPLA $\mathrm{A}_{2}$ are depicted in one letter code. Alignment is based on maximizing homology using Clustal W 1.60 software. The first amino acid residue in the rat heart enzyme (position +1$)$ is indicated. Differences between the sequences are given in bold and are depicted whithin boxes. The putative secretory signal peptide is also given in bold. 


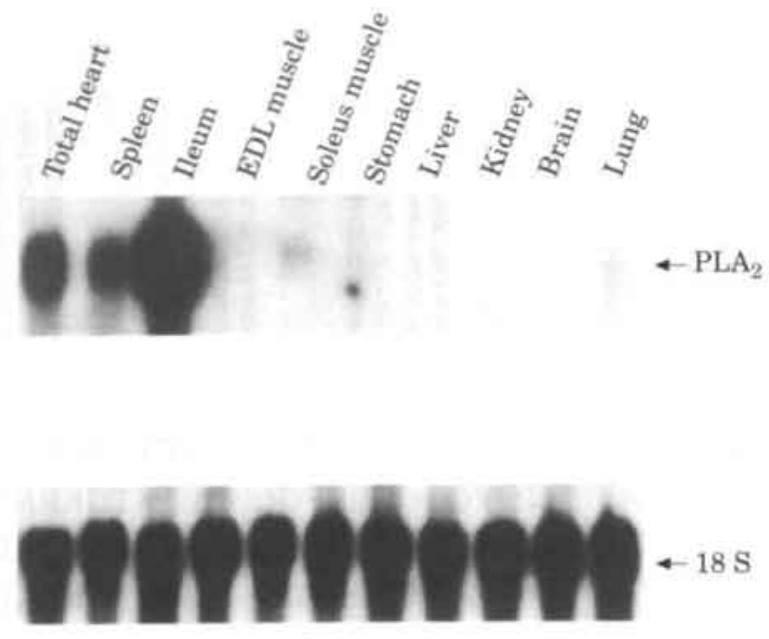

\section{Figure 4}

Northern blot analysis of different rat tissues. Total RNA $(10 \mu \mathrm{g})$ isolated from heart, spleen, ileum, extensor digitorum longus (EDL) muscle, soleus muscle, stomach, liver, kidney, brain and lung was analyzed. A 273 bp ${ }^{32} \mathrm{P}-$


The blot was stripped and reprobed for $18 \mathrm{~S}$ ribosomal RNA to check whether comparable amounts of RNA had been loaded.

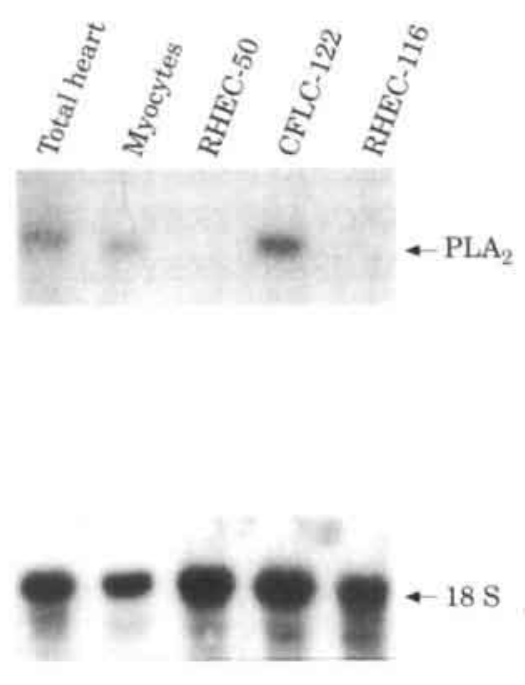

\section{Figure 5}

Northern blot analysis of different rat cardiac cell types. Total RNA (10 $\mu \mathrm{g}$ ) isolated from total heart, adult myocytes, the cardiac-derived fibroblast-like cell line CFLC-122 and two cardiac-derived stable endothelial cell lines RHEC-50 and RHEC-116 was analyzed. As probe, the ${ }^{32} \mathrm{P}$-labeled fragment of rat heart type IIA sPLA 2 CDNA was used. The blot was stripped and reprobed for $18 \mathrm{~S}$ ribosomal RNA to correct for differences in RNA loading. Picture depicts one of two independent Northern blot analyses with similar findings. 


\section{Stimulation of neonatal myocytes}

To monitor whether type IIA sPLA 2 transcription can be induced by cytokines in cardiomyocytes, similar as to what has been shown for several other cell types (Pfeilschifter et al., 1989, Nakano et al., 1990, Crowl et al., 1991), primary cultures of neonatal ventricular myocytes were stimulated with TNF- $\alpha(1 \mathrm{nM})$. In addition, the myocytes were stimulated with the $\alpha_{1}$-adrenergic agonist phenylephrine $(10 \mu \mathrm{M})$. The results show a five fold upregulation of type IIA sPLA ${ }_{2}$ transcript after TNF- $\alpha$ stimulation and a nearly two fold increase after addition of phenylephrine to the culture medium of neonatal rat cardiomyocytes (Figure 7).

\section{Discussion}

The significance of type ILA SPLA diversity

In this study we describe the cloning of the cDNA sequence of a type IIA SPLA present in rat cardiomyocytes and in the cardiac-derived fibroblast-like cell line CFLC122. It appears to be a low-molecular mass enzyme, the presence of which has been previously described in rat spleen, platelets, and liver (Ishizaki et al., 1989, Komada et al., 1989, Van Schaick et al., 1993).


Figure 6

Determination of cellular distribution by RT-PCR amplification. The presence of type IIA sPLA ${ }_{2}$ in different cardiac cell types was assessed by means of PCR with primers PLA-F1 and PLA-R1 on reverse transcribed RNA from adult myocytes, cardiac-derived endothelial cell line RHEC-50 and RHEC-116, and the cardiac-derived fibroblast-like cell line CFLC-122. As positive controls RTPCR amplifications were performed on RT-RNA from ileum and total heart. A PCR reaction without template was also included (control). Lane $M$, molecular weight standard (100 bp ladder, Gibco BRL.)
At the DNA level the differences with the spleen and platelet sequences are minimal and have no consequences for the amino acid composition. The differences with the cDNA sequence of type IIA sPLA $_{2}$ isolated from liver were more pronounced and resulted in the substitution of one amino acid residue. The question could be raised whether the differences between the previously reported rat type IIA SPLA $_{2} \mathrm{~S}$ and the one we cloned from rat heart represent cloning/sequencing artefacts, strain differences, or are the result of differential splicing of one or more related genes. Firstly, it should be noted that the sequence of a part of the cDNA that shows 
differences with the platelet and spleen type IIA sPLA ${ }_{2}$, has been obtained in three independent ways, i.e., after sequencing (i) the 273 bp product of the PCR reaction on reverse-transcribed myocyte RNA, (ii) the fragment picked up from the rat heart cDNA library, and (iii) the product obtained after performing the 5 RACE-PCR. Therefore, the occurrence of cloning or sequencing artefacts of the cardiac PLA $_{2}$ cDNA can be ruled out. Hence, it can concluded that the basepair differences are genuine.

With respect to strain differences, it is noteworthy that in various inbred mouse strains a naturally occurring thymidine insertion within the coding region of the mouse type IIA sPLA ${ }_{2}$ gene has been observed (Kennedy et al., 1995, MacPhee et al., 1995). In addition, the amino acid sequence deduced from platelet type IIA PLA ${ }_{2}$ cDNA (Komada et al.,1989) was found to be different from the previously determined amino acid sequence of the purified platelet enzyme as published by the same research group (Hayakawa et al. 1988). In this case, the discrepancy between the two sequences was also explained on the basis of strain differences. Accordingly, it could be taken into consideration that the few basepair differences between the sequence cloned from the heart in the present study, on the one hand, and the sequences cloned from spleen and platelets, on the other, are due to the use of different rat strains. Indeed, the rat heart type IIA sPLA ${ }_{2}$ cDNA of the present study was cloned from a heart cDNA library of Wistar-Kyoto rats, while the platelet type IIA $s P_{2} A_{2}$ cDNA was cloned from a megakaryocyte cDNA library of Sprague-Dawley rats (Komada et al., 1989).

The gene encoding rat type IIA sPLA ${ }_{2}$ has been cloned (Komada et al., 1990) and Southern blot analysis of genomic DNA revealed that only one single copy exists, which would imply that type IIA sPLA $\mathrm{ADNA}_{2}$ cloned from various cell types or tissues should be identical or derived by differential splicing. However, Chen and coworkers recently published cDNA sequences of two new, low molecular mass $\mathrm{PLA}_{2} \mathrm{~s}$, one cloned from a rat genomic library and relatively abundantly present within the heart and to a lesser extent within the lung (Chen et al., 1994a), and the other cloned from a rat brain library, the mRNA of which was detected in rat testis only (Chen et al., 1994b). These sequences exhibit a limited homology to the type IIA enzymes mentioned in the present study and was therefore designated type V sPLA $\mathrm{P}_{2}$

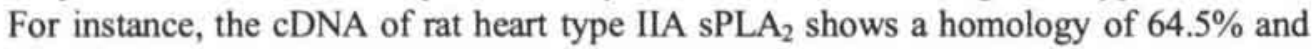
$43.8 \%$ at the DNA and protein level, respectively, with the sequence found by Chen and coworkers (1994a) in the heart. For the testis enzyme these values are even lower ( $59.7 \%$ and $29.5 \%$, respectively). In addition, when screening a rat megakaryocyte cDNA library for the cDNA of platelet type IIA sPLA ${ }_{2}$, Komada and coworkers (1989) found two highly homologous sequences that differed at various positions, which was taken as an indication for the presence of two or more type IIA isoforms. The latter findings point to the existence of several isoforms of type II $\mathrm{PLA}_{2} \mathrm{~S}$ in mammalians. Accordingly, based on the available data no conclusive answer can be given as to whether the observed minimal differences in the type IIA sPLA $\mathrm{P}_{2}$ cloned from various rat tissues/cells are due to strain differences and/or to the existence of splice variants. 


\section{Tissue/cellular distribution}

Via Northem blotting analysis we examined the tissue distribution of the type IIA sPLA $_{2}$, yielding high levels of mRNA in the ileum, and lower levels in spleen, heart, and soleus muscle, while no signal could be detected in EDL muscle, liver, lung, brain, stomach, and kidney. More interestingly, the mRNA of type IIA sPLA $\mathrm{P}_{2}$ was present in isolated cardiomyocytes and cardiac-derived fibroblast-like cells, but not in the immortalized cardiac-derived endothelial cell lines RHEC-116 and RHEC-50 as assessed by Northem blotting and RT-PCR, which points to the absence of a type IIA $\mathrm{sPLA}_{2}$ in the endothelial compartment of the heart. However, to definitively establish whether type IIA sPLA ${ }_{2}$ is not expressed in endothelial cells under in vivo conditions, in situ hybridization experiments on myocardial tissue are required.

The low intensity of the hybridization signal in total heart and in the different cardiac cell types suggests that the type IIA sPLA ${ }_{2}$ is present at relatively low abundance. This notion is supported by the finding that only one positive clone was picked up after screening more than a million plaques of the commercial rat heart cDNA library.

The presence of an eukaryotic secretory signal peptide at the $\mathrm{N}$-terminal end of

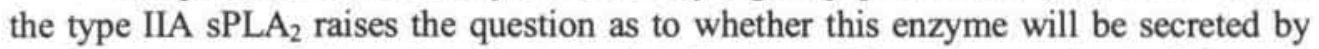
cardiac myocytes. Information about the localization of the other members of the type IIA sPLA ${ }_{2}$ does not give a conclusive answer. In platelets the type IIA sPLA ${ }_{2}$ is localized in secretory granula and is secreted after certain stimuli, the spleen type was found to be membrane-associated, whereas the liver form was purified from the mitochondrial fraction (Aarsman et al., 1989). Some insights into the possible localization of the type IIA sPLA $\mathrm{PL}_{2}$ in the cardiac myocyte is provided by an immunohistochemical study of Kriegsmann and colleagues (1993). Using a monoclonal antibody raised against bee venom type II PLA $A_{2}$ they observed crossimmunoreactivity at the level of the sarcolemma of cultured neonatal rat cardiac myocytes, which could indicate that the enzyme cloned in the present study is also membrane-associated.

\section{(Patho)physiological role of type IIA sPLA}

Myocardial ischemia and reperfusion are associated with disturbances in phospholipid homeostasis. The net loss of membrane phospholipids and concomitant accumulation of lysophospholipids and fatty acids are likely to compromise cellular integrity (Van der Vusse et al., 1992). Earlier findings support the notion that the degradation of phospholipids is directly due to the activation of myocardial phospholipases $A_{2}$, although an impairment of resynthesis processes cannot be excluded (Chien et al., 1984, Van Bilsen et al., 1989). 




Northern blot analysis of stimulated neonatal cardiomyocytes. $A$, Northern blot analysis of type IIA sPLA 2 mRNA in neonatal cardiomyocytes cultured for $16 \mathrm{~h}$ in serum-free designated $(-)$, in the presence of TNF- $\alpha$ (final concentration $1 \mathrm{nM}$ ) designated $(\mathrm{T})$, or phenylephrine (final concentration $10 \mu \mathrm{M}$ ) designated $(\mathrm{P})$. The signals in the RNA samples obtained with the ${ }^{32} \mathrm{P}$-labeled probe for rat heart type IIA sPLA $\mathrm{A}_{2}$ and the $18 \mathrm{~S}$ probe are designated. $B$, Quantitative presentation of Northern blot data. The PLA 2 signal was normalized to the $18 \mathrm{~S}$ signal. The $\mathrm{PLA}_{2} / 18 \mathrm{~S}$ ratio in control cells was set at 1.0 . The Northern blot data of two independent cell cultures are shown. In the other experiment the degree of induction was comparable (4.3- and 1.5-fold for TNF- $\alpha$ and phenylephrine, respectively).

Several lines of evidence suggest that type IIA sPLA ${ }_{2}$ plays a crucial role in the hydrolysis of myocardial phospholipids under these pathological conditions. Firstly, the composition of the fatty acids accumulating in the isolated rat heart after a period of ischemia and reperfusion argue in favor of the involvement of an aspecific PLA,

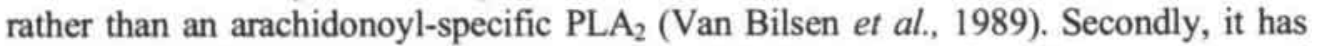
been known that reperfusion is associated with the influx of massive amounts of calcium, so that the activation of calcium-dependent phospholipases has to be anticipated. Finally, some immunological evidence exists for a role of type IIA sPLA in ischemia/reperfusion induced membrane phospholipid degradation. In a study by Prasad and colleagues (1991) it was shown that pretreatment of isolated rat hearts with antibodies raised against a snake venom type IIA $s P L A_{2}$ effectively inhibited the degradation of phospholipids and the release of cytoplasmic proteins during the acute reperfusion phase. Furthermore, antibodies against a type II sPLA $\mathrm{P}_{2}$ were found to decrease the rate of phospholipid hydrolysis in homogenates of rat hearts that had been subjected to a period of hypoxia and reoxygenation (Kikuchi-Yanoshita et al., 1993). 
All these observations point to a role of type IIA sPLA ${ }_{2}$ in phospholipid degradation and subsequent membrane destabilization after a period of ischemia and reperfusion.

Besides its requirement for calcium, very little is known about the regulation of type IIA sPLA 2 . The presence of a putative IL-6 responsive element in the 5 ' flanking region of the type IIA sPLA 2 gene has been demonstrated (Crowl et al., 1991). Upon stimulation with lipopolysaccharides or cytokines, such as IL-1, IL-6 or tumor necrosis

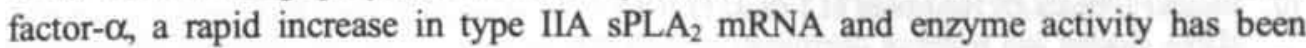
observed in rat vascular smooth muscle cells (Nakano et al., 1990), in hepatoma cells (Crowl et al., 1991), and in renal mesangial cells (Pfeilschifter et al., 1989). Northem blot data presented in this paper suggest that also in rat cardiac myocytes cytokines stimulate the transcription of the type IIA sPLA ${ }_{2}$ gene. In addition, the present findings indicate that the transcription level of type IIA $s P L A_{2}$ enzymes is upregulated in response to the $\alpha_{1}$-adrenergic agonist phenylephrine, suggesting that type IIA SPLA present in rat cardiac myocytes may be involved in the signalling pathways leading to cardiac hypertrophy. It should be noticed, however, that at the concentration used in the present study $(10 \mu \mathrm{M})$, phenylephrine may also exert some $\beta$-adrenergic effects. In this respect, it is worth mentioning that in neonatal rat cardiomyocytes $\beta$-adrenergic receptor stimulation was also coupled to a rise in phospholipase $\mathrm{A}_{2}$ activity (Wallukat et al, 1991).

In summary, a cDNA encoding the type IIA sPLA ${ }_{2}$ present in cardiac tissue was cloned, predicting an enzyme that, on the basis of the presence of an eukaryotic signal peptide, theoretically could be secreted from myocytes. Analysis of its tissue distribution shows it to be expressed at high levels in ileum, and at lower levels in heart, spleen, and soleus muscle. Within the heart it is present in cardiomyocytes and fibroblasts, but probably not in endothelial cells. Stimulation of cultured rat neonatal myocytes with TNF- $\alpha$ and PE shows an increase in the cellular level of mRNA coding for this type IIA sPLA $\mathrm{A}_{2}$, suggesting its involvement in cellular signal transduction. The demonstration of the presence of a type IIA sPLA $\mathrm{A}_{2}$ in cardiomyocytes and its cloning allow a more detailed analysis of the biological role of $\mathrm{PLA}_{2} \mathrm{~s}$ in the heart.

\section{References}

1. Aarsman AJ, De Jong JGN, Amoldussen E, Neys FW, Van Wassenaar PD, Van den Bosch H. Immunoaffinity purification, partial sequence, and subcellular localization of rat liver phospholipase A2.J Biol Chem 1989;264:10008-10014.

2. Chen J, Engle SJ, Seilhamer J, Tischfield JA. Cloning and characterization of novel rat and mouse low molecular weight $\mathrm{Ca}^{2+}$-dependent phospholipase $\mathrm{A}_{2}$ s containing 16 cysteins. $J$ Biol Chem 1994a;269:23018-23024.

3. Chen J, Engle S, Seilhamer JJ, Tischfield JA. Cloning, expression and partial characterization of a novel rat phospholipase A2. Biochim Biophys Acta 1994b;1215:115-120.

4. Chien KR, Han A, Sen A, Buja LM, Willerson JT. Accumulation of unesterified arachidonic acid in ischemic canine myocardium. Relationship to a phosphatidylcholine deacylation-reacylation cycle and the depletion of membrane phospholipids. Circ Res 1984;54:313-322.

5. Clark JD, Lin LL, Kriz RW, Ramesha CS, Sultzman LA, Lin Y, Milona N, Knopf JL. A novel arachidonic acid-cytosolic PLA 2 contains a $\mathrm{Ca}^{2+}$-dependent translocation domain with homology to PKC and GAP. Cell 1991;65:1043-1051.

6. Crowl RM, Stoller TJ, Conroy RR, Stoner CR. Induction of phospholipase $A_{2}$ gene expression in human hepatoma cells by mediators of the acute phase response. J Biol Chem 1991;266:2647-2651. 
7. Davidson FF, Dennis EA. Evolutionary relationships and implications for the regulation of phospholipase $\mathrm{A}_{2}$ from snake venom to human secreted forms. J Mol Evol 1990;31:228-238.

8. Hayakawa M, Kudo I, Tomita M, Nojima S, Inoue K. The primary structure of rat platelet phospholipase A2.J Biochem 1988;104:767-772.

9. Hazen SL, Stuppy RJ, Gross RW. Purification and characterization of canine myocardial cytosolic phospholipase $A_{2}$ - a calcium-independent phospholipase with absolute $s n-2$ regiospecificity for diacyl glycerophospholipids. J Biol Chem 1990;265;10622-10630.

10. Ishizaki J, Ohara O, Nakamura E, Tamaki M, Ono T, Yoshida N, Tereoka H, Tojo H, Okamoto M. cDNA cloning and sequence determination of rat membrane-associated phospholipase $\mathrm{A}_{2}$. Biochem Biophys Res Commun 1989;162:1030-1036.

11. Iwaki K, Sukhatme VP, Shubeita HE, Chien KR. Alpha- and beta-adrenergic stimulation induces distinct patterns of immediate early gene expression in neonatal rat myocardial cells. Fos/jun expression is associated with sarcomere assembly; Egr-1 induction is primarily an alpha 1-mediated response. J Biol Chem 1990;265:13809-13817.

12. Kennedy BP, Payette P, Mudgett J, Vadas P, Pruzanski W, Kwan M, Tang C, Rancourt DE, Cromlish WA. A natural disnuption of the secretory group II phospholipase $\mathrm{A}_{2}$ gene in inbred mouse strains. $J$ Biol Chem 1995;270:22378-22385.

13. Kikuchi-Yanoshita R, Yanoshita R, Kudo I, Arai H, Takamura T, Nokomoto K, Inoue K. Preferential hydrolysis of phosphatidylethanolamine in rat ischemic heart homogenates during in vitro incubation. J Biochem 1993;114:33-38.

14. Komada M, Kudo I, Inoue K. Structure of the gene coding for rat group II phospholipase $\mathrm{A}_{2}$. Biochem Biophys Res Commun 1990;168:1059-1065.

15. Komada M, Kudo I, Mizushima H, Kitamura N, Inoue K. Structure of cDNA coding for rat platelet phospholipase A2. J Biochem 1989;106:545-547.

16. Kriegsmann J, M ller WD, Richter W, Wunderlich J, Wallukat G. Demonstration of membraneassociated phospholipase $A_{2}$ in cultivated heart muscle cells by immunogold technique in surface replicas. Acta Histochem 1993;95:61-66.

17. Linssen MCJG, Van Nieuwenhoven FA, Duijvenstein AM, Glatz JFC, Van der Vusse GJ. Continuous endothelial cells from adult rat heart. In Vitro Cell Dev Biol 1993;29A:61-63.

18. Linssen MCJG, Vork MM, De Jong YF, Glatz JFC, Van der Vusse GJ. Fatty acid oxidation capacity and fatty acid-binding protein content of different cell types isolated from adult rat heart. Mol Cell Biochem 1990;98:19-25.

19. Nakano $\mathrm{T}$, Ohara $\mathrm{O}$, Tereoka $\mathrm{H}$, Arita $\mathrm{H}$. Group II phospholipase $\mathrm{A}_{2}$ mRNA synthesis is stimulated by two direct mechanisms in rat vascular smooth muscle cells. FEBS lett 1990;261:171-174.

20. Pfeilschifter J, Pignat W, Vosbeck K, Marki F. Interleukin-1 and tumor necrosis factor synergistically stimulate prostaglandin synthesis and phospholipase $A_{2}$ release from renal mesangial cells. Biochem Biophys Res Commun 1989;159: 385-394.

21. Prasad MR, Lawrentiu MP, Moraru II, Liu X, Maity S, Engelman RM, Das DK. Role of phospholipase $A_{2}$ and $C$ in myocardial ischemic reperfusion injury. Am J Physiol 1991;260:H873H877.

22. Sambrook J, Fritsch EF, Maniatis T. Molecular cloning: A Laboratory Manual, 2nd ed, Cold Spring Harbor Laboratory Press, Cold Spring Harbor, NY, 1989.

23. Sharp JD, White DL, Chiou XG. Molecular cloning and expression of human $\mathrm{Ca}^{2+}$-sensitive cytosolic phospholipase A2. J Biol Chem 226 1991;14850-14853.

24. Van Bilsen M, Van der Vusse GJ, Willemsen PHM, Coumans WA, Roemen ThHM, Reneman RS. Lipid alterations in isolated working rat hearts during ischemia and reperfusion: its relation to myocardial damage. Circ Res 1989;64:304-314.

25. Van Bilsen M, Van der Vusse GJ. Phospholipase $A_{2}$-dependent signalling in the heart. Cardiovasc Res 1995;30:518-529.

26. Van der Vusse GJ, Glatz JFC, Stam HCG, Reneman RS. Fatty acid homeostasis in the normoxic and ischemic heart. Physiol Rev 1992;72:881-940.

27. Van Schaick RHN, Verhoeven NM, Neijs FW, Aarsman AJ, Van den Bosch H. Cloning of the cDNA coding for $14 \mathrm{kDa}$ group II phospholipase $\mathrm{A}_{2}$ from rat liver. Biochem Biophys Res Commun 1991;1169:1-11.

28. Wallukat G, Nemecz G, Farkas T, Kuehn H, Wollenberger A. Modulation of the beta-adrenergic response in cultured rat heart cells. I. Beta-adrenergic supersensitivity is induced by lactate via a phospholipase $A_{2}$ and 15-lipoxygenase involving pathway. Moll Cell Biochem 1991;102:35-47. 
Chapter 4

\author{
Immunological determination of \\ type IIA secretory phospholipase $\mathrm{A}_{2}$
}




\begin{abstract}
In the present study the cDNA coding for type IIA phospholipase $A_{2}$ (type IIA sPLA $\mathrm{A}_{2}$ ) cloned from rat myocardium was used to generate

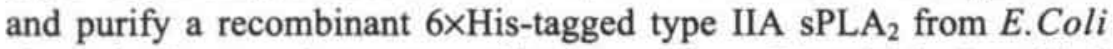
via a single step chromatographical procedure. The yield of purified recombinant type IIA sPLA ${ }_{2}$ typically amounted to $1 \mathrm{mg} /$ liter E.Coli. Against this purified fraction a polyclonal antibody was raised in rabbit. The ability of this antibody to detect type IIA $\mathrm{SPLA}_{2}$ in a number of cell types and tissues, including rat and mouse myocardium, via Western blotting procedures was compared with four other antismall molecular mass $\mathrm{PLA}_{2}$ antibodies. It was found that all five antibodies tested were able to detect purified recombinant type IIA sPLA $_{2}$. In addition, the detection level of a monoclonal antibody raised

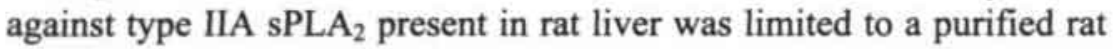
platelet fraction which contains relatively high amounts of type IIA sPLA $_{2}$. Finally, a commercially available polyclonal antibody originally raised against recombinant human type IIA $\mathrm{SPLA}_{2}$ present in synovial fluid specifically detected the protein not only in human and rat platelets, but also in rat ileum. None of the antibodies tested, however, was able to detect type IIA sPLA ${ }_{2}$ in cardiac tissue via Western blotting procedures. These results provide strong indication that under physiological conditions type IIA sPLA 2 protein levels in rat and mouse myocardium are relatively low and, hence, can not be detected by Western blotting using the techniques preesently available.
\end{abstract}




\section{Introduction}

Phospholipase $\mathrm{A}_{2}\left(\mathrm{PLA}_{2}\right)$ catalyzes the hydrolysis of phospholipids to generate fatty acids and lysophospholipids. To date, three major types of mammalian $\mathrm{PLA}_{2} \mathrm{~S}$ can be distinguished: high molecular mass cytoplasmic PLA (type IV $\mathrm{cPLA}_{2}$ ), $40 \mathrm{kD}$ $\mathrm{Ca}^{2+}$-independent plasmalogen specific PLA $\mathrm{P}_{2}$ (type VI iPLA ${ }_{2}$ ), and the $\mathrm{Ca}^{2+}$ dependent low molecular mass (14 kD) PLA 2 (Van Bilsen et al., 1995, Tischfield $e t$ al., 1997, De Windt et al., 1998). The mammalian 14-kD PLA ${ }_{2} \mathrm{~S}$ are subdivided into a type I or pancreatic PLA $A_{2}$, type IIA or secretory PLA ${ }_{2}$ and type V PLA $A_{2}$. Type IIA secretory phospholipase $\mathrm{A}_{2}$ (type IIA sPLA $\mathrm{A}_{2}$ ) is present at high concentrations in rat, mouse and human intestine (Ishizaki et al., 1989, Nevalainen et al., 1995, De Windt et al., 1997) and in the secretory granula of platelets (Aarsman et al., 1989), while varying amounts have been detected in most other tissues, among which cardiac tissue (Ishizaki et al., 1989, De Windt et al., 1997).

Type IIA sPLA has $_{2}$ been considered to play a role in the physiological deacylation-reacylation cycle of phospholipids (Van Bilsen et al., 1995, De Windt et al., 1998) and in signal transduction pathways involving the liberation of membrane phospholipid-derived arachidonic acid in a number of cell types (Van Bilsen et al., 1995). Furthermore, type IIA sPLA 2 activity may play a crucial role in the degradation of membrane phospholipids leading to cellular injury as observed during ischemia/reperfusion in the small intestine (Otamiri et al., 1987), the brain Lauritzen et al., 1994) and the heart (Van der Vusse et al., 1989, Van Bilsen et al., 1995, De Windt et al., 1998). To study the pathophysiological role of type IIA $\mathrm{sPLA}_{2}$ in the heart during ischemia and reperfusion the development of Western blotting analyses to quantitate type IIA sPLA $\mathrm{A}_{2}$ protein levels will be instrumental. Furthermore, the availability of specific anti-sPLA $\mathrm{A}_{2}$ antibodies will also enable future immunohistochemical localization studies at the light or electron microscopical level to determine the (sub)cellular localization of $\mathrm{PLA}_{2}$ in the heart and potential changes thereafter during ischemia and reperfusion.

A first attempt was made to detect cardiac type IIA $\mathrm{SPLA}_{2}$ in immunoblotting analyses by using a previously described monoclonal anti-rat liver type IIA sPLA ${ }_{2}$ antibody (De Jong et al., 1987, Van Schaick et al., 1993, Kriegsmann et al., 1993). This particular antibody, however, only detected type IIA $\mathrm{SPLA}_{2}$ in rat platelets among the various tissues tested. Therefore we decided to raise antibodies against type IIA SPLA ${ }_{2}$ ourselves, making use recombinant rat heart type IIA sPLA $\mathrm{A}_{2}$ and a bacterial expression system.

In the present study a recombinant rat heart type IIA $s \mathrm{PLA}_{2}$ was produced and purified from $E$. Coli to near homogeneity via a single step chromatographic purification procedure. A polyclonal antibody was raised against the recombinant rat heart type IIA sPLA ${ }_{2}$ in the rabbit. The presence of rat heart type IIA sPLA $\mathrm{P}_{2}$ in rat and mouse heart homogenates and various rat and mouse tissues was investigated by immunoblotting using the polyclonal anti-rat heart type IIA sPLA antibody. The applicability of this antibody to detect type IIA PLA $\mathrm{P}_{2}$ in Western blotting experiments was compared to that of a number of monoclonal and polyclonal anti-14 kD type II PLA $\mathrm{A}_{2}$ antibodies recently developed by other research 
groups (Van Schaick et al., 1993, Kriegsmann et al., 1993, Murakami et al., 1998) or commercially available.

\section{Materials and Methods}

\section{Chemicals}

Bovine serum albumin (BSA) was purchased from Boehringer Mannheim (Germany). Tween-20, glycine, imidazole and glycerol were purchased from Merck (Darmstadt, Germany). Urea and guanidine hydrochloride were purchased from Sigma (St. Louis, MO, USA) and ICN Biochemicals (Cleveland, OH, USA), respectively. Ni-NTA Agarose and Polyacrylamide were obtained from Qiagen (Leusden, The Netherlands) and Bio-Rad Laboratories (Hercules, CA, USA), respectively. Goat-anti-rabbit IgG/HRP complex (GARPO) and rabbit-antimouse/HRP complex (RAMPO) were both purchased from Dako A/S (Glostrup, Denmark). Monoclonal antibody against rat liver $\mathrm{sPLA}_{2}$ was a kind gift of Dr. Van den Bosch. Monoclonal antibody against bee venom PLA $\mathrm{A}_{2}$ was a kind gift of Dr. Kriegsmann. Rabbit polyclonal antibody against rat platelet $\mathrm{SPLA}_{2}$ was a kind gift of Dr. Murakami. Naja Naja venom PLA $\mathrm{A}_{2}$ and porcine pancreatic PLA $\mathrm{P}_{2}$ were obtained from Sigma and Boehringer Mannheim, respectively. All other chemicals used were of analytical grade and purchased from Merck.

\section{Construction of $6 \times$ His-tagged rat heart type IIA sPLA ${ }_{2}$}

For the generation and purification of the recombinant rat heart type IIA sPLA $\mathrm{P}_{2}$ an $\mathrm{N}$-terminal $6 \times \mathrm{His}$ extension was applied, which allows rapid purification of target proteins from E. Coli using a metal-chelating resin (The QIAexpressionist, Qiagen, Leusden, The Netherlands, Bush et al., 1991, Hofmann et al., 1991). To produce Nterminal $6 \times$ His-tagged rat heart type IIA $\mathrm{SPLA}_{2}$ in $E$. Coli, a vector containing the recently cloned full length rat heart type IIA sPLA ${ }_{2}$ cDNA (pCRII-PLA ${ }_{2}$ ) was digested with $\mathrm{Bcl} I$ to release a $479 \mathrm{bp}$ fragment containing the complete rat heart type IIA sPLA $A_{2}$ coding region except for the first $10 \mathrm{~N}$-terminal amino acids (De Windt et al., 1997). The Bcl I fragment was ligated into BamH I linearized pQE9, pQE10 and pQE11 vectors, which were subsequently designated PQE9-PLA pQE10-PLA $A_{2}$ and pQE11-PLA $A_{2}$, respectively. These vectors allow generation of $\mathrm{N}$ terminal $6 \times$ His-tagged recombinant heterologous proteins in E. Coli (Figure 1). Candidate clones were subjected to restriction analysis and sequenced using the T7 sequence kit (Pharmacia, Uppsala, Sweden). As expected, only pQE11-PLA contained the type IIA sPLA ${ }_{2}$ coding region in the correct reading frame (Figure 1). To achieve high levels and tight regulation of protein expression, $\mathrm{PQE} 11-\mathrm{PLA}_{2}$ was transformed to the K12 derived E. Coli strain M15[pREP4] (Qiagen).

\section{Induction and purification of $6 \times$ His-tagged rat heart type IIA SPLA ${ }_{2}$ from $E$. Coli} LB-broth (1 liter) containing $100 \mathrm{mg} / \mathrm{ml}$ ampicillin and $25 \mathrm{mg} / \mathrm{ml}$ kanamycin was inoculated with $E$. Coli M15[pREP4](pQE11-PLA $)_{2}$ and grown at $37 \ldots \mathrm{C}$ under vigorous shaking until a $\mathrm{OD}_{600}$ of 0.7 was reached. To induce recombinant $6 \times$ His-

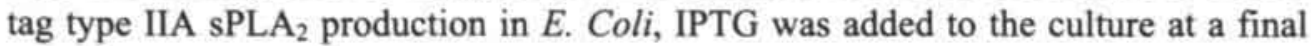


concentration of $2 \mathrm{mM}$ and the culture was continued to grow overnight. The next day cells were harvested by centrifugation at $5,000 \mathrm{~g}$ for $10 \mathrm{~min}$ at 4 ... A. All subsequent handlings were performed at room temperature, unless indicated otherwise. The pellet was resuspended in $6 \mathrm{M}$ guanidine hydrochloride, $0.1 \mathrm{M}$ $\mathrm{NaH}_{2} \mathrm{PO}_{4}, 0.01 \mathrm{M}$ Tris ( $\mathrm{pH} 8.0$ ) in one tenth of the original culture volume and cells were lysed by gentle vortexing and subsequent mixing for $30 \mathrm{~min}$. After centrifugation at $5,000 \mathrm{~g}$ for $10 \mathrm{~min}, 2 \mathrm{ml}$ of Ni-NTA resin was added to the supernatant and mixed gently for $30 \mathrm{~min}$. To pellet the resin, the suspension was centrifuged at $1,500 \mathrm{~g}$ for $5 \mathrm{~min}$. The recombinant protein was allowed to renaturate while immobilized to the Ni-NTA resin by repeated resuspension and recollection of the resin by centrifugation in $500 \mathrm{mM} \mathrm{NaCl}, 20 \%$ glycerol, $0.1 \mathrm{mM} \mathrm{NaH} \mathrm{PO}_{4}$, $0.01 \mathrm{mM}$ Tris- $\mathrm{HCl}, \mathrm{pH} 8.0$, containing consecutively $8.0,7.0,6.0,5.0,4.0,3.0,2.0$, $1.0,0.5$, and $0.25 \mathrm{M}$ Urea. ${ }^{18}$ The complete renaturation procedure lasted approximately $2 \mathrm{~h}$. After renaturation the proteins were eluted from the Ni-NTA resin by addition of 2 column volumes of $0.25 \mathrm{M}$ Urea, $500 \mathrm{mM} \mathrm{NaCl}, 0.1 \mathrm{mM}$ $\mathrm{NaH}_{2} \mathrm{PO}_{4}, 0.01 \mathrm{mM}$ Tris- $\mathrm{HCl}$ and $250 \mathrm{mM}$ imidazole ( $\mathrm{pH} 8.0$ ). The eluted proteins were extensively dialysed against PBS for $8 \mathrm{~h}$ at $4 \ldots \mathrm{C}$, aliquoted, and stored at -70 ...C until further use. Typically, this procedure yielded $1 \mathrm{mg} 6 \mathrm{His}-\mathrm{tag}$ type IIA sPLA $_{2}$ per liter of $E$. Coli M15[pREP4](pQE11-PLA ${ }_{2}$ ) culture.

\section{Antibody preparation}

Polyclonal antibodies were raised against purified recombinant soluble $6 \times$ His-tag rat heart type IIA PLA $_{2}$ in a Flemish giant rabbit by subcutaneous immunization with $250 \mu \mathrm{g}$ purified recombinant $6 \times$ His-tag type IIA sPLA 2 in PBS dissolved in Specol (Leenarts et al., 1995; Specol:PBS 1:1 v/v). The injection fluid $(2 \mathrm{ml})$ was divided equally over a number of injection sites along the backside of the rabbit. After four and five weeks the rabbit was boosted by intracuteneous injection of 250 $\mu \mathrm{g} 6 \times$ His-tag type IIA sPLA $_{2}$ in Specol $(1: 1 \mathrm{v} / \mathrm{v})$. Six weeks after the first immunization, the rabbit was boosted intravenously with $250 \mu \mathrm{g} 6 \times$ His-tag type IIA sPLA $_{2}$ in Specol and bleeded two days after the final boosting. Collected blood (approximately $100 \mathrm{ml}$ ) was allowed to cloth on ice, centrifuged at 1,500 $\mathrm{g}$ for 10 min and the serum was stored at $-70 \ldots \mathrm{C}$ until further use. Before the first immunization ( 0 -serum) and two days after each boost, $2 \mathrm{ml}$ of blood was collected in glass tubes and allowed to cloth on ice. After centrifugation at $1,500 \mathrm{~g}$ for 10 min, the resulting serum was stored at $-70 \ldots \mathrm{C}$ until further use. The whole porcedure was approved by the Institutional Animal Care and Use Committee of the Maastricht University.

The titer of the antisera was assessed as described previously (Vork et al., 1991). Briefly, serial dilutions of the antisera collected (0-serum, 4-, 5-week boosting, and final antisera) were added to a microtiterplate, previously coated with $10 \mathrm{ng}$ of purified recombinant $6 \times \mathrm{His}$-tag type IIA sPLA 2 . Detection was performed by incubation of GARPO diluted $1: 2,500$ in phoshate buffered saline containing $0.34 \mathrm{mM} \mathrm{NaCL}, 0.1 \%$ BSA and $0.05 \%$ Tween-20, pH 7.4 (PBT) and visualized using the TMP Enzymatic Kit (Roche Diagnostic Systems Inc., Somerville, NJ, USA) according to the supplier s instructions. The titer of the antisera was defined as the antiserum dilution at which the measured extinction amounted to $50 \%$ of the 
maximal extinction and amounted to $0,300,800$ and 1500 for the 0 -serum, 4-, and 5 -week boosting and final antiserum, respectively.

\section{Tissue/subcellular homogenate and sample preparation}

Tissues were homogenized in SET buffer ( $\mathrm{mM}$ sucrose, $10 \mathrm{mM}$ Tris-HCL, $2 \mathrm{mM}$ EDTA, $1 \mathrm{mM}$ PMSF, pH 7.4; $1: 10 \mathrm{v} / \mathrm{v}$ ) on ice using a Ultra-Turrax T25 (IKA Labortechnik, Staufen, Germany). Thereafter the homogenate was briefly sonicated (Soniprep 150, Beun-De Ronde, Abcoude, The Netherlands). Platelets were isolated from heparinized murine, rat and human blood by a one step centrifugation procedure at $160 \mathrm{~g}$ for $15 \mathrm{~min}$ and brief sonification on ice. Liver and heart subcellular fractions were obtained as described previously (Aarsman et al., 1989). Briefly, subsequent centrifugation steps of liver and heart homogenates at $600 \mathrm{~g}$ for $10 \mathrm{~min}, 3,600 \mathrm{~g}$ for $10 \mathrm{~min}, 10,000 \mathrm{~g}$ for $10 \mathrm{~min}, 26,500 \mathrm{~g}$ for $20 \mathrm{~min}$ and $104,000 \mathrm{~g}$ for $60 \mathrm{~min}$, resulted in fractions relatively enriched with nuclei and cell debris, heavy, intermediate, and light mitochondria, a microsomal fraction and a cytosolic fraction, respectively. Protein concentration of the homogenates was determined using the Micro BCA Protein Assay (Pierce, Rockford, IL, USA) following the manufacturer s instructions. Prior to sodium dodecyl sulfate - polyacrylamide gelelectrophoresis (SDS PAGE) an identical volume of sample buffer (125 mM Tris- $\mathrm{HCl}, 10 \%$ glycerol, $10 \%$ SDS, $5 \% \beta$-mercaptoethanol , $\mathrm{pH} 6.8$ ) was added to the samples and the electrophoresis samples were heated to $100 \ldots \mathrm{C}$ for $5 \mathrm{~min}$. For non-reducing SDS PAGE $\beta$-mercaptoethanol was omitted from the sample buffer.

\section{SDS-PAGE and Western blotting}

Proteins were separated by electrophoresis in 12 or $15 \%$ polyacrylamide gels in the presence of $0.1 \%$ SDS. The separated proteins were either stained with Coomassie Brilliant Blue, or were electrophoretically transferred to nitrocellulose membrane (Protan, Schleicher \& Schuell, Dassel, Germany). For Western blot analyses, nonspecific protein binding on the nitrocellulose filter was blocked by incubation with phosphate-buffered saline (PBS; $10 \mathrm{mM}$ phosphate, $154 \mathrm{mM} \mathrm{NaCl}, \mathrm{pH} 7.4$ ) containing $1 \% \mathrm{BSA}$, either for $2 \mathrm{~h}$ at room temperature or overnight at $4 \mathrm{iC}$ under continuous gentle shaking. First and secondary antibody incubation were performed in PBT at room temperature under gentle shaking for 2 and $1 \mathrm{hrs}$, respectively. First and secondary antibody preparations and their dilutions used in Western blotting analyses are presented in Table I. After antibody incubations the filter was washed four times with PBT under gentle shaking, treated with ECL Western blotting detection system (Amersham, Buckinghamshire, UK) according to the manufacturer s instructions and exposed to hyperfilm (Amersham). 


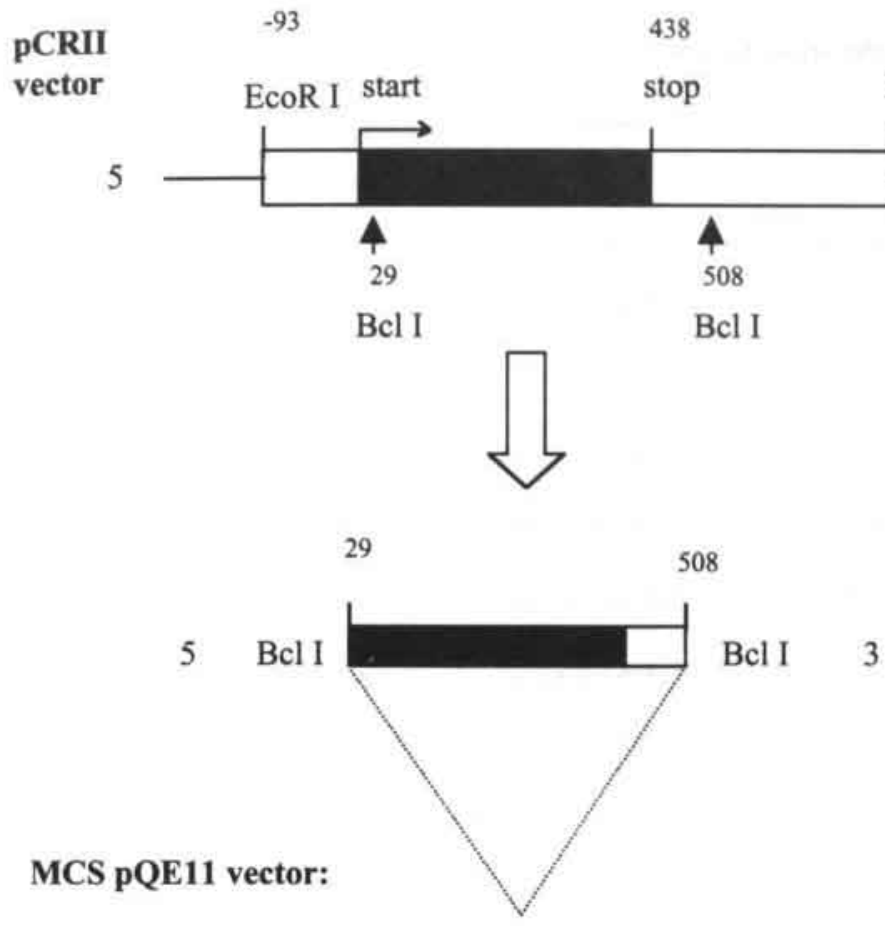

EcoR I/RBS

$6 \times$ His BamH I Sal I Pst I Hind III

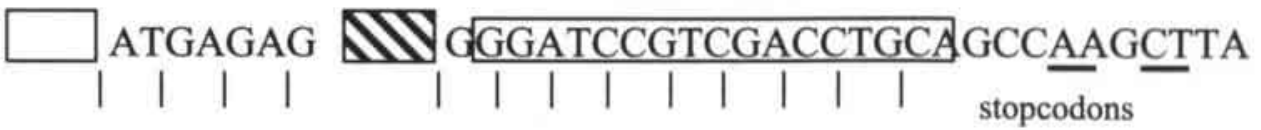

pQE11 vector
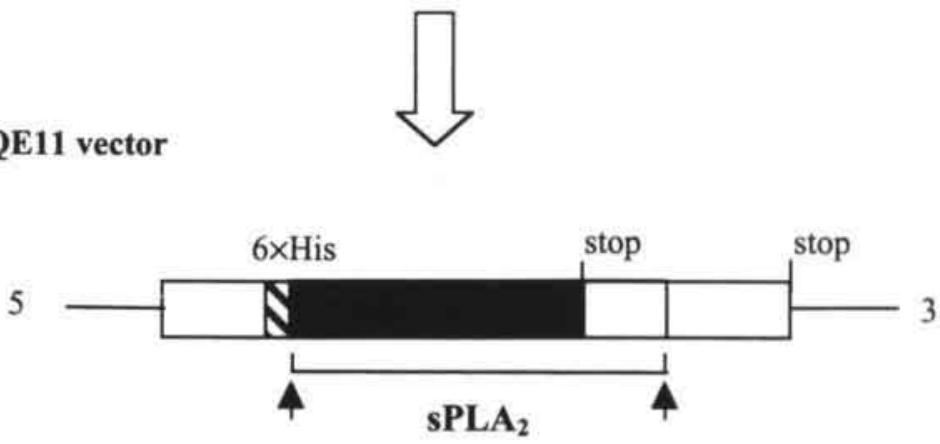

Figure 1

Overview of cloning strategy resulting in the construction of the bacterial expression vector pQE11-PLA $A_{2}$, which allows production of $6 \times$ His-tagged sPLA 2 . In the upper panel the outline of the pCRII-PLA $A_{2}$ plasmid is designated, containing the full length cDNA of rat heart sPLA Digestion of pCRII-PLA 2 with Bcl I released a 479 bp fragment containing the major part of the coding region and $80 \mathrm{bp}$ of the 3 -untranslated region of rat heart $\mathrm{PLA}_{2}$. Ligation of the latter fragment into the BamH I site of the multiple cloning site of the PQE11 vector resulted in the production of a N-terminal $6 \times$ His-tagged rat heart sPLA $\mathrm{A}_{2}$ in E. Coli. 
Table I

Overview of the antisera used in the present study.

Antigen Subclass Dilution

$\begin{array}{cccc}\text { Rat liver mitochondrial type IIA sPLA } & \text { Monoclonal, IgG } & 1: 5,000 & 12 \\ 6 \times \text { His-tag rat heart type IIA sPLA } & \text { Polyclonal } & 1: 100 & * \\ \text { Bee venom type II sPLA } & \text { Monoclonal, IgG } & 1: 20 & 15 \\ \text { Rat platelet type IIA sPLA } & \text { Monoclonal, IgG } & 1: 3,000 & 16 \\ \text { Recombinant human type IIA sPLA } 2 & \text { Polyclonal, IgG } & 1: 1,000 & 17 \\ \text { RGD 6 } \times \text { His-tag } & \text { Monoclonal, IgG } & 1: 1,000 & * * \\ \text { Rabbit IgG } & \text { Gaot polyclonal, IgG } & 1: 2,500 & * * * \\ \text { Mouse IgG } & \text { Rabit polyclonal, IgG } & 1: 2,500 & * * * *\end{array}$

\footnotetext{
*, Antibody raised against recombinant $6 x$ His-tag type IIA sPLA ${ }_{2}$ as described in the present study; **, recognizes $\mathrm{N}$-terminal $6 x \mathrm{His}$-tag protein epitope with amino acid sequence R-G-H-H-H-H-H-H (purchased from Qiagen, Westburg, Leusden, The Netherlands); ${ }^{* * *}$, recognizes rabbit IgG and is complexed with horseradish peroxidase (HRP; Dako A/S, Glostrup, Denmark); ${ }^{* * *}$, recognizes mouse $\mathrm{IgG}$ and is complexed with HRP (Dako A/S, Denmark).
}

\section{Results}

Application of anti-rat liver type IIA SPLA $A_{2}$ antibody

To detect the presence of type IIA sPLA 2 protein in (subcellular) rat heart (fractions), a monoclonal anti-rat liver type IIA sPLA ${ }_{2}$ antibody was first tested on subcellular fractions of liver homogenates, relatively enriched with cell nuclei, heavy, intermediate, and light mitochondria, microsomes and cytosol via immunoblotting procedures. In contrast to earlier studies (De Jong et al., 1987, Aarsman et al., 1989, Van Schaick et al., 1993) using the identical antibody and technical procedures, no signals were obtained in the various liver subcellular fractions (lanes 1-6, Figure 2), despite several technical modifications, nor in a number of subcellular heart and myocyte fractions (lanes 8-12, Figure 2),. However, in all Western blot analyses a strong signal of the expected size (14 kDa) was obtained in rat platelet fraction with the anti-rat liver type IIA sPLA 2 antibody. Platelets were included in the experiments since type IIA sPLA ${ }_{2}$ is relatively abundantly present in these cells (lane 7 , Figure 2 ). 


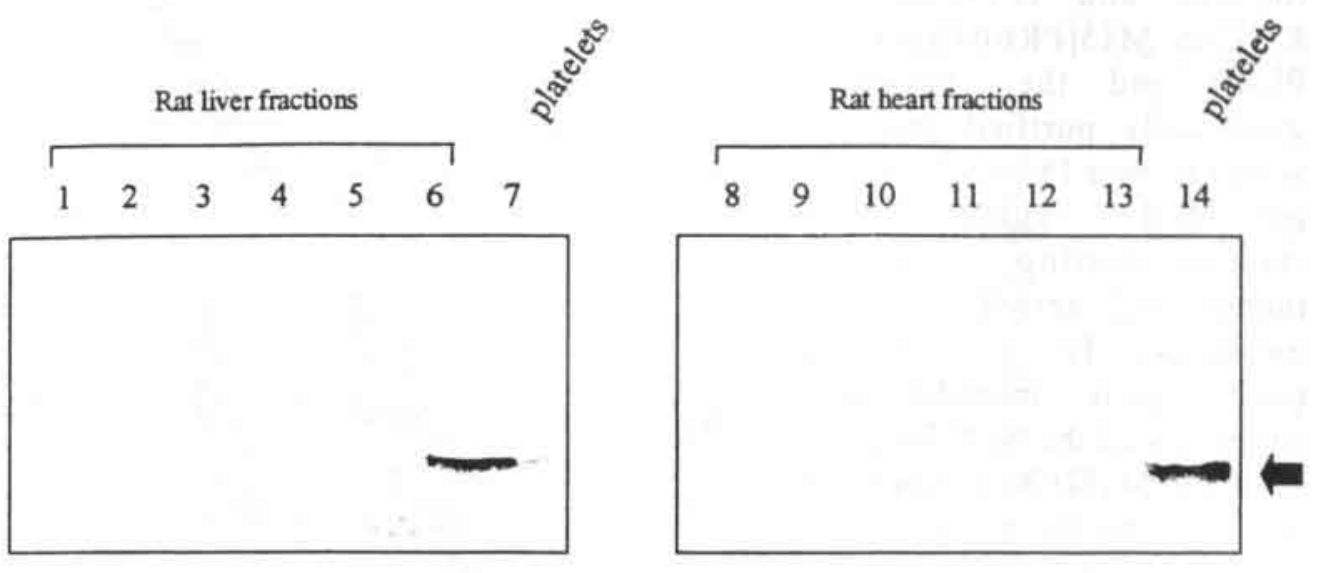

\section{Figure 2}

Result of a typical immunoblotting experiment using a monoclonal anti-rat liver type IIA sPLA 2 antibody on a number of rat liver subcellular fractions (left panel) and rat heart subcellular fractions (right panel). 1-6: rat liver fractions with 1, nuclei; 2 , heavy mitochondria; 3 , intermediate mitochondria; 4, light mitochondria; 5, microsomal fraction; 6, cytosolic fraction. 8-12: rat heart subcellular fractions with 8 , nuclei; 9 , heavy mitochondria; 10 , intermediate mitochondria; 111, light mitochondria; 12, microsomal fraction; 13, cytosolic fraction. Lanes 7 and 14 were included as a positive controls ( rat platelets). Black arrow indicates expected size of type IIA sPLA 2 .

\section{Production and purification of $6 \times$ His-tagged sPLA ${ }_{2}$}

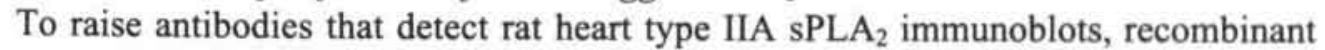
$6 \times$ His-tagged type IIA sPLA ${ }_{2}$ was produced as described in the Materials and Methods section. After overnight IPTG induction of E. Coli M15[PREP4](pQE11$\mathrm{PLA}_{2}$ ) at $37{ }^{\circ} \mathrm{C}$ and purification using a Ni-NTA resin, a relatively pure protein fraction was obtained consisting of a prominent $17-18 \mathrm{kDa}$ band as determined by Coomassie Brilliant Blue staining (solid arrow; Figure 3). In addition, two other protein bands of lower intensity were co-purified in a highly reproducible manner: a diffuse product smaller than the prominent $17-18 \mathrm{kDa}$ band and one sharp band which migrated as a $29 \mathrm{kDa}$ band on SDS-PAGE (open arrows; Figure 3). The slightly slower mobility of the intact $6 \times$ His-tagged type IIA sPLA $\mathrm{P}_{2}$ in SDS-PAGE experiments compared to native type IIA sPLA $(\sim 14 \mathrm{kDa})$ might be due to the presence of the $6 \mathrm{~N}$-terminal histidine residues in addition to the 21 amino acids $\mathrm{N}$ terminal signal peptide of type IIA sPLA $\mathrm{S}_{2}$, which is normally cleaved from the mature protein. 
To confirm the specific purification of a $6 \times$ His-tagged recombinant protein, noninduced and IPTG-induced E. Coli M15[PREP4](pQE11$\mathrm{PLA}_{2}$ ) and the chromatographically purified products were run on a $15 \%$ SDS-PAGE gel and subjected to immunoblotting using a monoclonal anti-His epitope antibody. To control the purification method and specificity of the Ni-NTA resin, E. Coli M15[PREP4](pQE16) (provided by the manufacturer) was IPTG-induced to produce a $25 \mathrm{kDa}$ recombinant $6 \times$ Histagged murine dihydrofolate reductase (DHFR) and purified using similar procedures as described for the purification of $6 \times$ His-tagged rat heart type IIA sPLA $_{2}$.

No signals were obtained in the non-IPTG induced $E$. Coli M15 [PREP4] (pQE11-PLA ${ }_{2}$ ), while in protein isolated from IPTG-induced E. Coli two strong signals were obtained, which electrophoresed at similar heights as the Ni-NTA agarose purified $17-18 \mathrm{kDa}$ and


\begin{abstract}
Figure 3
Coomassie Brilliant Blue staining of total protein in a $15 \%$ SDS-PAGE gel. First lane, molecular weight marker (MW); second lane, Ni-NTA purified protein fraction of IPTG-induced E.Coli M15[PREP4](pQE11-PLA $A_{2}$ ) as described in the Materials and Methods section.
\end{abstract}

5-10 $\mathrm{kDa}$ proteins fractions.

In both IPTG induced $E$. Coli M15[PREP4](pQE16) crude lysates and the purified fraction, $6 \times$ His-tagged murine DHFR was specifically recognized by the monoclonal anti- $6 \times$ His epitope antibody (data not shown). These results indicate the production and specific purification of a candidate recombinant $6 \times$ His-tagged type IIA sPLA ${ }_{2}$ protein which migrates in SDS-PAGE electrophoresis as a $17-18 \mathrm{kDa}$ protein. The detection of the smaller protein fraction of 5-10 $\mathrm{kDa}$ with this antibody points towards the co-purification of degradation products of $6 \times$ His-tagged type IIA sPLA $_{2}$. 

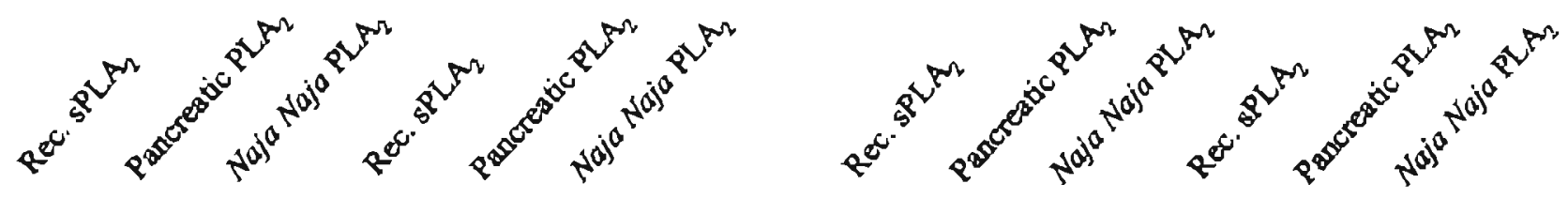



reducing

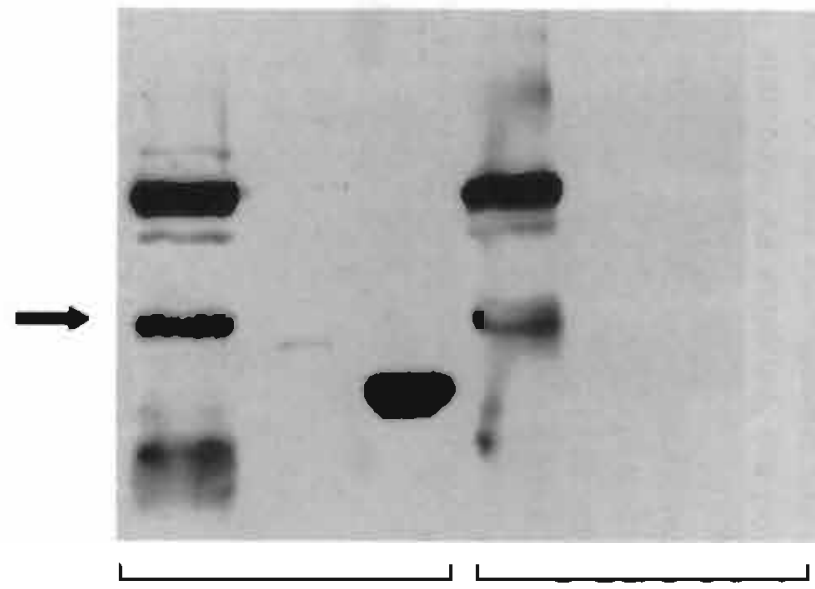

reducing

non-reducing

\section{Figure 4}

Coomassie Brilliant Bluc total protein staining (len pancl) and immunoblotting (right panel) of Ni-NTA purified 6xHis-tagged type IIA SPLA $A_{2}$ pancreatic PLA 2 and Naja Naja venom PLA $A_{2}$ electrophoresed under reducing and non-reducing conditions. Solid arrow denotes the recombinant $6 \times$ His-tagged type IIA sPLA, product of about $17=18 \mathrm{kD}$. For imnunoblotting the rabbit polyclonal anti-6xHis-tagged type IIA sPLA $_{2}$ antibody fraction was used. 




\section{Figure 5}

Result of a representative Western blot containing a number of rat and mouse tissues using the polyclonal anti-recombinant rat heart type IIA SPLA $\mathrm{A}_{2}$ antibody. The molecular weights of the molecular marker are indicated (MW). Naja Naja venom type PLA $\mathrm{A}_{2}$ was included as a positive control. Open arrow denotes product of expected size.

\section{Application of polyclonal anti-6xHis-tagged type IIA sPLA $A_{2}$ antibody}

After using this purified fraction to raise antibodies in the rabbit, the cross-reactivity of the polyclonal anti- $6 \times \mathrm{His}$ tagged type IIA sPLA $\mathrm{A}_{2}$ antibody was tested on purified recombinant $6 \times$ His tagged type IIA sPLA ${ }_{2}$, pancreatic PLA (type IA PLA $_{2}$ ) and Naja Naja venom PLA (type IB PLA $_{2}$ ) in immunoblotting experiments. Figure 4 demonstrates differences in electrophoretic mobility of the three small molecular mass $\mathrm{PLA}_{2} \mathrm{~S}$, prepared under reducing and non-reducing conditions, as demonstrated after staining the gel with Coomassie Brilliant Blue (left panel; Figure 4). Immunoblotting of an identical gel resulted in very strong signals in the recombinant type IIA sPLA ${ }_{2}$ lane, a weak signal in the lane with pancreatic PLA and a strong signal for Naja Naja venom PLA $\mathrm{P}_{2}$, following treatment of the protein samples under reducing conditions (right panel; Figure 4). In contrast, electrophoresis of the same preparations in the absence of reducing agents resulted only in a strong signal for recombinant type IIA sPLA $A_{2}$ and no detectable signals for pancreatic and Naja Naja $\mathrm{PLA}_{2}$ (right Panel; Figure 4). The latter result indicates that the polyclonal anti- $6 \times$ His-tagged type IIA sPLA $A_{2}$ antibody strongly reacts with the purified $6 \times$ His-tagged proteins under reducing as well as under non-reducing conditions. In addition, the polyclonal anti- $6 \times$ His-tagged type IIA sPLA $\mathrm{A}_{2}$ antibody reacted to a lesser extent with reduced and non-reduced type IA and IB PLA $\mathrm{P}_{2} \mathrm{~S}$ as 
compared to the $6 \times$ His-tagged type IIA sPLA 2 . A $29 \mathrm{kD}$ product purified from IPTG-induced E. Coli M15[PREP4](pQE11-PLA 2 ) gave rise to an additional and reproducible strong signal in immunoblotting experiments, while the purified degradation products of $5-10 \mathrm{kD}$ only gave a weak and diffuse signal in the immunoblot using the polyclonal anti-6xHis tagged type IIA sPLA $A_{2}$ antibody.

Figure 5 demonstrates the result of an immunoblot to detect the presence of type IIA sPLA $\mathrm{A}_{2}$ in a number of tissue homogenates using the polyclonal anti- $6 \times \mathrm{His}$ tagged type IIA sPLA $A_{2}$ antibody. As expected, the polyclonal anti- $6 \times$ His tagged


open arrow; Figure 5). In contrast, despite many technical modifications and antibody dilutions tested no signals of the expected mass of $14 \mathrm{kD}$ could be obtained in cell types and tissues which contain relatively high amounts of type IIA sPLA $_{2}$ such as rat platelets or rat ileum (Figure 5) or human platelets (data not shown). As could be expected from the latter result, no signals of were ever obtained in either rat or mouse heart homogenates (Figure 5).



\section{Figure 6}

Representative Western blot obtained with monoclonal anti-bee venom type PLA $A_{2}$ containing a rat ileum, rat platelets and rat heart homogenates. The molecular weights of the molecular marker are indicated (MW). Recombinant $6 \times$ His-tagged $\mathrm{PPLA}_{2}$ was included as a positive control. Solid arrow denotes specific detection of a product of expected size in the $6 \times$ His-tagged sPLA fraction. $^{2}$ 
Polyclonal anti-human sPLA 2
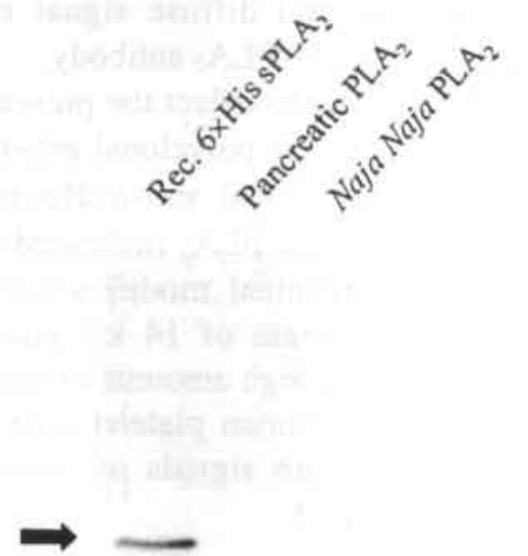

Polyclonal anti- $6 \times \mathrm{His}_{\mathrm{sPL}}$
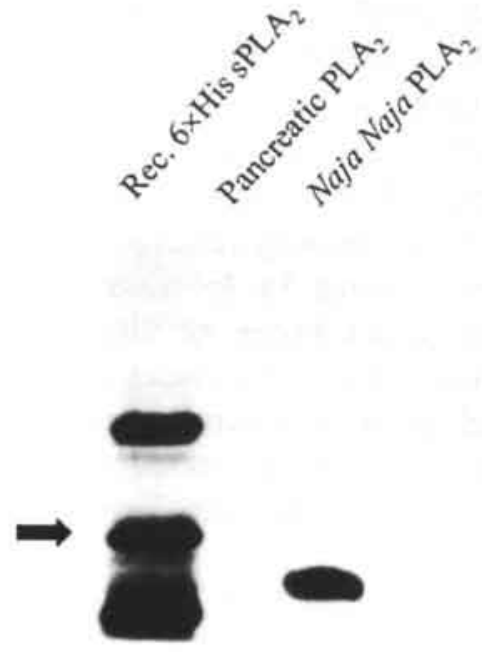

\section{Figure 7}

Immunoblots of Ni-NTA purified $6 \times$ His-tagged sPLA 2 , pancreatic PLA 2 and Naja Naja venom $\mathrm{PLA}_{2}$ electrophoresed under reducing conditions. For immunoblotting both the rabbit polyclonal anti-human synovial fluid $s \mathrm{PLA}_{2}$ antibody (left panel) and rabbit polyclonal anti$6 \times$ His-tagged sPLA 2 antibody (right panel) were used. Solid arrow denotes the specific detection of recombinant $6 \times$ His-tagged $\mathrm{PLA}_{2}$.

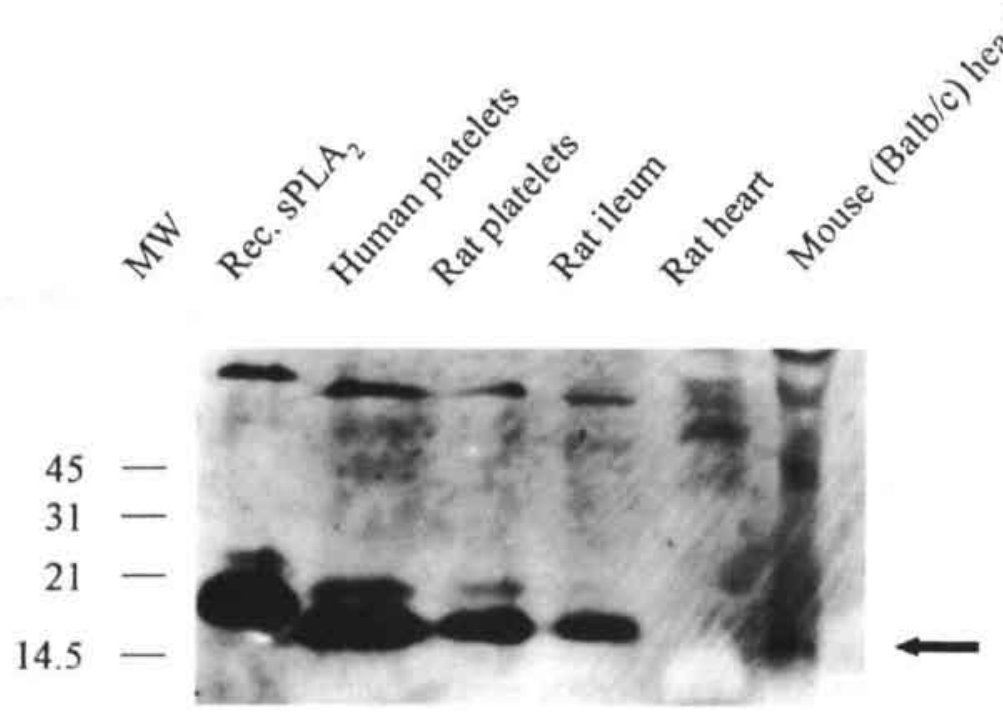

\section{Figure 8}

Representative Western blot obtained with polyclonal anti-human $\mathrm{SPLA}_{2}$ antbody containing human platelets, rat platelets, rat ileum, rat heart and mouse heart homogenates. The molecular weights of the molecular marker are indicated (MW). Recombinant $6 \times$ His-tagged PPLA $_{2}$ was included as a positive control. Solid arrow denotes expected size of $\mathrm{SPLA}_{2}$ in the various fractions. 


\section{Application of other anti-14 $\mathrm{kDa} P L A_{2}$ antibodies}

Due to the above negative results, we decided to test anti-14 $\mathrm{kDa} \mathrm{PLA}_{2}$ antibodies recently produced by other investigators to explore whether rat heart type IIA $s \mathrm{PLA}_{2}$ is present in cardiac tissue, using Western blotting. A monoclonal anti-bee venom $14 \mathrm{kDa}$ PLA $\mathrm{A}_{2}$ antibody (Figure 6) and a monoclonal anti-rat platelet type IIA sPLA ${ }_{2}$ antibody (data not shown) were tested on purified $6 \times$ His tagged type IIA sPLA 2 , rat ileum, rat platelet and rat or mouse heart homogenates. Figure 6 depicts a representative result obtained with monoclonal anti-bee venom PLA $\mathrm{A}_{2}$ in an immunoblot containing rat ileum, rat platelets, rat heart and $1 \mu \mathrm{g}$ recombinant type

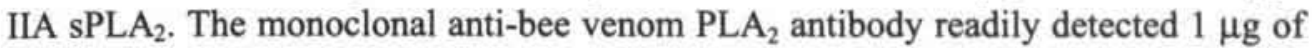
$6 \times$ His tagged type IIA sPLA ${ }_{2}$ fraction included as a positive control (Figure 6). In contrast, no signals could be obtained in any other cell type or tissue tested under conditions recommended by the suppliers.

Finally, a commercially available polyclonal anti-human synovial fluid type IIA sPLA ${ }_{2}$ antibody was tested for its specificity to discriminate between different types of PLA P $_{2}$ Figure 7 depicts two immunoblots each containing $1 \mu \mathrm{g}$ of $6 \times \mathrm{His}$

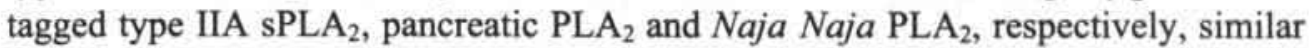
to the immunoblot as depicted in Figure 4. The polyclonal anti-human recombinant type IIA sPLA $A_{2}$ antibody detected specifically the $6 \times$ His tagged type IIA sPLA (left panel; Figure 7). As a reference, the result obtained with the polyclonal anti$6 \times$ His tagged type IIA sPLA ${ }_{2}$ antibody in a similar immunoblot is depicted in the right panel of Figure 7.

The ability of the polyclonal anti-human synovial fluid type IIA sPLA antibody to detect type IIA SPLA ${ }_{2}$ in human platelets, rat platelets, rat ileum and rat and mouse total heart homogenates was tested. A strong signal was obtained both in the $6 \times$ His tagged type IIA sPLA $A_{2}$ and human platelets fractions (lanes 1 and 2 ; Figure 8 ). The cross reactivity of this particular antibody, originally raised against human recombinant synovial type IIA sPLA ${ }_{2}$, was demonstrated by the fact that signals of about $14 \mathrm{kD}$ were obtained rat platelet and in rat ileum homogenates (lanes 3 and 4; Figure 8). In heart homogenates, however, no signals were observed, not even so after increasing the amounts of cardiac protein $(200 \mu \mathrm{g}$ protein/lane) and/or by increasing the concentration of the antibody 10 fold to a $100 \times$ dilution (data not shown).

\section{Discussion}

Experimental data on the quantity and subcellular distribution of type IIA sPLA $\mathrm{A}_{2}$ in cardiac tissue are scarce. In the present study a number of anti-14 kDa PLA 2 antibodies were tested for their ability to detect type IIA phospholipase $\mathrm{A}_{2}$ (type IIA sPLA $_{2}$ ) via immunoblotting procedures. Therefore, the availability of a sensitive and functional anti-type IIA sPLA ${ }_{2}$ antibody would be helpful in obtaining more specific information regarding the presence and localization of type IIA sPLA $\mathrm{A}_{2}$ in the myocardium. Western blotting procedures would further provide a relatively straight-forward procedure to quantitate relative differences in $\mathrm{SPLA}_{2}$ protein levels in cardiac tissue of transgenic mice generated with a cardiac-specific 
overexpression of type IIA sPLA 2 in order to provide more insight into the possible participation in vivo of $\mathrm{SPLA}_{2}$ in membrane degradation during cardiac ischemia and reperfusion.

In Table 2 the results obtained in Western blotting experiments with the antibodies tested in the present study are summarized. It was found that, in contrast to earlier studies ${ }^{7,11,12}$, a monoclonal antibody raised against type IIA SPLA $_{2}$ present in rat liver mitochondria was not able to detect type IIA sPLA 2 in liver and heart total homogenates or subcellular fractions. This particular antibody was able to detect type IIA sPLA 2 in a purified rat platelets fraction, a cell type that was included in the present study as a positive control since a number of studies indicate that type IIA sPLA 2 protein is abundantly present in this particular cell type (Aarsman et al., 1989, De Jong et al., 1993, Van Schaick et al., 1993, Murakami et al., 1988; Table 2). However, neither in ileum, which also contains relatively high amounts of type IIA sPLA , nor in cardiac tissue a signal could be detected.

Because of these results it was decided to produce a recombinant type IIA $\mathrm{sPLA}_{2}$ protein using a type IIA $\mathrm{SPLA}_{2}$ cDNA recently isolated from a rat heart cDNA library (De Windt et al., 1997). The cloning strategy applied to obtain recombinant type IIA sPLA $_{2}$ involved the bacterial expression of a $\mathrm{N}$-terminal $6 \times$ Histidine tag, which allows rapid and relatively easy purification of heterologously expressed proteins (Bush et al., 1991, Hofmann et al., 1991). Using this strategy a $6 \times$ His-tagged type IIA sPLA $\mathrm{A}_{2}$ was produced and purified to near homogeneity with a typical yield of $1 \mathrm{mg}$ total protein/liter E.Coli culture. Against this fraction a polyclonal antibody was raised in the rabbit. The resulting antibody easily detected purified $6 \times$ His-tagged type IIA $\mathrm{sPLA}_{2}$ fraction and other purified types of $\mathrm{PLA}_{2} \mathrm{~S}$, which confirms that the antibody raised against $6 \times$ His-tagged type IIA sPLA $\mathrm{A}_{2}$ contained antigenicity against this enzyme, but does not discriminate between the different (sub)types of small molecular weight PLA $\mathrm{A}_{2}$ enzymes. Unfortunately, this antibody did not demonstrate cross-reactivity with type IIA sPLA $A_{2}$ present in rat or human platelet fractions or rat ileum homogenates, nor in rat or murine cardiac homogenates (Table 2).

Therefore, it was decided to test a number of other antibodies used in other studies to detect type IIA sPLA 2 protein, albeit in other cell types or tissues than the myocardium (Kriegsmann et al., 1993, Murakami et al., 1988, Dorsam et al., 1995). Two monoclonal antibodies, one originally raised against $14 \mathrm{kDa}$ bee venom type $\mathrm{PLA}_{2}$ and one against rat platelet type IIA sPLA $\mathrm{A}_{2}$, gave similar results in Western blotting experiments. Both antibodies were able to detect $6 \times$ His-tagged type IIA SPLA $_{2}$, probably since this fraction contained relatively high amounts of the protein, but failed to detect type IIA sPLA 2 in platelets and rat ileum, both known to contain high amounts of type IIA sPLA $\mathrm{A}_{2}$, nor in cardiac homogenate (Table 2). This result is unexpected since the latter antibody was actually raised against rat type IIA sPLA 2 purified from rat platelets (Murakami et al., 1988). Up till now no satisfying explanation for the negative results obtained with latter antibody fractions can be provided.

Finally, a polyclonal antibody originally raised against type IIA sPLA $\mathrm{A}_{2}$ from human synovial exudate was tested in immunoblotting experiments (Dorsam et al., 1995). With this commercially available antibody type IIA sPLA 2 was readily 
detected in the purified $6 \times$ His-tagged protein fraction. Moreover, signals of about $14 \mathrm{kD}$ were obtained in positive control preparations such as human and rat platelets and rat ileum (Table 2). Unfortunately, no type IIA sPLA ${ }_{2}$ protein could be detected in cardiac homogenates, indicating that the levels of sPLA $\mathrm{P}_{2}$ protein in the heart are below the detection levels of immunoblotting detection procedures. The latter finding lends further support to previously obtained circumstantial evidence of relative low abundance of type IIA sPLA ${ }_{2}$ in myocardial cells (De Windt et al., 1997). This notion was based on the findings that only one positive type IIA sPLA cDNA clone was obtained after screening over one million plaques of a rat heart library. Additionally, low intensity of type IIA sPLA ${ }_{2}$ hybridization signals were found in total heart and in different cardiac cell types in Northern blotting experiments (De Windt et al., 1997). Moreover, results from other studies (Vervoordeldonk et al., 1996, Nakano et al., 1990) repeatedly indicate barely

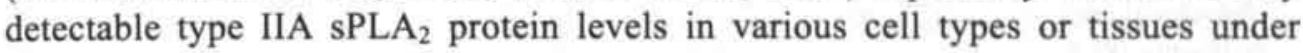
physiological circumstances via immunoblotting procedures, either with the antibodies of the present study or with other anti-type IIA sPLA ${ }_{2}$ antibodies. Only after stimulating cells with) cytokines like TNF $\alpha$ and/or IL-1 $\beta$ or with a number of growth factors a clear upregulation of type IIA sPLA ${ }_{2}$ protein levels and detection in Western blots is obtained (Vervoordeldonk et al., 1996, Nakano et al., 1990). These findings are in line with our own observations that type IIA sPLA ${ }_{2}$ mRNA levels are over five fold upregulated in cultured neonatal rat cardiomyocytes after stimulation with TNF $\alpha$ or IL-1 $\beta$ (De Windt et al., 1997). The results in the present study suggest that under physiological conditions cardiac type IIA sPLA $\mathrm{A}_{2}$ is present in amounts difficult to detect by means of Western blots. Future application of improved techniques, such as the use of radio-isotope imaging as an alternative detection procedure (Hunger et al., 1994), might increase the sensitivity of type IIA sPLA ${ }_{2}$ Western blotting to a level allowing the detection of type IIA sPLA $\mathrm{P}_{2}$ protein normal cardiac tissue.

In summary, a number of anti-PLA $A_{2}$ antibodies were tested for their ability to detect type IIA sPLA 2 in non-stimulated cardiac tissue. It was found that all antibodies used in the present study were able to detect a purified, recombinantly expressed $6 \times$ His-tagged type IIA sPLA $\mathrm{A}_{2}$ albeit with different sensitivity. Only a monoclonal anti-rat liver type IIA sPLA ${ }_{2}$ antibody and a commercially available, polyclonal anti-human synovial fluid type IIA sPLA $\mathrm{P}_{2}$ antibody were able to detect type IIA sPLA $\mathrm{A}_{2}$ in rat platelets and/or rat ileum to some extent, both preparations


antibodies tested were able to detect type IIA $\mathrm{SPLA}_{2}$ in non-stimulated cardiac homogenate, which indicates that relatively low amounts of type IIA SPLA 2 are present in cardiac tissue under physiological circumstances. 


\section{Table II}

Summery of results obtained in immunoblotting experiments with five seperate antibodies in detecting $\mathrm{SPLA}_{2}$ in purified fractions and in a number of tissues and cell types.

\begin{tabular}{lcccccc} 
Antigen & $\begin{array}{c}\text { 6xHis-tag } \\
\mathrm{sPLA}_{2}\end{array}$ & $\begin{array}{c}\text { Pancreatic } \\
\mathrm{sPLA}_{2}\end{array}$ & $\begin{array}{c}\text { Naja Naja } \\
\text { venom } \\
\mathrm{sPLA}_{2}\end{array}$ & $\begin{array}{c}\text { Rathuman } \\
\text { platelets }\end{array}$ & Rat ileum & $\begin{array}{c}\text { Rat } \\
\text { heart }\end{array}$ \\
\hline
\end{tabular}

\section{Antibodies tested}

$\begin{array}{llll}\begin{array}{c}\text { Monoclonal anti-rat } \\ \text { liver sPLA }\end{array} & + & \text { ND } & \text { ND } \\ \begin{array}{c}\text { Polyclonal anti- } \\ 6 \times \text { His-tag sPLA }\end{array} & + & + & + \\ \begin{array}{c}\text { Monoclonal anti-rat } \\ \text { platelet sPLA }\end{array} & + & \text { ND } & \text { ND } \\ \begin{array}{c}\text { Monoclonal anti-bee } \\ \text { venom sPLA }\end{array} & +/- & \text { ND } & \text { ND } \\ \begin{array}{c}\text { Polyclonal anti- } \\ \text { human sPLA }\end{array} & + & - & \\ & & & \end{array}$

ND, not determined; ++ , strong specific signal obtained against antigen; + , specific signal obtained against signal; +/- weak, but specific signal obtained against antigen; -, no signal obtained against signal.

\section{References}

1. Aarsman AJ, Leunissen-Bijvelt J, Van den Koedijk CDMA, Neys FW, Verkleij AJ, Van den Bosch $\mathrm{H}$. Phospholipase $\mathrm{A}_{2}$ activity in platelets. Immunopurification and localization of the enzyme in rat platelets. J Lipid Med 1989;1:49-61.

2. Bush GL, Tassin A, Friden H, Meyer DI. Purification of a translocation-competent secretory protein precursor using nickel ion affinity chromatography. J Biol Chem 1991;266:13811-13814.

3. de Jong JGN, Amesz H, Aarsman AJ, Lenting HBM, van den Bosch H. Monoclonal antibodies against an intracellular phospholipase $A_{2}$ from rat liver and their cross-reactivity with other phospholipases $A_{2}$. EurJ Biochem 1987;164:129-135.

4. De Windt LJ, Reneman RS, Van der Vusse GJ, Van Bilsen M. Phospholipase $\mathrm{A}_{2}$-mediated hydrolysis of cardiac phospholipids: the use of molecular and transgenic techniques. Mol Cell Biochem 1998;180:65-73.

5. De Windt LJ, Willemsen PHM, P pping S, Van der Vusse GJ, Reneman RS, Van Bilsen M. Cloning and cellular distribution of a group II phospholipase $\mathrm{A}_{2}$ expressed in the heart. $\mathrm{J} \mathrm{Mol} \mathrm{Cell}$ Cardiol 1997;29:2095-2106.

6. Dorsam G, Harris L, Payne M, Fry M, Franson R. Development and use of ELISA to quantify type II phospholipase $A_{2}$ in normal and uremic serum. Clin Chem 1995;41:862-866. 
7. Hoffmann A, Roeder RG. Purification of His-tagged proteins in non-denaturing conditions suggests a convenient method for protein interaction studies. Nucleic Acids Res 1991;19:63376338.

8. Hunger HD, Schmidt G, Flachmeier C, Quantitative western blotting using [ $\left.\gamma^{33} \mathrm{P}\right] \mathrm{ATP}$ and the ultrasensitive bio-imaging analyzer. Anal Biochem 1994;217:98-102.

9. Ishizaki J, Ohara O, Nakamura E, Tamaki M, Ono T, Yoshida N, Tereoka H, Tojo H, Okamoto M. cDNA cloning and sequence determination of rat membrane-associated phospholipase $\mathrm{A}_{2}$. Biochem Biophys Res Commun 162:1030-1036, 1989.

10. Kriegsmann J, Muller WD, Richter W, Wunderlich J, Wallukat G. Demonstration of membraneassociated phospholipase $A_{2}$ in cultivated heart muscle cells by immunogold-technique in surface replicas. Acta Histochem 1993;95: 61-66.

11. Lauritzen I, Heurtaux C, Lazdunski M. Expression of group II PLA $A_{2}$ in rat brain after severe forebrain ischemia and in endotoxin shock. Brain Res 1994;651: 353-356.

12. Leenarts PP, Hendriksen CF, Koedam MA, Claasen I, Claasen J. Comparison of adjuvants for immune potentiating properties and side effects in mice. Vet Immunol Immunopath 1995;48:123138.

13. Murakami M, Kobayashi T, Umeda M, Kudo I, Inoue $\mathrm{K}$. Monoclonal antibodies against rat platelet phospholipase $A_{2}$. J Biochem 1988;104:884-888.

14. Murakami M, Kudo I, Inoue K. Participation in cellular prostaglandin synthesis of type II phospholipase $\mathrm{A}_{2}$ secreted and anchored on cell-surface heparan sulfate proteoglycan. $J$ Biochem 1993;218:807-813.

15. Nakano $T$, Ohara $\mathrm{O}$, Teraoka $\mathrm{H}$, Arita $\mathrm{H}$. Group II phospholipase $A_{2}$ mRNA synthesis is stimulated by two distinct mechanisms in rat vascular smooth muscle cells. FEBS Lett 1990;261:171-174.

16. Nevalainen TJ, Gronhoos JM, Kallajoki M. Expression of group II phospholipase $\mathrm{A}_{2}$ in the human gastrointestinal tract. Lab Invest 1995 72:201-208.

17. Otamiri T, Franzen L, Lindmark D, Tageson C. Increased phospholipase $A_{2}$ and decreased lysophospholipase activity in the small intestinal mucosa after ischaemia and revascularization. Gut 1987;28:1445-1453.

18. Pruzanski W, Stefanski E, Vadas P, Ramamurthy NS. Inhibition of extracellular release of proinflammatory secretory phospholipase $\mathrm{A}_{2}\left(\mathrm{sPLA}_{2}\right)$ by sulfasalazine. Biochem Pharmacol 1997;53:1901-1907.

19. The QLAexpressionist (Qiagen, Leusden, The Netherlands), $19922^{\text {nd }}$ edition.

20. Tischfield JA. A reassessment of the low molecular weight phospholipase $A_{2}$ gene family in mammals. J Biol Chem 1997;272:17247-17250.

21. Van Bilsen $M$, Van der Vusse GJ. Phospholipase $A_{2}$-dependent signalling in the heart. Cardiovasc Res 1995;30:518-529.

22. Van der Vusse GJ, Van Bilsen M, Reneman RS. Is phopholipid degradation a critical event in ischemia- and reperfusion-induced damage. NIPS 4: 49-53, 1989.

23. Van Schaik RH, Van den Koeduk CD, Neijs FW, Aarsman AJ, Van den Bosch H. Monoclonal antibodies against rat liver mitochondrial phospholipase $\mathrm{A}_{2}$ : epitope analysis and application in western blotting. Int J Biochem 1993;25:433-439.

24. Vervoordeldonk MJBM, Pineda Torra IM, Aarsman AJ, Van den Bosch H. Aspirin inhibits expression of the interleukin-1_-inducible group II phospholipase A2. FEBS Lett 1996;397:108112.

25. Vork MM, Glatz JFC, Surtel DAM, Knubben HJM, Van der Vusse GJ. A sandwich linked immuno-sorbent assay for the determination of rat heart fatty acid-binding protein. Biochim Biophys Acta 1991;1075:199-205. 
Chapter 4 


\section{Chapter 5}

\section{Functional and metabolic evaluation of an improved isolated, left ventricular ejecting murine heart model.}

Published as:

LJ De Windt, J Willems, RS Reneman, GJ Van der Vusse, T Arts, M Van Bilsen. An improved isolated, left ventricular ejecting, murine heart model. Functional and metabolic evaluation. Eur J Physiol (Pfl gers Archiv) $1999 ; 437: 182-190$. 


\begin{abstract}
An improved isolated, left ventricular ejecting murine heart model is described and evaluated. Special attention was paid to the design and impedance characteristics of the artificial aortic outflow tract and perfusate composition, which contained glucose $(10 \mathrm{mM}+$ insulin), and pyruvate $(1.5 \mathrm{mM})$ as substrates. During antegrade perfusion (preload $10 \mathrm{~mm} \mathrm{Hg}$, afterload 50 $\mathrm{mm} \mathrm{Hg}, 2.5 \mathrm{mM} \mathrm{Ca}^{2+}$ ) proper design of the aortic outflow tract provided baseline values for cardiac output $(\mathrm{CO})$, left ventricular developed pressure (LVDP) and the first maximal derivative of left ventricular pressure ( $\mathrm{LV} \mathrm{dP} / \mathrm{dt}_{\max }$ ) of $11.1-1.7 \mathrm{ml} \cdot \mathrm{min}^{-1}, 83$ $-5 \mathrm{~mm} \mathrm{Hg}$ and $6283-552 \mathrm{~mm} \mathrm{Hg} \cdot \mathrm{s}^{-1}$, respectively, resembling findings in the intact mouse. During $100 \mathrm{~min}$ of normoxic antegrade perfusion $\mathrm{CO}$ decreased by less than $10 \%$. Varying pre and afterload resulted in typical Frank-Starling relationships with maximal $\mathrm{CO}$ values of $18.6-1.8 \mathrm{ml} \cdot \mathrm{min}^{-1}$ at pre and afterload pressure of 25 and $50 \mathrm{~mm} \mathrm{Hg}$, respectively. Left ventricular function curves were constructed at free $\left[\mathrm{Ca}^{2+}\right]$ of 1.5 and $2.5 \mathrm{mM}$ in the perfusion medium. Significantly higher values for CO, LVDP and $L V \mathrm{dP} / \mathrm{dt}_{\max }$ and $L V \mathrm{dP} / \mathrm{dt}_{\min }$ were obtained at $2.5 \mathrm{mM} \mathrm{Ca}^{2+}$ at all loading conditions investigated. Phosphocreatine and creatine levels remained stable throughout the perfusion period. Despite a small but significant decline in tissue ATP content, the sum of adenine nucleotides did not change during the normoxic perfusion period. The tissue content of glycogen showed a statistically significant increase.
\end{abstract}




\section{Introduction}

Advances in molecular biology have made it possible to experimentally alter the mammalian genome allowing the elucidation of the functional role of specific genes in the whole animal. Transgenic or gene targeting techniques have contributed to these advances. In this respect, the mouse is the animal model of choice, because of the relative ease by which DNA can be stably introduced into the germline and the availability of embryonic stem cell lines for gene-targeting. In cardiovascular research an increasing number of genetically altered murine models are being generated, which have proven to be of great importance for a better understanding of the underlying mechanisms in complex cardiovascular disorders (Chien, 1996, Franz et al., 1997).

Prerequisite for the evaluation of these cardiovascularly relevant altered murine phenotypes are adequate techniques to measure cardiac function. Efforts have been made to assess cardiac performance in the anesthetized open-chest mouse (Barbee et al., 1992, Milano et al., 1994, Lembo et al., 1996) and in the anesthetized or conscious closed-chest mouse (Hartley et al., 1995, Tanaka et al., 1996, Lorenz et al., 1997). In studies on cardiac function and metabolism, however, the use of isolated heart preparations is preferred, because hemodynamic performance can be assessed in a standardized way, while possible interferences such as changes in sympathetic drive, peripheral resistance, substrate supply and circulating hormone levels are avoided. For this purpose, isolated retrogradely perfused murine heart models have been developed independently by a number of investigators ( $\mathrm{Ng}$ et al., 1991, Marner et al., 1995, Plumier et al., 1995, Radford et al., 1996, Yoshida et al., 1996, Li et al., 1997, Matherne et al., 1997). Although these so-called Langendorff heart preparations are of use for specific applications, the antegradely perfused or left ventricular ejecting heart preparation is generally preferred, because of its more physiological resemblance and because cardiac performance can be analyzed more accurately. The development of such a model, however, is not without problems. Hemodynamic function in terms of cardiac output and contractility of the isolated ejecting mouse heart reported in previous studies (Ng et al., 1991, Bittner et al., 1996, Gauthier et al., 1998a and 1998b) differs markedly from the performance reported in the intact mouse (Barbee et al., 1992, Milano et al., 1994, Hartley et al., 1995, Lembo et al., 1996, Lorenz et al., 1997, Kass et al., 1998).

In the present study we developed an improved isolated, left ventricular ejecting mouse heart model paying special attention to the impedance characteristics of the aortic outflow tract, and to perfusate composition and temperature. The stability of the murine heart in this model was investigated during prolonged normoxic perfusion (up to $100 \mathrm{~min}$ ), using cardiac output, left ventricular developed pressure and the first maximal and minimal derivatives of left ventricular pressure as variables. Metabolic consequences of prolonged normoxic perfusion in this model were evaluated by measuring the tissue content of high energy phosphates and glycogen. Left ventricular function curves were obtained by stepwise variations of pre and afterload. The effect of perfusate calcium concentration on hemodynamic performance was addressed by varying preload, 
using perfusion media containing either 1.5 or $2.5 \mathrm{mM}$ nominally free $\mathrm{Ca}^{2+}$.

\section{Materials and methods}

\section{Chemicals}

All chemicals used for the Krebs-Henseleit solution were of the highest grade available and purchased from Merck (Darmstadt, Germany) except for $\mathrm{D}(+)$ glucose and pyruvate (Sigma Chemical Co., St. Louis, MO, USA).

\section{Perfusion system}

An assisted-mode perfusion system was used, which ensures proper coronary perfusion by an automatic switch from antegrade to retrograde perfusion when the heart is temporarily unable to generate its coronary perfusion in order to avoid unwanted underperfusion of the heart (Snoeckx et al., 1986, Van Bilsen et al., 1991). The perfusion system was placed in a temperature adjustable cage, the temperature of which was maintained at $38.5 ; C$. From a water-jacketed reservoir $(38.5 ; \mathrm{C})$ the perfusion fluid was pumped at a rate of $0.51 \mathrm{~min}^{-1}$ through a Millipore filter (pore size $1.2 \mu \mathrm{m}$ ) into a 1.01 bottle to suppress pressure pulsations generated by the pump. The perfusion solution passed through a filmoxygenator and was returned to the reservoir via an overflow (Figure 1).

In this way the total buffer solution was circulated, filtered, oxygenated and temperature controlled. The perfusion solution was periodically checked for $\mathrm{pH}$, $\mathrm{pO}_{2}$ and $\mathrm{pCO}_{2}$.



\section{Figure 1}

Schematic representation of the perfusion system for left ventricular ejecting mouse hearts. Arrows indicate the direction of the perfusate flow, $R$ : variable resistance used to adjust perfusion pressure (retrograde perfusion) or afterload pressure (antegrade perfusion), $B_{l}$ bubble trap in aortic line, $B_{2}$ compliance chamber, $B_{3}$ bubble trap in venous return line, $F_{1} 1 \mathrm{~N}$ inline flow probe, $F_{2} 2 \mathrm{~N}$ inline flow probe, $A O P$ aortic pressure transducer, $L V P$ left ventricular pressure transducer. 
$\mathrm{pH}$ values ranged between 7.40 and 7.45 , while $\mathrm{pO}_{2}$ exceeded $650 \mathrm{~mm} \mathrm{Hg}$.

Aortic pressure was regulated by the air compression in the bottle and by a variable hemodynamic resistance ( $R$ ) placed between bubble trap $B_{1}$ and the filmoxygenator. An inline $1 \mathrm{~N}$ flow probe ( $\mathrm{F}_{1}$; Transonic System Inc., Ithaca, NY, USA) was placed between bubble trap $B_{1}$ and the compliance chamber $\left(B_{2}\right)$ to measure retrograde and antegrade aortic flow. Left atrial filling pressure was determined by the height of the overflow level in the film-oxygenator. Entry of air-bubbles, if any, was prevented by a bubble trap $\left(\mathrm{B}_{3}\right)$ in the left atrial filling line. An inline $2 \mathrm{~N}$ flow probe $\left(\mathrm{F}_{2}\right.$; Transonic System Inc.) was placed before bubble trap $\mathrm{B}_{3}$ to measure atrial filling flow (venous return).

\section{Design of the aortic outflow tract}

In the design of an artificial system for isolated ejecting hearts, the hemodynamic characteristics of the aortic conduit are often neglected. This may result in a too high aortic impedance, leading to an unphysiologically high pressure load to the left ventricle, and subsequently to poor performance of the isolated heart (Van Bilsen et al., 1991). To avoid this situation, the aortic conduit was designed to match the hemodynamic characteristics of an isolated murine heart. The most critical part of the artificial aortic outflow tract is the short, rigid cannula between the heart and the compliance chamber distal to the aortic cannula. The major determinants of the pressure drop over the cannula are fluid mass acceleration (inertia term) and the loss of kinetic energy in the distal jet stream (Bernouilli term) (Van Bilsen et al., 1991). The viscous losses in the Poisseuille term appear to be negligible. The pressure drop in the cannula should be kept below $4 \mathrm{kPa}(31 \mathrm{~mm} \mathrm{Hg})$. Setting the pressure loss $\left(\mathrm{P}_{\mathrm{bem}}\right)$ due to the Bernouilli term to this maximum leads to the following condition for the internal diameter $d$ of the cannula:

$$
d \geq \sqrt{A O F \sqrt{\frac{\left(\rho \cdot k_{1}\right)}{P_{b e r n}}}}
$$

where $\mathrm{k}_{1}=\mathrm{a}$ constant, $\mathrm{AOF}=$ mean aortic flow and $\rho$ fluid density. Substitution of realistic values in equation (1), i.e., $\mathrm{AOF}=0.25 \mathrm{ml} . \mathrm{s}^{-1}$ (Barbee et al., 1992), $\rho=$ $1050 \mathrm{~kg} . \mathrm{m}^{-3}$ and $\mathrm{k}_{1} \approx 24$, results in $d \geq 0.79 \mathrm{~mm}$. To make the design of the cannula less critical, the internal cannula diameter should be chosen as large as possible. In our set-up we were able to set the diameter at $d=0.92 \mathrm{~mm}$.

An important second design criterium is to keep the fluid inertia term of the pressure drop, $\mathrm{P}_{\text {inert }}$, below about $2 \mathrm{kPa}(15.5 \mathrm{~mm} \mathrm{Hg})$. This condition results in a maximum value for the length of the cannula $l$ :

$$
l \leq \frac{d^{2} \cdot t_{\text {cycl }} \cdot P_{\text {inert }}}{\rho \cdot A O F \cdot k_{2}}
$$

Substituting for the diameter $d=0.92 \mathrm{~mm}$, for the cardiac cycle duration $\mathrm{t}_{\text {cycle }}=150$ 
$\mathrm{ms}$, for $\mathrm{P}_{\text {inen }}=2 \mathrm{kPa}(15.5 \mathrm{~mm} \mathrm{Hg})$ and for $\mathrm{k}_{2} \approx 237$, yields $l \leq 4.1 \mathrm{~mm}$. Based on these estimations an aortic cannula was made with a length of $4.0 \mathrm{~mm}$ and inner diameter of $0.92 \mathrm{~mm}$. The outer diameter was $1.1 \mathrm{~mm}$, which was just small enough for attachment of the murine aortic stump to the cannula (Hartley et al., 1995). A schematic drawing of the cannula is presented in Figure 2.
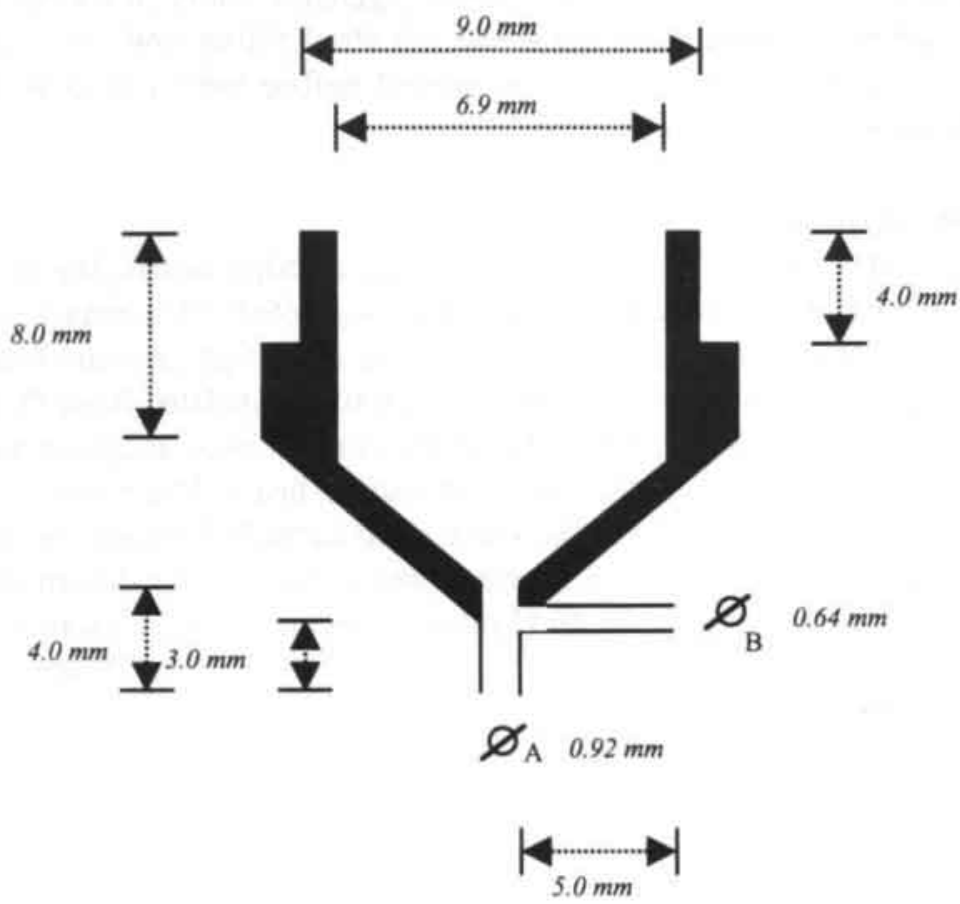

\section{Figure 2}

Detailed schematic representation of the dimensions of the outflow tract. $A$ indicates the cannula to which the aorta of the heart is attached. The inner diameter $\left(\varnothing_{A}\right)$ is $0.92 \mathrm{~mm}$. The position of the aortic pressure outlet $(B)$ is shown with an inner diameter $\left(\varnothing_{\mathrm{B}}\right)$ of $0.64 \mathrm{~mm}$.

Animals and surgery

Adult female and male Swiss mice (Iffa Credo, Lyon, France), average body weights $33.7-3.1 \mathrm{~g}$ and $46.1-1.6 \mathrm{~g}$, respectively, were kept under standard housing conditions with an artificial $12 \mathrm{~h}$ light cycle. The animals had free access to food (Diet SRM-A, Hope farms, Woerden, the Netherlands) and tap water. Experiments were approved by the Institutional Animal Care and Use Committee of the Maastricht University. 
Before surgery, the mice underwent mild $\mathrm{CO}_{2}$ anesthesia followed by a $50 \mathrm{mg} \cdot \mathrm{kg}^{-1}$ sodium pentobarbital injection i.p. (Nembutal, Sanofi Sante BV., Maassluis, the Netherlands). After thoracotomy the hearts (average weight of 197 29 and $266-26 \mathrm{mg}$, and heart weight/body weight ratio of $5.9-0.9$ and 5.8 - $0.5 \mathrm{mg} \cdot \mathrm{g}^{-1}$ for female and male mice, respectively) were quickly excised and placed in ice-chilled perfusion buffer. After removal of remnant lung and fat tissue, the aorta was connected to the aortic cannula and retrograde perfusion was started immediately at a perfusion pressure of 50 $\mathrm{mm} \mathrm{Hg}$, after which the hearts started to beat spontaneously. The left atrium was cannulated with an atrial 20-gauge cannula

(inner diameter $0.64 \mathrm{~mm}$, outer diameter $0.90 \mathrm{~mm}$, length $10.6 \mathrm{~mm}$ ) through one of the lung veins.

Left ventricular pressure was measured with a PE-50 catheter, inserted into the left ventricular cavity through the apex, connected to a Baxter Pressure transducer (Baxter Healthcare Corp., Irvine, CA, USA). Aortic pressure was measured through a side branch of the aortic cannula, located $3 \mathrm{~mm}$ above its entrance (Figure 2).

The hearts were perfused with a modified Krebs-Henseleit solution, consisting of (in mM): $\mathrm{NaCl}$ (118), $\mathrm{KCl}$ (4.7), $\mathrm{CaCl}_{2}$ (3.0), $\mathrm{MgSO}_{4}$ (1.2), $\mathrm{KH}_{2} \mathrm{PO}_{4}$ (1.2), $\mathrm{NaHCO}_{3}(25)$, Na-EDTA (0.5), D(+)-glucose (10) and Na-pyruvate (1.5), which was gassed with carbogen $\left(95 \% \mathrm{O}_{2}, 5 \% \mathrm{CO}_{2}\right)$. Due to the presence of 0.5 mM EDTA, the nominally free calium concentration of this perfusion medium was $2.5 \mathrm{mM}$. Insulin $(5 \mathrm{U} / \mathrm{l})$ was added to the perfusate. Due to losses (sticking to the glass wall of the perfusion system) the final insulin concentration in the circulating

\section{Table I}

Swistynamic values measured in isolated, ejecting hearts to adapt to the working mode.

\begin{tabular}{|c|c|}
\hline$H W(m g)$ & $197 \pm 29$ \\
\hline $\mathrm{CO}\left(\mathrm{ml} \cdot \mathrm{min}^{-1}\right)$ & $11.1 \pm 1.7$ \\
\hline$A O F\left(m l . m^{-1}\right)$ & $7.0 \pm 2.1$ \\
\hline$C F\left(\operatorname{ml} \cdot\right.$ min $\left.^{-1}\right)$ & $4.1 \pm 1.3$ \\
\hline$S V(\mu l)$ & $29 \pm 5$ \\
\hline $\operatorname{LVSP}(\mathrm{mm} \mathrm{Hg})$ & $88 \pm 5$ \\
\hline$L V E D P(m m ~ H g)$ & $5 \pm 3$ \\
\hline$L V d P / d t_{\max }\left(m m H g \cdot s^{-1}\right)$ & $6,283 \pm 552$ \\
\hline$L V d P / d t_{\min }\left(m m H g \cdot s^{-1}\right)$ & $-3,374 \pm 293$ \\
\hline
\end{tabular}

Data are expressed as means $\pm S D(n=8)$. Hearts were paced at 380 beats.min-1, pre- and afterload pressures were 10 and $50 \mathrm{~mm} \mathrm{Hg}$, respectively. $\mathrm{HW}$, heart weight; $\mathrm{CO}$, cardiac output; $\mathrm{AOF}$, aortic flow; $\mathrm{CF}$, coronary flow; $\mathrm{SV}$, stroke volume; LVSP, left ventricular systolic pressure; LVEDP, left ventricular end-diastolic pressure; $\mathrm{LV} \mathrm{dP/dt} t_{\max }$, first maximal derivative of left ventricular pressure; $\mathrm{LV} \mathrm{dP} / \mathrm{dt}_{\min }$, first minimal derivative of left ventricular pressure. 
perfusion medium amounted to $0.15 \mathrm{U} / 1$ as determined by an insulin radioimmunoassay (Amersham, Buckinghamshire, UK).

During preliminary experiments the performance of the isolated perfused murine heart was found to be highly sensitive to temperature fluctuations. Therefore efforts were undertaken to avoid excessive cooling of the hearts due to, for instance, evaporation of moisture from the epicardial surface. Moreover, the perfusate entering the heart was consistently $38-39\lceil\mathrm{C}$, similar to core body temperatures in the mouse (Conroy et al., 1980, Miller et al., 1994).

\section{Hemodynamic data}

All hemodynamic variables were continuously recorded on a personal computer, using specialized software (Hemodynamic Data Acquisition System, Technical Department Maastricht University), allowing the on-line acquisition, calculation and presentation of aortic flow (AOF), left ventricular systolic pressure (LVSP), left ventricular end-diastolic pressure (LVEDP), diastolic aortic pressure (AOPD) and the first maximal and minimal derivatives of left ventricular pressure ( $\mathrm{LV} \mathrm{dP} / \mathrm{dt}_{\max }$ and $\mathrm{LV} \mathrm{dP} / \mathrm{dt}_{\min }$ ). Left ventricular developed pressure (LVDP) was defined as the difference between LVSP and LVEDP. Cardiac output (CO) was defined as the sum of aortic flow (AOF) and coronary flow (CF). CF was determined from the difference between aortic flow (AOF), as measured by flow probe $F_{1}$, and left atrial filling flow, as measured by the inline flow probe $F_{2}$ (Figure 1).

In a separate test, it was investigated whether $\mathrm{LV} \mathrm{dP} / \mathrm{dt}_{\max }$ was limited by the frequency response of the pressure transducer (Baxter). In a closed container a pressure step was induced with a rise time of $2 \mathrm{~ms}$ as measured with a Millar pressure transducer. The rise time of the pressure measuring system used in the present study was $3 \mathrm{~ms}$. The rise times of LVP as measured experimentally were found to be about five times higher, i.e., $15-20 \mathrm{~ms}$. Therefore, it can be concluded that measured $\mathrm{LV} \mathrm{dP} / \mathrm{dt}_{\max }$ was not limited by the frequency response of the pressure measurement system.

\section{Experimental protocol}

In the experiments to test the stability of the preparation, antegrade perfusion was started by opening the left atrial conduit after an initial 10 min retrograde stabilization period at $50 \mathrm{~mm} \mathrm{Hg}$. The hearts were perfused at a left atrial filling pressure (preload) of $10 \mathrm{~mm} \mathrm{Hg}$, while diastolic aortic pressure (afterload) was kept at $50 \mathrm{~mm} \mathrm{Hg}$. Five minutes after the onset of antegrade perfusion, the hearts were paced via platina electrodes attached to the right atrium at a rate of 380 beats. $\mathrm{min}^{-1}$ until the end of the experiment, i.e., $100 \mathrm{~min}$ after the onset of antegrade perfusion. After completion of the experiments the ventricles of the individual hearts were separated from the atria and immediately frozen between aluminum clamps, previously cooled in liquid nitrogen, and stored at $-80 ; \mathrm{C}$ for further analysis. In a separate series of experiments, hearts were normoxically perfused for a $20 \mathrm{~min}$ stabilization period, after which the ventricles of the individual hearts were separated from the atria and immediately freeze clamped between aluminium clamps, previously cooled in liquid nitrogen, and stored at $-80{ }^{\circ} \mathrm{C}$ for further biochemical analysis. 
In another series of experiments left ventricular function curves were constructed by increasing left atrial filling pressure stepwise from 10 to 15,15 to 20 , and from 20 to $25 \mathrm{~mm}$ $\mathrm{Hg}$ at diastolic afterload pressures of 50,75 and 100 $\mathrm{mm} \mathrm{Hg}$, respectively. At each preload pressure the paced hearts ( 380 beats. $\mathrm{min}^{-1}$ ) were allowed to stabilize for $5 \mathrm{~min}$ during which hemodynamic data were recorded. After completion of data collection at the maximal preload pressure, hearts were allowed to recover in the antegrade mode for 10 min at baseline loading conditions (i.e., preload pressure of $10 \mathrm{~mm} \mathrm{Hg}$, afterload pressure of $50 \mathrm{~mm}$ $\mathrm{Hg}$ ), after which the next function curve was performed.

In a third series of experiments the influence of different free $\mathrm{Ca}^{2+}$ concentrations in the perfusate (1.5 and $2.5 \mathrm{mM}$ ) on left ventricular function was investigated.

To this end male murine hearts were perfused in an antegrade manner with Krebs-Henseleit perfusion medium containing $1.5 \mathrm{mM}$ nominally free $\mathrm{Ca}^{2+}(2.0$ $\mathrm{mM} \mathrm{CaCl} 2$ plus $0.5 \mathrm{mM}$ Na-EDTA). Hearts were allowed to equilibrate for $20 \mathrm{~min}$, after which left ventricular function curves were constructed by increasing preload pressure in a stepwise fashion from 10 to 15,15 to 20 , and 20 to $25 \mathrm{~mm} \mathrm{Hg}$ at a constant afterload pressure of $50 \mathrm{~mm} \mathrm{Hg}$. At each preload pressure the hearts were allowed to stabilize for $5 \mathrm{~min}$ during which LVP, AOP, CO, AOF and CF were recorded. After data collection at the maximal preload pressure, the hearts were allowed to recover in the antegrade mode for $10 \mathrm{~min}$ at pre and afterload pressures of 10 and $50 \mathrm{~mm} \mathrm{Hg}$, respectively. Hereafter $\mathrm{CaCl}_{2}$ was added to the perfusion medium to a nominally free $\mathrm{Ca}^{2+}$ concentration of $2.5 \mathrm{mM}$. Hearts were allowed to equilibrate for $10 \mathrm{~min}$, whereafter the same experimental protocol was followed. 
During the complete experiment hearts were paced at 400 beats. $\min ^{-1}$ due to the slightly higher intrinsic heart rate of the murine hearts.

\section{Biochemical analysis}

To assess the lactate content in the coronary effluent, samples of $1 \mathrm{ml}$ were immediately frozen in liquid nitrogen and stored at $-80\lceil\mathrm{C}$ for further analysis. To stabilize lactate dehydrogenase (LDH) activity in coronary effluent samples, bovine serum albumin was added to the samples (final concentration $3 \%$ ), after which they were frozen in liquid nitrogen and stored at $-80 ; \mathrm{C}$. Lactate and LDH in the coronary perfusate were assessed spectrophotometrically using a Cobas Bio autoanalyzer according to the method of Bergmeyer and Bernt ((1974) and Apstein et al. (1970), respectively. Tissue contents of high energy phosphates [adenine nucleotides, (phospho)creatine] and glycogen were determined as described previously (Van Bilsen et al., 1991, Van der Vusse et al., 1994).

\section{Statistical analysis}

The results are presented as mean values - standard deviations (SD). Differences within and between groups were evaluated for statistical significance using Student s t-test for paired and unpaired data, respectively. P values $<0.05$ were considered to be statistically significant.

\section{Results}

\section{Baseline hemodynamics and stability}

The baseline values of the various hemodynamic variables as measured $20 \mathrm{~min}$ after the start of antegrade perfusion are presented in Table 1. Under the conditions applied (10 $\mathrm{mm} \mathrm{Hg}$ preload pressure; $50 \mathrm{~mm} \mathrm{Hg}$ afterload pressure; pacing at 380 beats. $\min ^{-1}$ ) AOF, CF and $\mathrm{CO}$ amounted to $7.0-2.1,4.1-1.3$ and $11.1-1.7$ ml. $\mathrm{min}^{-1}$, respectively. Values of $88-5,5.0-3.2$ and $83-5 \mathrm{~mm} \mathrm{Hg}$ were found for left ventricular systolic pressure (LVSP), left ventricular end-diastolic pressure (LVEDP) and left ventricular developed pressure (LVDP), respectively. A representative tracing of a left ventricular pressure curve measured under basal conditions (pre and afterload pressures of 10 and $50 \mathrm{~mm} \mathrm{Hg}$, respectively) is shown in Figure 3.

To test the stability of the preparation, hearts were antegradely perfused for $100 \mathrm{~min}$. During this period CO decreased by about $10 \%$ (Figure 4). No significant changes were observed in LVEDP between the onset $(6.0-3.2 \mathrm{~mm} \mathrm{Hg})$ and the end of antegrade perfusion $(6.4-4.1 \mathrm{~mm} \mathrm{Hg})$. LVSP, and consequently LVDP, showed a decline of about $20 \%$. LV dP/dt $t_{\max }$ decreased by about $25 \%$, whereas LV $\mathrm{dP} / \mathrm{dt}_{\min }$ did not change significantly (Figure 4 ). The changes in hemodynamic function were confined to the first $40 \mathrm{~min}$ of perfusion, whereafter cardiac function did not show a statistically significant change. 


\section{Flow (ml.min ${ }^{-1}$ )}

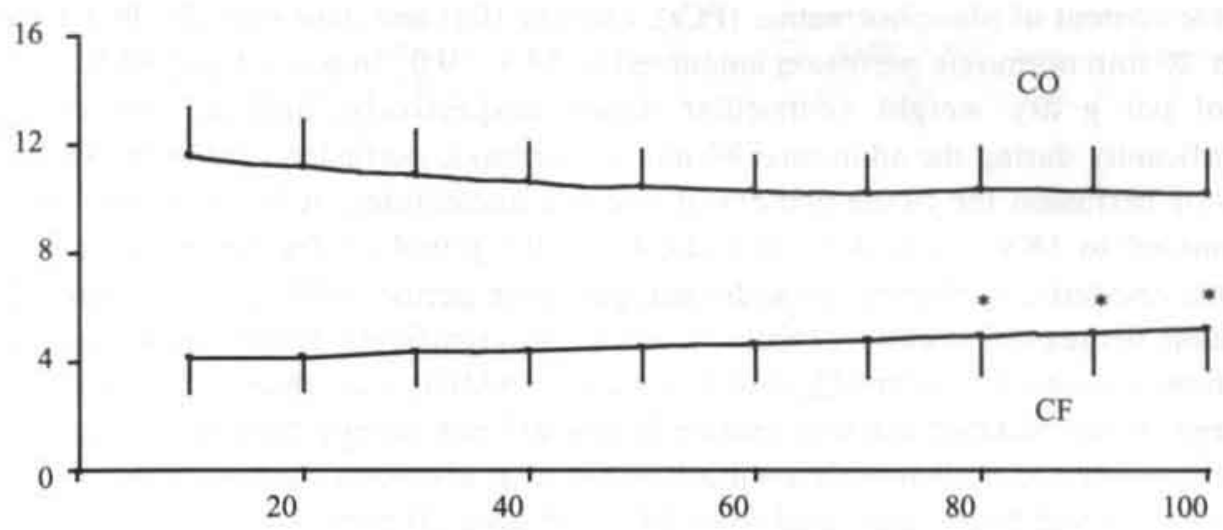
$\operatorname{LVDP}(\mathrm{mm} \mathrm{Hg})$
Time (min)

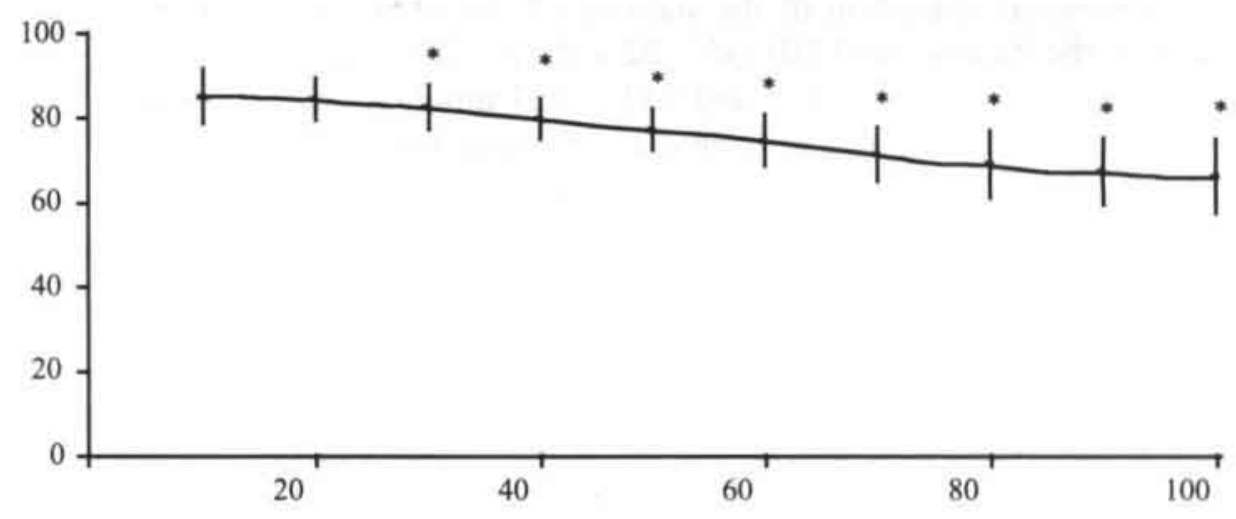

$\mathrm{LV} \mathrm{dP} / \mathrm{dt}\left(\mathrm{mm} \mathrm{Hg} . \mathrm{s}^{-1}\right)$

Time (min)



\section{Figure 4}

Cardiac output (CO) and coronary flow (CF; upper panel), left ventricular developed pressure (LVDP; middle panel), and in the lower panel the first maximal and minimal derivative of left ventricular pressure (LV P/dt $t_{\max }$ upper trace and $\mathrm{LV} \mathrm{dP/dt} \min _{\min }$ lower trace, respectively) as a function of time in the normoxically perfused, isolated working mouse heart under basal conditions ( 10 and 50 $\mathrm{mm} \mathrm{Hg}$ pre- and afterload, respectively). Data are expressed as means $\pm \mathrm{SD}(\mathrm{n}=8) . \quad \cdot \mathrm{P}<0.05$ vs value after $20 \mathrm{~min}$ of normoxic perfusion. 


\section{Metabolic analysis}

Tissue content of phosphocreatine $(\mathrm{PCr})$, creatine $(\mathrm{Cr})$ and their sum $[\Sigma(\mathrm{PCr}+\mathrm{Cr})]$ after 20 min normoxic perfusion amounted to $33.3-9.0,36.6-6.4$ and $69.9-12.0$ $\mu \mathrm{mol}$ per $\mathrm{g}$ dry weight ventricular tissue, respectively, and did not change significantly during the additional $80 \mathrm{~min}$ of normoxic perfusion (Table 2). After 20 min of perfusion the tissue content of adenine nucleotides, ATP, ADP and AMP, amounted to $18.9-2.0,4.3-0.5$ and $0.6-0.1 \mu \mathrm{mol}_{\mathrm{g}} \mathrm{g}^{-1}$ dry weight ventricular tissue, respectively. During the additional perfusion period of $80 \mathrm{~min}$ the tissue ATP content decreased slightly (Table 2), while no significant reduction in the total adenine nucleotide content [ $\Sigma$ (ATP + ADP + AMP) $]$ was observed. The energy charge of the isolated ejecting murine hearts did not change between 20 and 100 min of normoxic perfusion. In contrast, ventricular glycogen content of the isolated ejecting murine hearts increased from $245-68$ after 20 min to $409-100 \mu$ mol.g ${ }^{-1}$ dry weight after $100 \mathrm{~min}$ of normoxic antegrade perfusion.

Additional indication of the stability of the working heart preparation is provided by the finding that LDH $\left(45-22\right.$ and $22-20 \mathrm{mU}_{\mathrm{min}}^{-1}$. heart ${ }^{-1}$, onset vs. end; N.S.) and lactate $\left(0.60-0.12\right.$ and $0.91-0.23 \mu \mathrm{mol} \cdot \mathrm{min}^{-1}$.heart ${ }^{-1}$, onset vs. end; N.S.) release into the coronary effluent did not change between the onset $(0-10 \mathrm{~min})$ and the end of antegrade perfusion $(90-100 \mathrm{~min})$.

\section{Left ventricular function curves}

Left ventricular functions curves resembling Frank-Starling curves were constructed by varying both pre and afterload. At an afterload pressure of $50 \mathrm{~mm} \mathrm{Hg}$ a marked rise in $\mathrm{CO}$ was observed in response to the stepwise elevation of preload pressure, increasing from $12.0-0.6$ to $18.6-1.2 \mathrm{ml} \cdot \mathrm{min}^{-1}$ at preload values of 10 and $25 \mathrm{~mm}$ $\mathrm{Hg}$, respectively (Figure 5, Panel A). As expected, the increases in $\mathrm{CO}$ were less pronounced at afterload pressures of $75 \mathrm{~mm} \mathrm{Hg}$ and $100 \mathrm{~mm} \mathrm{Hg}$ (Figure 5, Panel A). At all afterload pressures CF increased approximately 1.5 fold from the lowest to the highest preload pressure level tested, reaching maximal values of $7.8-2.3$ $\mathrm{ml} \cdot \mathrm{min}^{-1}$ at an afterload pressure of $100 \mathrm{~mm} \mathrm{Hg}$ (Figure 5, Panel A). LVEDP substantially increased when preload pressure was enhanced (Figure 5, Panel B).

In general the left ventricular end-diastolic pressure (LVEDP) measured was lower than the preload pressure applied by the height of the oxygenator overflow level. Interestingly, at an afterload pressure of $50 \mathrm{~mm} \mathrm{Hg}$ the preload dependent increase in $\mathrm{CO}$ observed (Figure 5, Panel A) was not associated with significant rises in LVSP and LV dP/dt $t_{\max }$ (Figure 5, Panel B and C). In contrast, at afterload pressures of 75 and $100 \mathrm{~mm} \mathrm{Hg}$, LVSP and LV dP/dt $\mathrm{max}_{\max }$ displayed preload-dependent elevations (Figure 5, Panel B and C). LV dP/dt $\mathrm{din}_{\min }$ did not show a preload dependent change at any afterload tested, but showed a more negative value at 75 and $100 \mathrm{~mm}$ $\mathrm{Hg}$, indicating faster relaxation, than at $50 \mathrm{~mm} \mathrm{Hg}$. 


\section{Table II}

Tissue content of phosphocreatine (PCr), creatine ( $\mathrm{Cr}$ ), ATP, ADP, AMP, energy charge and glycogen of isolated left ventricular ejecting mouse hearts after 20 and $100 \mathrm{~min}$ of normoxic, antegrade perfusion.

Compound

( $\mu$ mol.g $g^{-1}$ dry weight)

\section{Duration of perfusion (min)}

\section{0}

100

\begin{tabular}{lcc}
\hline & $33.3 \pm 8.2$ & $31.3 \pm 4.7$ \\
$P C r$ & $36.6 \pm 5.9$ & $34.2 \pm 6.2$ \\
$C r$ & $69.9 \pm 10.9$ & $65.6 \pm 5.4$ \\
$\Sigma(P C r+C r)$ & & \\
& $18.9 \pm 1.8$ & $15.3 \pm 1.4^{*}$ \\
ATP & $4.3 \pm 0.4$ & $4.6 \pm 1.0$ \\
ADP & $0.6 \pm 0.1$ & $0.7 \pm 0.4$ \\
AMP & $23.8 \pm 2.0$ & $20.6 \pm 1.6$ \\
$\Sigma(A T P+$ ADP + AMP) & $0.89 \pm 0.01$ & $0.86 \pm 0.04$ \\
Energy charge & & $437 \pm 114^{*}$ \\
Glycogen (glucose units) & $245 \pm 68$ & \\
\hline
\end{tabular}

Values are presented as means $\pm S D$ (both groups $n=6$ ). Energy charge is defined as $(\mathrm{ATP}+0.5 \mathrm{ADP}) /(\mathrm{ATP}+\mathrm{ADP}+\mathrm{AMP})$ and is unitless.

\section{Effect of calcium on cardiac function}

To test the effect of the perfusate calcium concentration on cardiac performance, left ventricular function curves were constructed at $1.5 \mathrm{mM}$ and $2.5 \mathrm{mM}$ free calcium. At both concentrations typical Frank-Starling curves were obtained by increasing the preload pressure in a stepwise manner from 10 to $25 \mathrm{~mm} \mathrm{Hg}$ with intervals of $5 \mathrm{~mm} \mathrm{Hg}$ at an afterload pressure of $50 \mathrm{~mm} \mathrm{Hg}$. In both the low and normal calcium group a significant rise in $\mathrm{CO}$ was observed in response to the stepwise elevation of preload pressure. In the low calcium group $\mathrm{CO}$ increased from 
$11.9-2.6$ to $14.9-3.3 \mathrm{ml} \cdot \mathrm{min}^{-1}(\mathrm{P}<0.05)$ when elevating preload pressure from 10 to $25 \mathrm{~mm} \mathrm{Hg}$ (Figure 6). At the preload pressures tested $\mathrm{CO}$ values were significantly higher in the $2.5 \mathrm{mM} \mathrm{Ca}^{2+}$ group, increasing from $14.5-2.0 \mathrm{ml} . \mathrm{min}^{-1}$ to $21.8-2.6 \mathrm{ml}^{-1} \mathrm{~min}^{-1}$, when elevating preload pressure from 10 to $25 \mathrm{~mm} \mathrm{Hg}$ (Figure 6). Similarly, AOF values were about $45 \%$ lower in the low extracellular calcium group over the whole range of loading conditions tested $(7.0-1.9$ and 9.9 $-1.9 \mathrm{ml}^{-\mathrm{min}^{-1}}$ at preload pressure of 10 and $25 \mathrm{~mm} \mathrm{Hg}$, respectively) as compared to those measured at a nominally free $\mathrm{Ca}^{2+}$ concentration of $2.5 \mathrm{mM}(9.9-1.4$ and $14.2-2.2 \mathrm{ml} \cdot \mathrm{min}^{-1}$ at preload pressure of 10 and $25 \mathrm{~mm} \mathrm{Hg}$, respectively). In contrast, in both groups CF increased approximately 1.6 fold from the lowest to the highest preload pressure tested and did not demonstrate a significant difference between the two groups at corresponding loading conditions. LVEDP values demonstrated preload dependent elevations, but did not show significant differences between both groups at all corresponding preload pressures tested. In the low calcium group LVSP, $\mathrm{LV} \mathrm{dP/dt} t_{\max }$ and $\mathrm{LV} \mathrm{dP} / \mathrm{dt}_{\min }$ amounted to $80-16 \mathrm{~mm} \mathrm{Hg}$, $5100-1617 \mathrm{~mm} \mathrm{Hg} \cdot \mathrm{s}^{-1}$ and $-2885-476 \mathrm{~mm} \mathrm{Hg} \cdot \mathrm{s}^{-1}$, respectively, at baseline loading conditions. Elevation of the $\mathrm{Ca}^{2+}$-concentration in the perfusion medium to $2.5 \mathrm{mM}$ resulted in significantly higher values for LVSP, LV dP/dt $\max$ and $\mathrm{LVdP} / \mathrm{dt}_{\min }\left(109-17 \mathrm{~mm} \mathrm{Hg}, 7480-1632 \mathrm{~mm} \mathrm{Hg} \cdot \mathrm{s}^{-1}\right.$ and $-3537-705 \mathrm{~mm} \mathrm{Hg} . \mathrm{s}^{-1}$, respectively) at similar pre and afterload pressures.

\section{Discussion}

In the present study an improved isolated working mouse heart model is described. In developing this model special attention was paid to the characteristics of the aortic outflow tract and the composition and temperature of the perfusion medium. The design of the aortic outflow tract is critical to avoid a too high aortic impedance and, hence, a too high load to the ejecting left ventricle (Van Bilsen et al., 1991). A high impedance of the aortic outflow tract will lead to a high systolic left ventricular pressure and enhanced oxygen demand of the isolated heart (Neely et al., 1967, Kobayashi et al., 1983). The aortic cannula of the present study was designed using hemodynamic values as measured in the mouse in vivo (Barbee et al., 1992, Hartley et al., 1995) and the dimensions of the mouse ascending aorta (Hartley et al., 1995). The proper design of the aortic outflow tract likely explains the physiological hemodynamic values observed during ejection (see below).

Another factor influencing hemodynamic performance of isolated, perfused mouse heart preparations is the substrate composition of the perfusion medium. Pyruvate was included as co-substrate to the perfusate solution, as its beneficial effects on hemodynamic and metabolic stability of isolated heart preparations have been well documented (Van Bilsen et al., 1989 and 1991, De Groot et al., 1993). A concentration of $1.5 \mathrm{mM}$ pyruvate was chosen to substitute for all monocarboxylate substrates present in the physiological situations. Increasing the final concentration of pyruvate to $5 \mathrm{mM}$ in the Krebs-Henseleit buffer, previously described for isolated rat heart preparations (Snoeckx et al., 1986, Van Bilsen et al., 1989 and 1991), did not improve hemodynamic stability (data not shown). The presence of 
insulin in the perfusion medium and addition of pyruvate as co-substrate ensures sufficient extractable substrates for the isolated heart, as demonstrated by the accumulation of glycogen during prolonged normoxic perfusion.

The presence of insulin and pyruvate in the perfusion medium most likely contributed to the relative stability of ventricular high energy phosphate content during prolonged normoxic perfusion. The slight reduction of tissue ATP content is consistent with findings in the normoxically perfused working rat heart preparation. This imbalance between ATP degradation and formation in the isolated heart preparation is still incompletely understood (Van Bilsen et al., 1989). It should be noted that the total adenine nucleotide content, the energy charge and the phosphocreatine content remained constant during prolonged aerobic perfusion.

By including $0.5 \mathrm{mM} \mathrm{Na-EDTA}$ in the Krebs-Henseleit solution, an effective concentration of nominally free calcium of $2.5 \mathrm{mM}$ was achieved. As evidenced in the present study, $\mathrm{Ca}^{2+}$ concentrations lower than $2.5 \mathrm{mM}$, that are frequently being applied in isolated mouse heart studies $(\mathrm{Ng}$ et al., 1991, Grupp et al., 1993, Marber et al., 1995, Yoshida et al., 1996, Matherne et al., 1997, Li et al., 1997), clearly resulted in a lower cardiac output and contractility of the isolated ejecting mouse heart. The temperature of the perfusion medium and, hence, of the isolated hearts was set at 38- 39 ...C because this temperature corresponds well with the core body temperature of the intact laboratory mouse (Conroy et al., 1980, Miller et al., 1994).

It is shown that in the present experimental set-up, at loading conditions comparable to those reported by the groups of Bittner et al. (1996), Grupp et al. (1991 and 1993) and Gauthier et al. (1998a and 1998b) the hemodynamic function of the isolated working mouse heart is relatively stable for at least $100 \mathrm{~min}$. Cardiac output decreased by less than $10 \%$ over this period. More importantly, hemodynamic performance in terms of cardiac output and contractility compares favorable to the in vivo situation in contrast to the other studies. In the present study cardiac output increased from about 12 to $19 \mathrm{ml} \cdot \mathrm{min}^{-1}$ when preload was increased from 10 to $25 \mathrm{~mm} \mathrm{Hg}$ at a fixed afterload pressure of $50 \mathrm{~mm} \mathrm{Hg}$. These cardiac output values are close to those $\left(16 \mathrm{ml} \cdot \mathrm{min}^{-1}\right)$ found in mice in vivo (Barbee et al., 1992, Hartley et al., 1995) and significantly higher than the cardiac output values of 1 - $4 \mathrm{ml} \cdot \mathrm{min}^{-1}$ reported by Bittner et al (Bitnner et al., 1996) at comparable loading conditions as in the present study. 
A

Afterload pressure $(\mathrm{mm} \mathrm{Hg})$

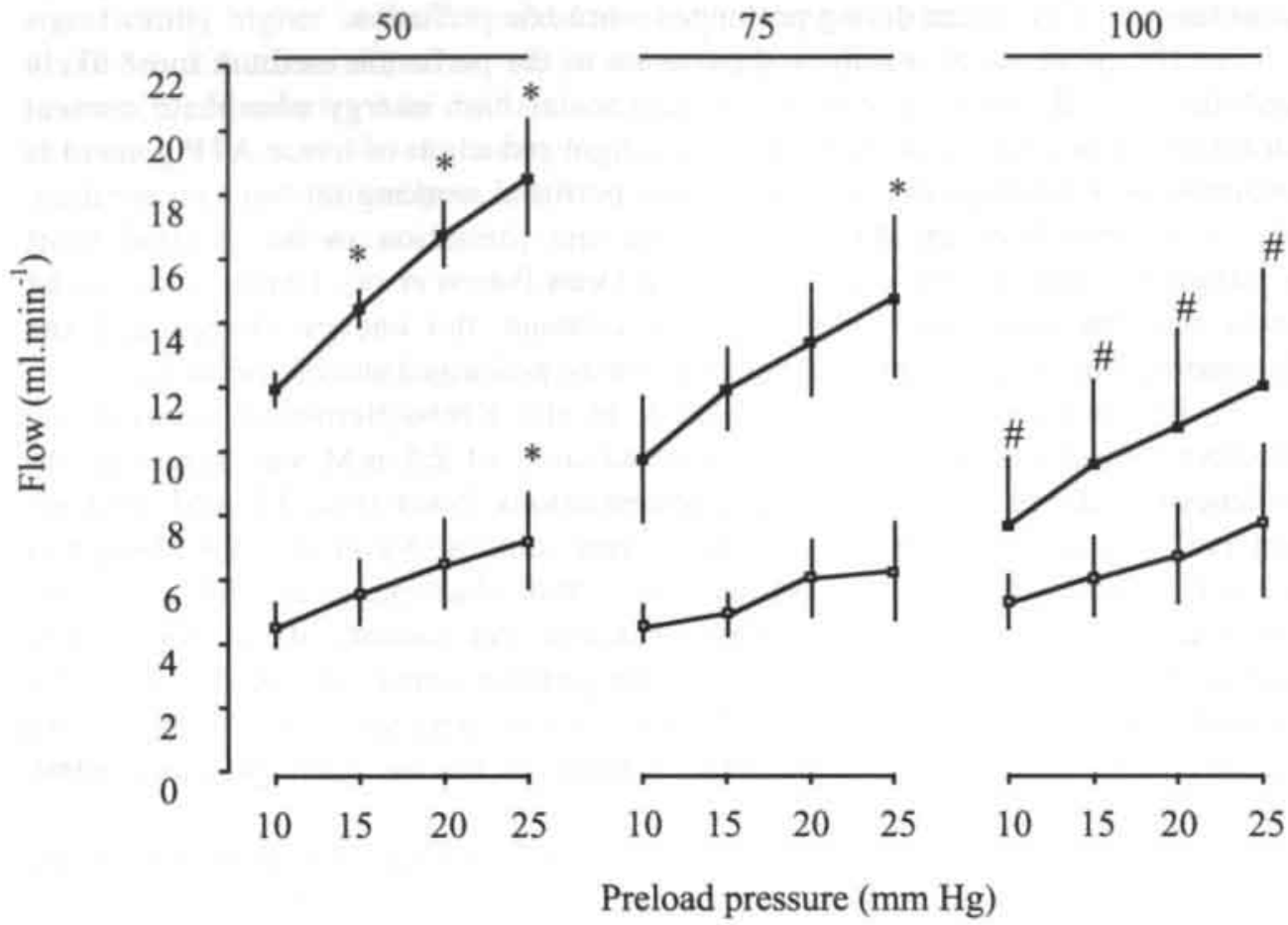

Afterload pressure $(\mathrm{mm} \mathrm{Hg})$

B

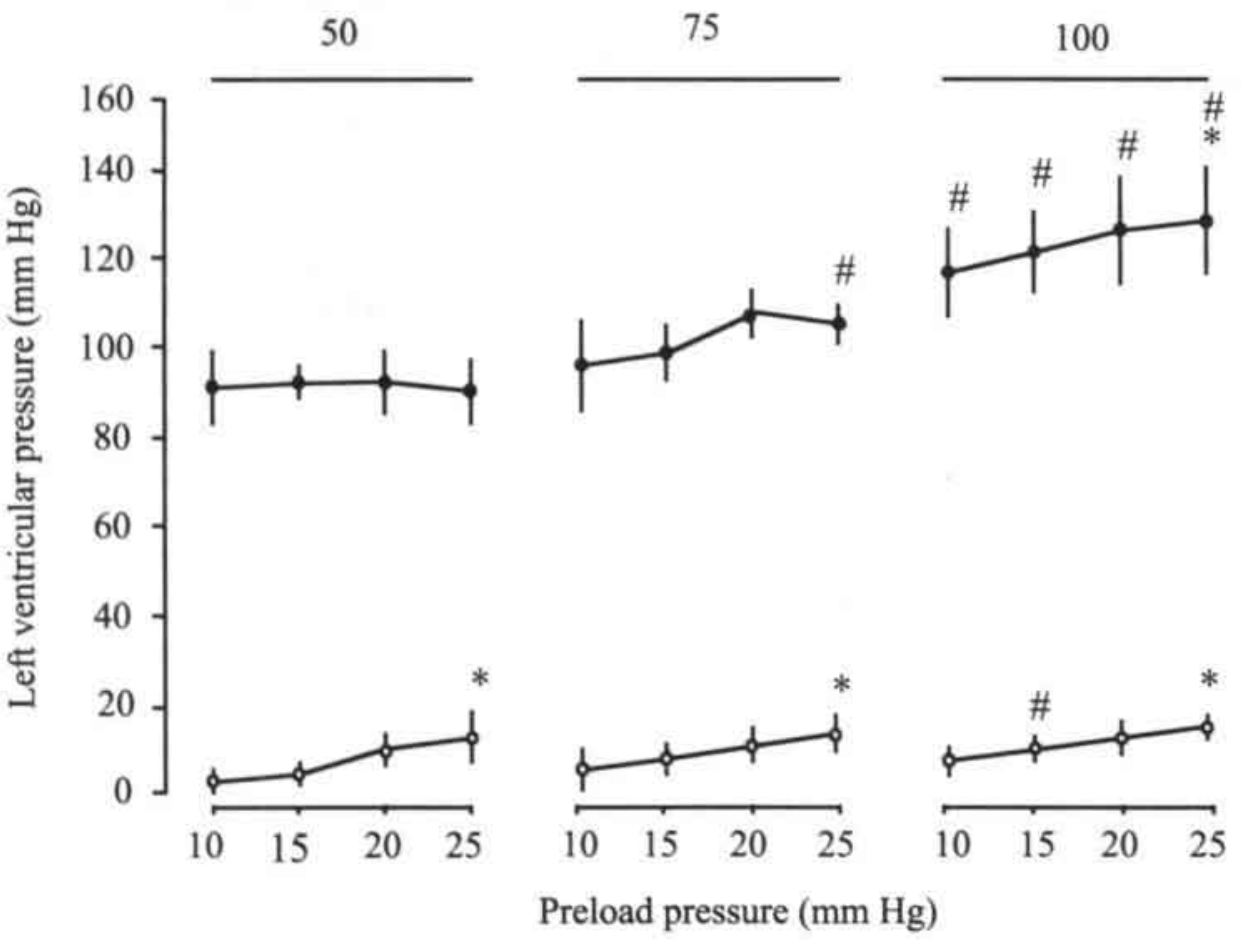


$\mathrm{C}$

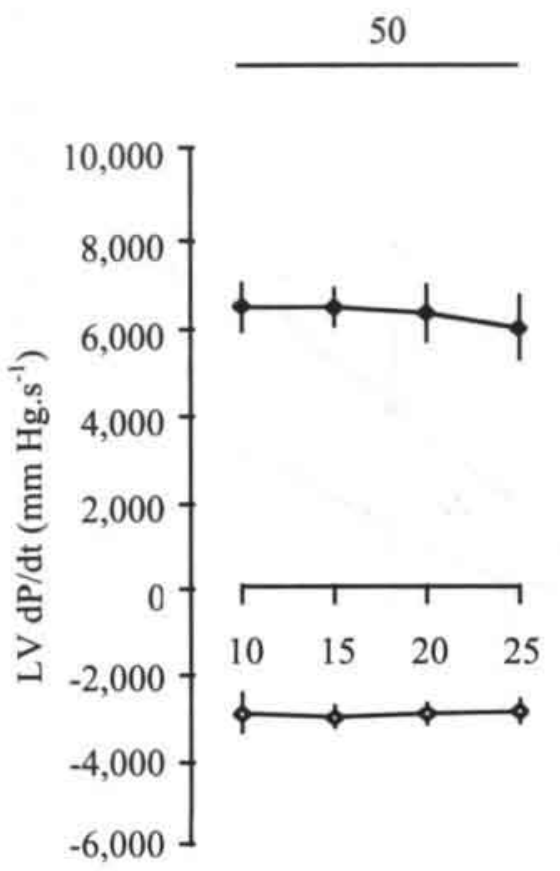

Afterload pressure ( $\mathrm{mm} \mathrm{Hg}$ )

75
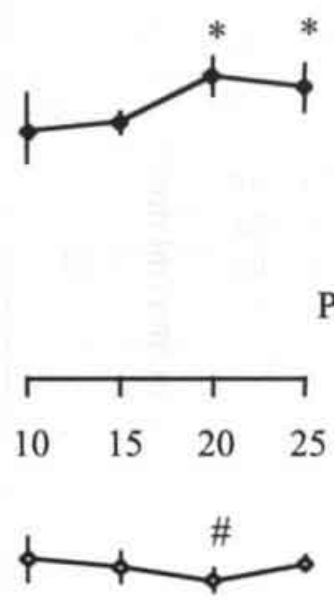

100

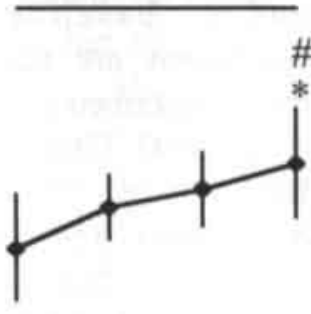

Preload pressure $(\mathrm{mm} \mathrm{Hg})$



\section{Figure 5}

Left ventricular function curves of normoxically perfused, isolated working mouse hearts. Shown are the effects of varying preload and afterload pressures on $\mathbf{A}$ cardiac output ( $\mathrm{CO}$; closed squares) and coronary flow (CF; open squares); B left ventricular systolic pressure (closed circles) and left ventricular end-diastolic pressure (open squares); and $\mathbf{C}$ the first maximal derivative of left ventricular pressure (closed diamonds) and the first minimal derivative of left ventricular pressure (open diamonds) in isolated antegradely perfused, murine hearts. * indicates $\mathrm{P}<0.05 \mathrm{vs}$ lowest preload pressure $(10 \mathrm{~mm}$ $\mathrm{Hg}$ ) at comparable afterload pressure, \# indicates $\mathrm{P}<0.05$ vs corresponding preload pressure.

A comparison with the functional characteristics reported by the group of Grupp (Ng et al., 1991, Grupp et al., 1993) is more difficult as these investigators standardly used a fixed left atrial inflow instead of a fixed filling pressure. Nevertheless, it is of interest to note that in their model at an afterload of $50 \mathrm{~mm} \mathrm{Hg}$ approximately $90 \%$ of cardiac output $\left(4.6\right.$ of $\left.5.1 \mathrm{ml} \cdot \mathrm{min}^{-1}\right)$ is used for coronary flow (Grupp et al., 1993). The model described in the present study compares favorably in this respect as less than $40 \%$ of cardiac output is used to supply the coronary vasculature. Most likely, these differences in performance are attributable to differences in the impedance of the aortic outflow tract, since in other studies longer and narrower cannulas were used, illustrating the importance of proper design of this part of the perfusion system. The stroke volumes values of $29-5 \mu \mathrm{l}$ 
resemble those reported for the in vivo situation by Barbee and colleagues $(26 \mu \mathrm{l})$ and Hartley and colleagues $(33 \mu \mathrm{l})$ (Barbee et al., 1992, Hartley et al., 1995).

The coronary flow rates

found in the present study

under baseline loading conditions are comparable to those described previously $(\mathrm{Ng}$ et al., 1991, Grupp et al., 1993, Bittner et al., 1996, Gauthier et al., 1998a and 1998b). The observation that coronary flow rates could increase by an additional $50 \%$ during the construction of left ventricular function curves, demonstrates that in the present model the murine coronary vascular bed is not fully dilated under basal conditions (10 and $50 \mathrm{~mm} \mathrm{Hg}$ pre and afterload pressure, respectively). Additionally, the absence of and increase in LDH and lactate release during prolonged perfusion indicates that the mouse hearts are not compromised with regard to oxygen supply.

The finding that the effective preload pressure (LVEDP) was lower than the applied left atrial filling pressure is consistent with findings in other isolated working mouse heart models (Ng et al., 1991, Grupp et al., 1993, Gauthier et al., 1998a and 1998b). It is of interest to note that this phenomenon was observed under all experimental conditions (varying pre and afterload). At present no explanation is at hand for this phenomenon.

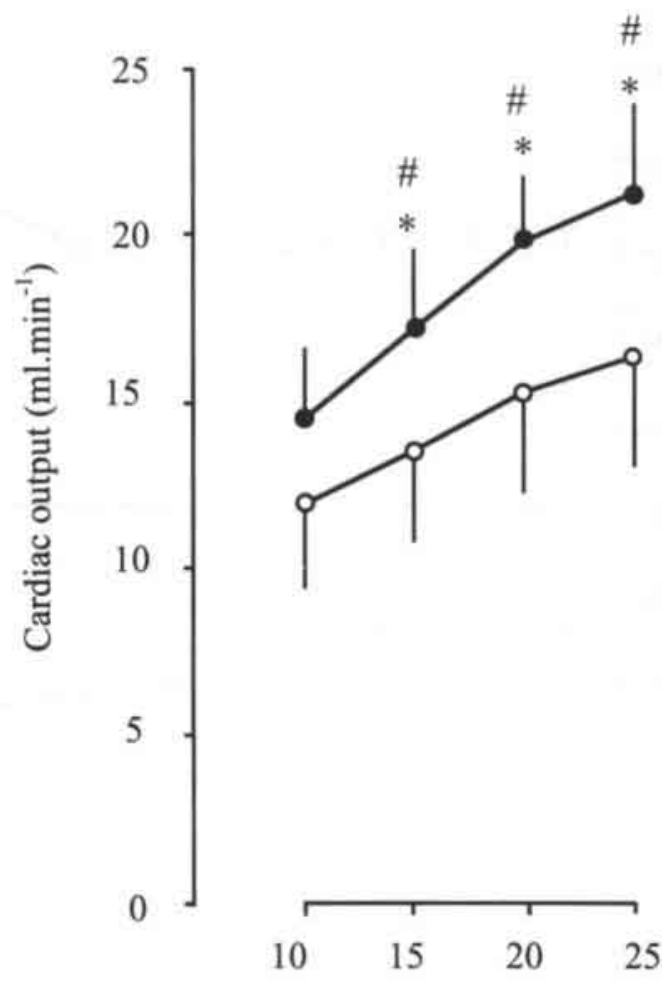

Preload pressure ( $\mathrm{mm} \mathrm{Hg}$ )

Figure 6: Left ventricular function curves of isolated working mouse hearts perfused with $1.5 \mathrm{mM}$ calcium (open circles) and $2.5 \mathrm{mM}$ calcium (closed circles). The curves were constructed by measuring cardiac output at varying preloads with the afterload kept constant at $50 \mathrm{~mm} \mathrm{Hg}$. Data are expressed as means $\pm \mathrm{SD}$ (both groups $\mathrm{n}=5$ ). * indicates $\mathrm{P}<0.05$ vs lowest preload $(10 \mathrm{~mm} \mathrm{Hg})$ at comparable $\mathrm{Ca}^{2+}$ concentration, \# indicates $\mathrm{P}<0.05$ vs corresponding preload pressure.

Only a few reports give insight into the in vivo contractile state of the mouse heart. Lembo et al. (1996) and Milano et al. (1994) reported values for LV $\mathrm{dP} / \mathrm{dt}_{\max }$ in open-chest mice of $4000-4500 \mathrm{~mm} \mathrm{Hg} . \mathrm{s}^{-1}$, while Lorenz et al. (1997) 
found LV dP/dt $\mathrm{d}_{\max }$ values of $7830-670 \mathrm{~mm} \mathrm{Hg} . \mathrm{s}^{-1}$ in anesthetized closed-chest mice. Again, the LV dP/dt $\max$ values of $6000-7500 \mathrm{~mm} \mathrm{Hg} . \mathrm{s}^{-1}$ found in the present study are comparable to the in vivo situation and considerable higher than those reported in other isolated ejecting mouse heart studies ( $\mathrm{Ng}$ et al., 1991, Grupp et al., 1993, Bittner et al., 1996, Gauthier et al., 1998a and 1998b). It should be noted, however, that in the conscious mouse (heart rates typically higher than 550 beats.min ${ }^{-1}$ ) LV dP/dt $\max$ values of more than $14,000 \mathrm{~mm} \mathrm{Hg} \cdot \mathrm{s}^{-1}$ should be anticipated (Kass et al., 1998). The observation that $\mathrm{LV} \mathrm{dP} / \mathrm{dt}_{\max }$ does not change when increasing preload at an afterload of $50 \mathrm{~mm} \mathrm{Hg}$ may be explained by the fact that the aortic valve opens before the physiological maximal value of the first derivative of left ventricular pressure has been reached, as earlier discussed by Reneman and Pollack (1971). This notion is supported by the finding that at higher afterloads LV dP/dt $\max$ increases with enhanced preload pressure. Therefore, the use of this parameter of contractile performance has to be interpreted in the light of the actual pre and afterload pressures applied.

In conclusion, the model described in the present study allows detailed evaluation of the performance of isolated, antegradely perfused mouse hearts. Because the functional characteristics of the isolated heart model in general corresponds well with in vivo findings, the present model will be asset in the interpretation of the function of specific gene products investigated in transgenic and gene-targeting mouse models for heart diseases.

\section{References}

1. Apstein CS, Puchner SE, Brachfeld N. Improved automated lactate determination. Anal Biochem 1970;38:20-34.

2. Barbee RW, Perry BD, R RN, Murgo JP. Microsphere and dilution techniques for the determination of blood flows and volumes in conscious mice. Am J Physiol 1992;263:R728-R733.

3. Bergmeyer HU, Bernt E. UV assay for lactate dehydrogenase with pyruvate and NADH. In: Methods of Enzymology, Weinheim Verlag Chemie GmbH, 1974;2:574-579.

4. Bittner HB, Chen EP, Peterseim DS, Van Trigt P. A work-performing heart preparation for myocardial performance analysis in murine hearts. J Surg Res 1996;64:57-62.

5. Chien KR. Genes and physiology: molecular physiology in genetically engineered animals. $J$ Clin Invest 1996;97:901-909.

6. Conroy PJ, Von Burg W, Passalacqua W, Sutherland RM. The effect of misonidazole on some physiologic parameters in mice. Pharmacol Exp Ther 1980;212:47-52.

7. De Groot MJM, Coumans WA, Willemsen PHM, Van der Vusse GJ. Substrate-induced changes in the lipid content of ischemic and reperfused myocardium. Its relation to hemodynamic recovery. Circ Res 1993;72:176-186.

8. Franz W-M, Mueller OJ, Hartong R, Frey N, Katus HA. Transgenic animal models: new avenues in cardiovascular physiology. J Mol Med 1997;75:115-129.

9. Gauthier NS, Headrick JP, Matherne GP. Myocardial function in the working mouse heart overexpressing cardiac $\mathrm{A}_{1}$ adenosine receptors. J Mol Cell Cardiol 1998a;30:187-193.

10. Gauthier NS, Matherne GP, Morrison RR, Headrick JP. Determination of function in the isolated working mouse heart: issues in experimental design. J Mol Cell Cardiol 1998b;30:453-461. 
11. Grupp IL, Subramaniam A, Hewett TE, Robbins J, Grupp G. Comparison of normal, hypodynamic, and hyperdynamic mouse hearts using isolated work-performing heart preparations. Am J Physiol 1993;265:H1401-H1410.

12. Hartley CJ, Michael LH, Entman ML. Noninvasive measurement of ascending aortic blood velocity in mice. Am J Physiol 1995;268:H499-H505.

13. Kass DA, Hare JM, Georgakopoulos D. Murine cardiac function: a cautionary tail. Circ Res 1998;82:519-522.

14. Kobayashi K, Neely JR. Mechanisms of pyruvate dehydrogenase activation by increased cardiac work. J Mol Cell Cardiol 1983;15:369-382.

15. Lembo G, Rockman HA, Hunter JJ, Steinmetz H, Koch WJ, Ma L, Prinz MP, Ross J Jr, Chien KR, Powell-Braxton L. Elevated blood pressure and enhanced myocardial contractility in mice with severe IGF-1 deficiency. J Clin Invest 1996;98:2648-2655.

16. Li G, Chen Y, Saari JT, Kang YJ. Catalase-overexpressing transgenic mouse heart is resistant to ischemia-reperfusion injury. Am J Physiol 1997;273: H1090-H1095.

17. Lorenz JN, Robbins J. Measurement of intraventricular pressure and cardiac performance in the intact closed-chest anesthetized mouse. Am J Physiol 1997;272:H1137-H1146.

18. Marber MS, Mestril R, Chi S, Sayen MR, Yellon DM, Dillmann WH. Overexpression of the rat inducible $70-\mathrm{kD}$ heat stress protein in a transgenic mouse increases the resistance of the heart to ischemic injury. J Clin Invest 1995;95:1446-1456.

19. Matherne GP, Linden J, Byford AM, Gauthier NS, Headrick JP. Transgenic $A_{1}$ adenosine receptor overexpression increases myocardial resistance to ischemia. Proc Natl Acad Sci USA 1997;94:65416546.

20. Milano CA, Allen LF, Rockman HA, Dolber PC, McMinn TR, Chien KR, Johnson TD, Bond RA, Lefkowitz RJ. Enhanced myocardial function in transgenic mice overexpressing the $\beta_{2}$-adrenergic receptor. Science 1994;264:582-586.

21. Miller DB, O Callaghan JP. Environment-, drug- and stress-induced alterations in body temperature affect the neurotoxicity of substituted amphetamines in the C57BL/6J mouse. Pharmacol Exp Ther 1994:270:752-760.

22. Neely JR, Liebermeister H, Battersby EJ, Morgan HE. Effect of pressure development on oxygen consumption by isolated rat heart. Am J Physiol 1967;212:804-814.

23. Ng WA, Grupp IL, Subramaniam A, Robbins J. Cardiac myosin heavy chain mRNA expression and myocardial function in the mouse heart. Circ Res 1991;69:1742-1750.

24. Plumier J-CL, Ross BM, Currie RW, Angelidis CE, Kazlaris H, Kollias G, Pagoulatos GN. Transgenic mice expressing the human heat shock protein 70 have improved post-ischemic myocardial recovery. J Clin Invest 1995;95:1854-1860.

25. Radford NB, Fina M, Benjamin IJ, Moreadith RW, Graves KH, Zhao P, Gavva S, Wiethoff A, Sherry AD, Malloy CR, Williams RS. Cardioprotective effects of $70-\mathrm{kDa}$ heat shock protein in transgenic mice. Proc Natl Acad Sci USA 1996;93:2339-2342.

26. Reneman RS, Pollack G. Cyclopropane and contractility. Anesthesiology 1971;35:550-551.

27. Snoeckx LHEH, Van der Vusse GJ, Coumans WA, Willemsen PHM, Van der Nagel T, Reneman RS. Myocardial function in normal and spontaneously hypertensive rats during reperfusion after a period of global ischemia. Cardiovasc Res 1986;20:67-75.

28. Tanaka N, Dalton N, Mao L, Rockman HA, Peterson KL, Gottshall KR, Hunter JJ, Chien KR, Ross $\mathrm{J}$ Jr. Transthoracic echocardiography in models of cardiac disease in the mouse. Circulation 1996;94:1109-1117.

29. Van Bilsen M, Snoeckx LHEH, Arts T, Van der Vusse GJ, Reneman RS (1991) Performance of the isolated, ejecting heart: effects of aortic impedance and exogenous substrates. Pfl gers Archiv-Eur J Physiol 1991;419:7-12.

30. Van Bilsen M, Van der Vusse GJ, Coumans WA, De Groot MJM, Willemsen PHM, Reneman RS. Degradation of adenine nucleotides in ischemic and reperfused rat heart. Am J Physiol 1989;257:H47-H54.

31. Van der Vusse GJ, Coumans WA, Van der Veen FH, Drake A, Flameng W, Suy R. ATP, creatine phosphate, and glycogen content in human myocardial biopsies: markers for the efficacy of cardioprotection during aorta-coronary bypass surgery. Vasc Surg 1994;18:127-134.

32. Yoshida T, Watanabe M, Engelman DT, Engelman RM, Schley JA, Maulik N, Ho Y, Oberly TD, Das D. Transgenic mice overexpressing glutathione peroxidase are resistant to myocardial ischemia reperfusion injury. J Mol Cell Cardiol 1996;28:1759-1767. 


\section{Chapter 6}

\section{Functional recovery, energy metabolism and lipid homeostasis in the ischemic-reperfused mouse heart.}

Submitted as full paper as:

LJ De Windt, J Willems, GJ Van der Vusse, RS Reneman, M Van Bilsen. Assesment of ischemia tolerance of the isolated left ventricular ejecting mouse heart: Functional and biochemical correlates. (Am J Physiol)

Parts of this study were published as:

LJ De Windt, J Willems, GJ Van der Vusse, RS Reneman, M Van Bilsen. Ischemia-reperfusion induced damage in isolated left ventricular ejecting mouse heart. Faseb J 1998;12:A75 (Abstract). 


\section{Abstract}

In the murine heart the effects of ischemia and reperfusion on cardiac high energy metabolism and lipid metabolism were investigated and related to functional recovery and the degree of irreversible cell damage. To this end, isolated ejecting murine hearts were subjected to 10,15 and $20 \mathrm{~min}$ of normothermic, no-flow ischemia, whether or not followed by $60 \mathrm{~min}$ of reperfusion. During ischemia cardiac ATP levels gradually declined, which was associated with a transient rise in ADP and a sharp increase in AMP content (from a pre-ischemic value of $0.6 \pm 0.1 \mu \mathrm{mol} . \mathrm{g}^{-1}$ dry weight to $6.3 \pm 2.0 \mu \mathrm{mol} . \mathrm{g}^{-1}$ dry weight after $20 \mathrm{~min}$ of ischemia). During reperfusion hemodynamic function almost completely recovered following $10 \mathrm{~min}$ of ischemia $(83 \pm 14 \%$ recovery of cardiac output [CO]), but was severely depressed following 15 and $20 \mathrm{~min}$ of ischemia $(40 \pm 24$ and $31 \pm 24 \%$ recovery of $\mathrm{CO}$, respectively). Reperfusion following $20 \mathrm{~min}$ of ischemia was accompanied by disturbed reflow as evidenced by delayed wash-out of lactate dehydrogenase ( $\mathrm{LDH})$ and post-ischemic accumulation of small molecular weight degradation products such as lactate and (oxy)purines. The percentage necrotic cells as assessed by cumulative release of $\mathrm{LDH}$ during reperfusion was calculated to be $4.8,8.4$ and $10.0 \%$ of total cardiac muscle cells following 10,15 and 20 min of ischemia, respectively. Reperfusion per se was associated with an enhanced degradation of phospholipids as indicated by the accumulation of fatty acids (FA) in reperfused hearts $(0.9 \pm 0.1$ $\mu \mathrm{mol} . \mathrm{g}^{-1}$ and $3.6 \pm 1.3 \mu \mathrm{mol} . \mathrm{g}^{-1}$ dry weight in pre-ischemic and reperfused hearts following $20 \mathrm{~min}$ of ischemia, respectively). In the reperfused heart a positive correlation was found between levels of FA $(r=0.70)$ and arachidonic acid $(r=0.65)$ on the one hand and cumulative release of $\mathrm{LDH}$ during reperfusion on the other. The latter observation strongly suggests that membrane phospholipid degradation and loss of cellular viability are closely related phenomena. 


\section{Introduction}

Murine models are increasingly used to study the molecular mechanisms of cardiac dysfunction following ischemia and reperfusion due to the widespread availability of transgenic and gene-targeted models. The isolated heart preparation is particularly suitable to assess ischemia/reperfusion-induced functional and biochemical alterations independent of potentially compensatory extra-cardiac factors. So far, functional and structural alterations in the mouse heart following global ischemia and reperfusion have almost exclusively been investigated by means of retrogradely perfused heart preparations (Hampton et al., 1998, Eberli et al., 1998). In addition, Langendorff perfused hearts from transgenic mice have been used to document the protective effects of heat shock protein 72 (Marber et al., 1995; Plumier et al., 1995; Radford et al., 1996; Trost et al., 1998), catalase (Li et al., 1997), $\mathrm{A}_{1}$ adenosine receptor (Matherne et al., 1997) and $\mathrm{Cu}-\mathrm{Zn}$ superoxide dismutase (Wang et al., 1997) on postischemic functional recovery. Furthermore, changes in high energy phosphate metabolism were subject of study in a number of genetically altered murine hearts (Headrick et al., 1998; Spindler et al., 1998; Saupe et al., 1998), either or not in conjunction with ischemia/reperfusion.

An important limitation of the isolated Langendorff perfused heart model is that it does not perform external work. As a consequence, this empty-beating heart model has limited physiological resemblance and the biological significance of the functional parameters obtained is uncertain. These disadvantages can largely be overcome by using a left ventricular ejecting (working) heart preparation allowing, in addition to pump performance, the accurate assessment of left ventricular diastolic and systolic function. Using isolated rat hearts it has been shown that with the use of these parameters left ventricular dysfunction following an ischemic insult can be adequately described (Van Bilsen et al., 1989a and 1989b, De Groot et al., 1993a and 1993b, Cornelussen et al., 1997).

In a previous study we developed and characterized a normoxically perfused isolated working murine heart model in terms of functional stability and its reponse to changes in workload (De Windt et al., 1999). Up to now detailed information of the murine heart regarding the functional recovery and its relation to post-ischemic energy status and lipid metabolism are lacking. The first main objective of the present study was to delineate the vulnerability of the isolated murine heart towards normothermic ischemia followed by reperfusion. Therefore, we determined the degree of hemodynamic recovery and alterations in cardiac high energy phosphate levels and related compounds after ischemia, varying in duration from 10 to $20 \mathrm{~min}$ followed by reperfusion. Moreover, post-ischemic release of LDH was monitored to estimate the degree of irreversibly damaged cardiac cells. The second main objective was to assess whether and to which extent ischemia and/or reperfusion-induced damage of the murine heart is associated with disturbances in membrane phospholipid homeostasis reflected by accumulation of tissue fatty acids, including arachidonic acid. 


\section{Materials and methods}

\section{Chemicals}

All chemicals used for the Krebs-Henseleit solution were of the highest grade available and purchased from Merck (Darmstadt, Germany), except for $\mathrm{D}(+)$ glucose and pyruvate (Sigma Chemical Co., St. Louis, MO, USA). Insulin was purchased from Novo Nordisk A/S (Bagsvaerd, Denmark).

\section{Animals and surgery}

For this study 3-4 month old female Swiss mice (Iffa Credo, Lyon, France) with an average body weight of $32.7 \pm 2.4 \mathrm{~g}$ were used. The mice were kept under standard housing conditions with an artificial $12 \mathrm{~h}$ light cycle with free access to standard rodent food (Diet SRM-A, Hope farms, Woerden, the Netherlands) and tap water. All experimental protocols were approved by the Institutional Animal Care and Use Committee of the Maastricht University.

\section{Isolated working mouse heart preparation}

The isolated ejecting mouse heart preparation used in the present study has been described in detail before (De Windt et al., 1999). Briefly, animals were anesthetized by $50 \mathrm{mg} . \mathrm{kg}^{-1}$ sodium pentobarbital, i.p. (Nembutal, Sanofi Sante BV., Maassluis, the Netherlands). After thoracotomy the hearts were quickly excised and transferred to ice-chilled perfusion buffer (for composition see below). Remnant thymic and fatty tissue was carefully removed and the ascending aorta was cannulated with a recently described aortic cannula that was designed to match the hemodynamic aortic impedance characteristics of the isolated murine heart (De Windt et al., 1999). Retrograde perfusion was started immediately at a perfusion pressure of $50 \mathrm{~mm} \mathrm{Hg}$, after which the hearts started to beat spontaneously. The left atrium was cannulated with an atrial cannula through one of the lung veins. The recirculating modified Krebs-Henseleit perfusion buffer was prefiltered by a microfilter $(0.45 \mu \mathrm{m}$ diameter; Millipore Corp.) and consisted of the following composition: $118 \mathrm{mM} \mathrm{NaCl}, 4.7 \mathrm{mM} \mathrm{KCl}, 3.0 \mathrm{mM} \mathrm{CaCl}_{2}, 1.2 \mathrm{mM} \mathrm{MgSO}_{4}, 1.2 \mathrm{mM}$ $\mathrm{KH}_{2} \mathrm{PO}_{4}, 25 \mathrm{mM} \mathrm{NaHCO}, 0.5 \mathrm{mM} \mathrm{Na}$-EDTA, $10 \mathrm{mM} \mathrm{D}(+)$-glucose, $1.5 \mathrm{mM} \mathrm{Na}$ pyruvate and $5 \mathrm{U} / 1$ insulin. The buffer was continously gassed with $95 \% \mathrm{O}_{2}-5 \%$ $\mathrm{CO}_{2}$. Care was taken to maintain the temperature of the perfusate, and thus the heart, at $38.5 ; \mathrm{C}$. Left ventricular pressure was measured with a PE-50 catheter, inserted into the left ventricular cavity through the apex (De Windt et al., 1999) and connected to a Baxter pressure transducer (Baxter Healthcare Corp., Irvine, CA, USA). Aortic pressure was measured through a side branch located $3 \mathrm{~mm}$ above the entrance of the aortic cannula using a pressure transducer (Baxter Healthcare Corp.).

\section{Hemodynamic data}

All hemodynamic variables were continuously recorded on a personal computer, using specialized software (Hemodynamic Data Acquisition System, Technical Department Maastricht University), allowing the on-line acquisition, presentation and calculation of left atrial filling flow, aortic flow (AOF), left ventricular systolic 
pressure (LVSP), left ventricular end-diastolic pressure (LVED), diastolic aortic pressure (AODP) and the first maximal and minimal derivatives of left ventricular pressure (LV dP/dt $t_{\max }$ and $\left.L V d P / d_{\min }\right)$. Left ventricular developed pressure (LVDP) was defined as the difference between LVSP and LVEDP. Cardiac output (CO) was defined as the sum of AOF and coronary flow (CF). CF was determined from the difference between $\mathrm{AOF}$, as measured by a $1 \mathrm{~N}$ inline aortic flow probe and left atrial filling flow as measured by a $2 \mathrm{~N}$ inline flow probe placed in the left atrial inflow tract (De Windt et al., 1999). Calculated CF data were periodically checked by timed collection of the coronary perfusate. $\mathrm{CF}$ data were used to calculate coronary resistance (CR), which was defined as AODP divided by CF normalized for individual heart weights.

\section{Experimental protocol}

During all experiments, antegrade perfusion was started by opening the left atrial conduit after an initial $10 \mathrm{~min}$ retrograde stabilization period at 50 $\mathrm{mm} \mathrm{Hg}$. Left atrial filling pressure was set at $10 \mathrm{~mm}$ $\mathrm{Hg}$, while diastolic aortic pressure was kept at 50 $\mathrm{mm} \mathrm{Hg}$. Except for the ischemic period and during the first $5 \mathrm{~min}$ of reperfusion, the hearts were paced artificially throughout the whole experiment at a frequency of 380 beats. $\mathrm{min}^{-1}$, which is slightly higher than the intrinsic rate of an isolated, perfused murine heart of this strain.

For ischemia/reperfusion experiments, the hearts were normoxically perfused for $20 \mathrm{~min}$ as described above (preischemic period).

\section{Table I}

Pre-ischemic hemodynamic values measured in isolated, left ventricular ejecting murine hearts.

\begin{tabular}{|c|c|}
\hline $\mathrm{CO}\left(\mathrm{ml} \cdot \mathrm{min}^{-1}\right)$ & $10.8 \pm 1.8$ \\
\hline$C F\left(m l \cdot \min ^{-1}\right)$ & $3.8 \pm 1.8$ \\
\hline$A O F\left(\operatorname{ml} \cdot \min ^{-1}\right)$ & $6.8 \pm 1.8$ \\
\hline$S V(\mu l)$ & $27 \pm 6$ \\
\hline$L V D P(\mathrm{~mm} \mathrm{Hg})$ & $77 \pm 9$ \\
\hline $\operatorname{LVSP}(\mathrm{mm} \mathrm{Hg})$ & $86 \pm 9$ \\
\hline LVPDia $(\mathrm{mm} \mathrm{Hg})$ & $1 \pm 3$ \\
\hline LVEDP $(\mathrm{mm} \mathrm{Hg})$ & $7 \pm 4$ \\
\hline$L V d P / d t_{\max }\left(m m H g \cdot s^{-1}\right)$ & $5,652 \pm 831$ \\
\hline$L V d P / d t_{\min }\left(m m H g \cdot s^{-1}\right)$ & $-3,054 \pm 415$ \\
\hline
\end{tabular}

Data are expressed as means $\pm \mathrm{SD}(\mathrm{n}=13)$. Isolated hearts were perfused at a pre and afterlaod of $10 \mathrm{~mm} \mathrm{Hg}$, respectively. Hearts were paced at 380 beats.min ${ }^{-1}$. CO, cardiac output; CF, coronary flow; AOF, aortic flow; SV, stroke volume; LVDP, left ventricular developed pressure; LVSP, left ventricular systolic pressure; LVPDia, left ventricular diastolic pressure; LVEDP, left ventricular end-diastolic pressure; LV dP/dt $\mathrm{max}_{\text {max }}$, first maximal derivative of left ventricular pressure; LV $\mathrm{dP} / \mathrm{dt}_{\min }$, first minimal derivative of left ventricular pressure. 
Just prior to the ischemic period the water-jacketed chamber was filled with warm $\left(38.5^{\circ} \mathrm{C}\right)$ perfusate solution until the heart was completely submersed, pacing was stopped, and the aortic and atrial lines were clamped for 10,15 or 20 min to create normothermic, global ischemia. After the ischemic period, the water-jacketed chamber was emptied and hearts were reperfused retrogradely at a perfusion pressure of $50 \mathrm{~mm} \mathrm{Hg}$ for $10 \mathrm{~min}$. Subsequently, the left atrial conduit was reopened and the hearts were allowed to work in the antegrade mode at a preload pressure of $10 \mathrm{~mm} \mathrm{Hg}$ and a diastolic aortic pressure of $50 \mathrm{~mm} \mathrm{Hg}$ for an additional $50 \mathrm{~min}$.

Hearts were freeze-clamped either after the 20 min stabilization period (preischemia), after 10,15 or $20 \mathrm{~min}$ of no-flow normothermic ischemia (endischemia), or following ischemia and $60 \mathrm{~min}$ of reperfusion (ischemia/reperfusion). To assess the lactate content in the coronary effluent samples of $1 \mathrm{ml}$ were immediately frozen in liquid nitrogen and stored at $-80 i \mathrm{C}$ for further analysis. For the determination of lactate dehydrogenase (LDH) activity in coronary effluent samples, bovine serum albumin was added to the samples (final concentration $3 \%$ ), after which they were frozen in liquid nitrogen and also stored at $-80\lceil\mathrm{C}$.

\section{Biochemical analysis}

$\mathrm{LDH}$ and lactate content in the coronary perfusate were assessed spectrophotometrically using a Cobas Bio autoanalyzer as described earlier (Bergmeyer and Bernt et al., 1974, Apstein et al., 1970).

Tissue contents of adenine and guanine nucleotides, IMP, and (oxy)purines was determined by high-performance liquid chromatography (Varian Vista 5500 HPLC) according to a variation of the procedures of Wynants and Van Belle (1985) and as described previously in detail (Van Bilsen et al., 1989a). Briefly, aliquots of deeply frozen tissue were extracted with perchloric acid and samples of the neutralized extract were applied to a precolumn (LiChroCART 4-4, Merck, Germany) and a reversed phase LiChrosorb RP-18 column (stainless steel, narrow bore, $250 \times 4 \mathrm{~mm} \mathrm{ID}$, Merck). Stepwise gradient elution (flow speed $0.8 \mathrm{ml} \cdot \mathrm{min}^{-1}$ ), using two solvents, was applied to separate the compounds of interest. Solvent A [aqueous buffer of $\mathrm{NH}_{4}\left(\mathrm{H}_{2} \mathrm{PO}_{4}\right) 150 \mathrm{mM}, \mathrm{pH}=6.0$ ] was prepared by mixing $\mathrm{H}_{3} \mathrm{PO}_{4}$ and $\mathrm{NH}_{4} \mathrm{OH}$. Solvent B consisted of a 1:1 ( $\left.\mathrm{vol} / \mathrm{vol}\right)$ mixture of acetonitrile and methanol. Each run started with a 6 min elution period of $100 \%$ solvent A. From 6 to 11 min solvent $\mathrm{A}$ was reduced to $95 \%$ and solvent $\mathrm{B}$ increased to $5 \%$. From 11 to 27 min solvent $\mathrm{A}$ was further decreased to $85 \%$, after which solvent $\mathrm{A}$ was increased to $100 \%$ within $2 \mathrm{~min}$. Peaks were detected at $254 \mathrm{~nm}$ using an ultraviolet detector (Varian UV-200, flow cell $4.5 \mathrm{ml}$, path length $4 \mathrm{~mm}$, spectral band width $5 \mathrm{~nm}$ ). The sensitivity was set at 0.005 AUFS at a time constant of $0.5 \mathrm{~s}$. Peaks were identified by comparing retention times with known standards.

The determination of cardiac fatty acids, phospholipids and triacylglycerols was performed as recently described in detail (Van der Vusse and Roemen, 1995). All fatty acyl values were expressed as moles per gram dry weight. Dry weight was determined in a subset of hearts by freeze drying overnight and amounted to $14.6 \%$ of wet weight, which corresponds to a conversion factor of 6.85 for wet weight to dry weight murine ventricular tissue. 


\section{Table II}

Total tissue content of individual purines and their sum in pre-ischemic, ischemic and ischemic-reperfused mouse hearts.

\begin{tabular}{lllllllll}
\hline$n$ & 6 & 6 & 10 & 6 & 9 & 5 & 11 \\
\hline
\end{tabular}

Pre-I $\quad 10 \min I \quad 10 \min I / R \quad 15 \min I \quad 15 \min I / R \quad 20 \min I \quad 20 \min I / R$

\begin{tabular}{|c|c|c|c|c|c|c|c|}
\hline$A$ & $0.07 \pm 0.02$ & $0.82 \pm 0.35^{*}$ & $0.20 \pm 0.20^{\#}$ & $1.07 \pm 0.57^{*}$ & $0.09 \pm 0.07^{\#}$ & $1.87 \pm 0.45^{*}$ & $0.41 \pm 0.20^{\prime \prime} \bullet$ \\
\hline$I$ & ND & $0.71 \pm 0.26$ & $0.03 \pm 0.02^{\#}$ & $1.27 \pm 0.65$ & $0.32 \pm 0.45^{\#}$ & $1.85 \pm 0.38$ & $1.20 \pm 1.31$ \\
\hline$H X$ & $0.04 \pm 0.02$ & $0.21 \pm 0.04^{*}$ & $0.28 \pm 0.31$ & $0.34 \pm 0.08^{*}$ & ND & $0.48 \pm 0.14^{*}$ & $0.32 \pm 0.08$ \\
\hline$X$ & ND & ND & $0.81 \pm 0.53$ & $0.08 \pm 0.07^{\#}$ & $0.93 \pm 0.72$ & $0.21 \pm 0.12$ & $1.00 \pm 0.70^{\#}$ \\
\hline
\end{tabular}

Total $\quad 0.08 \pm 0.03 \quad 1.60 \pm 0.60^{*} 0.74 \pm 0.73^{*} 6.75 \pm 1.65^{*} 0.88 \pm 1.21^{\# *} 4.13 \pm 0.72^{*} 2.28 \pm 2.08^{*}$

Data are expressed as means - SD. Presented are individual purines in $\mu \mathrm{mol} . \mathrm{g}^{-1}$ dry weight ventricular tissue. $\mathrm{n}$ indicates number of hearts analyzed. Pre-I, Pre-ischemia; I, ischemia; $\mathrm{R}$, reperfusion. Total refers to the sum of adenosine (A), inosine (I), hypoxanthine (HX) and xanthine (X) and is expressed as $\mu$ mol. ${ }^{-1}$ dry weight. * indicates $\mathrm{P}<0.05$ vs pre-ischemic value, \# indicates $\mathrm{P}<0.05$ vs corresponding end-ischemic value. ND, not detectable.

\section{Statistical analysis}

The results are presented as mean values - standard deviations (SD). All statistical analyses were performed using InStat 3.0 software (GraphPad Software Inc., San Diego, CA). Changes in functional variables in time were statistically analyzed by repeated measures ANOVA with Tukey s HSD post-hoc correction test for multiple comparisons. Differences between values of functional variables and biochemical parameters between experimental groups were analyzed using one-way ANOVA followed by the Tukey s test. Linear regression was performed with the least squares method and the Pearson rank correlation coefficient $(r)$ was used to estimate the strength of the relation between two variables. In all tests significance was accepted at $P$ values $<0.05$. 
Table III

Total tissue content of GTP, GDP, IMP, NADP and NAD in pre-ischemic, ischemic and ischemicreperfused mouse hearts.

$\begin{array}{llllllll}N & 6 & 6 & 10 & 6 & 9 & 5 & 11\end{array}$

Pre-I $10 \min I \quad 10 \min I / R \quad 15 \min I \quad 15 \min I / R \quad 20 \min I \quad 20 \min I / R$

$\begin{array}{llllllll}\text { GTP } & 1.3 \pm 0.1 & 0.9 \pm 0.2 & 0.9 \pm 0.3 & 0.7 \pm 0.2^{*} & 0.8 \pm 0.2 & 0.5 \pm 0.1^{*} & 0.7 \pm 0.2^{*} \\ \text { GDP } & 0.2 \pm 0.1 & 0.3 \pm 0.0 & 0.2 \pm 0.1 & 0.3 \pm 0.1 & 0.2 \pm 0.1 & 0.2 \pm 0.0 & 0.2 \pm 0.1 \\ \text { GMP } & \text { ND } & \text { ND } & \text { ND } & 0.1 \pm 0.1 & \text { ND } & 0.1 \pm 0.1 & 0.1 \pm 0.1 \\ \text { IMP } & 0.2 \pm 0.1 & 0.2 \pm 0.1 & 0.1 \pm 0.1 & 0.2 \pm 0.1 & 0.2 \pm 0.2 & 0.4 \pm 0.2 & 0.4 \pm 0.2 \\ & & & & & & & \\ \text { NADP } & 0.1 \pm 0.0 & 0.1 \pm 0.0 & 0.1 \pm 0.1 & 0.1 \pm 0.0 & 0.1 \pm 0.0 & 0.1 \pm 0.0 & 0.1 \pm 0.1 \\ \text { NAD } & 3.4 \pm 0.3 & 3.2 \pm 0.7 & 3.2 \pm 0.7 & 3.4 \pm 0.2 & 2.7 \pm 0.5 & 3.0 \pm 0.5 & 2.6 \pm 0.7\end{array}$

Data are expressed as means - SD in $\mu \mathrm{mol} . \mathrm{g}^{-1}$ dry weight ventricular tissue. $\mathrm{n}$ indicates number of hearts analyzed. Pre-I, Pre-ischemia; I, ischemia; R, reperfusion; ND, not detectable. * indicates $P<0.05$ vs nre-ischemic value.

\section{Results}

\section{Functional recovery}

Pre-ischemic values of the hemodynamic variables tested were not significantly different between the experimental groups and, hence, pooled data are presented in Table I. Following $10 \mathrm{~min}$ of global ischemia and $60 \mathrm{~min}$ of reperfusion functional recovery was almost complete. $\mathrm{CO}$ recovered to $83 \pm 14 \%$ of its pre-ischemic value ( $\mathrm{P}<0.05$ vs pre-ischemia), while no significant difference was observed between pre-ischemic and post-ischemic CF (Figure 1A). Similarly, post-ischemic LVDP, $\mathrm{LV} \mathrm{dP/dt} \mathrm{max}_{\max }$ and LV dP/dt $\mathrm{din}_{\min }$ all recovered to near pre-ischemic values (Figure 1C).

Extending the ischemic duration to $15 \mathrm{~min}$ resulted in a depression of the recovery of $\mathrm{CO}$ and AOF (Figure 1A). Post-ischemic LVDP amounted to $62 \pm 18 \%$ of its pre-ischemic value $\left(\mathrm{P}<0.05\right.$ vs pre-ischemia). Recovery of $\mathrm{LV} \mathrm{dP} / \mathrm{dt}_{\max }$ and $\mathrm{LV} \mathrm{dP/dt}$ min was also more severely depressed after $15 \mathrm{~min}$ of ischemia (Figure 1C).

Hemodynamic recovery was severely impaired following $20 \mathrm{~min}$ of ischemia. CO recovered to only $31 \pm 24 \%$ of its pre-ischemic value ( $P<0.01$ vs pre-ischemia; Figure 1A), while in the majority of hearts virtually no recovery of AOF was observed. Additionally, CF was severely compromised and amounted to 
$2.6 \pm 1.9 \mathrm{ml} \cdot \mathrm{min}^{-1}$, corresponding to a doubling of calculated coronary resistance (CR) from a pre-ischemic value of $15.8 \pm 7.6 \mathrm{~mm} \mathrm{Hg} \cdot \mathrm{min} \cdot \mathrm{ml}^{-1}$ to $30.0 \pm 21.8 \mathrm{~mm}$ Hg.min. $\mathrm{ml}^{-1}(\mathrm{P}<0.05)$. Due to a marked rise in LVEDP and a reduction in systolic function LVDP recovered to only $28 \pm 21 \%$ of its pre-ischemic value $(\mathrm{P}<0.01$ vs. pre-ischemia; Figure 1B).

\section{Enzyme and lactate release}

Pre-ischemic LDH release was low in all groups and amounted on the average to 37 $\pm 22 \mathrm{mU} \cdot \mathrm{min}^{-1}$. Following $10 \mathrm{~min}$ of global ischemia a small additional release of $\mathrm{LDH}$ was observed during the initial $20 \mathrm{~min}$ of the reperfusion phase. During 60 min of reperfusion, the cumulative release of LDH into the coronary effluent amounted to $2.9-0.8 \mathrm{U}$ in this group. The cumulative release of LDH increased as a function of the duration of the preceding ischemic period and amounted to 5.1 $1.7 \mathrm{U}$ and $6.1-2.7 \mathrm{U}$ following 15 and $20 \mathrm{~min}$ of ischemia, respectively. To estimate the percentage of irreversibly damaged cells, the cumulative release of $\mathrm{LDH}$ was normalized to the total LDH content of the murine heart ( $60.5 \mathrm{U} / \mathrm{heart})$. Accordingly, the percentage of necrotic cardiac myocytes was calculated to be 4.8 , 8.4 and $10.0 \%$ following 10,15 and $20 \mathrm{~min}$ of ischemia, respectively.

Prior to the onset of ischemia cardiac lactate release into the coronary effluent amounted to $0.8-0.2 \mu \mathrm{mol} \cdot \mathrm{min}^{-1}$. Following 10 and $15 \mathrm{~min}$ of ischemia a significantly higher lactate release rate was observed during the first $5 \mathrm{~min}$ of reperfusion $\left(1.6-0.1\right.$ and $1.6-0.6 \mu \mathrm{mol}$. $\mathrm{min}^{-1}$, respectively; $\mathrm{P}<0.05$ vs preischemia), reflecting the wash-out of lactate accumulated during the preceding ischemic period. Thereafter, lactate release returned to pre-ischemic values. In contrast, following $20 \mathrm{~min}$ of ischemia no significant washout of lactate was observed in the initial reperfusion phase. Lactate release amounted to $0.9-0.3$ $\mu \mathrm{mol} . \mathrm{min}^{-1}$ and remained constant during the remainder of the reperfusion phase.

\section{Tissue adenine nucleotides and degradation products}

The pre-ischemic tissue content of ATP, ADP and AMP amounted to $18.9-2.0$, $4.3-0.5$ and $0.6-0.1 \mu \mathrm{mol} . \mathrm{g}^{-1}$ dry weight, respectively, corresponding to an adenylate energy charge (EC) of $0.89 \pm 0.01$ (Figure 2). The sum of adenine nucleotide degradation products, i.e., adenosine, inosine, hypoxanthine and xanthine, was very low in normoxically perfused pre-ischemic ventricular tissue (Table II).

During 10 and $15 \mathrm{~min}$ of ischemia tissue ATP content progressively decreased, while ADP and AMP levels increased (Figure 2). Extension of the ischemic duration to $20 \mathrm{~min}$ was associated with marked reductions in both ATP and ADP content. In contrast, tissue AMP levels increased dramatically. As a result, the tissue adenylate EC fell to $0.42 \pm 0.16$ following $20 \mathrm{~min}$ of ischemia (Figure 2). Adenine nucleotide degradation products substantially increased (Table II). 

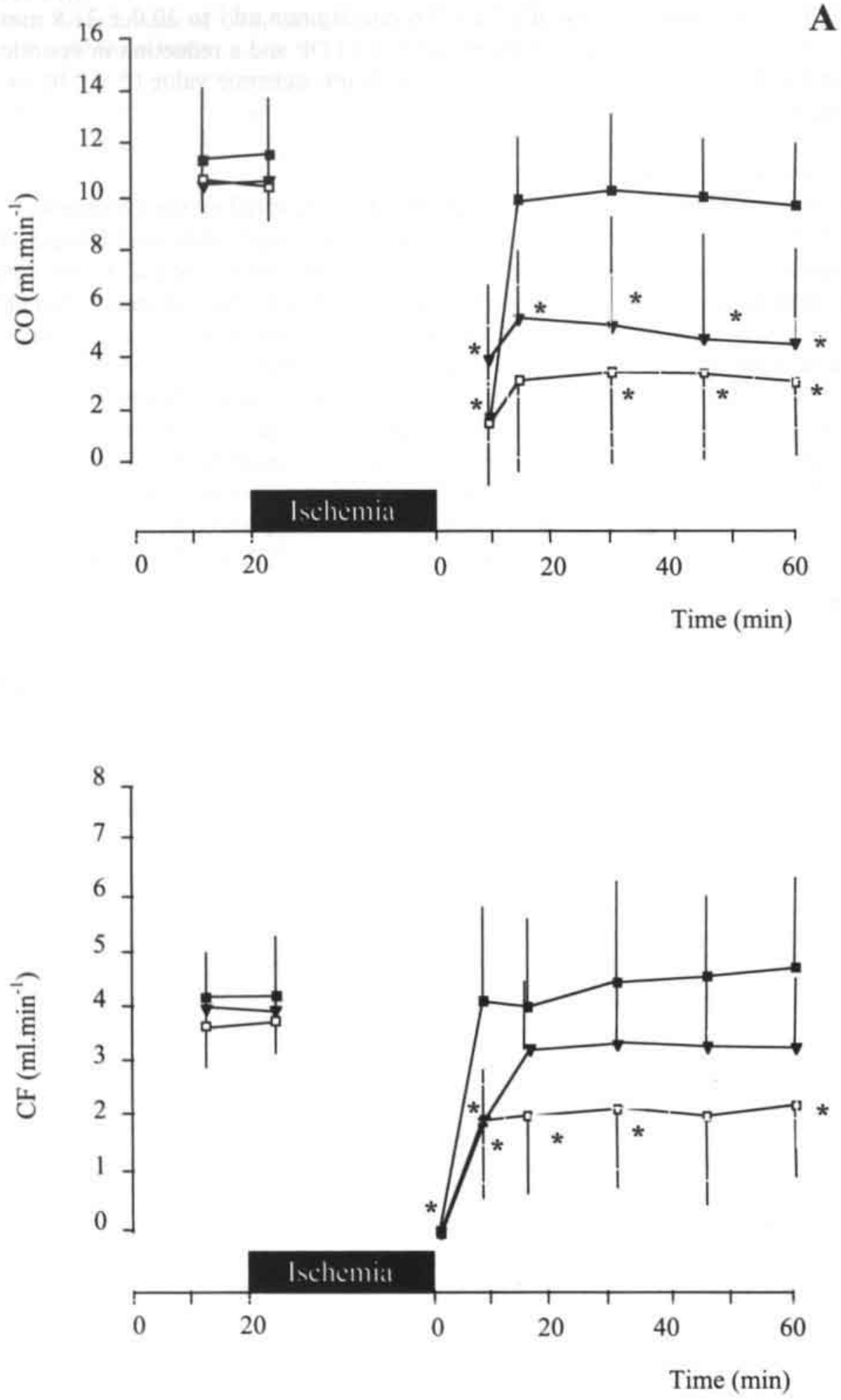
B


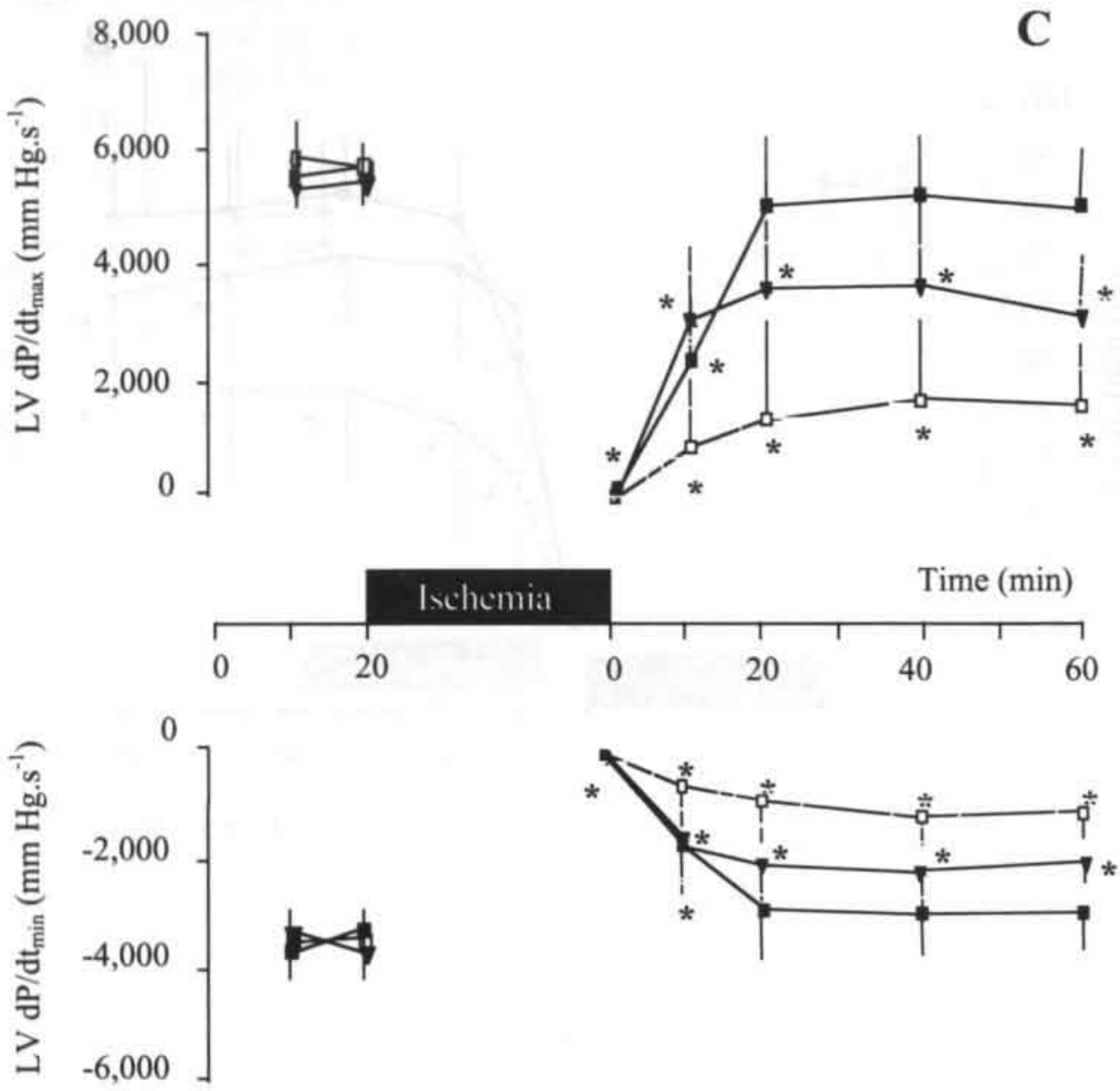

\section{Figure 1}

Post-ischemic recovery of cardiac output and coronary flow (CO and CF; Figure 1A), left ventricular systolic pressure and left ventricular end-diastolic pressure (LVSP and LVEDP; Figure $1 \mathrm{~B}$ ) and first maximal and minimal derivative of left ventricular pressure (LV $\mathrm{dP} / \mathrm{dt}_{\max }$ and $\mathrm{LV} \mathrm{dP} / \mathrm{dt}_{\min }$; Figure $1 \mathrm{C}$ ) following 10 (closed rectangles), 15 (closed triangles) and $20 \mathrm{~min}$ (open rectangles) of normothermic no-flow ischemia. Indicated on the $\mathrm{x}$-axis is the $20 \mathrm{~min}$ pre-ischemic perfusion time in $\mathrm{min}$, the global ischemic period and $60 \mathrm{~min}$ of reperfusion. Data are expressed as means - SD $(n=10$, following 10 and 15 min of ischemia; $\mathrm{n}=11$, following $20 \mathrm{~min}$ of ischemia). indicates $\mathrm{P}<0.05$ vs postischemic recovery following $10 \mathrm{~min}$ of ischemia.

Restoration of flow for 60 min resulted in an almost complete recovery of tissue ATP levels following $10 \mathrm{~min}$ of ischemia. In contrast, following an ischemic insult of 15 or 20 min only partial restoration of tissue ATP content was observed (Figure 2). Tissue ADP and AMP levels returned to pre-ischemic values regardless of the duration of the preceding ischemic episode (Figure 2). EC recovered to preischemic values following 10 and $15 \mathrm{~min}$ of ischemia, but only to $0.79 \pm 0.09$ 
following $20 \mathrm{~min}$ of ischemia and reperfusion ( $\mathrm{P}<0.05$ vs pre-ischemia). Restoration of flow resulted in decreased tissue content of adenine degradation products relative to ischemic hearts regardless of the ischemic duration. At the end of reperfusion, however, hearts subjected to 10 or $15 \mathrm{~min}$ of ischemia demonstrated a significantly lower tissue (oxy)purine content than hearts subjected to $20 \mathrm{~min}$ of ischemia and $60 \mathrm{~min}$ of reperfusion (Table II). The tissue content of lactate in reperfused hearts was found to be $15.4 \pm 11.3,21.0 \pm 9.6$ and $41.1 \pm 24.8 \mu \mathrm{mol} . \mathrm{g}^{-1}$ dry weight following 10,15 and 20 min of ischemia, respectively. The finding of markedly enhanced tissue levels of lactate and adenine degradation products in hearts subjected to $20 \mathrm{~min}$ of ischemia plus reperfusion, in combination with a substantially elevated postischemic coronary resistance, is indicative of impaired recovery of coronary flow in this group.

\section{GTP, GDP, GMP, IMP and NAD $(P)$}

Similar to ATP, guanine triphosphate (GTP) was gradually degraded in ischemic tissue following $20 \mathrm{~min}$ of ischemia $(\mathrm{P}<0.05$ vs pre-ischemia; Table III). This reduction, however, was not associated with significant changes in GDP and GMP levels. Restoration of flow during $60 \mathrm{~min}$ was not sufficient to restore tissue GTP content back to pre-ischemic values, regardless of the preceding ischemic duration. Tissue NAD and NADP contents remained unaffected during ischemia, or ischemia followed by $60 \mathrm{~min}$ of reperfusion (Table III).

\section{Tissue fatty acids, triacylglycerol and phospholipids}

The total pre-ischemic tissue content of fatty acids (FA), phospholipids (PL) and triacylglycerols (TG) in the murine hearts and their relative fatty acid composition is shown in Table IV. The fatty acyl composition of the PL and FA pool demonstrated high resemblances with a relative abundance of palmitic (16:0), stearic (18:0), linoleic (18:1) and docosahexaenoic acid (22:6), with each species accounting for $10-20 \%$ of total fatty acids present (Table IV). The poly-unsaturated FA arachidonic acid (20:4) accounted for $6.7 \pm 0.7$ and $4.0 \pm 0.4 \%$ of total fatty acids in the PL and FA pool, respectively (Table IV). Cardiac TG s mainly comprised of 16:0, 18:1 and 18:2 moieties, each representing about $30 \%$ of all TG fatty acyl moieties. In contrast to the FA and PL pool, 18:0, 20:4 and 22:6 accounted for only a small percentage of fatty acids esterified in the TG pool (Table IV).

Oxygen deprivation for 10,15 or 20 min did not affect the tissue PL and TG content (Tables VI and VII). Total cardiac FA content declined significantly in hearts subjected to 10 or $15 \mathrm{~min}$ of ischemia ( $\mathrm{P}<0.05$ vs pre-ischemia). Increasing the ischemic duration with an additional 5 min resulted in an elevation of cardiac FA content relative to the end-ischemic value at $15 \mathrm{~min}$ of ischemia (Figure 3 and Table V). The reduction in total FA content was associated with marked changes in the mol \% of individual FA species (Table V). In general, the mol \% of saturated FA species increased, whereas the mol $\%$ of poly-unsaturated FA s declined. In this respect the shift in the mol \% of 16:0 and 22:6 were most outspoken. A small but significant increase of 22:6 in the PL pool and a decrease in the amount of 16:0 and a small increase in the amount of 18:2 esterified in the TG pool were observed. 
Reperfusion itself resulted in a marked increase in tissue FA content following 10 and $15 \mathrm{~min}$ of ischemia, respectively ( $\mathrm{P}<0.05$ vs pre-ischemia; Figure $3)$. The increase in tissue FA was found to be most pronounced in hearts previously deprived of oxygen for $20 \mathrm{~min}(\mathrm{P}<0.01$ vs pre-ischemia). Irrespective of the duration of the preceding ischemic episode, reperfusion was accompanied by a substantial rise in the tissue content of 18:2, 20:4 and 22:6, in both absolute amounts (not shown) and in the percentage contribution to the total FA pool (Table V). Following reperfusion the amounts of the polyunsaturated fatty acyl species 20:4 and 22:6 in the PL pool tended to decrease compared to end-ischemic values, the decrease reaching statistical significance only for 22:6 following $10 \mathrm{~min}$ of ischemia and $60 \mathrm{~min}$ of reperfusion (Table VI). The relative fatty acyl composition of the cardiac TG pool showed a significant change only in the 18:2 content, which decreased during reperfusion following $20 \mathrm{~min}$ of ischemia (Table VII).

\section{Discussion}

\section{Hemodynamic function in the ischemic-reperfused mouse heart}

In the present study it is demonstrated that murine hearts tolerated $10 \mathrm{~min}$ of ischemia well, as evidenced by a near complete recovery of hemodynamic function and adenylate energy charge and the limited LDH release upon reperfusion. Nonetheless, reperfusion was associated with a marked rise in the tissue FA content, reflecting release of FA from endogenous lipid pools. Extending the ischemic duration to 15 or 20 min resulted in a diminished recovery of cardiac function, more pronounced decreases in the adenylate energy charge, enhanced tissue FA accumulation and release of cytosolic proteins.

The nearly complete recovery of hemodynamic function after $10 \mathrm{~min}$ of global ischemia is at variance with earlier observations of Bittner and colleagues, who reported that $6 \mathrm{~min}$ of global ischemia using their working mouse heart preparation was already sufficient to induce substantial impairment of postischemic cardiac output (Bittner et al., 1996, Chen et al., 1997). The apparent discrepancy between these studies and the present one are not clear. However, the pre-ischemic hemodynamic values of the quoted studies deviate to such an extent from the in vivo murine cardiac function and the present study, probably as a result of a higher aortic impedance and differences in perfusate composition, that comparisons are hard to make. This issue has been discussed earlier in more detail (De Windt et al., 1999). In all other studies to date the so-called isolated Langendorff perfused heart model was typically used to study ischemia and reperfusion-induced cardiac dysfunction of isolated hearts, either or not derived from trangenic animals (Eberli et al., 1998, Li et al., 1997, Marber et al., 1995, Headrick et al., 1998, Matherne et al., 1997, Plumier et al., 1995, Radford et al., 1996, Sumeray et al., 1998, Trost et al., 1998, Wang et al., 1998, Yoshida et al., 1996, Xi et al., 1998). The minimal duration of flow-deprivation required to induce marked functional impairment on Langendorff perfused isolated mouse hearts in these studies ranges from $30 \mathrm{~min}$ (Yoshida et al., 1996) to as long as $50 \mathrm{~min}$ (Li et al., 1997). A number of factors may account for the large variation in ischemia tolerance of the murine hearts as reported by the various research groups. 

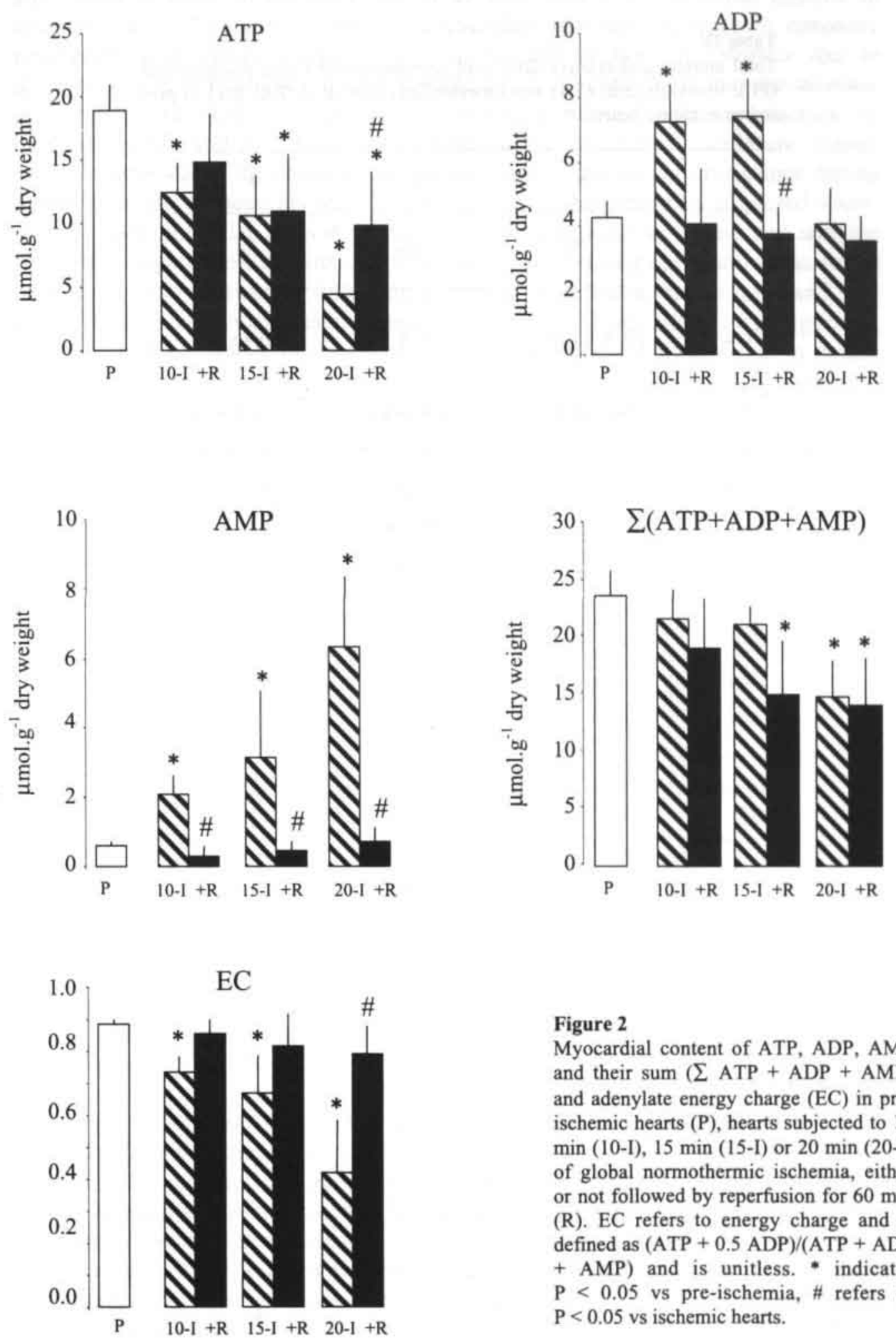

Figure 2

Myocardial content of ATP, ADP, AMP and their sum ( $\Sigma$ ATP + ADP + AMP) and adenylate energy charge (EC) in preischemic hearts $(\mathrm{P})$, hearts subjected to 10 $\min (10-\mathrm{I}), 15 \mathrm{~min}$ (15-I) or $20 \mathrm{~min}$ (20-I) of global normothermic ischemia, either or not followed by reperfusion for $60 \mathrm{~min}$ (R). EC refers to energy charge and is defined as (ATP + 0.5 ADP)/(ATP + ADP + AMP) and is unitless. * indicates $\mathrm{P}<0.05$ vs pre-ischemia, \# refers to $\mathrm{P}<0.05$ vs ischemic hearts. 


\section{Table IV}

Total amount and relative fatty acid composition of tissue phospholipid (PL), triacylglycerol (TG) and (unesterified) fatty acid (FA) pool in preischemic mouse hearts.

\begin{tabular}{llll}
\hline$n$ & \multicolumn{1}{c}{6} & 4 & 4 \\
\hline & $P L$ & $T G$ & $F A$ \\
& & & \\
\cline { 2 - 4 } Total & $198.4 \pm 10.3$ & $40.8 \pm 5.3$ & $0.9 \pm 0.1$ \\
& & & \\
$16: 0$ & $19.0 \pm 0.5$ & $30.9 \pm 6.2$ & $18.0 \pm 1.6$ \\
$16: 1$ & $0.5 \pm 0.1$ & $4.5 \pm 1.2$ & $0.7 \pm 0.1$ \\
$18: 0$ & $18.6 \pm 0.8$ & $5.4 \pm 1.1$ & $17.0 \pm 2.5$ \\
$18: 1$ & $11.4 \pm 0.6$ & $29.2 \pm 4.0$ & $13.2 \pm 0.6$ \\
$18: 2$ & $15.9 \pm 0.5$ & $27.3 \pm 5.9$ & $12.5 \pm 0.8$ \\
$20: 0$ & $0.2 \pm 0.1$ & $0.2 \pm 0.1$ & $0.4 \pm 0.1$ \\
$20: 4$ & $6.7 \pm 0.7$ & $0.9 \pm 0.1$ & $4.0 \pm 0.4$ \\
$22: 4$ & $0.2 \pm 0.0$ & $0.3 \pm 0.1$ & $0.7 \pm 0.1$ \\
$22: 6$ & $22.7 \pm 1.4$ & $4.3 \pm 1.0$ & $28.7 \pm 3.5$ \\
& & & \\
\hline
\end{tabular}

Data are expressed as means \pm SD. Total refers to total (unesterified) fatty acid and is expressed as mmol.g ${ }^{-1}$ dry weight. Individual fatty acids are presented as percentages of total tissue fatty acid.

Factors likely to play a role are variations in nominally free $\mathrm{Ca}^{2+}$ concentrations in the perfusate, choice of substrates, temperature of the isolated hearts during global ischemia and differences in workload (perfusion pressure, retrograde versus antegrade perfusion).

The findings in the present study are in line with the earlier expressed notion of a higher susceptibility of the mouse heart to ischemia and reperfusioninduced damage as compared to other species (Headrick et al., 1998). Using also an assisted mode perfusion setup and comparable experimental conditions as in the present study, De Groot and colleagues found substantial cardiac dysfunction as measured by recovery of cardiac output, coronary resistance, post-ischemic LDH release and ventricular accumulation of arachidonic acid in isolated working rat hearts only following ischemic periods of $30 \mathrm{~min}$ or longer (De Groot et al., 1993a). Reperfusion of mouse hearts following $20 \mathrm{~min}$ of ischemia was associated with a 
significant increase in coronary resistance and, hence, a substantial decline in coronary flow. Although it cannot be excluded that this increase in coronary resistance results from a reduced oxygen demand of the left ventricle due to decreased work performance during reperfusion, it is more likely that the increase in coronary resistance is caused by ischemia-induced hypercontracture of cardiomyocytes and/or substantial damage to the coronary vasculature. Latter notion is stressed by the observation that the increase in coronary resistance during reperfusion and reduced myocardial perfusion is accompanied by impaired washout of small molecular mass degradation compounds such as lactate and adenine nucleotide degradation products. Indeed, a relatively strong correlation was found between coronary resistance following $60 \mathrm{~min}$ of reperfusion, on the one hand, and post-ischemic ventricular accumulation of lactate, on the other $(r=0.87$; Figure 4). Although not the subject of the present study, it may be anticipated that in mouse hearts subjected to $20 \mathrm{~min}$ of global ischemia especially the inner layers of the left ventricle will be affected by flow impairment (De Groot et al., 1993b).

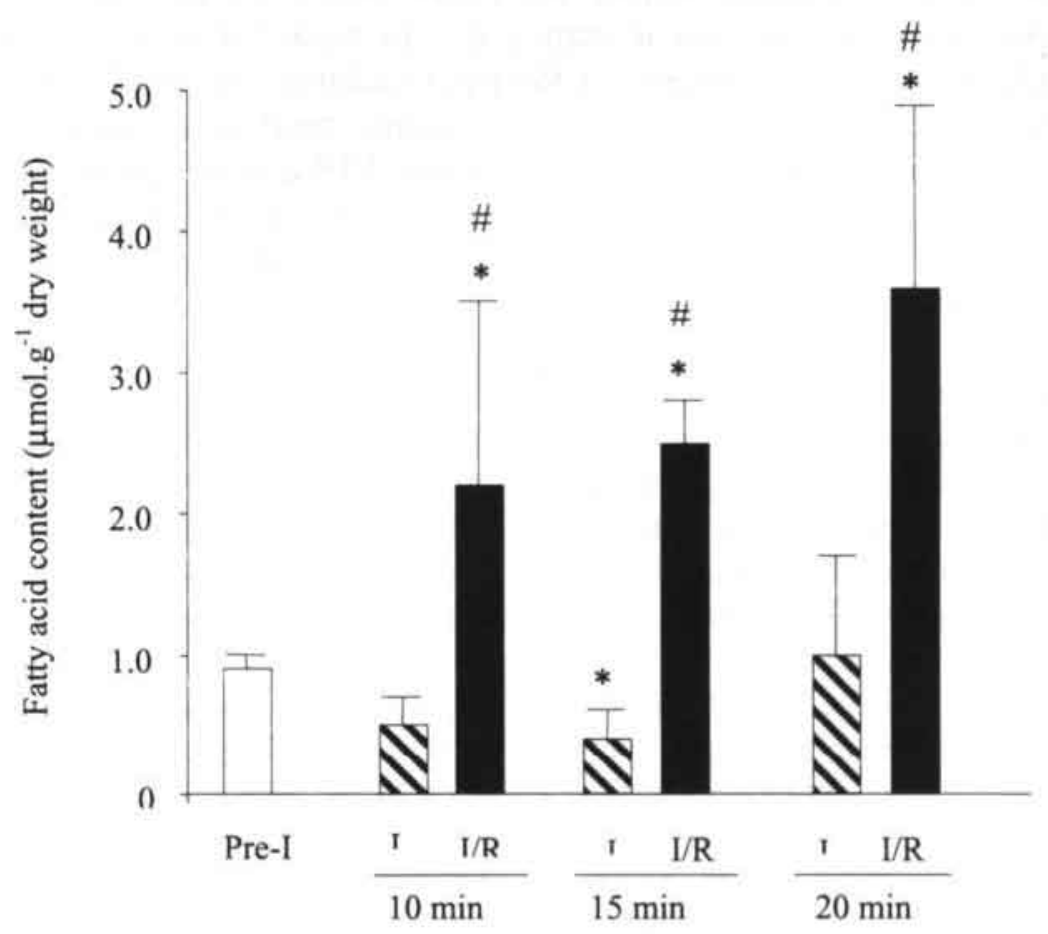

Figure 3.

Tissue content of (unesterified) fatty acids in the pre-ischemic myocardium and in mouse hearts subjected to 10,15 and 20 min of ischemia, either or not followed by reperfusion. Data are expressed as means $\pm S D(n=4$ for preischemic hearts, $\mathrm{n}=5$ for $10 \mathrm{~min} \mathrm{~L} / \mathrm{R}, 20 \mathrm{~min} \mathrm{I}$ and $20 \mathrm{~min} \mathrm{I} / \mathrm{R}$, and $\mathrm{n}=6$ for the remaining groups). I, ischemia; $R$, reperfusion. * indicates $P<0.05$ vs pre-ischemia, \# indicates $\mathrm{P}<0.05$ vs corresponding end-ischemic period. 


\section{Energy metabolism in the ischemic-reperfused mouse heart}

Prolonged ischemic duration resulted in a substantial reduction of ATP (to less of $25 \%$ of pre-ischemia) and tissue accumulation of AMP and (oxy)purines, mainly adenosine and inosine. The accumulation of AMP suggests a limited activity of endo-5 -nucleotidase during ischemia or a confinement of AMP to a compartment distinct from the localization of this enzyme (Van Bilsen et al., 1989a). Similarly, the accumulation of adenosine and inosine, combined with relatively low tissue levels of hypoxanthine and xanthine strongly suggests a constraint at the level of nucleoside phosphorylase in the ischemic murine heart. This might be caused by inhibition of the enzyme under ischemic conditions or a difference in localization of inosine production and nucleoside phosphorylase in the mouse heart. Similar findings were obtained in the isolated working rat heart subjected to varying periods of ischemia and reperfusion (Van Bilsen et al., 1989a, De Groot et al., 1993b)

The recovery of ATP and adenylate energy charge during reperfusion indicates that mitochondrial ATP production is not seriously hampered by the preceding ischemic insult or hampered by accumulating fatty acids. The data suggest that the reduced total adenine nucleotide pool (sum of ATP, ADP and AMP) at the end of reperfusion is mainly due to wash-out of its degradation products, which prevents resynthesis of the parent adenine nucleotides. Although post-ischemic hemodynamic function of the murine heart is severely impaired following $20 \mathrm{~min}$ of ischemia, the recovery of tissue ATP content and the adenylate energy charge still amounted to about 60 and $80 \%$ of pre-ischemic levels, respectively, demonstrating a dissociation between hemodynamic recovery and post-ischemic energy metabolism.

\section{Lipid homeostasis in the ischemic-reperfused mouse heart}

The small but significant transient decrease in tissue fatty acid levels during initial ischemia is in accordance with previous findings in the ischemic rat heart, in which also a biphasic pattern in tissue fatty acid content was observed (Van Bilsen et al., $1989 \mathrm{~b})$. In these studies it was also found that substantial amounts of glycerol accumulated during early ischemia, which indicates increased triacylglycerol-fatty acid cycling (Van Bilsen et al., 1989b, De Groot et al., 1993a). The observation that the arachidonoyl content of the tissue (unesterified) fatty acid pool increased during prolonged ischemia is in favor of a switch from increased triacylglycerol cycling to enhanced deacylation and/or decreased reacylation of the phospholipid pool during more prolonged ischemia (Van der Vusse et al., 1992). Restoration of flow resulted in a substantial elevation of fatty acids, the level being dependent on the length of the preceding ischemic episode. The high contribution of poly-unsaturated fatty acids such as arachidonic acid and docosahexaenoic acid relative to saturated fatty acids is in agreement with an accelerated net degradation of the cardiac phospholipid pool during the reperfusion phase (Van der Vusse et al., 1992, Van der Vusse et al., 1998).

It is of interest to note that in the mouse hearts under investigation the phospholipidplasmalogen content is substantially lower than earlier reported values in the rat heart (Van Bilsen et al., 1989), guinea pig heart (Arthur et al., 1985) and bovine heart (Shaikh et al., 1981). Ischemia and reperfusion did not affect the absolute 
Table $v$

Relative fatly acid composition of the ventricular (unesterified) fatty acid content in pre-ischemic. ischemie and ischemic-reperfused mouse heans

\begin{tabular}{|c|c|c|c|c|c|c|c|}
\hline$n$ & 4 & 6 & $s$ & 6 & 6 & 6 & $s$ \\
\hline & Pre-1 & $10 \mathrm{~min} /$ & $\begin{array}{l}10 \min 1+ \\
60 \min R\end{array}$ & $15 \min 1$ & $\begin{array}{l}15 \min 1 . \\
60 \min R\end{array}$ & $20 \min 1$ & $\begin{array}{l}20 \mathrm{~min} 1 . \\
00 \mathrm{~min} R\end{array}$ \\
\hline Taral & $0.9 \pm 0.1$ & $0.5=0.2$ & $2.2 \div 1.3^{7 t}$ & $0.4 \pm 0.2^{n}$ & $2.5 \pm 0.3^{\mu^{*}}$ & $1.0 \pm 0.7$ & $30-13^{*}$ \\
\hline $16: 0$ & $18.0=1.6$ & $32.7 \pm 5.7^{\prime \prime}$ & $21.8 \pm 1.6^{\prime \prime}$ & $31.9 \pm 3.5^{n}$ & $22.1 \div 2.7^{\mathrm{nt}}$ & $31.3 \pm 6.1^{\circ}$ & $22.2 \div 1.9^{\text {In }}$ \\
\hline $16: 1$ & $0.7 \pm 0.1$ & $4.1+1.1^{7}$ & $0.4 \leq 0.2^{\circ}$ & $4.0 \pm 1.9^{n}$ & $0.5 \pm 0.3^{\circ}$ & $2.4 \pm 1.4$ & $1.4 \pm 1.8$ \\
\hline $18: 0$ & $17.0 \pm 2.5$ & $22.3 \div 5.0$ & $27.1 \pm 3.9^{\prime \prime}$ & $27,0 \pm 5,4^{5}$ & $27.7 \approx 3.5^{5 .}$ & $21.6 \pm 3.4$ & $21.3 \pm 2.3^{4}$ \\
\hline $18: 1$ & $13.2 \pm 0.6$ & $14.0=1.9$ & $15.9=1.8$ & $12.5 \pm 2.7$ & $16.3 \div 2.3^{n}$ & $13.5 \pm 2.0$ & $15.8=1.5^{\prime \prime}$ \\
\hline $18: 1$ & $12.5=0.8$ & $11.2=2.1$ & $15.9=1.4^{00}$ & $9.8 \pm 3.2$ & $12.1 \pm 3.1$ & $14.1 \pm 2.3$ & $14.9 \pm 2.5$ \\
\hline $20: 0$ & $0.4 \pm 0.1$ & $1.8=2.7$ & $0.5 \pm 0.2$ & $0.8=0.2$ & $0.2 * 0.1$ & $0.5 \pm 0.4$ & $0.1 \neq 0.1$ \\
\hline 20.4 & 4.010 .4 & $1.8=1.7$ & $2.9 \pm 0.2^{\prime \prime}$ & $0.8=0.9$ & $3.0 \pm 0.8^{\circ}$ & $2.2+1.4$ & $4.4 \pm 1.0^{\circ}$ \\
\hline $22: 4$ & $0.7=0.1$ & N.D. & $0.4 \pm 0.1^{n}$ & N.D. & $0.5 \pm 0.1^{\circ}$ & $0.8 \pm 0.2$ & $0.3 \pm 0.1$ \\
\hline $22: 6$ & $28.7 \pm 3.5$ & $7.2 \pm 2.7$ & $15.8 \pm 2.22^{10^{\circ}}$ & $3.0 \pm 3.2^{\prime \prime}$ & $15.0=3.8^{10}$ & $9.3 \pm 5.0^{a}$ & $14.7 \pm 1.5^{\mathrm{nz}}$ \\
\hline
\end{tabular}

Data are expressed as means $\pm \mathrm{SD}$. Presented are percentages of total tissue (unesterified) fatty acids, $\boldsymbol{n}$ indicates number of heans analyzed.

I: ischemia, R: reperfusion. Total refers to lotal ventricular (unesterified) fatty acid content and is expressed as umol. $\mathrm{g}^{-1}$ dry weight! Values less than $0.1 \%$

are indicated with N.D (not detectable) - indicates $P<0.05$ vs corresponding end-ischemic value." indicates $P<0.05$ vs pre-ischermic value. 
Total amount or ventricular phospholipids and relative fatty acyl composition in pre-ischernic, ischemic and ischemic-reperfused murine hearts.

\begin{tabular}{|c|c|c|c|c|c|c|c|}
\hline$n$ & $s$ & 6 & 5 & 6 & 0 & $s$ & $s$ \\
\hline & Pent & $10 \min 1$ & $\begin{array}{l}10 \min 1, \\
60 \min R\end{array}$ & $15 \min 1$ & $\begin{array}{l}15 \min \\
60 \min R^{\prime}\end{array}$ & $20 \operatorname{mix} 1$ & $\begin{array}{l}20 \min 1+ \\
60 \min R\end{array}$ \\
\hline Toral & $198.4=10.3$ & $213.0 \neq 9.5$ & $194.0=45.6$ & $210.7=20.0$ & $202.7=20,8$ & $244.7 \pm 21.9$ & $200.0=11.2$ \\
\hline $16: 0$ & $19.0 \pm 0.5$ & $19.4,0.3$ & $18.8 * 0.4$ & $18+ \pm 0.7$ & $19.4=0.6$ & $19.4 \pm 1.0$ & $19.3=0.1$ \\
\hline $16-0$ M. & $0.2 \pm 0.0$ & $0.4=0.1$ & $2.0 \pm 1.2^{*}$ & $1.1 \pm 1.1$ & $2.3 \pm 0.3^{\circ}$ & $1.3 \pm 1.1$ & $2.5 \pm 0.3^{\circ}$ \\
\hline 16.1 & $0.5=0.1$ & $0.4 \times 0.1$ & $0.4 \pm 0.1$ & $0.4=0.0$ & $0.5=0.1$ & $0.4 \times 0.1$ & $0.5=0.1$ \\
\hline is 0 & $18.6 \pm 0.8$ & $17.6=0.4$ & $18.0=0.7$ & $17.7=0.5$ & $18.3 \pm 0.7$ & $17.7 \pm 0.5$ & $18.2=0.5$ \\
\hline $18.0 \mathrm{pt}$ & $0.5=0.0$ & $0.2=0.0$ & $0.8 \pm 0.4$ & $0.4=0.3$ & $0.9=0.2$ & $0.4 \pm 0.3$ & $0.9 \pm 0.1$ \\
\hline 18.1 & $11.4=0.6$ & $110=0 \%$ & $112=0.8$ & $11.0=0,6$ & $11.1 \pm 0.7$ & $10.9 \leq 0.6$ & $11.2 \pm 0.4$ \\
\hline $1 s / \mathrm{m}$ & $1.1+0.3$ & $0.1 \leq 0.0$ & $0.4: 0.1^{2}$ & $0.2+0.1$ & $0.4+0.0^{\circ}$ & $0.2 \pm 0.2$ & $0.5 \neq 0.1^{\circ}$ \\
\hline 18: & $15.9 \pm 0.5$ & $17.0=0.8$ & $16.5 \geq 0.5$ & $163=0.7$ & $16.2=0.9$ & $17.3=1.0$ & $16.4 \pm 0.9$ \\
\hline soo & $0.2=0.1$ & $0.2=0.1$ & $0.3 \div 0.2$ & $0.3 \div 0.1$ & $0.2=0.1$ & $0.3 \pm 0.1$ & $0.3 \neq 0.0$ \\
\hline 20. & $6.7 * 0.7$ & $7.2+0.5$ & $6.9 \pm 0.3$ & $7.2 \times 0.6$ & $6.6=0.5$ & $1.2 \pm 0.6$ & $70 \pm 0.3$ \\
\hline $22: 4$ & $0.2 \pm 0.0$ & $0.2=0.1$ & $0.2 \neq 0.6$ & $0.3 \div 0.1$ & $0.3 \pm 0.01$ & $0.3 \pm 0.1$ & $0.3 \times 0,0$ \\
\hline 23.6 & $22.7 \pm: .4$ & $25.6 \div 1.0^{\circ}$ & $22.3 \pm 0.4^{\circ}$ & $24.8 \pm 2.7^{\circ}$ & $22.1 \pm 0.7$ & $23.5 \pm 2.6$ & $21.6 \div 0.5$ \\
\hline
\end{tabular}

Data are expressed as means 4 SD. Presented are percentages of total tissue fatly acyl composition. $n$ indicates number of hearts analyzed. I: ischemia R: reperfusion,

Toul refers to total ventricular phospholipid content and is expressed as umol $\mathrm{E}^{-1}$ dry weight, PL refers ta the dimethylacesal form of the corresponding fatty aldehyde.

- indicates $P<0.05$ us pre -inehemic value. $A$ indicates $P<0.05$ ws earresponding end-ischemic value. 
rable vil

Total amount and relative fatty acyl composition of ventricular triacylglycerol in pre-ischemic, ischemic and ischemic-reperfused murine heans.

\begin{tabular}{|c|c|c|c|c|c|c|c|}
\hline$n$ & $s$ & 6 & 5 & 6 & 6 & 6 & 5 \\
\hline & Pre-f & 10 min 1 & $\begin{array}{l}10 \min l+ \\
60 \min R\end{array}$ & $15 \mathrm{~min} /$ & $\begin{array}{c}15 \min 1+ \\
60 \min R\end{array}$ & 20 тін 1 & $\begin{array}{c}20 \min 1+ \\
60 \min A\end{array}$ \\
\hline Toial & $408 \pm 5,3$ & $41.9 \pm 8.9$ & $31.1=7.4$ & $38.5 \pm 7.4$ & $27.8=13.4$ & $49.8 \pm 18.5$ & $34.0 \pm 9.6$ \\
\hline $14: 0$ & $2.0 \pm 0.2$ & $1.9 \pm 0.4$ & $2.2 \div 0.2$ & $1.9=0.6$ & $2.2=0.6$ & $1.9 \pm 0.4$ & $2.1 \pm 0.4$ \\
\hline $16: 0$ & $30.9 \pm 0.2$ & $25.2 \div 3.8$ & $25.0 \pm 0.7$ & $22.7 \pm 2.9^{4}$ & $24.5 \pm 2.3$ & $23.7 \div 2.8^{\prime \prime}$ & $24.0 \pm 1.8$ \\
\hline $16: 1$ & $4.5 \pm 1.2$ & $3.4=1.5$ & $2.8 \pm 0.3$ & $2.7 \pm 0.3$ & $3.4=1.7$ & $3.1+1.0$ & $3.4 \pm 1.2$ \\
\hline 18.0 & $5.4 \pm 1.1$ & $4.5 \pm 0.2$ & $4.8 \pm 0.3$ & $4.6 \pm 0.3$ & $4.6 \pm 0.6$ & $4.8 \pm 0.6$ & $4.6 \pm 0.4$ \\
\hline $18: 1$ & $29.2=4.0$ & $29.2 \div 1.7$ & $28.1 \pm 0.8$ & $29.2 * 1.1$ & $27.5=1.8$ & $27.5 \pm 1.9$ & $27.2 \neq 1.8$ \\
\hline $18: 2$ & $27.3 \pm 5.9$ & $288=24$ & $28.2: 1.9$ & $31.3=2.8^{\prime}$ & $28.0+3.3$ & $31.2 \pm 2.8^{\prime \prime}$ & $27.2 \pm 1.8 \cdot$ \\
\hline $18: 3$ & $0.1 \neq 0.1$ & $0.1 \div 0.0$ & $0.1 \neq 0.1$ & $0.1 \pm 0.0$ & $0.1 \pm 0.1$ & $0.1 \pm 0.0$ & $0.1=0.0$ \\
\hline $20: 0$ & $0.2 \pm 0.1$ & $0.1 \div 0.1$ & $0.2 \pm 0.0$ & $0.2 \pm 0.1$ & $0.2 \div 0.1$ & $0.2=0.1$ & $0.2 \pm 0.1$ \\
\hline $20: 2$ & $0.9 \pm 0.1$ & $1.1 \pm 0.4$ & $1.3 \pm 0.2$ & $1.3=0.5$ & $1.5 \pm 0.4$ & $1.3=0.2$ & $1.5=0.4$ \\
\hline $22: 4$ & $0.3 \pm 0.1$ & $0.4=0.2$ & $0.4 \pm 0.1$ & $0.4 \pm 0.2$ & $0.4 \pm 0.1$ & $0.4 \pm 0.1$ & $0.4 \pm 0.1$ \\
\hline $22: 6$ & $4.3+1.0$ & $4.9=2.5$ & $5.7 \pm 1.2$ & $5.4+2.0$ & $6.3 \pm 1.1$ & $5.4 \pm 2.1$ & $7.2 \pm 2.1$ \\
\hline
\end{tabular}

Data are expressed as means $\mathbf{S D}$. Presented are percentages of total fatty acyl composition. $\boldsymbol{f}$ indicates number of hearts analyzed. I: ischemia, $\mathrm{R}$ : reperfusion. Total refers to total ventricular triacylglycerol content and is expressed as $\mu$ mol. $\mathrm{g}^{-1}$ dry weight. " indicates $\mathrm{P}<0.05 \mathrm{vs}$ pre-ischemia, $\#$ indicates $\mathrm{P}<0.05 \mathrm{vs}$ 
amount of plasmalogen, but caused a change in the nature of the aliphatic chain connected via an ether-bond to the glycerol backbone. The cause and significance of this alteration remains to be elucidated, especially in view of the potential importance of type VI plasmalogen-specific phospholipases $A_{2}$ in phospholipid hydrolysis in the ischemic myocardium (Hazen et al., 1991, ).

\section{Post-ischemic tissue fatty acid accumulation and irreversible cell damage}

The positive correlation between the amount of LDH released during reperfusion, reflecting irreversible cardiac muscle cell injury, on the one hand, and ventricular total fatty acid or arachidonic acid accumulation during reperfusion, on the other (Figure 5), which can also be observed in the rat heart (Van Bilsen et al., 1989b), supports the notion of a causative relation between accelerated phospholipid degradation during ischemia and/or reperfusion, on the one hand, and irreversible cell damage, on the other (Van der Vusse et al., 1992, Van der Vusse et al., 1998). The data in the present study suggest that the basic mechanisms leading to disturbances in the lipid homeostasis during ischemia and reperfusion as documented and studied in ischemic-reperfused hearts derived from other species are also applicable to the murine heart. A distinct advantage of the availability of an isolated working mouse heart model is the current technological facilities to alter the expression level of one of the putative contributing factors, such as cardiac phospholipases $A_{2}$, to more definitively establish their roles in the sequela of events leading to ischemia and reperfusion-induced cardiac dysfunction.

In conclusion, the model described in the present study allows detailed evaluation of the performance of isolated, antegradely perfused mouse hearts during transient ischemia. The results of the present study are indicative of a high susceptibility of the mouse heart to ischemia and reperfusion-induced damage. This model will be asset in the interpretation of the function of specific genes investigated in transgenic and gene-targeted mouse models for heart diseases.

\section{References}

1. Apstein CS, Puchner SE, Brachfeld N. Improved automated lactate determination. Anal Biochem 1970;38: 20-34.

2. Arthur G, Covic L, Wientzek M, Choy PC. The distribution and acyl composition of plasmalogens in guinea pig heart. Lipids 1985;20:693-698.

3. Bergmeyer HU, Bernt E. UV assay for lactate dehydrogenase with pyruvate and NADH. In: Methods of Enzymology, Weinheim Verlag Chemie GmbH 1974; 2: 574-579.

4. Bittner HB, Chen EP, Peterseim DS, Van Trigt P. A work-performing heart preparation for myocardial performance analysis in murine hearts. J Surg Res 1996;64:57-62.

5. Chen EP, Bittner HB, Davis D, Folz RJ, Van Trigt P. Extracellular superoxide dismutase transgene overexpression preserves postischemic myocardial function in isolated murine hearts. Circulation 1996;94:II412-II417.

6. Chien KR, Han A, Sen A, Buja LM, Willerson JT. Accumulation of unesterified arachidonic acid in ischemic canine myocardium. Circ Res 1984;54:538-546.

7. Das DK, Engelman RM, Rousou JA, Breyer RH, Otani H, Lemeshow S. Role of membrane phospholipids in myocardial injury induced by ischemia and reperfusion. Am J Physiol 1986;251:H71-H79. 




Tissue lactate content ( $\mu$ mol.g ${ }^{-1}$ dry weight)

\section{Figure 4}

Relationship between post-ischemic coronary resistance and tissue content of lactate in reperfused ventricles of hearts subjected to $10(\mathrm{O}), 15(\mathbf{m})$ and $20 \mathrm{~min}(\Delta$ ) of global, normothermic ischemia.

8. De Groot MJ, Coumans WA, Willemsen PH, Van der Vusse GJ. Substrate-induced changes in the lipid content of ischemic and reperfused myocardium. Its relation to hemodynamic recovery. Circ Res 1993a; 72:176-186.

9. De Groot MJ, Van der Vusse GJ. The effects of exogenous lactate and pyruvate on the recovery of coronary flow in the rat heart after ischaemia. Cardiovasc Res 1993b 27:1088-1093.

10. De Windt LJ, Willems J, Reneman RS, Van der Vusse GJ, Arts T, Van Bilsen M. An improved isolated, left ventricular ejecting murine heart model. Functional and metabolic evaluation. Pfl gers Archiv-Eur J Physiol 1999;437:182-190.

11. Eberli FR, Sam F, Ngoy S, Apstein CS, Colucci WS. Left ventricular structural and functional remodeling in the mouse after myocardial infarction: assessment with the isovolumetricallycontracting langendorff heart. J Mol Cell Cardiol 1998;30:1443-1447.

12. Gallagher KP, Osakada G, Matsuzaki M, Kemper WS, Ross J. Myocardial blood flow and function with critical coronary stenosis in exercising dogs. Am J Physiol 1982;243:H698-H707.

13. Hazen SL, Ford DA, Gross W. Activation of a membrane associated phospholipase $\mathrm{A}_{2}$ during rabbit myocardial ischemia which is highly selective for plasmalogen substrate. $J$ Biol Chem 1991;266:5629-5633.

14. Hampton TG, Amende I, Travers KE, Morgan JP. Intracellular calcium dynamics in mouse model of myocardial stunning. Am J Physiol 1998;274:H1821-1827. 

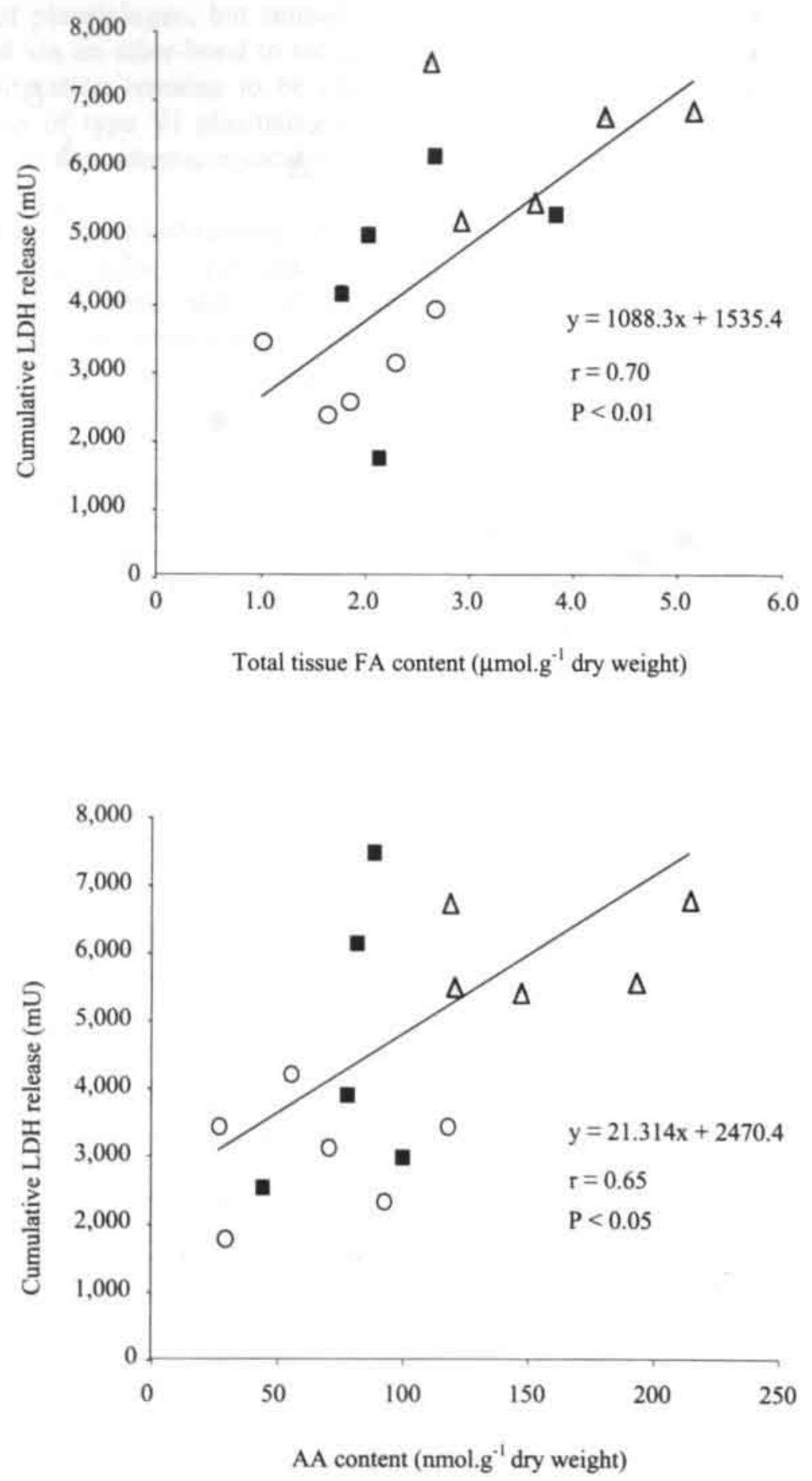

\section{Figure 5}

Relationship between cumulative LDH release into coronary effluent during $60 \mathrm{~min}$ of reperfusion and unesterified fatty acid content (top panel) or arachidonic acid content (bottom panel) in the reperfused heart subjected to $10(\mathrm{O}), 15(\boldsymbol{\Xi})$ or $20 \mathrm{~min}(\Delta)$ of global, no-flow ischemia. 
15. Headrick JP, Gauthier NS, Berr SS, Morrison RR, Matherne GP. Transgenic $A_{1}$ adenosine receptor overexpression markedly improves myocardial energy state during ischemia-reperfusion. J Mol Cell Cardiol 1998;30:1059-1064.

16. Kjekshus JK. The coronary circulation in normal and ischemic hearts. Scand J Clin Lab Invest 1984:44(suppl 173):9-18.

17. Kloner RA, Ganote CE, Jennings RB. The no-reflow phenomenon after temporary occlusion in the dog. J Clin Invest 1974;54:1494-1508.

18. Li G, Chen Y, Saari JT, Kang YJ. Catalase-overexpressing transgenic mouse heart is resistant to ischemia-reperfusion injury. Am J Physiol 273: H1090-H1095, 1997.

19. Marber MS, Mestril R, Chi S, Sayen MR, Yellon DM, Dillmann WH. Overexpression of the rat inducible $70-\mathrm{kD}$ heat stress protein in a transgenic mouse increases the resistance of the heart to ischemic injury. J Clin Invest 95: 1446-1456, 1995.

20. Matherne GP, Linden J, Byford AM, Gauthier NS, Headrick JP. Transgenic $A_{1}$ adenosine receptor overexpression increases myocardial resistance to ischemia. Proc Natl Acad Sci USA 94: 6541-6546, 1997.

21. Plumier, J-CL., Ross BM, Currie RW, Angelidis CE, Kazlaris H, Kollias G, Pagoulatos GN. Transgenic mice expressing the human heat shock protein 70 have improved post-ischemic myocardial recovery. J Clin Invest 95: 1854-1860, 1995.

22. Radford NB, Fina M, Benjamin IJ, Moreadith RW, Graves RW, Zhao P, Gavva S, Wiethoff A, Sherry AD, Malloy $\mathrm{CR}$, Williams RS. Cardioprotective effects of 70-kDa protein in transgenic mice. Proc Natl Acad Sci USA 93: 2339-2342, 1996.

23. Roemen THM, Keizer H, Van der Vusse GJ. Quantitative assessment of $\gamma$-linoleic acid in human blood and plasma with capillary gas chromatography. J Chromatogr 1990;528:447-452.

24. Saupe KW, Spindler M, Tian R, Ingwall JS. Impaired cardiac energetics in mice lacking musclespecific isoenzymes of creatine kinase. Circ Res 1998;82:898-907.

25. Shaikh NA, Downar E. Time course of changes in porcine myocardial phospholipid levels during ischemia. Circ Res 1981;49:316-325.

26. Sumeray MS, Yellon DM. Characterisation and validation of a murine model of global ischaemia-reperfusion injury. Mol Cell Biochem 1998;186:61-68.

27. Trost SU, Omens JH, Karlon WJ, Meyer M, Mestril R, Covell JW, Dillmann WH. Protection against myocardial dysfunction after a brief ischemic period in transgenic mice expressing inducible heat shock protein 70. J Clin Invest 1998;101:855-862.

28. Van Bilsen M, Van der Vusse GJ, Coumans WA, De Groot MJM, Willemsen PHM, Reneman RS. Degradation of adenine nucleotides in ischemic and reperfused rat heart. Am J Physiol 1989a;257:H47-H54.

29. Van Bilsen M, Van der Vusse GJ, Willemsen PHM, Coumans WA, Roemen THM, Reneman RS. Lipid alterations in isolated, working rat hearts during ischemia and reperfusion: its relation to myocardial damage. Circ Res 1989b;64:304-314.

30. Van der Vusse GJ, Glatz JFC, Stam HCG, Reneman RS. Fatty acid homeostasis in the normoxic and ischemic heart. Physiol Rev 1992;72:881-940.

31. Van der Vusse GJ, Reneman RS, Van Bilsen M. Accumulation of arachidonic acid in ischemic/reperfused cardiac tissue: possible causes and consequences. Prostaglandins Leukot Essent Fatty Acids 1997;57:85-93.

32. Van der Vusse GJ and Roemen THM. Gradient of fatty acids from blood plasma to skeletal muscle in dogs. J Appl Physiol 1995;78:1839-1843.

33. Vatner S. Correlation between acute reductions in myocardial blood flow and function in consious dogs. Circ Res 1980;47:201-207.

34. Wang P, Chen H, Qin H, Sankarapandi S, Becher MW, Wong PC, Zweier JL. Overexpression of human copper,zinc-superoxide dismutase (SOD1) prevents postischemic injury. Proc Natl Acad Sci USA 1998;95:4556-4560.

35. Wynants J, Van Belle H. Single-run high performance liquid chromatography of nucleotides, nucleosides and major purine bases and its application to different tissue extracts. Anal Biochem $1985 ; 144: 258-266$.

36. Yoshida T, Watanabe M, Engelman DT, Engelman RM, Schley JA, Maulik N, Ho Y, Oberly TD, Das DK. Transgenic mice overexpressing glutathione peroxidase are resistant to myocardial ischemia reperfusion injury. J Mol Cell Cardiol 28:1759-1767, 1996. 
37. $\mathrm{Xi} \mathrm{L}$, Hess ML, Kukreja RC. Ischemic preconditioning in isolated perfused mouse heart: reduction in infarct size without improvement of postischemic ventricular function. $\mathrm{Mol}$ Cell Biochem 1998;186:69-77.

\section{Appendix}

\section{(Phospho)creatine content in murine heart}

Routinely the ventricular phosphocreatine $(\mathrm{PCr})$ and creatine $(\mathrm{Cr})$ in pre-ischemic, ischemic and ischemic-reperfused murine ventricles were determined using the HPLC techniques. $\mathrm{PCr}$ and creatine $(\mathrm{Cr})$ content in pre-ischemic hearts amounted to $33.3 \pm 8.2$ and $36.6 \pm 5.4 \mu \mathrm{mol} . \mathrm{g}^{-1}$ dry weight, respectively, as determined by HPLC. Following $10 \mathrm{~min}$ of ischemia the tissue PCr content tended to decrease to the expense of $\mathrm{Cr}$, but this decrease did not reach the level of significance (Table VIII). However, extending the ischemic duration to 15 or $20 \mathrm{~min}$ of ischemia resulted in a substantial decrease of $\mathrm{PCr}$ content to $19.2 \pm 1.6$ and $18.7 \pm 4.6$ $\mu$ mol. $\mathrm{g}^{-1}$ dry weight, respectively, and significant increases in tissue $\mathrm{Cr}$ content, as determined by HPLC (Table VIII). Large fluctuations were observed in the sum of $\mathrm{PCr}$ and $\mathrm{Cr}$ following the different experimental procedures, reaching statistical significantly lower end-ischemic values compared to post-ischemic values. The $\mathrm{PCr}$ values in ischemic hearts were considered to be less reliable as close inspection of the chromatogram revealed additional peaks with almost identical RF values as the original $\mathrm{PCr}$ peak.

To explore this issue in more detail, a subset of hearts were subjected to 100 min of normoxic perfusion and $\mathrm{PCr}$ content was determined by both HPLC as well as fluorometrically. $\mathrm{PCr}$ content amounted to $22.0 \pm 7.8$ and $23.3 \pm 3.8 \mu \mathrm{mol} . \mathrm{g}^{-1} \mathrm{dry}$ weight as determined by HPLC and fluorometry $(n=4)$, respectively. Subjecting the hearts to $20 \mathrm{~min}$ of ischemia resulted in a tissue $\mathrm{PCr}$ content of $26.7 \pm 2.3$ and $14.8 \pm 2.0 \mu \mathrm{mol} . \mathrm{g}^{-1}$ dry weight as determined by HPLC and fluorometry $(\mathrm{n}=3)$, respectively. Finally, following $20 \mathrm{~min}$ of ischemia and $60 \mathrm{~min}$ of reperfusion, $\mathrm{PCr}$ content amounted to $11.4 \pm 7.0$ and $11.3 \pm 6.8 \mu \mathrm{mol} . \mathrm{g}^{-1}$ dry weight as determined by HPLC and fluorometry, respectively (Table VIII). The above findings indicate consistingly lower readings of tissue $\mathrm{PCr}$ content as determined by HPLC as compared to fluorometry, and, hence, $\mathrm{PCr}$ values obtained with HPLC techniques in ischemic hearts should be considered with caution. 


\section{Table VIII}

Total tissue content phosphocreatine $(\mathrm{PCr})$ and creatine $\left(\mathrm{Cr}_{\mathrm{r}}\right)$ and their sum in pre-ischemic, ischemic and ischemic-reperfused mouse hearts

\begin{tabular}{|c|c|c|c|c|c|c|c|}
\hline$n$ & 5 & 6 & 10 & 6 & 9 & 5 & 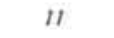 \\
\hline & Pre-l & $10 \mathrm{~min} /$ & $\begin{array}{c}10 \min 1+ \\
60 \min R\end{array}$ & $15 \mathrm{~min} 1$ & $15 \min 1+$ & $20 \min I$ & $\begin{array}{l}20 \min 1+ \\
60 \min R\end{array}$ \\
\hline$P C r$ & $333 \neq 82$ & $23.1 \neq 7.7$ & $291 \neq 76$ & $192 \pm 16^{\circ}$ & $276 \pm 61^{\circ}$ & $187 \pm 46^{\circ}$ & $256=81$ \\
\hline $\mathrm{Cr}$ & $366 \pm 54$ & $562 \pm 10.2^{\circ}$ & $347 \pm 71^{\circ}$ & $556 \pm 50^{\circ}$ & $28.5 \pm 72^{\circ}$ & $600 \pm 116^{\circ}$ & $313=72^{\circ}$ \\
\hline $\mathrm{PC}_{\mathrm{r}}+\mathrm{Cr}_{\mathrm{r}}$ & $699=109$ & $793 \neq 155$ & $645=95$ & $749 \neq 43$ & $561=6.2^{\circ}$ & $787 \pm 155$ & $568 \times 94^{\circ}$ \\
\hline
\end{tabular}

Data are expressed as means $=$ SD Data are presented in umol $g$ dry weight ventricular tissue $n$ indicates number of hearts analyzed Pre-t. pre-ischemia.

I. ischemia, $R$, reperfusion - indicates $\mathrm{P}<0.05$ vs pre-ischemic value, \# indicates $\mathrm{P}<0.05$ vs corresponding end-ischemic value. 



\section{Chapter 7}

\section{Reduced ischemia tolerance} of hearts from mice with targeted deletion of the insulin-like growth factor-1 gene. 


\section{Abstract}

In the present study the ischemia tolerance of hearts derived from heterozygous, insulin-like growth factor-1 (IGF-1) knockout mice (IGF-1 +/-) was assessed in an isolated left ventricular ejecting mouse heart preparation. Pre-ischemic coronary flow (CF) was significantly lower and left ventricular end-diastolic pressure (LVEDP) was significantly higher in IGF-1 +/- hearts. During reperfusion following $15 \mathrm{~min}$ of ischemia functional recovery was more compromised in IGF-1 +/- hearts as compared to hearts from wildtype littermates, as evidenced by a reduced recovery of cardiac output ( $11 \pm 5$ vs $31 \pm 15$ $\%$ recovery; $\mathrm{P}<0.05)$ and left ventricular developed pressure $(26 \pm 11$ vs $57 \pm 11 \%$ recovery; $\mathrm{P}<0.05$ ). The percentage irreversibly damaged cardiac cells following $15 \mathrm{~min}$ of ischemia was higher in IGF-1 +/than wildtype hearts, as indicated by the greater release of LDH into the coronary effluent during reperfusion $\left(11.6 \pm 4.1\right.$ and $5.1 \pm 2.6 \mathrm{U.g}^{-1}$ heart weight per $60 \mathrm{~min}$, respectively). In contrast, following $20 \mathrm{~min}$ of ischemia and $60 \mathrm{~min}$ of reperfusion hemodynamic recovery and the amount of LDH released from the heart was similar in IGF-1 $+/$ - and wildtype hearts. Cardiac high-energy phosphate content was not significantly different in reperfused hearts from IGF $+/$ - and wildtype mice following 15 as well as $20 \mathrm{~min}$ of ischemia. In contrast, tissue fatty acid levels were higher in the reperfused IGF-1 $+/$ - heart following $15 \mathrm{~min}$ of ischemia due to substantial elevation of all major fatty acid species, including arachidonic acid $(115 \pm 32$ and $41 \pm 10$ nmol. $\mathrm{g}^{-1}$ dry weight in IGF-1 +/- and wildtype hearts, respectively; $\mathrm{P}<0.05$ ), suggesting increased net phospholipid degradation in IGF $+/$ - hearts. Collectively, these data indicate increased ischemic vulnerability of the IGF-1 +/- heart, suggesting that IGF-1 affords cardiac protection towards ischemia/reperfusion if the ischemic insult does not exceed 15 minutes. 


\section{Introduction}

Insulin-like growth factor-1 (IGF-1) is part of the insulin family of peptides and acts as a pleiotropic growth factor in many tissues and cell types (for a review see Delafontaine, 1996). Recent studies indicate that IGF-1 may have beneficial effects in myocardial infarction and in the hypertrophied and failing heart (Reiss et al., 1994, Jin et al., 1995, Duerr et al., 1996, Tanaka et al., 1998). In transgenic mice with cardiac-specific overexpression of IGF-1 necrotic and apoptotic cell death following coronary artery ligation was found to be reduced and cardiac function was found to be better as compared to wildtype littermates ( $\mathrm{Li}$ et al., 1997, 1999).

In an earlier study, however, no differences in hemodynamic performance following myocardial infarction were found between heterozygous IGF-1 deficient mice and their wildtype littermates (Palmen et al., 1999). Therefore, in the present study, it was tested whether partial deficiency of this growth factor would reduce the vulnerability of the heart towards global ischemia followed by reperfusion. To this end, hearts from heterozygous IGF-1 deficient mice, originally described by Powell-Braxton and colleagues (Powell-Braxton et al., 1993), and their wildtype littermates were perfused ex vivo in the working ejecting mode and subjected to either 15 or $20 \mathrm{~min}$ of global ischemia followed by reperfusion for $60 \mathrm{~min}$. The experiments were performed on isolated hearts to avoid differences in loading conditions and neurohumoral status which have been shown to be present in in vivo studies (Lembo et al., 1996). The extent of tissue damage was assessed by measuring recovery of hemodynamic function and the release of lactate dehydrogenase $(\mathrm{LDH})$ into the coronary effluent, a marker of irreversible cell damage, during reperfusion. In addition, tissue levels of high energy phosphates were monitored. Accumulation of fatty acids, if any, was used as a marker of disturbances in membrane phospholipid homeostasis in the ischemic/reperfused heart (Van der Vusse et al., 1992).

\section{Materials and Methods}

\section{Chemicals}

All chemicals used for the Krebs-Henseleit solution were of the highest grade available and purchased from Merck (Darmstadt, Germany) except for $\mathrm{D}(+)$ glucose and pyruvate (Sigma Chemical Co., St. Louis, MO, USA). Insulin was purchased from Novo Nordisk A/S (Bagsvaerd, Denmark).

\section{Animals}

The IGF-1 deficient mice used in this study were originally generated by PowellBraxton and colleagues (Powell-Braxton et al., 1993) by disruption of the coding sequence in exon 3 of the murine igf-1 locus in AB.1 embryonic stem cells, upon which recombinant clones were injected into $\mathrm{C} 57 \mathrm{BL} / 6 \mathrm{~J}$ blastocysts. Resulting heterozygous (+/-) and homozygous (-/-) IGF-1 deficient mice were well characterized (Powell-Braxton et al., 1993). More than $95 \%$ of the homozygous 
IGF-1 knockout mice die at birth and have $<60 \%$ of the body weight of wildtype littermates. In contrast, heterozygous IGF-1 deficient mice are healthy and fertile in spite of a $30-40 \%$ reduction of circulating IGF-1 levels. Heterozygous IGF-1 deficient mice are 10-20\% smaller than their wildtype littermates and no obvious abnormalities or differences can be detected upon histological examination (PowellBraxton et al., 1993). In the present study only male IGF-1 +/- mice $(\mathrm{n}=10)$ and their wildtype littermates $(n=10)$ were included. The mice were kept under standard housing conditions with an artificial $12 \mathrm{~h}$ light cycle and had free access to standard rodent food (Diet SRM-A, Hope farms, Woerden, the Netherlands) and tap water. All experimental protocols were approved by the Institutional Animal Care and Use Committee of the Maastricht University.

\section{Genotyping}

Genotyping of the two mouse strains was performed by genomic PCR analysis to detect the presence of the targeted vector in the murine igf-1 locus. Briefly, genomic DNA was isolated from tails using a Qiamp genomic DNA prep kit (Qiagen, Leusden, The Netherlands). PCR analysis was performed using primers directed against the neomycin cassette of the original targeting vector, which were designated L62 (5 -primer) [5 -TGCTCTGATGCCGC-CGTGTTCCGC-3 ] and L72 (3 -primer) [5 GGTCCGCCACACCCAGCCGGCCAC-3 ]. PCR reactions were cycled 40 times at $94{ }^{\circ} \mathrm{C}$ for $1 \mathrm{~min}$, at $55^{\circ} \mathrm{C}$ for $1 \mathrm{~min}$ and at $72^{\circ} \mathrm{C}$ for $2 \mathrm{~min}$, with an additional amplification cycle of $10 \mathrm{~min}$ at $72^{\circ} \mathrm{C}$ using $1 \mu \mathrm{g}$ of genomic DNA as template and $50 \mathrm{pmol}$ of each primer. Detection of a specific product of about $600 \mathrm{bp}$ was anticipated in the presence of the gene targeting vector and, hence, the targeted genomic igf- 1 allele in IGF- 1 +/-mice.

\section{Isolated working mouse heart preparation}

The isolated ejecting mouse heart preparation used in the present study was previously described in detail (De Windt et al., 1999). Briefly, hearts of anesthetized mice were mounted on the perfusion system and retrograde perfusion was started immediately at a perfusion pressure of $50 \mathrm{~mm} \mathrm{Hg}$. Subsequently, the left atrium was cannulated with an atrial cannula through one of the lung veins. The oxygenated $\left(95 \% \mathrm{O}_{2}-5 \% \mathrm{CO}_{2}\right)$ Krebs-Henseleit perfusion buffer consisted of: 118 $\mathrm{mM} \mathrm{NaCl}, 4.7 \mathrm{mM} \mathrm{KCl}, 3.0 \mathrm{mM} \mathrm{CaCl}_{2}, 1.2 \mathrm{mM} \mathrm{MgSO}_{4}, 1.2 \mathrm{mM} \mathrm{KH}_{2} \mathrm{PO}_{4}, 25 \mathrm{mM}$ $\mathrm{NaHCO}_{3}, 0.5 \mathrm{mM}$ Na-EDTA, $10 \mathrm{mM} \mathrm{D(+)-glucose,} 1.5 \mathrm{mM} \mathrm{Na-pyruvate}$ and 100 $\mathrm{mU} / 1$ insulin. Left ventricular pressure was measured with a PE-50 catheter, inserted into the left ventricular cavity through the apex, connected to a Baxter pressure transducer (Baxter Healthcare Corp., Irvine, CA, USA). Aortic pressure was measured through a side branch located $3 \mathrm{~mm}$ above the entrance of the aortic cannula by means of a pressure transducer (Baxter Healthcare Corp.).

\section{Hemodynamic data}

All hemodynamic variables were continuously recorded on a personal computer, using specialized software (Hemodynamic Data Acquisition System, Technical Department, Maastricht University), allowing the on-line acquisition, presentation and calculation of left atrial filling flow, aortic flow (AOF), left ventricular systolic 
pressure (LVSP), left ventricular end-diastolic pressure (LVED), diastolic aortic pressure (AODP) and the first maximal and minimal derivatives of left ventricular pressure $\left(\mathrm{LV} \mathrm{dP/dt}\right.$ max and $\left.L V \mathrm{dP} / \mathrm{dt}_{\min }\right)$. Left ventricular developed pressure (LVDP) was defined as the difference between LVSP and LVEDP. Cardiac output (CO) was defined as the sum of AOF and coronary flow (CF). CF was determined from the difference between $\mathrm{AOF}$, as measured by an $1 \mathrm{~N}$ inline aortic flow probe, and left atrial filling flow, as measured by a $2 \mathrm{~N}$ inline flow probe placed in the left atrial inflow tract. Calculated CF data were periodically checked by timed collection of the coronary perfusate.

\section{Experimental protocol}

Hearts were normoxically perfused in the antegrade mode for $20 \mathrm{~min}$ (pre-ischemic period), whereupon the hearts were subjected to normothermic $(38.5$...C) no-flow global ischemia for either 15 or $20 \mathrm{~min}$ (see Chapter 6 for details). Following this ischemic period the hearts were reperfused retrogradely (perfusion pressure $50 \mathrm{~mm}$ $\mathrm{Hg}$ ). After $10 \mathrm{~min}$ the left atrial conduit was re-opened and the hearts were perfused in the antegrade mode (preload $10 \mathrm{~mm} \mathrm{Hg}$, afterload $50 \mathrm{~mm} \mathrm{Hg}$ ) for an additional $50 \mathrm{~min}$. Except for the ischemic period and during the first $5 \mathrm{~min}$ of reperfusion, the hearts were paced throughout the experimental protocol at 450 beats. $\min ^{-1}$, a frequency slightly higher than the intrinsic denervated heart rate of this mouse strain. Coronary effluent was collected and samples were immediately frozen in liquid nitrogen and stored at $-80^{\circ} \mathrm{C}$ for further biochemical analysis. To stabilize lactate dehydrogenase (LDH) activity in coronary effluent samples, bovine serum albumin was included (final concentration 3\%). After completion of the experimental protocol the ventricles of the individual hearts were separated from the atria and immediately frozen between aluminum clamps, previously cooled in liquid nitrogen, and stored at $-80 i \mathrm{C}$ for further analysis.

\section{Biochemical analysis}

LDH content in the coronary perfusate was assessed spectrophotometrically using a Cobas Bio autoanalyzer as described earlier (Bergmeyer and Bernt et al., 1974). Tissue content of adenine nucleotides, IMP, nucleosides and (oxy)purines was determined by high-performance liquid chromatography (Varian Vista 5500 HPLC) as described in detail earlier (Chapter 6 and Van Bilsen et al., 1989). The determination of cardiac fatty acids, phospholipids and triacylglycerols was performed as described in detail before (Chapter 6 and Van der Vusse and Roemen, 1995). All values were expressed as moles per gram dry weight of ventricular tissue.

\section{Statistical analysis}

The results are presented as mean values - standard deviations $(M \pm S D)$. All statistical analyses were performed using InStat 3.0 software (GraphPad Software Inc., San Diego, Ca). Differences between values of functional variables and biochemical parameters were statistically analyzed using one-way ANOVA followed by the Tukey s test. Linear regression was performed with the least squares method and the Pearson rank correlation coefficient $(r)$ was used to estimate 
the strength of the relation between two variables. In all tests significance was accepted at $P$ values $<0.05$.

\section{Results}

\section{Genotyping}

Heterozygous mice with the targeting vector, disrupting the igf- 1 gene, integrated into the genome, demonstrated a prominent PCR product of about $600 \mathrm{bp}$, whereas this product was absent in wildtype littermates (Figure 1). The IGF-1 $+/$ - hearts used in the present study tended to be slightly smaller than wildtype hearts $(215 \pm 31$ and $225 \pm 30 \mathrm{mg}$ wet weight, respectively; $\mathrm{n}=10$ for both groups), but the difference did not reach the level of significance. Similarly, heart weight-to-body weight ratios did not differ significantly between wildtype and IGF-1 $+/$ - mice $(6.3 \pm 0.7$ and 6.4 $\pm 0.4 \mathrm{mg} / \mathrm{g}$, respectively).

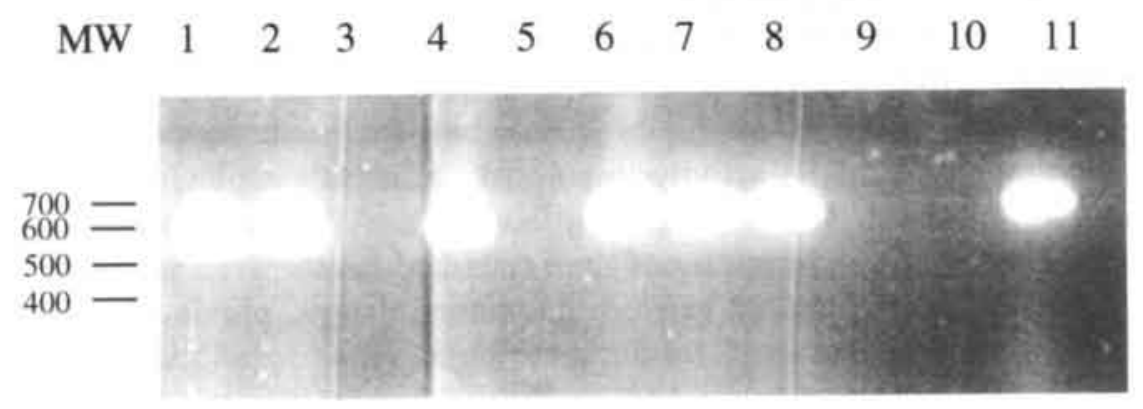

Figure 1. Example of IGF-1 PCR genotyping. Heterozygous IGF-1 deficient animals were identified by the presence of a prominent PCR product of about $600 \mathrm{bp}$ following PCR on their genomic DNA as template, resulting from amplification of the integrated neomycine gene as part of the targeting vector (lanes $2,3,5$ and 8 ; IGF-1 +/-), while in wildtype littermates this product was absent (lanes $1,4,6$, 7; wt).

\section{Functional recovery}

Baseline hemodynamic performance, as measured during the pre-ischemic phase, of wildtype and IGF-1 +/- hearts is depicted in Table I. No significant differences in $\mathrm{CO}$ and $\mathrm{AOF}$ were observed between both groups. Coronary flow rate, however, was approximately $25 \%$ lower $(\mathrm{P}<0.05)$ in IGF-1 $+/$ - hearts than in wildtype hearts. In addition, LVEDP was substantially higher in IGF-1 +/- hearts than in wildtype hearts. Baseline contractility as measured by $L V \mathrm{dP} / \mathrm{dt}_{\max }$ and $\mathrm{LV} \mathrm{dP/dt}$ min was similar in wildtype and IGF-1 +/- hearts (Table I).

Following $15 \mathrm{~min}$ of global ischemia and $60 \mathrm{~min}$ of reperfusion $\mathrm{CO}$ recovered to $31 \pm 15 \%$ and $11 \pm 5 \%$ of the corresponding pre-ischemic values in wildtype and IGF-1 +/- hearts, respectively $(\mathrm{P}<0.05$; Table II, Figure 2$)$. LVDP 
recovered to $57 \pm 11 \%$ and $26 \pm 11 \%$ of their corresponding pre-ischemic values in wildtype and IGF-1 +/- hearts, respectively ( $\mathrm{P}<0.05$; Table II and Figure 2 ). In both groups the decrease in post-ischemic LVDP could be attributed to both a rise in LVEDP and a decrease in LVSP. Post-ischemic LV dP/dt $\mathrm{d}_{\max }$ and LV dP/dt $t_{\min }$ tended to be lower for IGF-1 +/- hearts, but the difference did not reach the level of significance (Table II and Figure 2).

When the ischemic period was extended to $20 \mathrm{~min}$ in IGF $+/$ - hearts functional recovery during reperfusion was as poor as in the $15 \mathrm{~min}$ ischemia group (Table II). In contrast, in wildtype hearts further deterioration of cardiac function was observed (Table II). As a result, following $20 \mathrm{~min}$ of ischemia hemodynamic recovery was severely depressed in all hearts and comparable between the two groups. For instance, $\mathrm{CO}$ recovered to only $17 \pm 20 \%$ and $9 \pm 11 \%$ of their corresponding pre-ischemic value in wildtype and IGF-1 +/- hearts, respectively (N.S.; Figure 2).

\section{Table I}

Pre-ischemic values of functional parameters of isolated, left ventricular ejecting hearts from wildtype (wt) and heterozygous IGF-1 deficient mice [IGF-1(+/-)].

$\mathrm{CO}\left(\mathrm{ml} \cdot \mathrm{min}^{-1} \cdot \mathrm{g}^{-1}\right)$

CF $\left(\mathrm{ml}^{\mathrm{min}} \mathrm{min}^{-1} \cdot \mathrm{g}^{-1}\right)$

AOF $\left(\mathrm{ml} \cdot \mathrm{min}^{-1} \cdot \mathrm{g}^{-1}\right)$

LVEDP $(\mathrm{mm} \mathrm{Hg})$

$\operatorname{LVSP}(\mathrm{mm} \mathrm{Hg})$

LVDP $(\mathrm{mm} \mathrm{Hg})$

$L V d P / d t_{\max }\left(m m ~ H g . s^{-1}\right)$

$L V d P / d t_{\min }\left(m m H g . s^{-1}\right)$
$55.3 \pm 5.7$

$13.5 \pm 3.6$

$42.2 \pm 7.1$

$8 \pm 3$

$87 \pm 8$

$77 \pm 10$

$6,393 \pm 818$

$-3,802 \pm 865$
$48.2 \pm 11.4$

$10.2 \pm 2.7 *$

$37.2 \pm 10.6$

$13 \pm 2 * *$

$85 \pm 10$

$72 \pm 7$

$6,808 \pm 1,102$

$-3,685 \pm 514$

Data are expressed as means $\pm \mathrm{SD}$ (both groups $\mathrm{n}=10$ ). Isolated hearts were perfused in the antegrade mode for $20 \mathrm{~min}$ at a pre and afterload of 10 and $50 \mathrm{~mm} \mathrm{Hg}$, respectively, and paced at 450 beats. $\min ^{-1}$. CO, cardiac output; CF, coronary flow; AOF, aortic flow; LVDP, left ventricular developed pressure; LVSP, left ventricular systolic pressure; LVEDP, left ventricular end-diastolic pressure; LV dP/dt $t_{\max }$, first maximal derivative of left ventricular pressure; $L V \mathrm{dP} / \mathrm{dt}_{\min }$, first minimal derivative of left ventricular pressure. * indicates $\mathrm{P}<0.05,{ }^{* *}$ indicates $\mathrm{P}<0.01$ between wildtype and IGF-1 (+/-) mice. 


\section{Enzyme release}

Pre-ischemic LDH release was comparable in wildtype and IGF- $1+/$ - hearts and amounted to $0.2 \pm 0.1$ and $0.3 \pm 0.1 \mathrm{U} \cdot \mathrm{min}^{-1} \cdot \mathrm{g}^{-1}$, respectively (N.S.; $\mathrm{n}=10$ for both groups). In contrast, the post-ischemic cumulative LDH release was significantly higher in IGF-1 +/- hearts than in wildtype hearts following the shortest ischemic period tested and amounted to $11.6 \pm 4.1$ and $5.1 \pm 2.6 \mathrm{U}_{\mathrm{g}}{ }^{-1}$ per $60 \mathrm{~min}$, respectively $(\mathrm{P}<0.05 ; \mathrm{n}=5$ in both groups). Following $20 \mathrm{~min}$ of ischemia the cumulative release of $\mathrm{LDH}$ release amounted to $19.4 \pm 5.7$ and $14.7 \pm 4.1 \mathrm{U}_{\mathrm{g}}{ }^{-1}$ for wildtype and IGF-1 +/- hearts, respectively, (N.S.; $n=5$ in both groups).

\section{Metabolic recovery}

In reperfused hearts previously subjected to $15 \mathrm{~min}$ of ischemia the tissue levels of phosphocreatine $(\mathrm{PCr})$ and creatine $(\mathrm{Cr})$ were not significantly different between both groups (Table III). Also, tissue ATP, ADP and AMP levels and adenylate energy charge (EC) were similar between wildtype and IGF-1 +/- hearts (Table III). The tissue content of adenine nucleotide degradation products (i.e., sum of adenosine, inosine, hypoxanthine en xanthine), glycogen and lactate did not differ between both groups either (Table III).

Following $20 \mathrm{~min}$ of ischemia and $60 \mathrm{~min}$ of reperfusion no significant differences were observed in tissue PCr, ATP, ADP, AMP and EC between wildtype and IGF-1 +/- hearts (Table III). The same holds for the tissue content of (oxy)purines, glycogen and lactate (Table III). In reperfused hearts previously subjected to $20 \mathrm{~min}$ of ischemia in both groups the tissue content of (oxy)purines and lactate tended to be higher than after $15 \mathrm{~min}$ of ischemia. The tissue lactate content was significantly higher in IGF $+/$ - than in wildtype hearts.

\section{Fatty acids, phospholipids, triacylglycerols}

No significant differences in either the cardiac phospholipid (PL) and triacylglycerol (TG) content (Figure 3 ) or the fatty acid composition of these lipid pools (data not shown) were observed between wildtype and IGF $+/$ - hearts following either 15 or $20 \mathrm{~min}$ of ischemia and reperfusion. However, following 15 $\mathrm{min}$ of ischemia and reperfusion the tissue content of total (unesterified) fatty acids (FA) was significantly higher in IGF-1 $+/$ - than in wildtype hearts (Figure 3). As demonstrated in Figure 4, tissue levels of all individual fatty acid species were 2 to 2.5 -fold higher in reperfused IGF-1 +/- than in wildtype hearts. In contrast, in reperfused IGF $+/$ - and wildtype hearts previously subjected to $20 \mathrm{~min}$ of ischemia total tissue FA levels (Figure 3) and the levels of individual FA species, including arachidonic acid (data not shown), showed no significant differences.

\section{Discussion}

The findings in the present study indicate that IGF-1 may have a protective effect in myocardial ischemia of short duration, bacause the myocardium of heterozygous IGF-1 deficient mice was more sensitive to ischemia/reperfusion than that of the wildtype littermates following $15 \mathrm{~min}$ of ischemia. After $20 \mathrm{~min}$ of ischemia, 
however, the differences between the strains had disappeared. These results support the notion that the trophic effects of IGF-1 delay cardiac ischemia/reperfusioninduced dysfunction (Ross et al., 1996). The findings are also in line with observations of protective effects on hemodynamic function of IGF-1 following myocardial infarction in transgenic mice overexpressing IGF-1 specifically in the mouse heart (Li et al., 1997).

\section{Table II}

Hemodynamic function of reperfused wildtype (wt) and IGF-1 (+/-) hearts following 15 and $20 \mathrm{~min}$ of global ischemia and $60 \mathrm{~min}$ of reperfusion.



Data are expressed as means $\pm \mathrm{SD}$ ( $\mathrm{n}=5$ for wt and IGF-1 (+/-) following each ischemic period). Isolated hearts were perfused in the antegrade mode at a pre and afterload of 10 and $50 \mathrm{~mm} \mathrm{Hg}$, respectively, and paced at 450 beats. $\min ^{-1}$. $\mathrm{CO}$, cardiac output; $\mathrm{CF}$, coronary flow; AOF, aortic flow; LVDP, left ventricular developed pressure; LVSP, left ventricular

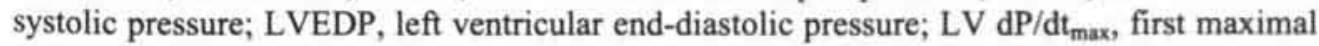
derivative of left ventricular pressure; $\mathrm{LV} \mathrm{dP} / \mathrm{dt}_{\min }$, first minimal derivative of left ventricular pressure. * indicates $\mathrm{P}<0.05$ between wt and IGF-1 (+/-) following identical ischemic period, \# indicates $\mathrm{P}<0.05$ vs group with identical genotype subjected to $15 \mathrm{~min}$ of ischemia 



Figure 2. Post-ischemic percentage recovery of hemodynamic variables in isolated wildtype hearts (wt; open bars) and IGF-1 deficient (IGF-1 +/-; closed bars) following 15 (upper panel) or 20 min of global ischemia (lower panel). Data are presented as means \pm SD. CO, cardiac output; CF, coronary flow; LVDP, left ventricular developed pressure; LVSP, left ventricular systolic pressure; $\mathrm{LV} \mathrm{dP} / \mathrm{dt}_{\max }$, first maximal derivative of left ventricular pressure; $\mathrm{LV} \mathrm{dP} / \mathrm{dt}_{\min }$, first minimal derivative of left ventricular pressure. * indicates $\mathrm{P}<0.05$ between wildtype and IGF $+/-$. 

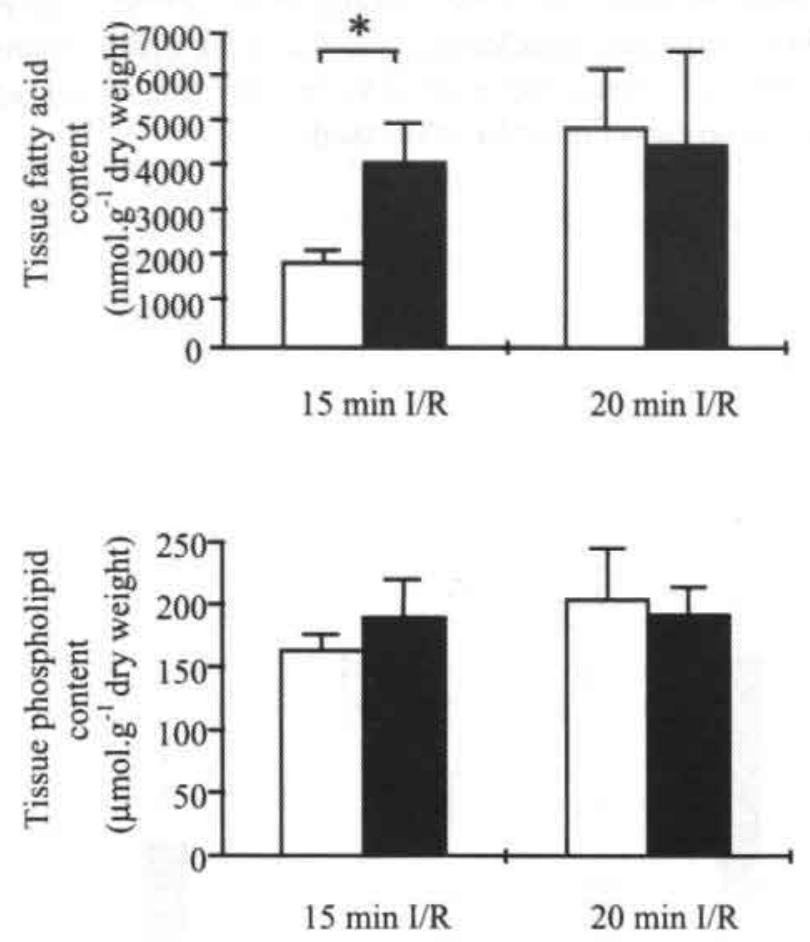

\section{Figure 3}

Post-ischemic ventricular content of the total (unesterified) fatty acid, phospholipid and triacylglycerol content in $1 \mathrm{GF}-1$ deficient (IGF-1 +/-; closed bars) and wildtype hearts (wt; open bars) following 15 and $20 \mathrm{~min}$ of ischemia. Data are presented as means $\pm \mathrm{SD}$. * indicates $\mathrm{P}<0.05$ between IGF-1 $+\%$ and wt.

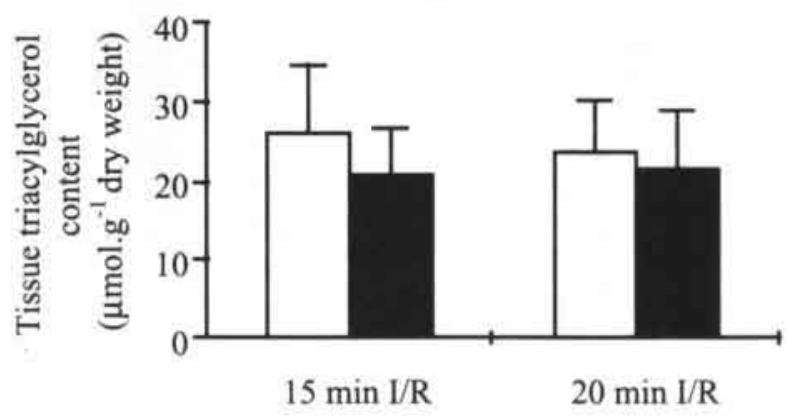

Following $15 \mathrm{~min}$ of global ischemia a significantly greater extent of irreversibly damaged cardiac muscle cells were found in the IGF-1 +/- mouse heart. The present findings corroborate with observed protective effects of IGF-1 towards necrotic and apoptotic cell death following myocardial infarction in transgenic mice with cardiac-specific overexpression of IGF-1 (Li et al., 1997) and following nonocclusive coronary artery constriction in the mouse (Li et al., 1999). Similar beneficial effects of IGF-1 on cardiac performance of regional infarction have been documented in experimental rat heart models where IGF-1 was administered exogenously (Reiss et al., 1994, Jin et al., 1995, Duerr et al., 1996). The exact mechanism through which IGF-1 exerts its protective effect is incompletely understood. Previous studies provide indications that IGF-1 has potent antiapoptotic effects on the cardiomyocyte both in vivo and in vitro (Reiss et al., 1994, 
Li et al., 1997, Parrizas et al., 1997, Wang et al., 1998a, Wang et al., 1998b, Leri et al., 1999, Palmen et al., 1999). Although accelerated cardiac cell death in the absence of IGF-1 may provide an attractive explanation for the observed phenomena, other possible explanations should not be dismissed.



Post-ischemic ventricular content of the major individual fatty acid species in wildtype hearts (wt; open bars) and IGF-1 deficient (IGF-1 +/-; closed bars) folowing $15 \mathrm{~min}$ of ischemia. Individual fatty acid species are indicated by their chemical notation. Data are presented as means $\pm \mathrm{SD}$.

* indicates $\mathrm{P}<0.05$ between IGF-1 $+/$ - and wt.

In this respect the observed differences in baseline normoxic hemodynamic performance between IGF-1 deficient and wildtype hearts deserve attention. Of note are the observed differences in end-diastolic left ventricular pressure and coronary flow. The significantly higher left ventricular end-diastolic pressure indicates diastolic dysfunction and filling abnormalities in the heterozygous IGF-1 deficient (IGF-1 +/-) heart under normoxic conditions. Another IGF-1 targeted mouse model, the so-called IGF-1 midi mouse in which plasma IGF-1 levels are approximately $30-40 \%$ of normal, also display alterations in cardiac performance in 
terms of fluid ejection and left ventricular pressure development as measured in vivo (Lembo et al., 1996). The significantly lower baseline coronary flow rate in IGF-1 +/- hearts than in wildtype hearts is in line with a recent observation of reduced capillary density in the hearts of the same IGF-1 +/- mice (Palmen et al., 1999 ) and the reported requirement of IGF-1 for the proper development of the microvasculature in other tissues (Sonntag et al., 1997, Tonshoff et al., 1998). Reduced capillary density and, hence, diminished tissue perfusion may contribute to the reduced ischemia tolerance under conditions of chronic IGF-1 shortage.

The present data demonstrate enhanced accumulation of (unesterified) fatty acids, including arachidonic acid, indicative of increased net phospholipid degradation, in IGF +/- reperfused hearts subjected to $15 \mathrm{~min}$ of ischemia. The present findings, however, do not allow to conclude that the increased net phospholipid degradation is directly related to enhanced phospholipase activity in the hearts of IGF $+/$ - mice. Nonetheless, relatively strong correlations were observed between the extent of arachidonic acid accumulation in reperfused hearts, on the one hand, and the cumulative release of LDH or recovery of cardiac output during the reperfusion phase, on the other (Figure 5).

A number of studies have provided evidence for an inhibitory effect of IGF-1 on phospholipase activity via trancriptional as well as post-transcriptional mechanisms in various cell systems (Berenbaum et al., 1994, Jacques et al., 1997;Pruzanski et al., 1998). It is tempting to speculate that mutatis mutandis reduced IGF-1 levels are associated with a stimulatory effect on cardiac phospholipase activity. Collectively, these observations suggest that phospholipase $\mathrm{A}_{2}$-mediated net degradation of membrane phospholipids might play a role in the events associated with the increased ischemia vulnerability of the IGF-1 deficient heart.

In conclusion, using an isolated working murine heart model, it was found that hearts from mice with chronically reduced IGF-1 levels are more susceptible to cardiac dysfunction following no-flow ischemia of short duration, as demonstrated by reduced recovery of cardiac output, increased irreversible cell damage, and higher tissue fatty acid levels following $15 \mathrm{~min}$ of ischemia and reperfusion. These findings lend additional support to the notion that IGF-1 exerts salutatory effects on the ischemic/reperfused myocardium. The present findings also support the notion that the ex vivo ejecting mouse heart model as characterized in Chapter 5 and Chapter 6 allows the detection of both subtle differences in hemodynamic function under baseline conditions and small differences in susceptibility towards global ischemia and reperfusion between hearts derived from gene-targeted or transgenic mouse models and their wildtype littermates.

\section{References}

1. Berenbaum F, Thomas G, Poiraudeau S, Bereziat G, Corvol MT, Masliah J. Insulin-like growth factors counteract the effect of interleukin-1 beta on type II phospholipase $A_{2}$ expression and arachidonic acid release by rabbit articular chondrocytes. FEBS Lett 1994;340:51-55. 


\section{Table III}

Tissue high energy phosphate, glycogen and lactate content of ischemic-reperfused wildtype (wt) and IGF-1 (+/-) hearts.

\begin{tabular}{|c|c|c|c|c|}
\hline & $15 \mathrm{~m}$ & schemia & $20 \mathrm{~m}$ & Ischemia \\
\hline & $w t$ & $I G F-1(+/-)$ & $w t$ & $I G F-1(+1-)$ \\
\hline$P C r$ & $18.1 \pm 5.2$ & $15.0 \pm 6.6$ & $15.4 \pm 6.9$ & $17.2 \pm 7.7$ \\
\hline $\mathrm{Cr}$ & $31.8 \pm 7.0$ & $29.1 \pm 6.9$ & $31.9 \pm 9.7$ & $38.6 \pm 5.8$ \\
\hline$A T P$ & $11.6 \pm 2.4$ & $8.4 \pm 3.3$ & $7.8 \pm 3.7$ & $6.6 \pm 2.0$ \\
\hline$A D P$ & $3.5 \pm 0.5$ & $3.0 \pm 0.9$ & $3.0 \pm 0.5$ & $2.7 \pm 0.3$ \\
\hline$A M P$ & $0.6 \pm 0.2$ & $0.7 \pm 0.3$ & $1.0 \pm 0.5$ & $1.2 \pm 0.5$ \\
\hline$E C$ & $0.84 \pm 0.03$ & $0.81 \pm 0.04$ & $0.77 \pm 0.10$ & $0.75 \pm 0.06$ \\
\hline (Oxy)purines & $0.3 \pm 0.6$ & $0.8 \pm 1.2$ & $1.7 \pm 1.8$ & $3.5 \pm 2.7$ \\
\hline Glycogen & $200 \pm 111$ & $144 \pm 84$ & $125 \pm 25$ & $167 \pm 61$ \\
\hline Lactate & $5.7 \pm 6.4$ & $11.9 \pm 3.8$ & $18.3 \pm 21.3$ & $44.0 \pm 12.5$ \\
\hline
\end{tabular}

Data are expressed as means \pm SD in $\mu$ mol.g-1 dry weight from ventricular tissue freeze clamped following $60 \mathrm{~min}$ of reperfusion ( $\mathrm{n}=5$ for both wt and IGF-1 (+/-) hearts). EC, energy charge is defined as (ATP + $0.5 \mathrm{ADP}) /(\mathrm{ATP}+\mathrm{ADP}+\mathrm{AMP})$ and is unitless; PCr, phosphocreatine; $\mathrm{Cr}$, creatine; (oxy)purines are defined as the sum of adenosine, inosine, hypoxanthine and xanthine. indicates $\mathrm{P}<0.05$ vs group with identical genotype subjected to $15 \mathrm{~min}$ of ischemia.

2. Bergmeyer HU, Bernt E. UV assay for lactate dehydrogenase with pyruvate and NADH. In: Methods of Enzymology, Weinheim Verlag Chemie GmbH, 1974; 2: 574-579.

3. De Windt LJ, Willems J, Reneman RS, Van der Vusse GJ, Arts T, Van Bilsen M. An improved isolated, left ventricular ejecting murine heart model. Functional and metabolic evaluation. Pf gers Archiv-Eur J Physiol 1999;437:182-190.

4. De Windt LJ, Willemsen PHM, P pping S, Van der Vusse GJ, Reneman RS, Van Bilsen M. Cloning and cellular distribution of a group II phospholipase $\mathrm{A}_{2}$ expressed in the heart. $\mathrm{J} \mathrm{Mol} \mathrm{Cell}$ Cardiol 1997;29:2095-2106.

5. Delafontaine $P$. Insulin-like growth factor- 1 and its binding proteins in the cardiovascular system. Cardiovasc Res 1995;30:825-834.

6. Duerr RL, McKiman MD, Gim RD, Clark RG, Chien KR, Ross J Jr. Cardiovascular effects of insuline-like growth factor-1 and growth hormone in chronic left ventricular failure in the rat. Circulation 1996;93:2188-2196. 

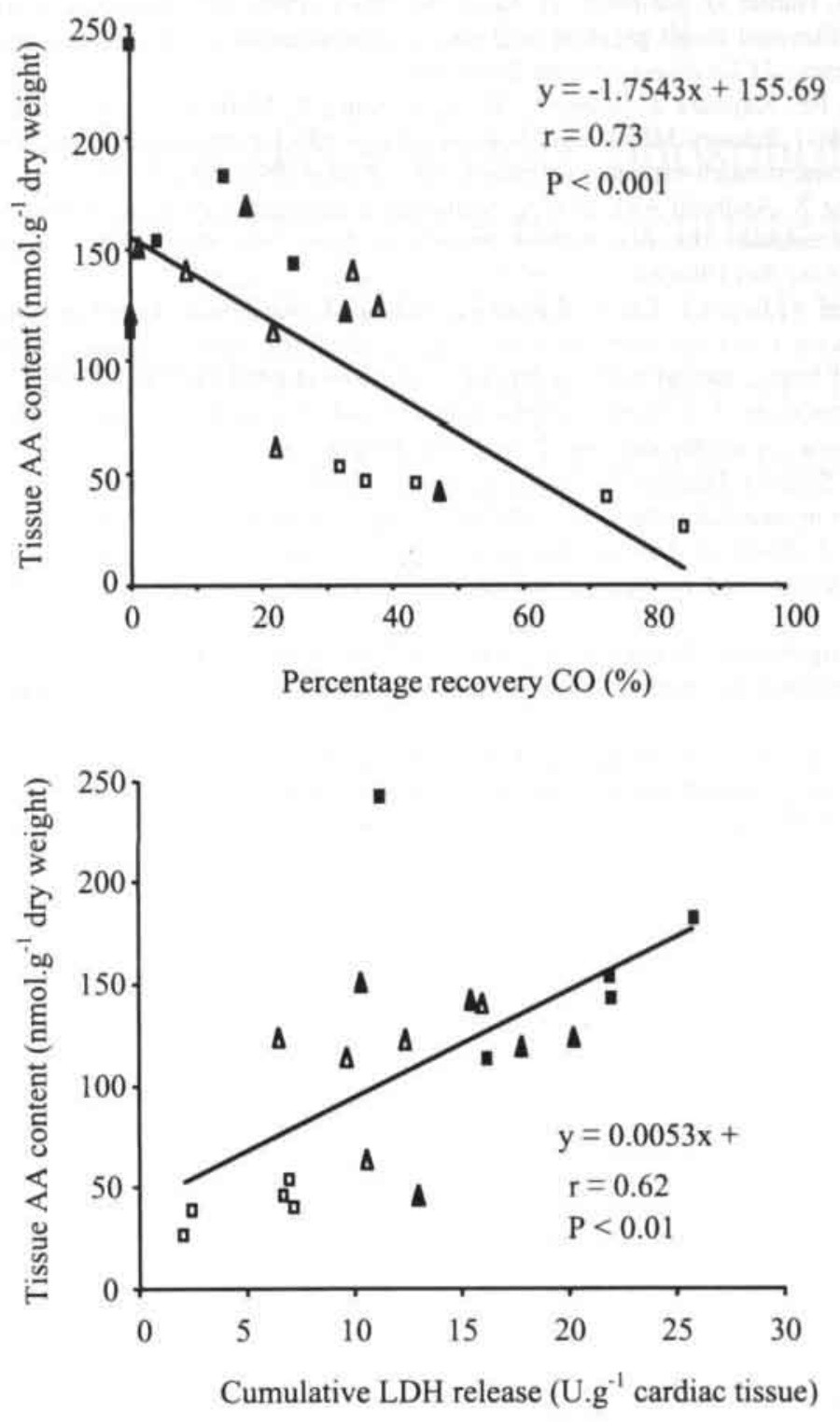

Figure 5.

Correlation between percentage recovery of cardiac output $(\mathrm{CO})$ and post-ischemic tissue arachidonic acid content (upper panel) and cumulative $\mathrm{LDH}$ release during reperfusion and post-ischemic tissue arachidonic acid content (lower panel) in IGF-1 deficient (open and closed triangles) and wildtype hearts (open and closed rectangles) following 15 or $20 \mathrm{~min}$ $\mathrm{min}$ of ischemia and 60 min of reperfusion, respectively.

7. Freestone NS, Ribaric S, Mason WT. The effect of insulin-like growth factor-1 on adult rat cardiac contractility. Mol Cell Biochem 1996;163:223-229.

8. Jacques C, Bereziat G, Humbert L, Olivier J-L, Torvol M-T, Masliah J, Berenbaum F. Posttranscriptional effect of insulin-like growth factor- 1 on interleukin- $1 \beta$-induced type IIsecreted phospholipase $\mathrm{A}_{2}$ gene expression in rabbit articular chondrocytes. $J$ Clin Invest 1997;99:1864-1872.

9. Jin H, Yang R, Gillet N, Clark RG, Ko A, Paoni NF. Beneficial effect of growth hormone and insulin-like growth factor- 1 in experimental heart failure in rats treated with chronic $\mathrm{ACE}$ inhibition. J Cardiovas Pharmacol 1995;26;420-425. 
10. Lembo G, Rockman HA, Hunter JJ, Steinmetz H, Koch WJ, Ma L, Prinz MP, Ross J Jr, Chien KR, Powell-Braxton L. Elevated blood pressure and enhanced myocardial contractility in mice with severe IGF-1 deficiency. $J$ Clin Invest 1996;98:2648-2655.

11. Leri A, Liu Y, Claudio PP, Kajstura J, Wang X, Wang S, Kang P, Malhotra A, Anversa P. Insulin-like growth factor-1 induces $\mathrm{Mdm} 2$ and down-regulates p53, attenuating the myocyte renin-angiotensin system and streatch-mediated apoptosis. Am J Pathol 1999;154:567-580.

12. Li B, Setoguchi M, Wang X, Andreoli AM, Leri A, Malhotra A, Kajstura J, Anversa P. Insulinlike growth factor-1 attenuates the detrimental impact of nonocclusive coronary artery constriction on the heart. Circ Res 1999;84:1007-1019.

13. Li Q, Li, B, Wang X, Leri A, Jana KP, Liu Y, Kajstura J, Baserga R, Anversa P. Overexpression of insulin-like growth factor-1 in mice protects from myocyte death after infarction, attenuating ventricular dilatation, wall stress, and cardiac hypertrophy. J Clin Invest 1997;100:1991-1999.

14. Liu SJ, McHowat J. Stimulation of different phospholipase $A_{2}$ isoforms by TNF- $\alpha$ and IL-1 $\beta$ in adult rat ventricular myocytes. Am J Physiol 1998;275:H1462-H1472.

15. Palmen M, Bronsaer R, Smits J, Daemen M, Doevendans PA. Impaired cardiac remodeling in IGF-1 deficient mice after myocardial infarction. J Mol Cell Cardiol 1999;43:A85 (Abstract).

16. Parrizas M, Saltiel AR, LeRoith D. Insulin-like growth factor-1 inhibits apoptosis using the phosphatidylinositol 3'-kinase and mitogen-activated protein kinase pathways. J Biol Chem 1997;272:154-161.

17. Powell-Braxton L, Hollingshead P, Warburton C, Dowd M, Pitts-Meek S, Dalton D, Gillet N, Stewart TA. IGF-1 is required for normal embryonic growth in mice. Genes \& Development 1993;7:2609-2617.

18. Redealli G, Malhotra A, Li B, Li P, Sonnenblick EH, Hofmann PA, Anversa P. Effects of constitutive overexpression of insulin-like growth factor-1 on the mechanical characteristics and molecular properties of ventricular myocytes. Circ Res 1998;82:594-603.

19. Reiss K, Kajstura J, Zhang X, Li P, Olivetti G, Anversa P. Acute myocardial infarction leads to upregulation of the IGF-1 autocrine system, DNA replication, and nuclear mitotic division in the remaining viable cardiac myocytes. Exp Cell Res 1994;213:463-472.

20. Ross $\mathrm{J}$ Jr, Hongo M. The role of hypertrophy and growth factors in heart failure. $J$ Card Fail 1996;2:S121-S128.

21. Sonntag WE, Lynch CD, Cooney PT, Hutchins PM. Decrease in cerebral microvasculature with age are associated with the decline in growth hormone and insulin-like growth factor-1. Endocrinology 1997; 138:3515-3520.

22. Tanaka N, Ryoke T, Hongo M, Mao L, Rockman HA, Clark RG, Ross J Jr. Effects of growth hormone and IGF-1 on cardiac hypertrophy and gene expression in mice. Am J Physiol 1998;275:H393-H399.

23. Tonshoff B, Kaskel FJ, Moore LC. Effects of insulin-like growth factor 1 on renal juxtamedullary microvasculature. Am J Physiol 1998;274:F120-F128.

24. Van Bilsen M, Van der Vusse GJ, Willemsen PHM, Coumans WA, Roemen THM, Reneman RS. Lipid alterations in isolated, working rat hearts during ischemia and reperfusion: its relation to myocardial damage. Circ Res 1989b;64:304-314.

25. Van Bilsen $M$, Van der Vusse GJ. Phospholipase $A_{2}$-dependent signalling in the heart. Cardiovasc Res 1995;30:518-529.

26. Van der Vusse GJ, Reneman RS, Van Bilsen M. Accumulation of arachidonic acid in ischemic/reperfused cardiac tissue: possible causes and consequences. Prostaglandins Leukot Essent Fatty Acids 1997;57:85-93.

27. Van der Vusse GJ, Roemen THM, Prinzen FW, Coumans WA, Reneman RS. Uptake and tissue content of fatty acids in dog myocardium under normoxic and ischemic conditions. Circ Res 1982;50:538-546.

28. Van der Vusse GJ, Van Bilsen M, Reneman RS. Is phospholipid degradation a critical event in ischemia- and reperfusion-induced damage. NIPS 1989;4:49-53.

29. Wang L, Ma W, Markovich R, Chen J-W, Wang PH. Regulation of cardiomyocyte apoptotic signaling by insulin-like growth factor-1. Circ Res 1998b;83:516-522.

30. Wang L, Ma W, Markovich R, Lee W-L, Wang PH. Insulin-like growth factor-1 modulates induction of apoptotic signaling in H9c2 cardiac muscle cells. Endocrinology 1998a;139:13541360 . 
Chapter 8

\section{Type IIA secretory phospholipase $\mathrm{A}_{2-}$} deficiency fails to attenuate decline in mechanical function, cellular viability and accumulation of fatty acids in the ischemicreperfused mouse heart.

Submitted as:

LJ De Windt, J Willems, TM Roemen, WA Coumans, RS Reneman, GJ Van der Vusse, M Van Bilsen. Type IIA secretory phopholipase $\mathrm{A}_{2}$-deficiency fails to attenuate cardiomyocyte damage in the ischemic-reperfused mouse heart. (Am J Physiol) 


\section{Abstract}

In the present study the role of type IIA secretory phospholipase $\mathrm{A}_{2}$ (type IIA sPLA ${ }_{2}$ ) in cardiac ischemia/reperfusion-induced fatty acid accumulation, cellular damage and loss of function was investigated by subjecting isolated ejecting hearts derived from wildtype (C57BL/Ks) and type IIA sPLA ${ }_{2}$-deficient mice (C57BL/6) to $17.5 \mathrm{~min}$ of global ischemia followed by $60 \mathrm{~min}$ of reperfusion. Pre-ischemic cardiac output (CO), aortic flow (AOF) and coronary flow (CF) normalized for heart weight was comparable between the two groups. Post-ischemic functional and metabolic recovery between type IIA sPLA ${ }_{2}$ wildtype and type IIA sPLA ${ }_{2}$ deficient hearts did not demonstrate significant differences $(37 \pm 23$ and $39 \pm 25 \%$ recovery of $\mathrm{CO}$, respectively; recovery of energy charge to $0.79 \pm 0.04$ and $0.83 \pm 0.05$, respectively). The post-ischemic tissue content of total unesterified fatty acids (FA) and arachidonic acid amounted to $2671 \pm 1151$ and 70 \pm 32 nmol.g ${ }^{-1}$ dry weight for wildtype and $2683 \pm 911$ and $107 \pm 87$

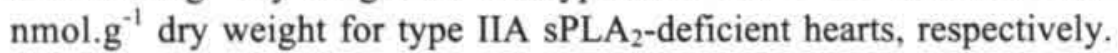
Cumulative lactate dehydrogenase release into the coronary effluent during reperfusion, reflecting irreversible cell damage, amounted to $10526 \pm 3610$ and $11306 \pm 3545 \mathrm{mU} \cdot \mathrm{g}^{-1}$ wet weight for $\mathrm{C} 57 \mathrm{BL} / \mathrm{Ks}$ and C57BL/6 hearts, respectively. In addition, no differences were observed in either total phospholipid and triacylglycerol content or their respective fatty acyl composition between the two strains. Based on these results it is doubtful whether cardiac type IIA sPLA $A_{2}$ plays a substantial role, if any, in acute ischemia/reperfusion-induced injury of cardiac structures. 


\section{Introduction}

Type IIA secretory phospholipase $\mathrm{A}_{2}$ (type IIA sPLA $\mathrm{A}_{2}$ ) catalyzes the hydrolysis of $s n-2$ fatty acyl ester bonds of phospholipids, yielding lysophospolipids and unesterified fatty acids (FA), including arachidonic acid (AA). Type IIA sPLA $\mathrm{A}_{2}$ has been detected in a wide variety of cell types where it plays a role in AA-dependent cell signaling, in the physiological turnover of membrane phospholipids and in inflammatory processes such as rheumatoid arthritis and septic shock (Vadas et al., 1993, Lin et al., 1996, Murakami et al., 1995). Likewise, type IIA sPLA ${ }_{2}$ transgenic mice display more severe inflammatory responses to proinflammatory stimuli (Grass et al., 1996, Nevelainen et al., 1997, Fox et al., 1996). Additionally, its activity has been associated with intestinal tumorigenesis (Cornier et al., 1997), and brain and intestinal ischemia-reperfusion injury (Otamiri et al., 1987, Lauritzen et al., 1994).

In contrast to other tissues (Balsinde et al., 1996, Reddy et al., 1997, Murakami et al., 1998), the physiological role of phospholipase $\mathrm{A}_{2}\left(\mathrm{PLA}_{2}\right)$ and its potential involvement in ischemia and reperfusion-induced cellular damage has not been well defined in cardiac tissue. Cardiac $\mathrm{PLA}_{2} \mathrm{~S}$ have been implicated in the deacylation cycle of the physiological membrane phospholipid turnover (Van der Vusse et al., 1992), in mediating the rate-limiting step in the AA cascade (Van Bilsen et al., 1995), and in playing a role in myocardial ischemia and reperfusioninduced phospholipid degradation (Van der Vusse et al., 1982, Chien et al., 1984, Otani et al., 1989, Van Bilsen et al., 1989b). Accelerated hydrolysis of cardiac membrane phospholipids during ischemia and reperfusion is thought to contribute to membrane destabilization and concomitant generation of biologically active lipid second messengers, which ultimately precipitate to electrophysiological dysfunction and cellular injury (Gross et al., 1992, Corr et al., 1995, Van der Vusse et al., 1992). The assessment whether $\mathrm{PLA}_{2}$ activity indeed is crucial in the transition from reversible to irreversible myocardial ischemia and reperfusion-induced injury and identification of the dominant cardiac $\mathrm{PLA}_{2}(\mathrm{~s})$ responsible in this process could therefore be of therapeutic importance.

It should, however, be noted that until now at least four different types of PLA $_{2}$ enzymes have been detected in myocardial tissue; the high molecular mass (85-100 kDa) arachidonoyl-specific type IV cytosolic PLA 2 (Sharp et al., 1993), the calcium-independent, plasmalogen-specific type VI PLA 2 (Hazen et al., 1993), and the functionally closely related type IIA and type V secretory $\mathrm{PLA}_{2} \mathrm{~S}$ (Chen $e t$ al.,


mediating cardiac $\mathrm{I} / \mathrm{R}$-induced membrane phospholipid-degradation remains a matter of continuing speculation (Gross et al., 1992, Van Bilsen et al., 1995, Van der Vusse et al., 1997, De Windt et al., 1998). In this light, the recent finding of a number of inbred mouse strains which display a frameshift mutation in the pla2ga gene, resulting in the absence of a functional type IIA sPLA $\mathrm{A}_{2}$ enzyme, is of interest (Kennedy et al., 1995, MacPhee et al., 1995).

In an attempt to establish the role of type IIA sPLA $\mathrm{A}_{2}$ in mediating cardiac ischemia and reperfusion-induced membrane phospholipid degradation, isolated ejecting hearts from the wildtype C57BL/Ks and the type IIA sPLA ${ }_{2}$-deficient 
C57BL/6 strain were subjected to $17.5 \mathrm{~min}$ of global, normothermic ischemia followed by $60 \mathrm{~min}$ of reperfusion. Loss of function was monitored by hemodynamic variables as cardiac output (CO), left ventricular developed pressure (LVDP) and the first maximal and minimal derivative of left ventricular pressure (LV dP/dt $t_{\max }$ and $L V \mathrm{dP} / \mathrm{dt}_{\min }$ ). The percentage irreversibly damaged cardiomyocytes was determined by the cumulative LDH release into the coronary effluent during the reperfusion phase. Post-ischemic high energy phosphate and glycogen content was determined to compare the metabolic state of the hearts. Postischemic cardiac AA content was assessed to specifically monitor potential differences in PLA 2 activity.

\section{Materials and Methods}

\section{Chemicals}

All chemicals used for the Krebs-Henseleit solution were of the highest grade available and purchased from Merck (Darmstadt, Germany) except for $\mathrm{D}(+)$ glucose and pyruvate (Sigma Chemical Co., St. Louis, MO, USA). Insulin was purchased from Novo Nordisk A/S (Bagsvaerd, Denmark).

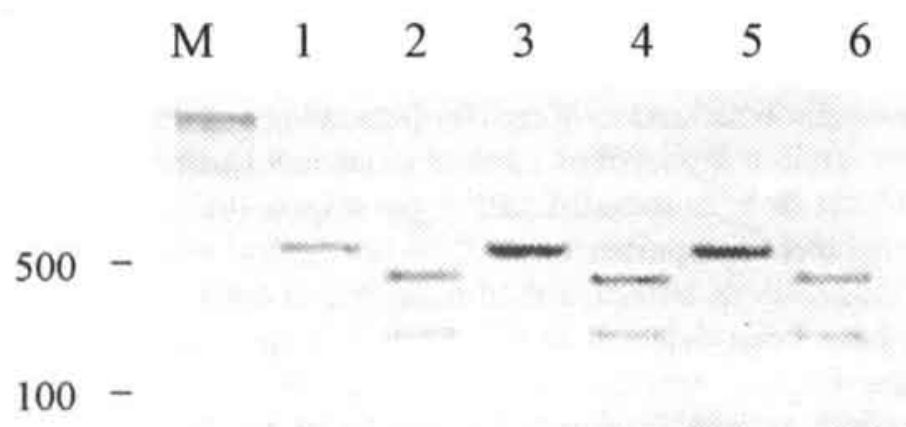

Figure 1. Genomic PCR analysis of pla2ga gene. Analysis by PCR amplification of exon 3 of the pla2ga gene of genomic DNA isolated from C57BL/Ks (lanes 2, 4, 6) and C57BL/6 mice (lanes 1, 3, 5). After amplification as described under Materials and Methods PCR product were digested by BamHI. As demonstrated, pla2ga exon 3 derived from C57BL/Ks mice was readily digested by BamHI resulting in two fragments of about 200 and $300 \mathrm{bp}$ (lane $2,4,6$ ). In contrast, $T$ insertional mutation disrupted the pla2ga exon 3 BamHI site in C57BL/6 mice (lane $1,3,7$ ). 


\section{Animals}

Adult male inbred C57BL/Ks

(wildtype pla2ga gene) and inbred C57BL/6 mice (mutated pla2ga gene) were purchased from $M$ \& B, Ry, Denmark and B \& K, Hull, United Kingdom, respectively. The animals were allowed to adjust to the new housing conditions for two weeks before

\section{Table I}

Characteristics of the C57BL/Ks mice $\left[\operatorname{sPLA}_{2}(+/+)\right]$ and C57BL/6 mice $\left[\operatorname{sPLA}_{2}(-/-)\right]$ used in the present study.

\begin{tabular}{lcc}
\hline & $s P L A_{2}(+/+)$ & $s P L A_{2}(-/-)$ \\
\cline { 2 - 3 } Age (weeks) & $15 \pm 2$ & $18 \pm 2^{\circ}$ \\
$B W(g)$ & $23.7 \pm 2.2$ & $30.2 \pm 1.6^{*}$ \\
$H W(m g)$ & $204 \pm 8$ & $249 \pm 17^{*}$ \\
$\left.H W / B W\left(\mathrm{mg}^{-1}\right)^{-1}\right)$ & $8.6 \pm 0.3$ & $8.3 \pm 0.5$ \\
\hline
\end{tabular}

Data are expressed as means $\pm \mathrm{SD}(\mathrm{n}=11$ and 10 for $\operatorname{sPLA}_{2}(+/+)$ and $\operatorname{sPLA}_{2}(-/-)$, respectively). BW, body weight; $\mathrm{HW}$, heart weight. ${ }^{*}$ indicates $\mathrm{P}<0.05$ between sPLA $_{2}(+/+)$ and sPLA $2(-/-)$. admission to experimental use.

The mice were kept under standard housing conditions with an artificial $12 \mathrm{~h}$ light cycle. Standard rodent food (Diet SRM-A, Hope farms, Woerden, the Netherlands) and tap water were freely accessible. All experimental protocols were approved by the Institutional Animal Care and Use Committee of the Maastricht University.

\section{PCR genotyping}

Genotyping of the two mouse strains to detect functional type IIA sPLA 2 deficiency was performed as described previously (Kennedy et al., 1995). Briefly, genomic DNA was isolated from tails using a Qiamp genomic DNA prep kit (Qiagen, Leusden, The Netherlands). PCR analysis of type IIA sPLA $\mathrm{A}_{2}$ exon 3 was performed using the following primers: 5 -primer (5 -CTGGCTTTCCTTCCTGTCAGCCTGG CC-3 ); 3 -primer (5 -GGAAACCACTGGGACACTGAGGTAGTG-3 ). PCR reactions were cycled 35 times at $94{ }^{\circ} \mathrm{C}$ for $30 \mathrm{~s}, 60^{\circ} \mathrm{C}$ for $30 \mathrm{~s}$ and $72^{\circ} \mathrm{C}$ for $30 \mathrm{~s}$, with an additional amplification cycle of $10 \mathrm{~min}$ at $72^{\circ} \mathrm{C}$ using $100 \mathrm{ng}$ of genomic

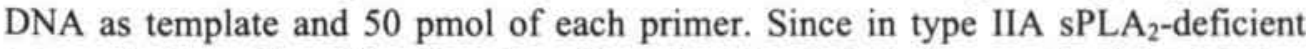
mouse strains a thymidine insertion disrupts a BamHI site in exon 3 of the Pla2ga gene, PCR products were digested with BamHI prior to subjection to gel electrophoresis to confirm disruption of the BamHI restriction site and, hence, occurrence of the mutation.

\section{Isolated working mouse heart preparation}

The isolated ejecting mouse heart preparation used in the present study was previously described in detail (De Windt et al., 1999). Briefly, animals were anesthetized by a $50 \mathrm{mg} \cdot \mathrm{kg}^{-1}$ sodium pentobarbital injection i.p. (Nembutal, Sanofi Sante BV., Maassluis, the Netherlands). After thoracotomy the hearts were quickly excised and transferred to ice-chilled perfusion modified Krebs-Henseleit buffer 
(for composition see below). Remnant thymic and adipose tissue was carefully removed and the ascending aorta was cannulated with a recently described aortic cannula designed to match the hemodynamic aortic impedance characteristics of the isolated murine heart (De Windt et al., 1999). Retrograde perfusion was started immediately at a perfusion pressure of $50 \mathrm{~mm} \mathrm{Hg}$, after which the hearts started to beat spontaneously. The left atrium was cannulated with an atrial cannula through one of the lung veins. The recirculating modified Krebs-Henseleit perfusion buffer was prefiltered by a microfilter $(0.45 \mu \mathrm{m}$ diameter; Millipore Corp.) and consisted of the following composition: $118 \mathrm{mM} \mathrm{NaCl}, 4.7 \mathrm{mM} \mathrm{KCl}, 3.0 \mathrm{mM} \mathrm{CaCl}, 1.2 \mathrm{mM}$

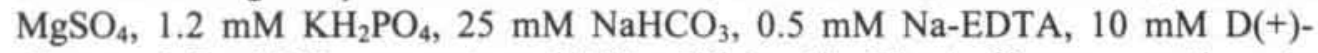
glucose, $1.5 \mathrm{mM}$ Na-pyruvate and $100 \mathrm{mU} / \mathrm{l}$ insulin. The buffer was continously gassed with $95 \% \mathrm{O}_{2}-5 \% \mathrm{CO}_{2}$. Cardiac output (CO) was defined as the sum of aortic flow (AOF) and coronary flow (CF). CF was determined from the difference between aortic flow (AOF), as measured by an $1 \mathrm{~N}$ inline flow probe (Transonic System Inc., Ithaca, NY, USA) and left atrial filling flow as measured by an $2 \mathrm{~N}$ inline flow probe (Transonic System Inc.) placed in the left atrial filling line. Aortic pressure was measured through a side branch located $3 \mathrm{~mm}$ above the entrance of the aortic cannula using a pressure transducer (Baxter Healthcare Corp.). Left ventricular pressure was measured with a PE-50 catheter, inserted into the left ventricular cavity through the apex (De Windt et al., 1999), connected to a Baxter pressure transducer (Baxter Healthcare Corp., Irvine, CA). Left ventricular developed pressure (LVDP) was defined as the difference between left ventricular systolic (LVSP) and end-diastolic pressure (LVEDP).

\section{Experimental protocol}

Hearts were perfused under normoxic conditions for $20 \mathrm{~min}$ in the antegrade mode following an initial $10 \mathrm{~min}$ retrograde perfusion period to adjust to the perfusion apparatus (pre-ischemic period). Just prior to the ischemic period the water-jacketed chamber was filled with perfusate solution until the heart was completely submersed, pacing was stopped, and the aortic and atrial lines were clamped to create a normothermic $\left(38.5^{\circ} \mathrm{C}\right)$ global ischemia. During prelimenary experiments a limited number of wildtype C57BL/Ks hearts were subjected to either $15,17.5$ or $20 \mathrm{~min}$ of ischemia and their post-ischemic functional recovery and LDH release was monitored. It was found that $15 \mathrm{~min}$ of ischemia resulted in a near complete post-ischemic functional recovery and minimal LDH release. In contrast, $20 \mathrm{~min}$ of ischemia resulted in a substantial loss of function (less than $10 \%$ recovery of CO) and loss of about $10 \%$ of total cardiac LDH content. To this end, it was decided to subject all hearts in the present study to $17.5 \mathrm{~min}$ of ischemia to obtain a loss of function and $\mathrm{LDH}$ release in $\mathrm{C} 57 \mathrm{BL} / \mathrm{Ks}$ hearts which still allows measurable potential improvement or deterioration of these parameters in the absence of type IIA sPLA 2 . After the ischemic period, the water-jacketed chamber was emptied and hearts were reperfused in a retrograde manner at 


\section{Table II}

Pre-ischemic hemodynamic values measured in isolated, left ventricular ejecting murine hearts from the C57BL/Ks $\left[\mathrm{sPLA}_{2}(+/+)\right]$ and C57BL/6 $\left[\mathrm{sPLA}_{2}(-/-)\right]$ strain.

\begin{tabular}{|c|c|c|}
\hline & $s P L A_{2}(+/+)$ & $s P L A_{2}(-/)$ \\
\hline $\mathrm{CO}\left(\mathrm{ml} \cdot \mathrm{min}^{-1} \cdot \mathrm{g}^{-1}\right)$ & $49.0 \pm 8.9$ & $52.3 \pm 11.0$ \\
\hline$A O F\left(\mathrm{ml} \cdot \mathrm{min}^{-1} \cdot \mathrm{g}^{-1}\right)$ & $37.9 \pm 7.1$ & $44.3 \pm 7.8$ \\
\hline$C F\left(\operatorname{ml} \cdot \min ^{-1} \cdot g^{-1}\right)$ & $7.4 \pm 1.3$ & $8.0 \pm 1.6$ \\
\hline$L V D P(m m ~ H g)$ & $68 \pm 9$ & $86 \pm 14^{*}$ \\
\hline LVSP $(m m ~ H g)$ & $85 \pm 9$ & $97 \pm 15^{*}$ \\
\hline$L V E D P(\mathrm{~mm} \mathrm{Hg})$ & $7 \pm 4$ & $5 \pm 3$ \\
\hline$L V d P / d t_{\max }\left(m m H g \cdot s^{-1}\right)$ & $6,461 \pm 1,398$ & $8,578 \pm 1,734 *$ \\
\hline$L V d P / d t_{\min }\left(m m H g . s^{-1}\right)$ & $-3,435 \pm 434$ & $-4,102 \pm 545^{*}$ \\
\hline
\end{tabular}

Data are expressed as means $\pm \operatorname{SD}\left(n=9\right.$ and 8 for $\operatorname{sPLA}_{2}(+/+)$ and $\operatorname{sPLA}_{2}(-/-)$, respectively). Isolated hearts were perfused in the antegrade mode at a pre and afterload

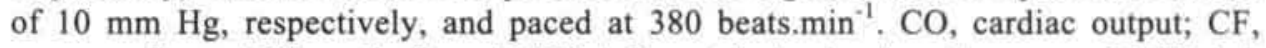
coronary flow; AOF, aortic flow; LVDP, left ventricular developed pressure; LVSP, left ventricular systolic pressure; LVEDP, left ventricular end-diastolic pressure; LV $\mathrm{dP} / \mathrm{dt}_{\max }$, first maximal derivative of left ventricular pressure; $\mathrm{LV} \mathrm{dP} / \mathrm{dt}_{\min }$, first minimal derivative of left ventricular pressure. ${ }^{*}$ indicates $\mathrm{P}<0.05$ between $\operatorname{sPLA}_{2}(+/+)$ and $\operatorname{sPLA}_{2}(-/-)$.

a perfusion pressure of $50 \mathrm{~mm} \mathrm{Hg}$ for $10 \mathrm{~min}$. The left atrial conduit was re-opened and the hearts were allowed to work in the antegrade mode at a preload pressure of $10 \mathrm{~mm} \mathrm{Hg}$ and a diastolic aortic pressure of $50 \mathrm{~mm} \mathrm{Hg}$ for an additional $50 \mathrm{~min}$. Except for the ischemic period and during the first $5 \mathrm{~min}$ of retrograde perfusion in the reperfusion phase, the hearts were paced throughout the whole experiment at a frequency of 380 beats. $\min ^{-1}$ that was slightly higher than their intrinsic denervated heart rate. Coronary perfusate was collected and samples were immediately frozen in liquid nitrogen and stored at $-80^{\circ} \mathrm{C}$ for further biochemical analysis. To stabilize lactate dehydrogenase (LDH) activity in coronary effluent samples, bovine serum 
albumin was included (final concentration 3\%). After completion of the experimental protocol the ventricles of the individual hearts were separated from the atria and immediately frozen between aluminum clamps, previously cooled in liquid nitrogen, and stored at $-80{ }_{i} \mathrm{C}$ for further analysis.

\section{Biochemical analysis}

LDH content in the coronary perfusate were assessed spectrophotometrically using a Cobas Bio autoanalyzer as described earlier (Bergmeyer and Bernt et al., 1974).

Tissue content of adenine and guanine nucleotides, IMP, nucleosides, (oxy)purines and (phospho)creatine was determined by high-performance liquid chromatography (Varian Vista 5500 HPLC) as described previously in detail (Chapter 6 and Van Bilsen et al., 1989a).

The determination of cardiac fatty acids, phospholipids and triacylglycerols was performed by thin-layer chromatography followed by gas chromatography as recently described in detail (Van der Vusse and Roemen, 1995).

All values were expressed as moles per gram dry weight tissue. Dry weight was determined in a subset of hearts by freeze drying overnight and amounted to $14.6 \%$ of wet weight, which corresponds to a conversion factor of 6.85 for wet weight to dry weight murine ventricular tissue.

\section{Statistical analysis}

The results are presented as mean values - standard deviations (SD). All statistical analyses were performed using InStat 3.0 software (GraphPad Software Inc., San Diego, Ca). Changes in functional variables were statistically analyzed by repeated measures ANOVA with Tukey s HSD post-hoc correction test for multiple comparisons. Differences between values of functional variables between experimental groups were analyzed using one-way ANOVA followed by the Tukey s test. Differences between values of biochemical parameters were tested using Student s t-test. In all tests significance was accepted at $P$ values $<0.05$.

\section{Results}

\section{Genotyping}

To confirm thymidine insertional mutation in exon 3 of the pla2ga gene in the inbred C57BL/6 strain and its absence in the inbred C57BL/Ks strain, exon 3 was amplified from a number of individual mice from both strains and digested with BamHI. Full length genomic PCR products from both strains were of the expected length of $500 \mathrm{bp}$. The C57BL/6 exon 3 PCR fragments could not be digested by BamHI, indicating disruption of the wildtype BamHI site, while digestion of the C57BL/Ks PCR products resulted in two cleavage signals of 300 and $200 \mathrm{bp}$, respectively (Figure 1). In the remainder of this chapter C57BL/Ks and C57BL/6 mice are referred to as $\operatorname{sPLA}_{2}(+/+)$ and $\operatorname{sPLA}_{2}(-/)$ mice, respectively. Table I presents some morphometric characteristics (age, body weight, heart weight) of the mice used in the present study. It should be noted that the $\mathrm{sPA}_{2}(+/+)$ mice used in the present study had substantially lower heart and body weights as the $\operatorname{SPLA}_{2}(-/-)$ 
mice, which partially may be related to small differences in age and/or vendors of the inbred mice (Table I).

\section{Functional recovery}

Pre-ischemic values of the hemodynamic variables tested of both experimental groups are presented in Table II. No significant differences were found in absolute pre-ischemic CF and LVEDP values between the two groups tested. Absolute values for $\mathrm{CO}, \mathrm{AOF}, \mathrm{LVSP}, \mathrm{LV} \mathrm{dP} / \mathrm{dt}_{\max }$ and $\mathrm{LV} \mathrm{dP} / \mathrm{dt}_{\min }$ were significantly lower for hearts from sPLA $\mathrm{A}_{2}(+/+)$ than for $\mathrm{SPLA}_{2}(-/-)$ hearts. When corrected for heart weight, however, $\mathrm{CO}$ and $\mathrm{AOF}$ were comparable between both strains and amounted to $49.0 \pm 8.9$ and $37.9 \pm 7.1 \mathrm{ml} \cdot \mathrm{min}^{-1} \cdot \mathrm{g}^{-1}$ for $\mathrm{sPLA}_{2}(+/+)$ hearts and 52.3 \pm 11.0 and $44.3 \pm 7.8 \mathrm{ml} \cdot \mathrm{min}^{-1} \cdot \mathrm{g}^{-1}$ for sPLA $_{2}(-/-)$ hearts, respectively (N.S.). Preischemic CF normalized to heart weight amounted to $7.4 \pm 1.3$ and $8.0 \pm 1.6$ ml.min ${ }^{-1} \cdot \mathrm{g}^{-1}$ for $\mathrm{sPLA}_{2}(+/+)$ and $\operatorname{sPLA}_{2}(-/-)$ hearts, respectively $(\mathrm{P}<0.05$; Table II)).

\section{Table III}

Percentage recovery of hemodynamic parameters of $\operatorname{sPLA}_{2}(+/+)$ and $\operatorname{sPLA}_{2}(-/-)$ hearts following $17.5 \mathrm{~min}$ of ischemia and $60 \mathrm{~min}$ of reperfusion.

\begin{tabular}{lll}
\hline & $s P L A_{2}(+/+)$ & $s P L A_{2}(-/-)$ \\
\cline { 2 - 3 } CO & $37 \pm 23$ & $39 \pm 25$ \\
$C F$ & $15 \pm 19$ & $21 \pm 34$ \\
$L V D P$ & $127 \pm 46$ & $104 \pm 58$ \\
$L V S P$ & & \\
$L V E D P$ & $69 \pm 21$ & $57 \pm 27$ \\
$L V d P / d t_{\max }$ & $76 \pm 15$ & $68 \pm 25$ \\
$L V d P / d t_{\min }$ & $253 \pm 15$ & $231 \pm 105$ \\
& $65 \pm 18$ & $70 \pm 32$ \\
& $67 \pm 24$ & $55 \pm 29$
\end{tabular}

Data are expressed as means $\pm \mathrm{SD}\left(\mathrm{n}=9\right.$ and 8 for $\operatorname{sPLA}_{2}(+/+)$ and $\operatorname{sPLA}_{2}(-/-)$, respectively). Isolated hearts were perfused in the antegrade mode at a pre and afterlaod of $10 \mathrm{~mm} \mathrm{Hg}$, respectively, and paced at 380 beats. $\mathrm{min}^{-1}$. CO, cardiac output; CF, coronary flow; AOF, aortic flow; LVDP, left ventricular developed pressure; LVSP, left ventricular systolic pressure; LVEDP, left ventricular end-diastolic pressure; LV dP/dt $t_{\max }$, first maximal derivative of left ventricular pressure; $\mathrm{LV} \mathrm{dP} / \mathrm{dt}_{\min }$, first minimal derivative of left ventricular pressure. ${ }^{*}$ indicates $\mathrm{P}<0.05$ between $\operatorname{sPLA}_{2}(+/+)$ and $\operatorname{sPLA}_{2}(-/-)$. 
Following $17.5 \mathrm{~min}$ of global, normothermic ischemia and $60 \mathrm{~min}$ of reperfusion $\mathrm{CO}$ recovered to $19.6 \pm 16.8$ and $20.4 \pm 13.9 \mathrm{ml} \cdot \mathrm{min}^{-1} \cdot \mathrm{g}^{-1}$, representing $37 \pm 23$ and $39 \pm 25 \%$ of the corresponding pre-ischemic values in sPLA $_{2}(+/+)$ and $\operatorname{sPLA}_{2}(-/-)$ hearts, respectively (N.S.). LVDP values recovered to $46 \pm 13$ and $47 \pm 19 \mathrm{~mm} \mathrm{Hg}$ at the end of the reperfusion period in wildtype and type IIA sPLA $\mathrm{P}_{2}$ deficient hearts, respectively (N.S.). The decrease in postischemic LVDP was caused by both a rise in LVEDP and a reduction of LVSP, which decreased to $64 \pm 14$ and $64 \pm 25 \mathrm{~mm}$ $\mathrm{Hg}$ in $\mathrm{sPLA}_{2}(+/+)$ and sPLA $(-/-)$ hearts following 60 min of reperfusion $(\mathrm{P}<$ 0.05 vs pre-ischemia; Table III). In both groups, post-ischemic $L V \mathrm{dP} / \mathrm{dt}_{\max }$ and LV $\mathrm{dP} / \mathrm{dt}_{\min }$ were substantially reduced in the acute reperfusion phase as compared to their pre-ischemic values and amounted to $4240 \pm 1507$ and $-2306 \pm 841 \mathrm{~mm} \mathrm{Hg} . \mathrm{s}^{-1}$ for $\operatorname{sPLA}_{2}(+/+)$ and $4527 \pm 2085$ and $-2748 \pm 1058 \mathrm{~mm} \mathrm{Hg} \cdot \mathrm{s}^{-1}$ for $\mathrm{sPLA}_{2}(-/-)$ hearts, respectively (Table III).

\section{Enzyme release}

To measure the extent of irreversibly damaged cardiac muscle cells following ischemia and reperfusion, the release of LDH into the coronary effluent was continuously monitored throughout the experimental protocol. Pre-ischemic LDH

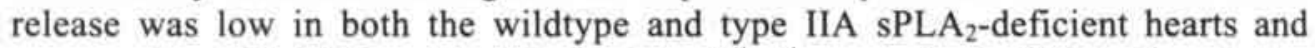
amounted to $162 \pm 113$ and $148 \pm 51 \mathrm{mU} \cdot \mathrm{min}^{-1} \cdot \mathrm{g}^{-1}$, respectively (N.S.). Cumulative LDH release collected during $60 \mathrm{~min}$ of reperfusion was not significantly different between the two strains $\left(10526 \pm 3610\right.$ and $11306 \pm 3545 \mathrm{mU} \cdot \mathrm{g}^{-1}$ wet heart weight for $\mathrm{SPLA}_{2}(+/+)$ and $\mathrm{sPLA}_{2}(-/-)$ hearts, respectively (N.S.).

\section{Metabolic recovery}

Post-ischemic values of ventricular ATP content in SPLA $_{2}(+/+)$ and $\operatorname{sPLA}_{2}(-/-)$ amounted to $8.2 \pm 2.3$ and $10.3 \pm 3.5 \mu \mathrm{mol}^{-1} \mathrm{~g}^{-1}$ dry weight tissue, respectively. ADP and AMP values were low and comparable in both strains (Table IV). The adenylate energy charge (EC) amounted to $0.79 \pm 0.04$ and $0.83 \pm 0.05$ for $\mathrm{sPLA}_{2}(+/+)$ and sPLA $_{2}(-/-)$ hearts, respectively (N.S.). No significant differences were observed either between the two groups for total tissue glycogen content at the end of reperfusion. Tissue content of small molecular weight degradation products such as (oxy)purines and lactate were low and comparable in both groups (Table IV).

\section{Fatty acids, phospholipids, triacylglycerols}

Pre-ischemic total fatty acid (FA) levels were low and comparable in pre-ischemic sPLA $_{2}(+/+)$ and sPLA ${ }_{2}(-/-)$ hearts $\left(198 \pm 80\right.$ and $334 \pm 127$ nmol.g ${ }^{-1}$ dry weight, respectively; N.S.). Similarly, no significant differences were either found in preischemic arachidonic acid levels in the pre-ischemic myocardium of both strains (Table V). Total fatty acid levels significantly increased following ischemia and reperfusion in both groups and amounted to $2671 \pm 1151$ and $2683 \pm 911 \mathrm{nmol} . \mathrm{g}^{-1}$ dry weight for $\mathrm{sPLA}_{2}(+/+)$ and $\mathrm{sPLA}_{2}(-/-)$ hearts, respectively (Table V). Among the most abundant saturated FA species to accumulate were palmitic $(\mathrm{C} 16: 0)$ and stearic acid (C18:0), each representing about $20 \%$ of total accumulated FA (Table $\mathrm{V})$. Of the individual poly-unsaturated FA species accumulating in the postischemic heart the majority was comprised of linoleic acid (C18:2) and 
docosahexaenoic acid (C22:6); about 20 and $13 \%$, respectively in both groups (Table IV). No significant differences with respect to the arachidonic acid (AA; C20:4) levels, a sensitive marker reflecting membrane phospholipid degradadion, was found between the two mouse strains. The tissue content of AA at the end of the reperfusion period amounted to $70 \pm 32$ and $107 \pm 87 \mathrm{nmol}^{-1} \mathrm{~g}^{-1}$ dry weight for sPLA $_{2}(+/+)$ and sPLA $(-/-)$ hearts, respectively, representing $2.6 \pm 0.3$ and $3.6 \pm$ $1.7 \%$ of the total post-ischemic tissue FA pool, respectively (Table V).

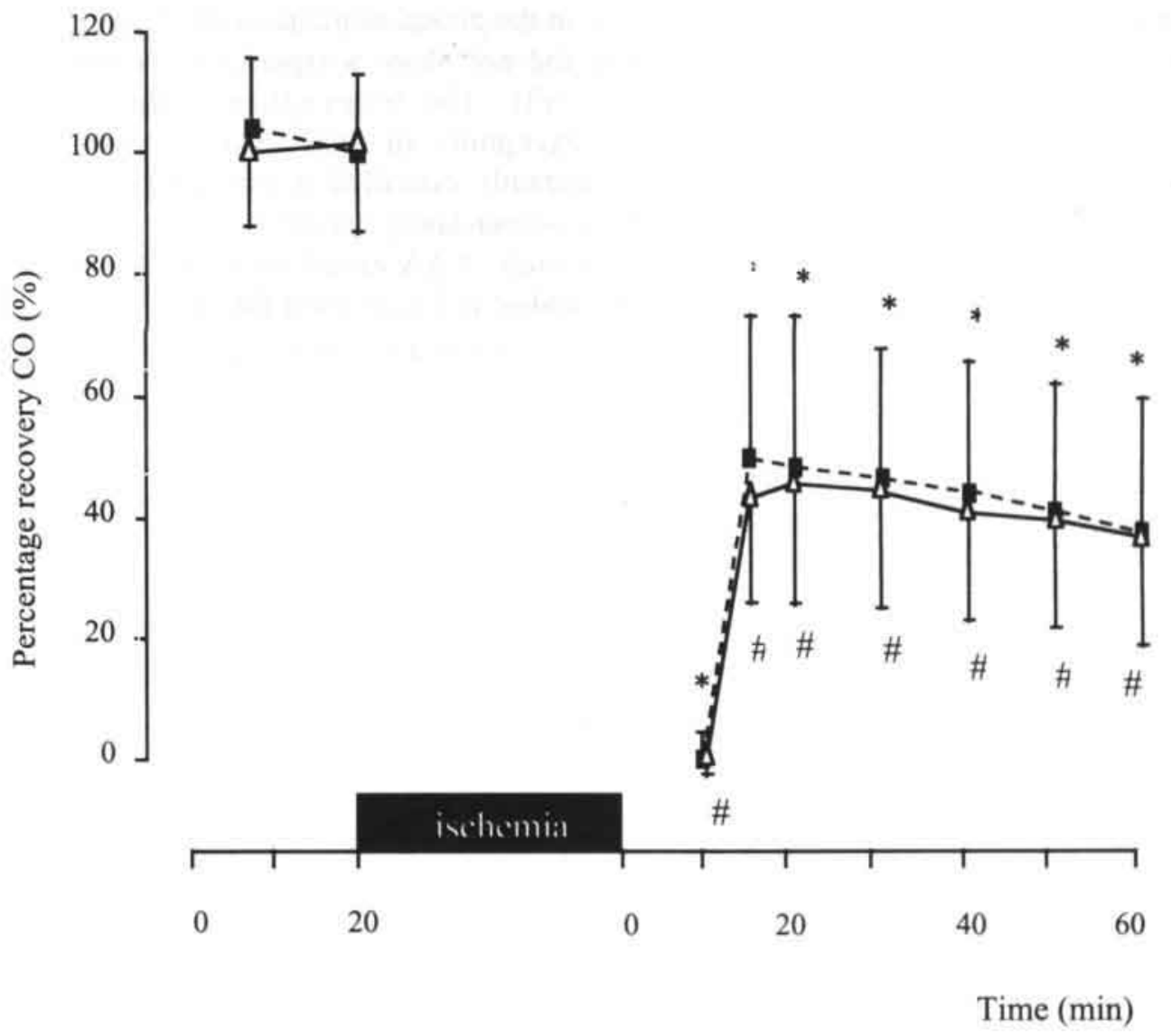

Figure 2

Post-ischemic recovery of cardiac output $(\mathrm{CO})$ of isolated ejecting $\mathrm{SPLA}_{2}(+/+)$ (closed rectangles) and SPLA $_{2}(-/)$ hearts (open triangles) following $17.5 \mathrm{~min}$ of normothermic no-flow ischemia. Data are expressed as means - SD $\left(\mathrm{n}=10\right.$ and 11 for $\operatorname{SPLA}_{2}(+/+)$ and $\operatorname{sPLA}_{2}(-/)$ hearts, respectively). * indicates $\mathrm{P}<0.05$ vs respective pre-ischemic value of sPLA $_{2}(+/+)$ hearts, \# indicates $\mathrm{P}<0.05$ vs respective pre-ischemic value of $\operatorname{sPLA}_{2}(-/-)$ hearts. 
Pre-ischemic total cardiac phospholipid (PL) and triacylglycerol (TG) levels were comparable between both strains (Table VI and VII). Total post-ischemic phospholipid and triacylglycerol content did not differ between the two groups and amounted to $170 \pm 22$ and $174 \pm 9 \mu \mathrm{mol} . \mathrm{g}^{-1}$ dry weight for total PL content and $34 \pm$ 11 and $38 \pm 10 \mu \mathrm{mol} . \mathrm{g}^{-1}$ dry weight for total TG content in $\mathrm{sPLA}_{2}(+/+)$ and $\mathrm{SPLA}_{2}$ $(-/-)$ hearts, respectively. The fatty acyl composition of both esterified lipid pools did not differ between hearts from both strains (Table VI). The total amount of fatty acids esterified at the glycerol backbone via an ether bond was low in both strains and amounted to $4.0 \pm 3.2$ and $4.5 \pm 3.6 \%$ of FA present in the PL pool of sPLA $(+/+)$ and sPLA $_{2}(-/-)$ hearts, respectively. Among the most abundant FA species esterified in the PL pool were palmitic, stearic, linoleic and docosahexaenoic acid, each representing about $20 \%$ of the total amount of esterified FA. AA accounted for $6.3 \pm 0.7$ and $6.5 \pm 0.8 \%$ of FA present in the phospholipid pool of $\operatorname{sPLA}_{2}(+/+)$ and SPLA $_{2}(-/)$ hearts, respectively, and did not show a significant difference between the two mouse strains (Table VI). The triacylglycerol fatty acyl composition was different from the PL pool, in that stearic acid and docosahexaenoic acid were much less abundantly esterified in this lipid pool. In general poly-unsaturated FA species were less abundantly present in the TG pool in both mouse strains (Table VI). The total amount of AA esterified in the ischemicreperfused TG pool was very low in both strains and accounted for only $1.6 \pm 0.5$ and $1.7 \pm 0.3 \%$ of total FA species in sPLA ${ }_{2}(+/+)$ and sPLA $_{2}(-/-)$ hearts (N.S.).

\section{Table IV}

Ventricular high energy phosphate, (oxy)purine, glycogen and lactate content of reperfused $\operatorname{sPLA}_{2}(+/+)$ and $\operatorname{sPLA}_{2}(-/)$ hearts.

$$
s P L A_{2}(+/+) \quad s P L A_{2}(-/)
$$

$\begin{array}{lll}A T P & 8.2 \pm 2.3 & 10.3 \pm 3.5 \\ A D P & 3.4 \pm 0.4 & 3.1 \pm 0.5 \\ A M P & 0.8 \pm 0.3 & 1.0 \pm 1.1 \\ E C & 0.79 \pm 0.04 & 0.83 \pm 0.05 \\ \text { (oxy)purines } & 0.08 \pm 0.10 & 0.03 \pm 0.04 \\ \text { glycogen } & 232 \pm 50 & 259 \pm 99 \\ \text { lactate } & 19.5 \pm 9.3 & 23.6 \pm 19.8\end{array}$

Data are expressed as means $\pm \mathrm{SD}$ in $\mu \mathrm{mol} . \mathrm{g}^{-1}$ dry weight from ventricular tissue freeze clamped following $17.5 \mathrm{~min}$ of ischemia and $60 \mathrm{~min}$ of reperfusion $(\mathrm{n}=9$ and $\mathrm{n}=8$ for sPLA $_{2}(+/+)$ and $\mathrm{PLA}_{2}(-/-)$ hearts, respectively). EC, energy charge and is defined as $(\mathrm{ATP}+0.5 \mathrm{ADP}) /(\mathrm{ATP}+\mathrm{ADP}+\mathrm{AMP})$ and is unitless; (oxy)purines are defined as the sum of adenosine, inosine, hypoxanthine and xanthine. 


\section{Discussion}

In the present study the role of type IIA secretory phospholipase $\mathrm{A}_{2}$ (type IIA $\mathrm{sPLA}_{2}$ ) in cardiac ischemia/reperfusion-induced loss of function and phospholipid degradation was explored by using isolated, left ventricular-ejecting mouse hearts derived from the inbred $\mathrm{C} 57 \mathrm{BL} / \mathrm{Ks}$ and $\mathrm{C} 57 \mathrm{BL} / 6$ mouse strains, the latter mouse

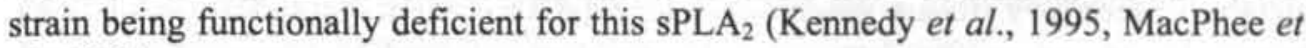
al., 1995).

\section{Table V}

Total tissue content and fatty acyl composition of the (unesterified) fatty acid pool of preischemic and ischemic-reperfused sPLA $\mathrm{PL}_{2}(+/)$ and $\operatorname{sPLA}_{2}(-/-)$ hearts.

\begin{tabular}{|c|c|c|c|c|}
\hline & \multicolumn{2}{|c|}{$s P L A_{2}(+/+)$} & \multicolumn{2}{|c|}{$s P L A_{2}(-/-)$} \\
\hline & Pre & $I / R$ & Pre & $I / R$ \\
\hline Total & $198 \pm 80$ & $2,671 \pm 1,151 *$ & $334 \pm 127$ & $2,683 \pm 911^{*}$ \\
\hline 16:0 & $35 \pm 25$ & $594 \pm 240 *$ & $59 \pm 24$ & $586 \pm 206^{*}$ \\
\hline $16: 1$ & - & $29 \pm 16$ & - & $32 \pm 15$ \\
\hline 18:0 & $43 \pm 16$ & $533 \pm 213^{*}$ & $59 \pm 22$ & $518 \pm 121^{*}$ \\
\hline $18: 1$ & $35 \pm 12$ & $459 \pm 226^{*}$ & $42 \pm 21$ & $518 \pm 121^{*}$ \\
\hline $18: 2$ & $30 \pm 11$ & $554 \pm 315^{*}$ & $35 \pm 11$ & $520 \pm 231^{*}$ \\
\hline $20: 0$ & - & $11 \pm 10$ & - & $31 \pm 40$ \\
\hline $20: 4$ & $3 \pm 5$ & $70 \pm 32 *$ & $9 \pm 14$ & $107 \pm 87^{*}$ \\
\hline $22: 4$ & - & $3 \pm 6$ & - & $3 \pm 5$ \\
\hline $22: 6$ & $47 \pm 29$ & $345 \pm 160 *$ & $74 \pm 26$ & $337 \pm 93 *$ \\
\hline
\end{tabular}

Data are expressed as means $\pm \mathrm{SD}$ in nmol. $\mathrm{g}^{-1}$ dry weight ventricular tissue $(\mathrm{n}=5$ and $\mathrm{n}=6$ for pre-ischemic $\mathrm{SPLA}_{2}(+/+)$ and $\operatorname{sPLA}_{2}(-/-)$ hearts, respectively; $\mathrm{n}=9$ and $\mathrm{n}=8$ for reperfused sPLA $_{2}(+/+)$ and sPLA $_{2}(-/-)$ hearts, respectively). Pre: pre-ischemic, I/R: ischemic-reperfused. Individual fatty acids are denoted by their chemical notation. - notdetectable. ${ }^{*}$ indicates $\mathrm{P}<0.05$ vs corresponding pre-ischemic value. 
Although pre-ischemic values of a number of functional parameters in C57BL/6 hearts were slightly but significantly higher as compared to those in C57BL/Ks hearts, post-ischemic percentual functional recovery was comparable between the two strains. Similarly, the amount of irreversibly damaged cardiac muscle cells, as assessed by the extent of LDH release into the coronary effluent, was comparable between the two strains. In addition, no significant differences were observed in metabolic recovery, tissue arachidonic acid (AA) content, total fatty acid (FA) accumulation, or in the fatty acyl composition of cardiac phospholipids and triacylglycerols between hearts from both strains. The data in the present study argue against a major role of type IIA sPLA ${ }_{2}$ in acute ischemia and reperfusioninduced AA accumulation, cellular injury and loss of function.Aim of the present study was to determine whether type ILA sPLA ${ }_{2}$ plays a significant role in cardiac membrane phospholipid degradation as reflected by AA accumulation during experimental ischemia and reperfusion at the intact organ level. Potential experimental caveats of the present study might be caused by the fact that some differences in age and pre-ischemic hemodynamic values were observed between the experimental groups, the latter difference not being easily explainable by the age factor. However, in the present study we preferred randomization of the perfusion experiments with the $\operatorname{sPLA}_{2}(+/+)$ and $\mathrm{sPLA}_{2}(-/-)$ mice over agematching of the two experimental groups. Although the two mouse strains are genetically identical for $86 \%$ (Naggert et al., 1995, Lueders, 1995, Kennedy et al., 1997), it can not be excluded that the remaining unidentical $14 \%$ of the genome might account for undetermined phenotypical differences which might precipitate in differences in cardiac ischemia tolerance, if any, between the two strains. A more laborious approach to avoid this potential caveat would involve back-crossing of the mutation into the wildtype genotype or the creation of a targeted disruption of the pla2ga gene in a pla2ga genetic wildtype background (Kennedy et al., 1997).

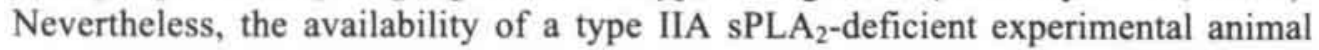
model has enabled a number of groups to demonstrate the specific contribution of this enzyme in cellular prostaglandin generation (Reddy et al., 1997, Murakami et al., 1997), intestinal tumorigenesis (Cormier et al., 1997) and the gastric epithelial response to Helicobacter infection (Wang et al., 1998). We used a similar experimental approach and demonstrated that complete absence of functional type IIA sPLA $\mathrm{A}_{2}$ failed to attenuate ischemia and reperfusion-induced AA accumulation, irreversible cell damage and functional recovery. These findings therefore present for the first time evidence against a significant role for type IIA sPLA $\mathrm{A}_{2}$ in cardiac membrane phospholipid degradation as observed during ischemia and reperfusion at the whole organ level. 


\section{Table VI}

Total tissue content and fatty acyl composition of the tissue phospholipid pool in preischemic and ischemic-reperfused sPLA ${ }_{2}(+/+)$ and $\operatorname{sPLA}_{2}(-/)$ hearts.

\begin{tabular}{|c|c|c|c|c|}
\hline & \multicolumn{2}{|c|}{$s P L A_{2}(+/+)$} & \multicolumn{2}{|c|}{$s P L A_{2}(-/)$} \\
\hline & Pre & $I / R$ & Pre & $I / R$ \\
\hline Total & $180 \pm 21$ & $170 \pm 22$ & $171 \pm 23$ & $174 \pm 9$ \\
\hline 14:0 & $0.2 \pm 0.0$ & $0.2 \pm 0.0$ & $0.2 \pm 0.0$ & $0.2 \pm 0.0$ \\
\hline 16:0 & $17.5 \pm 0.3$ & $17.8 \pm 0.6$ & $17.7 \pm 0.3$ & $17.7 \pm 0.7$ \\
\hline $16: 0_{P L}$ & $1.7 \pm 0.3$ & $1.2 \pm 1.3$ & $2.1 \pm 0.3$ & $1.3 \pm 1.2$ \\
\hline $16: 1$ & $0.5 \pm 0.1$ & $0.4 \pm 0.0$ & $0.5 \pm 0.1$ & $0.4 \pm 0.1$ \\
\hline 18:0 & $17.7 \pm 0.4$ & $19.5 \pm 2.6$ & $17.7 \pm 0.2$ & $19.2 \pm 2.4$ \\
\hline $18: 0_{P L}$ & $1.0 \pm 0.3$ & $0.6 \pm 0.6$ & $1.3 \pm 0.2$ & $0.7 \pm 0.6$ \\
\hline 18:1 & $8.9 \pm 0.4$ & $9.1 \pm 0.5$ & $9.5 \pm 0.4$ & $9.6 \pm 0.6$ \\
\hline $18: 1_{P L}$ & $0.4 \pm 0.1$ & $0.2 \pm 0.2$ & $0.5 \pm 0.1$ & $0.3 \pm 0.3$ \\
\hline 18:2 & $17.0 \pm 0.1$ & $18.6 \pm 0.6 *$ & $16.3 \pm 0.3^{\#}$ & $18.1 \pm 0.7^{*}$ \\
\hline $20: 4$ & $6.4 \pm 0.3$ & $6.3 \pm 0.7$ & $6.5 \pm 0.3$ & $6.5 \pm 0.8$ \\
\hline $22: 6$ & $26.4 \pm 0.9$ & $24.1 \pm 0.8$ & $25.4 \pm 1.2$ & $24.1 \pm 0.9$ \\
\hline
\end{tabular}

Total amounts are given in $\mu$ mol.g ${ }^{-1}$ dry weight ventricular tissue and fatty acyl composition is given as relative composition (in \%). Data are expressed as means $\pm \mathrm{SD}$ ( $\mathrm{n}$ $=5$ and $\mathrm{n}=6$ for pre-ischemic values for $\mathrm{sPLA}_{2}(+/+)$ and $\mathrm{sPLA}_{2}(-/-)$ hearts, respectively; $\mathrm{n}=8$ for both ischemic-reperfused sPLA $\mathrm{PL}_{2}(+/+)$ and $\mathrm{sPLA}_{2}(-/-)$ hearts). $P L$ indicates the plasmalogen form of the particular fatty acid. Phospholipids are expressed as fatty acyl equivalents. * indicates $\mathrm{P}<0.05$ vs corresponding pre-ischemic value, \# indicates $\mathrm{P}<0.05$ corresponding lipid pool of different genotype. 
Type IIA sPLA $\mathrm{A}_{2}$ has been implicated as a candidate for cardiac ischemia/reperfusion induced membrane phopholipid degradation because of its $\mathrm{Ca}^{2+}$-dependency and non-specific hydrolytic action towards phopholipids (Van Bilsen et al., 1995, De Windt et al., 1998). In accordance with this notion it was found that in the postischemic rat or mouse heart, accumulation of individual FA species is not confined to AA only, but demonstrates a more general elevation of all major FA species present in the phospholipid pool (Van Bilsen et al., 1989b, Chapter 6). Moreover, earlier studies have demonstrated that antibodies raised against type IIA SPLA ${ }_{2}$ and chemical inhibition resulted in a reduction of both ischemia and reperfusioninduced membrane degradation and cellular damage of the rat heart (Das et al., 1986, Prasad et al., 1991).

\section{Table VII}

Total tissue content and fatty acyl composition of the tissue triacylglycerol pool in preischemic and ischemic-reperfused sPLA $(+/+)$ and PPLA $_{2}(-/-)$ hearts.

\begin{tabular}{|c|c|c|c|c|}
\hline & \multicolumn{2}{|c|}{$s P L A_{2}(+/+)$} & \multicolumn{2}{|c|}{$s P L A_{2}(-/-)$} \\
\hline & Pre & $I / R$ & Pre & $L / R$ \\
\hline Total & $31 \pm 7$ & $34 \pm 11$ & $36 \pm 10$ & $38 \pm 10$ \\
\hline $14: 0$ & $1.4 \pm 0.4$ & $1.2 \pm 0.1$ & $1.2 \pm 0.2$ & $1.3 \pm 0.2$ \\
\hline $16: 0$ & $20.1 \pm 2.1$ & $18.2 \pm 2.2$ & $18.7 \pm 0.7$ & $18.2 \pm 2.9$ \\
\hline 16:1 & $2.0 \pm 0.7$ & $0.8 \pm 0.2 *$ & $1.4 \pm 0.3$ & $0.9 \pm 0.1^{*}$ \\
\hline $18: 0$ & $5.0 \pm 0.6$ & $4.0 \pm 0.4^{*}$ & $4.6 \pm 0.1$ & $4.0 \pm 0.3^{*}$ \\
\hline 18:1 & $29.5 \pm 2.1$ & $24.3 \pm 2.9$ & $27.2 \pm 1.5$ & $25.5 \pm 2.2$ \\
\hline $18: 2$ & $28.8 \pm 1.8$ & $34.5 \pm 2.1^{*}$ & $28.6 \pm 1.7$ & $36.2 \pm 1.2^{*}$ \\
\hline $20: 4$ & $1.1 \pm 0.3$ & $1.6 \pm 0.5$ & $1.1 \pm 0.2$ & $1.7 \pm 0.3$ \\
\hline $22: 6$ & $8.4 \pm 3.0$ & $10.9 \pm 4.6$ & $12.7 \pm 1.9$ & $8.4 \pm 2.4$ \\
\hline
\end{tabular}

Total amounts are given in $\mu$ mol.g ${ }^{-1}$ dry weight ventricular tissue and fatty acyl composition is given as relative composition (in \%). Data are expressed as means $\pm \mathrm{SD}$ $\left(\mathrm{n}=5\right.$ and $\mathrm{n}=6$ for pre-ischemic values for $\operatorname{sPLA}_{2}(+/+)$ and $\operatorname{sPLA}_{2}(-/-)$ hearts, respectively; $\mathrm{n}=8$ for both ischemic-reperfused $\operatorname{sPLA}_{2}(+/+)$ and $\operatorname{sPLA}_{2}(-/-)$ hearts). triacylglycerols are expressed as fatty acyl equivalents. ${ }^{*}$ indicates $\mathrm{P}<0.05$ vs corresponding pre-ischemic value. 
Furthermore, since reperfusion is associated with an elevation of intracellular $\mathrm{Ca}^{2+}$, the involvement of this $\mathrm{Ca}^{2+}$-dependent, nonspecific hydrolytic enzyme was anticipated. The present study clearly demonstrates, however, that a complete functional absence of type IIA sPLA ${ }_{2}$ neither results in a reduction of membrane phospholipid degradation as measured by the tissue AA content, nor in a reduction in the degree of cellular injury or post-ischemic functional recovery.Among the other candidate cardiac PLA $\mathrm{A}_{2}$ enzymes responsible for ischemia/reperfusion-induced phospholipid hydrolysis are type V sPLA $A_{2}$, type IV cPLA ${ }_{2}$ and type VI iPLA all other major mammalian $\mathrm{PLA}_{2}$ species (type IB sPLA $A_{2}$, type IIC sPLA ${ }_{2}$ and type $\mathrm{X} \mathrm{sPLA}{ }_{2}$ ) remain to be detected in cardiac tissue (Tischfield et al., 1997). In light of the present study, the identification, cloning and characterization of the other low molecular weight, $\mathrm{Ca}^{2+}$-dependent secretory phospholipase $\mathrm{A}_{2}$ (type $\mathrm{V}$ sPLA $\mathrm{S}_{2}$ ) abundantly present in the heart is of interest (Chen et al., 1994, Chen et al., 1998). Recent characterization of the recombinant human enzyme indicated a limited fatty acid preference of linoleoyl > palmitoyl > arachidonoyl acyl moieties at the $s n-2$ position of PE and PC (Chen et al., 1998). More importantly, it was demonstrated that both $\mathrm{SPLA}_{2} \mathrm{~s}$ are functionally redundant to each other in terms of $\mathrm{AA}$ liberation (Murakami et al., 1998). Therefore, It is feasible that type IIA and type V sPLA 2 fulfill similar redundant functions in the heart as far as ischemia and reperfusioninduced AA or FA accumulation, lysophospholipid accumulation and concomitant cellular damage are concerned. The individual relevance and relationship between both cardiac $\mathrm{SPLA}_{2}$ enzymes remains subject to future experimental study.

Interestingly, targeted disruption of the intracellularly located type IV cPLA $_{2}$ resulted in a significant reduction of post-ischemic brain infarct size in the mouse (Bonventre et al., 1997). Because of its intracellular localization and specificity towards arachidonoyl acyl moieties in diacyl phospholipid species, a role of this particular enzyme in cardiac ischemia and reperfusion-induced AA liberation and cellular injury has as yet not been anticipated (Van der Vusse et al., 1997, De Windt et al., 1998). Regarding the promising results obtained in the ischemic brain (Bonventre et al., 1997), however, a more thorough investigation of the role of this enzyme in the ischemic-reperfused heart seems justified and the focus of future studies.

Finally, Hazen and coworkers have demonstrated that the activity of type VI iPLA $A_{2}$ is greatly enhanced soon after the onset of cardiac ischemia (Hazen et al., 1991), making this plasmalogen-specific enzyme another candidate for ischemia and reperfusion-induced membrane anomalies in the heart. The significance of this particular $\mathrm{PLA}_{2}$ in ischemia and reperfusion-associated phospholipid degradation and cardiac muscle cell death is subject of debate, however, since a number of studies demonstrated that the diacyl form rather than the plasmalogen form of phospholipids is subject to hydrolysis, while Davis and coworkers demonstrated that the levels of lysoplasmenylcholine and lysoplasmenylethanolamine did not increase in the ischemic rat heart (Davies et al., 1992). Additionally, the time course of arachidonic acid accumulation during reperfusion does not coincide with that of type VI iPLA 2 , since the activity of this enzyme quickly goes down to normal levels after ischemia, whereas AA continues to accumulate (Van der Vusse et al., 1982, Van Bilsen et al., 1989, De Windt et al., 1999). Furthermore, Vesterqvist and 
colleagues reported a marked decrease in type VI iPLA $A_{2}$ activity in isolated rabbit hearts subjected to a prolonged period of global ischemia, using intact isolated sarcolemmal membranes as substrate to measure enzyme activity, while Hazen and colleagues used exogenously added phospholipid substrates (Hazen et al., 1991, Vesterqvist et al., 1996). The conflicting results might, however, be explained in the light of the different experimental models used. In this way, choline plasmalogen content in the rat heart represents $<2 \%$ of choline phospholipids compared to $57 \%$ in canine and $36 \%$ in human myocardium (Davies et al., 1992). Together with the findings that over $95 \%$ of phospholipase $A_{2}$ activity in the human end-staged failed heart was identified as type VI iPLA 2 (Hazen et al., 1992) and the potent arrhythmogenic properties and slow clearance of plasmalogen-derived lysophospholipids (Gross et al., 1992, Caldwell et al., 1998), a more throrough investigation of the role of type VI iPLA ${ }_{2}$ in the pathophysiological cardiac phospholipid metabolism in different experimental models is certainly required.

Clearly, the individual role of each cardiac $\mathrm{PLA}_{2}$ in phospholipid hydrolysis as observed during ischemia and reperfusion will remain subject of future investigation. In this light, loss-of-function experimental approaches are particularly efficient in delineating the role of each PLA $\mathrm{P}_{2}$ isozyme but does not exclude whether ( PLA $_{2}$-mediated) membrane phospholipid degradation per se might play a pivotal role in the transition from reversible to irreversible injury or whether it merely reflects autolysis of irreversibly damaged cardiac muscle cells (Van der Vusse et al., 1994). Gain-of-function experiments with a pre-existing increased type IIA sPLA $_{2}$ activity as generated previously (Fox et al., 1996, Grass et al., 1996, Nevelainen et al., 1997) might therefore provide a more straightforward approach to study the relevance of membrane phospholipid degradation in the ischemicreperfused heart (De Windt et al., 1998).

In conlusion, the findings in the present study provide evidence against a decisive role of type IIA sPLA ${ }_{2}$ in ischemia/reperfusion-induced arachidonic acid accumulation, cellular injury and cardiac metabolic and functional dysfunction. Future studies using mouse models with either a cardiac-specific overexpression of $\mathrm{PLA}_{2}$ activity or a targeted disruption of other cardiac candidate PLA $\mathrm{A}_{2}$ enzymes might delineate whether PLA $\mathrm{A}_{2}$-mediated phospholipid degradation contributes to the development of ischemia/reperfusion-induced cellular death in vivo and/or which type of $\mathrm{PLA}_{2}$ is involved in this pathophysiological process.

\section{References}

1. Apstein CS, Puchner SE, Brachfeld N. Improved automated lactate determination. Anal Biochem 1970;38: 20-34.

2. Atsumi G, Murakami M, Tajima M, Shimbara S, Hara N, Kudo I. The perturbed membrane of cells undergoing apoptosis is susceptible to type II secretory phospholipase $A_{2}$ to liberate arachidonic acid. Biochim Biophys Acta 1997;1349:43-54.

3. Balsinde J, Dennis EA. Distinct roles in signal transduction for each of the phospholipase $A_{2}$

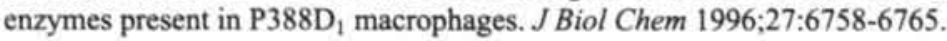


4. Bergmeyer HU, Bernt E. UV assay for lactate dehydrogenase with pyruvate and NADH. In: Methods of Enzymology, Weinheim Verlag Chemie GmbH, 1974; 2: 574-579.

5. Bonventre JV, Huang Z, Taheri MR, O Leary E, Li E, Moskowitz MA, Sapirstein A. Reduced fertility and postischaemic brain injury in mice deficient in cytosolic phospholipase $\mathrm{A}_{2}$. Nature 1997:390:622-625.

6. Caldwell RA, Baumgarten CM. Plasmalogen-derived lysophospholipid induces a depolarizing cation current in rabbit ventricular myocytes. Circ Res 1998;83:533-540.

7. Chen J, Engle SJ, Seilhamer JJ, Tischfield JA. Cloning and recombinant expression of a novel human low molecular weight $\mathrm{Ca}^{2+}$-dependent phospholipase $\mathrm{A}_{2}$. J Biol Chem 1994;269:23652368.

8. Chen $\mathrm{Y}$ and Dennis EA. Expression and characterization of human group $\mathrm{V}$ phospholipase $\mathrm{A}_{2}$. Biochim Biophys Acta 1998;1394:57-64.

9. Chien KR, Han A, Sen A, Buja LM, Willerson JT. Accumulation of unesterified arachidonic acid in ischemic canine myocardium. Relationship to a phosphatidyl deacylation-reacylation cycle and the depletion of membrane phospholipids. Circ Res 1984;54:313-322.

10. Cornier RT, Hong KH, Halberg RB, Hawkins TL, Richardson P, Mulherkar R, Dove WF, Landr ES. Secretory phospholipase Pla2g2a confers resistance to intestinal tumorigenesis. Nat Genet 1997;17:88-91.

11. Corr PB, McHowat J, Yan G, Yamada KA. Lipid-derived amphiphiles and their contribution to arrhythmogenesis during ischemia. In: Physiology and pathophysiology of the heart. Sperelakis N, ed. Boston, Mass: Kluwer Academic Publishers, 1995:527-545.

12. Das DK, Engelman RM, Rousou JA, Breyer RH, Otani H, Lemeshow S. Role of membrane phospholipids in myocardial injury induced by ischemia and reperfusion. Am J Physiol 1986;251:H71-H79.

13. Davies NJ, Schultz R, Olley PM, Strydnadka KD, Panas DL, Lopaschuk GD. Lysoplasmenylethanolamine accumulation in ischemic/reperfused isolated fatty acid-perfused hearts. Circ Res 1992;70:1161-1168.

14. De Windt LJ, Reneman RS, Van der Vusse GJ, Van Bilsen M. Phospholipase $\mathrm{A}_{2}$-mediated hydrolysis of cardiac phospholipids: the use of molecular and transgenic techniques. $\mathrm{Mol} \mathrm{Cell}$ Biochem 1998;180:65-73.

15. De Windt LJ, Willems J, Reneman RS, Van der Vusse GJ, Arts T, Van Bilsen M. An improved isolated, left ventricular ejecting murine heart model. Functional and metabolic evaluation. Pf gers Archiv-Eur J Physiol 1999;437:182-190.

16. De Windt LJ, Willemsen PHM, P pping S, Van der Vusse GJ, Reneman RS, Van Bilsen M. Cloning and cellular distribution of a group II phospholipase $\mathrm{A}_{2}$ expressed in the heart. $J \mathrm{Mol} \mathrm{Cell}$ Cardiol 1997;29:2095-2106.

17. Fox N, Song M, Schrementi J, Sharp JD, White DL, Snyder DW, Hartley LW, Carlson DG, Bach NJ, Dillard RD, Draheim SE, Bobbitt JL, Fisher L, Mihelich ED. Transgenic model for the discovery of novel human secretory non-pancreatic phospholipase $A_{2}$ inhibitors. Eur J Pharmacol 1996;308:195-203.

18. Grass DS, Felkner RH, Chiang MY, Wallace RE, Nevalainen TJ, Bennett CF, Swanson ME. Expression of human group II PLA $\mathrm{P}_{2}$ in transgenic mice results in epidermal hyperplasia in the absence of inflammatory infiltrate. J Clin Invest 1996;97:2233-2241.

19. Gross RW. Myocardial phospholipases $\mathrm{A}_{2}$ and their membrane substrates. Trends Cardiovasc Med 1992;2:115-121.

20. Hazen SL, Ford DA, Gross W. Activation of a membrane associated phospholipase $A_{2}$ during rabbit myocardial ischemia which is highly selective for plasmalogen substrate. $J$ Biol Chem 1991;266:5629-5633.

21. Hazen SL, Gross RW. Identification and characterization of human myocardial phospholipase $\mathrm{A}_{2}$ from transplant recipients suffering from end-stage ischemic heart disease. Circ Res 1992;70;486495.

22. Kennedy BP, Payette P, Mudgett J, Vadas P, Pruzanski W, Kwan M, Tang C, Rancourt DE, Cromlish W. A natural disruption of the secretory group II phospholipase $A_{2}$ gene in inbred mouse strains. J Biol Chem 270;22378-22385, 1995.

23. Kennedy BP, Vadas P, Pruzanski W. Secretory PLA $A_{2}$-deficient and transgenic mice in phospholipase $\mathrm{A}_{2}$ research. In: Phospholipase $A_{2}$, basic and clinical aspects in inflammatory disease. Uhl W, Nevelainen TJ, Buchler MW, eds. Basel Karger 1997;24:65-71. 
24. Lauritzen I, Heurtaux C, Lazdunski M. Expression of group II PLA 2 in rat brain after severe forebrain ischemia and in endotoxin shock. Brain Res 1994;651: 353-356.

25. Lin MK, Farewell V, Vadas P, Bookman AA, Keystone EC, Pruzanski W. Secretory phospholipase $A_{2}$ as an index of disease activity in rheumatoid arthritis. Prospective double blind study of 212 patients. $J$ Rheumatol 1996;23:1162-1166.

26. Lueders KK. Differences in intracistrenal A-particle and GLN proviral loci suggest a genetic contribution from a DBA/2-like strain in generation of the C57B1/Ks strain. Mamm Genome 1995;6:134-136.

27. MacLellan WR, Schneider MD. Death by design: programmed cell death in cardiovascular biology and disease. Circ Res 1997;81:137-144.

28. MacPhee M, Chepenik KP, Lidell RA, Nelson KK, Stracusa LD, Buchberg AM. The secretory phospholipase $\mathrm{A}_{2}$ gene is a candidate for the $\mathrm{Mom} 1$ locus, a major modifier of $A P C^{M}$-induced intestinal neoplasia. Cell 1995;81:957-966.

29. Murakami M, Kudo I, Inoue K. Secretory phospholipases $\mathrm{A}_{2}$. J Lipid Med Cell Signal 1995;12:119-130.

30. Murakami M, Kuwata H, Amakasu Y, Shimbara S, Nakatani Y, Atsumi G-I, Kudo I. Prostaglandin $E_{2}$ amplifies cytosolic phospholipase $A_{2}$ - and cyclooxygenase-2-dependent delayed prostaglandin $\mathrm{E}_{2}$ generation in mouse osteoblast cells. J Biol Chem 1997;272:19891-19897.

31. Murakami M, Shimbara S, Kambe T, Kuwata H, Winstead MV, Tischfield JA, Kudo I. The function of five distinct mammalian phospholipase $\mathrm{A}_{2} \mathrm{~S}$ in regulating arachidonic acid release. $J$ Biol Chem 1998;273:14411-14423.

32. Naggert JK, Mu J-L, Frankel W, Bailey DW, Paigen B. Genomic analysis of the C57BI/Ks mouse strain. Mamm Genome 1995;6:131-133.

33. Nevalainen TJ, Laine VJ, Grass DS. Expression of human group II phospholipase $A_{2}$ in transgenic mice. J Histochem Cytochem 1997:45:1109-1119.

34. Otamiri T, Franzen L, Lindmark D, Tageson C. Increased phospholipase $A_{2}$ and decreased lysophospholipase activity in the small intestinal mucosa after ischemia and revasculariation. Gut 1987;28:1445-1453.

35. Otani H, Prasad MR, Jones RM, Das DK. Mechanism of membrane phospholipid degradation in ischemic-reperfused rat hearts. Am J Physiol 1989;257:H252-H258.

36. Prasad MR, Lawrentiu MP, Moraru II, Liu X, Maity S, Engelman RM, Das DK. Role of phospholipase $A_{2}$ and $C$ in myocardial ischemic reperfusion injury. Am J Physiol 1991;260: H873-H877.

37. Reddy ST, Winstead MV, Tischfield JA, Herschman HR. Analysis of the secretory phospholipase $\mathrm{A}_{2}$ that mediates prostaglandin production in mast cells. J Biol Chem 1997;272:13591-13596.

38. Tischfield JA. A reassessment of the low molecular weight phospholipase $A_{2}$ gene family in mammals. J Biol Chem 1997;272:17247-17250.

39. Vadas P, Browning I, Edelson J, Pruzanski W. Extracellular phospholipase $A_{2}$ expression and inflammation: the relationship with associated disease states. $J$ Lipid Mediat 1993;8:1-30.

40. Van Bilsen M, Van der Vusse GJ, Coumans WA, De Groot MJM, Willemsen PHM, Reneman RS. Degradation of adenine nucleotides in ischemic and reperfused rat heart. Am J Physiol 1989a;257:H47-H54.

41. Van Bilsen M, Van der Vusse GJ, Willemsen PHM, Coumans WA, Roemen THM, Reneman RS. Lipid alterations in isolated, working rat hearts during ischemia and reperfusion: its relation to myocardial damage. Circ Res 1989b;64:304-314.

42. Van Bilsen $M$, Van der Vusse GJ. Phospholipase $A_{2}$-dependent signalling in the heart. Cardiovasc Res 1995;30:518-529.

43. Van der Vusse GJ, Glatz JFC, Stam HCG, Reneman RS. Fatty acid homeostasis in the normoxic and ischemic heart. Physiol Rev 1992;72:881-940.

44. Van der Vusse GJ, Reneman RS, Van Bilsen M. Accumulation of arachidonic acid in ischemic/reperfused cardiac tissue: possible causes and consequences. Prostaglandins Leukot Essent Fatty Acids 1997;57:85-93.

45. Van der Vusse GJ, Roemen TH. Gradient of fatty acids from blood plasma to skeletal muscle in dogs. J Appl Physiol 1995; 78:1839-1843.

46. Van der Vusse GJ, Roemen THM, Prinzen FW, Coumans WA, Reneman RS. Uptake and tissue content of fatty acids in dog myocardium under normoxic and ischemic conditions. Circ Res 1982;50:538-546. 
47. Van der Vusse GJ, Van Bilsen M, Reneman RS. Is phopholipid degradation a critical event in ischemia- and reperfusion-induced damage. NIPS 1989;4:49-53.

48. Vesterqvist O, Sargent CA, Grover GJ, Ogletree ML. Myocardial calcium-independent phospholipase $\mathrm{A}_{2}$ activity during global ischemia in isolated rabbit hearts. Cardiovas Res 1996;31: 932-940.

49. Wang TC, Goldenring JR, Dangler C, Ito S, Mueller A, Jeon WK, Koh TJ, Fox JG. Mice lacking secretory phospholipase $\mathrm{A}_{2}$ show altered apopotosis and differentiation with Heliobacter felis infection. Gastroenterol 1998;114:675-689. 



\section{Chapter 9}

\section{Prelimenary results on} generating transgenic mice with a cardiac-specific overexpression of type IIA secretory phospholipase $\mathrm{A}_{2}$. 


\section{Abstract}

In the present study transgenic mice were generated to selectively overexpress type IIA sPLA ${ }_{2}$ in the myocardium. To this end, the rat type IIA sPLA ${ }_{2}$ cDNA was cloned downstream of the $250 \mathrm{bp}$ ventricular myosin light chain-2 (MLC-2v) promoter. Following multiple rounds of oocyte micro-injections one founder was obtained and germline transmission was confirmed by PCR. Additionally, a dot blot procedure was developed which allowed for determination of the copy number of transgene integration, amounted to 9 copies per haploid genome, and identification of heterozygous and homozygous transgenic animals. However, Northern blot and RT-PCR analysis of myocardial RNA demonstrated that homozygous transgenic MLC- $2_{\mathrm{v}^{-}}$ $\mathrm{SPLA}_{2}$ mice did not overexpress type IIA $\mathrm{SPLA}_{2}$ in the heart. Subsequently, the cDNA of rat type IIA $\mathrm{SLAA}_{2}$ was cloned downstream of the $\alpha$-myosin heavy chain promoter ( $\alpha$-MHC). Following one round of micro-injections, multiple founder animals were identified by using a specific PCR analysis of the genome. The existence of potential $\alpha$-MHC-sPLA ${ }_{2}$ founder candidates was confirmed by Southern blot analysis. Interestingly, among these candidates the founder animal with the highest number of transgene copies as determined by Southern blot analysis became ill soon after birth and died a few weeks later. This finding coincidences with the activation of the $\alpha$-MHC promoter and might indicate that very high


cardiac function in the mouse. 


\section{Introduction}

The current technological ability to genetically alter the mouse in combination with miniaturized physiological in vivo and ex vivo experimental setups offers the opportunity to study the (patho)physiological role of single genes (Chien et al., 1996). To more specifically target a given gene to the myocardium in a gain-infunction approach, independent laboratories have performed efforts to use promoter constructs to specifically and exclusively drive transgene expression in the heart in vivo (Figure 1). The majority of these promoter constructs were from genes encoding cardiac proteins expressed abundantly and exclusively in the myocardium. In this way promoter constructs for $\alpha$-myosin heavy chain $(\alpha-\mathrm{MyHC})$, ventricular myosin light chain-2 (MLC-2 ${ }_{\mathrm{v}}$ ) and cardiac troponin I have been used to drive transgene expression to the ventricular compartment of the myocardium in vivo (Subramaniam et al., 1991, Lee et al., 1992, De Lisi et al., 1998), while promoters of the atrial natriuretic peptide (ANF) and atrial myosin light chain-2 (MLC-2 $\mathrm{A}$ ) drive heterologous expression to the atria (Field et al., 1988, Doevendans, 1998).

A number of reports provided circumstantial evidence that phospholipase $\mathrm{A}_{2}\left(\mathrm{PLA}_{2}\right)$ mediated membrane phospholipid degradation might play a pivotal role in the transition from reversible to irreversible cellular injury during cardiac ischemia and reperfusion (Van der Vusse et al., 1982, Chien et al., 1984, Das et al., 1986, Otani et al., 1989, Van Bilsen et al., 1989, Van der Vusse et al., 1989, Prasad et al., 1991,Van der Vusse et al., 1997). To study the significance of ischemia/reperfusion-mediated cardiac membrane phospholipid degradation in the transition of reversible to irreversible cellular injury and, consequently, the extent of functional recovery, experiments were initiated to generate mice with a cardiacspecific overexpression of type IIA phospholipase $A_{2}$ in vivo. Subjecting the hearts from these transgenic animals to ischemia/reperfusion in a recently developed isolated ejecting mouse heart preparation (De Windt et al., 1999) will help to understand the role of this particular type of $\mathrm{PLA}_{2}$ in the development of irreversible cell damage and loss of cardiac function during ischemia and reperfusion. To this end, the recently cloned and characterized cDNA coding for

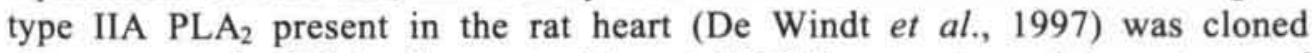
downstream of a $250 \mathrm{bp}$ fragment of the rat MLC-2 promoter and downstream of the mouse $\alpha$-MyHC promoter to specifically target type IIA $\mathrm{SPLA}_{2}$ to the cardiac ventricles.

\section{Materials and Methods}

\section{Animals}

The MLC- ${ }_{\mathrm{v}}$-SPLA $\mathrm{S}_{2}$ transgenic mouse colony was maintained and bred under standard housing conditions with an artificial $12 \mathrm{~h}$ light cycle and free access to tap water and standard rodent food (Diet SRM-A, Hope farms, Woerden, the Netherlands). In all experiments involving surgical procedures, animals were 
anesthetized with a $50 \mathrm{mg} \cdot \mathrm{kg}^{-1}$ sodium pentobarbital injection i.p. (Nembutal, Sanofi Sante BV, Maassluis, the Netherlands) prior to surgery. All experimental protocols were approved by the Institutional Animal Care and Use Committee of the Maastricht University.

\section{PCR genotyping}

To detect the presence of the transgene in individual MLC- $2_{\mathrm{v}}-\mathrm{sPLA} 2$ and $\alpha-\mathrm{MHC}$ sPLA $\mathrm{A}_{2}$ mice the genomic DNA was isolated from tail clips using a Qiamp genomic DNA prep kit (Qiagen, Leusden, the Netherlands) and subjected to PCR genotyping. In both PCR analyses a 3 -primer designated PLA-R3 [5 GAATCATTTGCCCAAACTC-3 ], directed against bp 73 - 91 of the cDNA coding for rat heart type IIA sPLA 2 (De Windt et al., 1997), was used. For the MLC- $2_{\mathrm{v}}$-sPLA $\mathrm{A}_{2}$ transgenic line a 5 -primer designated MLC-F1 [5 TCTGCCTACCTACAACTGCC-3 ] specific for the rat MLC-2v promoter was used, while in the case of $\alpha$-MyHC-sPLA 2 transgenic mice a 5 -primer designated MHC-F1 [5-GGAAACCACTGGGACAC-3 ], specific for the mouse $\alpha$-MHC promoter was used. PCR reactions were cycled 35 times at $94{ }^{\circ} \mathrm{C}$ for $30 \mathrm{~s}$, at

${ }^{\circ} \mathrm{C}$ for $60 \mathrm{~s}$ and at $72^{\circ} \mathrm{C}$ for $90 \mathrm{~s}$, with an additional amplification cycle of $10 \mathrm{~min}$ at $72^{\circ} \mathrm{C}$ using $100 \mathrm{ng}$ of genomic DNA, $50 \mathrm{pmol}$ of each primer and $1.5 \mathrm{U}$ Taq polymerase (Gibco BRL). In both MLC- $2_{\mathrm{v}}-\mathrm{sPLA} \mathrm{A}_{2}$ as well as $\alpha-\mathrm{MHC}$-sPLA 2 PCR genotyping a specific PCR product of about $300 \mathrm{bp}$ is anticipated if the transgene is present in the genome.

In a subset of FVB/N mice (MLC- $2_{\mathrm{y}}$-sPLA $\mathrm{S}_{2}$ mouse strain) the genomic DNA was used as template in a PCR reaction for genotype the mice in order to detect the genomic type IIA sPLA ${ }_{2}$ mutation as described previously (Chapter 8). The genomic DNA of all the mice tested this way were found to consistent with the wildtype genome, suggesting that the type IIA sPLA mutation is absent in the genetic background of the transgenic MLC-2 - -sPLA 2 mice.

\section{Dot blot determination of copy number}

Genomic dot blot analysis was used to determine the copy number of the transgene in the MLC- $2 \mathrm{v}-\mathrm{sPLA} \mathrm{A}_{2}$ transgenic line using a modification of a method described earlier (Hogan et al., 1986, Subramaniam et al., 1991). In short, genomic DNA was isolated from tail clips using the Qiamp genomic DNA isolation kit according to the manufacturer s directions (Qiagen) and quantitated spectrophotometrically in triplo. Subsequently, $5 \mu \mathrm{g}$ of genomic DNA from each individual mouse was digested overnight with excess EcoRI $(5 \mathrm{U} / \mu \mathrm{g})$. The digested genomic DNA was resuspended in denaturating buffer $(10 \mathrm{mM}$ Tris, $0.2 \mathrm{M} \mathrm{NaOH}, 1 \mathrm{mM}$ EDTA, 100 $\mathrm{mM} \mathrm{NaCl}$ ), heated to $70^{\circ} \mathrm{C}$ for $5 \mathrm{~min}$ and spotted in dots in duplo onto nylon filter (Amersham) in serial 2-fold dilutions using denaturing buffer starting with $1 \mu \mathrm{g}$ down to $62.5 \mathrm{ng}$. As a standard a set of blots was generated using Hind III linearized pMLCSVOA-sPLA 2 (see Figure 2) in serial 2-fold dilutions from $100 \mathrm{pg}$ down to $6.25 \mathrm{pg}$. After UV crosslinking and baking for $30 \mathrm{~min}$ at $80^{\circ} \mathrm{C}$, the blots were prehybridized for $2 \mathrm{~h}$ in $6 \times \mathrm{SSC}, 5 \times$ Denhardt s, $0.5 \%$ sodium dodecyl sulfate and $100 \mu \mathrm{g} / \mathrm{ml}$ salmon sperm DNA at $58^{\circ} \mathrm{C}$. Subsequently, the blots were 
probed overnight with $1.10^{6} \mathrm{cpm} \cdot \mathrm{ml}^{-1} \alpha-{ }^{32} \mathrm{P}$-labeled PLA probe (De Windt et al., 1997 ) in the same solution. The probe used was a Xho I/Pst I fragment of part of the cDNA coding for rat heart type II secretory PLA ${ }_{2}$ in a pBluescript vector (De Windt et al., 1997). Following two washes with $2 \times$ SSC, $0.1 \%$ SDS, the blots were exposed to storage phosphor screens for $24 \mathrm{~h}$ and scanned and quantified using a PhosphorImager and the ImageQuant software (Molecular Dynamics, Sunnyvale, CA, USA).

\section{Northern blot analysis}

Total RNA from MLC-2 ${ }_{v}-\mathrm{PLA}_{2}$ transgenic hearts (both ventricles and atria), from the hearts of their corresponding wildtype littermates and from rat ileum was isolated with the use of TRIzol Reagent (Gibco BRL). The RNA (10 $\mu \mathrm{g}$ and $5 \mu \mathrm{g}$ for cardiac tissue and ileum, respectively) was size-fractionated on a $1 \%$ agarose, $18 \%$ formaldehyde gel according to the method described in Sambrook et al. (1989). The RNA was transferred to a nylon filter (Hybond-N, Amersham) by capillary transfer overnight. After UV crosslinking and baking at $80^{\circ} \mathrm{C}$ for $2 \mathrm{~h}$, the filters were prehybridized for 2 $\mathrm{h}$ in $6 \times \mathrm{SSC}, 5 \times$ Denhardt s solution, $0.5 \%$ SDS, $100 \mu \mathrm{g} / \mathrm{ml}$ salmon sperm DNA at 58 ${ }^{\circ} \mathrm{C}$ and hybridized in the same solution with $10^{6} \mathrm{cpm} / \mathrm{ml}$ of ${ }^{32} \mathrm{P}$-labeled PLA- probe (Xho I/Pst I fragment of rat heart type IIA sPLA ${ }_{2}$ cDNA). Final washing conditions were $1 \times \mathrm{SSC}$ with $0.1 \% \mathrm{SDS}$ at $50^{\circ} \mathrm{C}$ for $30 \mathrm{~min}$. To correct for possible differences in loading and transfer, the immobilized RNA on the filters was visualized by methylene blue staining prior to hybridization. The Northern blots were exposed to storage phosphor screens for $90 \mathrm{~h}$ and subsequently scanned and quantified using a PhosphorImager and the ImageQuant software (Molecular Dynamics, Sunnyvale, CA, USA).

\section{$R T-P C R$}

Total RNA from MLC- $2 \mathrm{v}$-sPLA 2 mouse hearts and their corresponding nontransgenic littermates was prepared with the use of TRIzol Reagent (Gibco $\mathrm{BRL}$ ). Reverse transcription (RT) was performed with Superscript ${ }^{\mathrm{TM}}$-II RNAse $\mathrm{H}^{\mathrm{C}}$ reverse transcriptase (Gibco BRL) according to the instructions of the supplier. Polymerase chain reaction (PCR) was performed on a DNA thermal cycler (Perkin Elmer Co., Norwark, USA) using Thermus Aquaticus (Taq) polymerase (Gibco BRL). After an initial incubation of $5 \mathrm{~min}$ at $95^{\circ} \mathrm{C}$, the reactions were cycled 15 , 20 or 25 times at $94{ }^{\circ} \mathrm{C}$, at $55^{\circ} \mathrm{C}$, and at $72{ }^{\circ} \mathrm{C}$, all for $1 \mathrm{~min}$. An additional extension reaction at $72{ }^{\circ} \mathrm{C}$ for $10 \mathrm{~min}$ was included after cycle 25 . Samples were size-fractionated by agarose gel electrophoresis and visualized after staining with ethidium bromide. RT-PCR was performed using a 5 primer designated PLA-F1 [5'-GAGTTTGGGCAAATGATTC-3'] and a 3 primer designated PLA-R1 [5'CAGCTTTATCGCACTGGCA-3']. PLA-F1 and PLA-R1 correspond to bp 73-91 and bp 328-346 of the sequence of type IIA sPLA ${ }_{2}$ present in the heart (De Windt $e t$ al., 1997). 


\section{Cardiac-specific Gene of promotor interast}

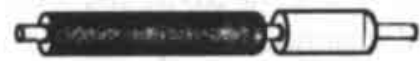

\section{Cloning of gene of interest \\ behind suitable promotor}

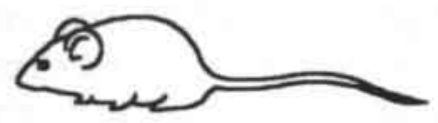

Collection oocytes from superovulating donor mouse



Transfer injected oocytes in reproductive tract pseudopregnant mouse
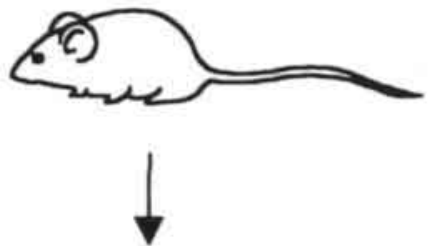

\section{Southern blot/PCR assay on genomic DNA for incorporation of transgene}

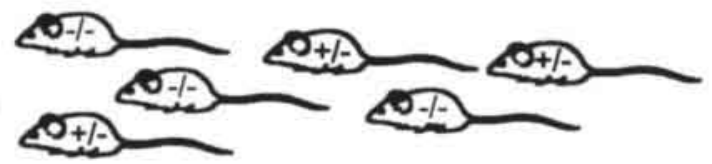

\section{Selection positive} founder animals
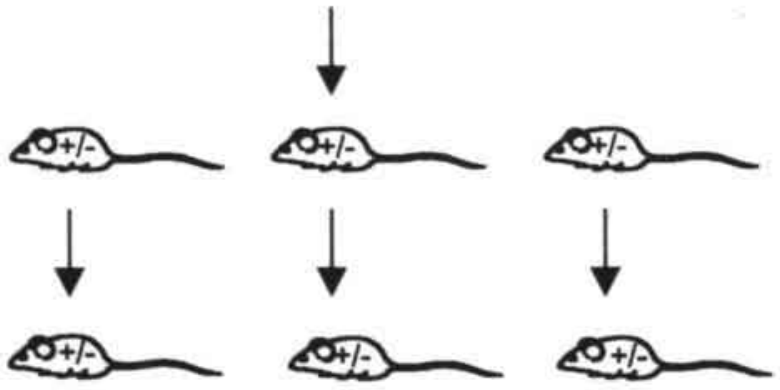

Figure 1. Schematic overview of the generation of transgenic mice. The gene of interest is placed under control of a promoter sequence (e.g. a cardiac-specific promoter such as the $\alpha$-MyHC promoter) to target the expression of the gene to a specific organ, in this case the heart. The transgene is micro-injected into the male pronucleus of uncleaved fertilized oocytes. The oocytes are subsequently transferred into the reproductive tract of a pseudopregnant foster mouse, where the oocytes come to term. Genomic DNA is tested by Southern blot or PCR procedures to determine whether the transgene has been integrated into the mouse genome. In the different transgenic lines different numbers of transgenes at different integration sites are usually incorporated. After confirmation of overexpression of the transgene at the RNA and protein level and documentation of the copy number of the transgene integration, the phenotype of the transgenic mouse lines is investigated.

(Figure reprinted with permission from De Windt et al., 1998). 


\section{Results}

\section{Cloning of $M L C-2{ }_{v}-s P L A_{2}$ construct}

To obtain a MLC-2 $\mathrm{v}_{\mathrm{v}} \mathrm{SPLA} \mathrm{A}_{2}$ expression vector to drive type IIA sPLA $\mathrm{A}_{2}$ specifically to the heart of mice, a number of subcloning strategies were applied to clone full length cardiac type IIA sPLA $\mathrm{ADNA}_{2}$ downstream of the $250 \mathrm{bp}$ fragment of the rat MLC- 2 vene promoter. To this end, type IIA $s \mathrm{PLA}_{2}$ was excised from a parental pBluescript vector (De Windt et al., 1997) via an EcoR I/Not I double digest and inserted into a EcoR I/Not I linearized PCRII vector. Resulting PCRII-sPLA $\mathrm{A}_{2}$ was digested with Spe I to release a $\sim 900 \mathrm{bp}$ fragment containing the full length type IIA sPLA $\mathrm{PDNA}_{2}$ clone (Figure 2). Finally, this Spe I fragment was ligated into the multiple cloning site of pMLCSVOA, a vector containing the $250 \mathrm{bp}$ trunctated rat MLC -2 v promoter upstream and a luciferase poly adenylation (poly A) signal downstream of the multiple cloning site, respectively. Resulting transgenic vector (pMLCSVOA-sPLA $A_{2}$ ) was subjected to extensive restriction digest and sequencing analysis to confirm correct orientation and integrity of the open reading frame of sPLA $_{2}$. The transgenic vector was digested with Hind III and Kpn I, which cut immediately 5 of the promoter and 3 of the polyadenylation site, respectively (Figure 2). In this manner, no contaminating plasmid vector sequences were included into the microinjected DNA. Subsequent DNA purification and transgene animal generation was performed as described previously using standard techniques at the Department of Medicine, University of California - San Diego, CA USA (Hogan et al., 1986, Lee et al., 1992). Following multiple rounds of microinjections only one male founder was obtained and subsequently shipped to the Maastricht University, The Netherlands, where all further breeding and analysis of the transgenic line occurred.

\section{Propagation and morphometric analysis of $M L C-2_{v}-S P L A_{2}$ mice}

To confirm integration of the transgenic construct, a genomic DNA PCR strategy was developed involving a 5 primer specific for the MLC -2 v promoter and a 3 primer specifically directed to the type IIA sPLA ${ }_{2}$ sequence. In Figure 3 a typical PCR result of a litter from the original male founder with a wildtype female FVB/N mouse is presented. As demonstrated, a highly specific detection of the transgene was obtained through this method of screening. In this way, the transgenic line was propagated until the third generation (F3). Two breeding pairs, both containing one transgenic and one wildtype parent of the F1 generation, were set up to yield 39 pups in 9 litters, of which 19 were PCR positive. Subsequently, a breeding strategy was followed involving two (heterozygous) transgenic parents of the F2 generation to obtain pups with double copies of the transgene (homozygous transgenic) in a Mendelian fashion. Morphometric analysis, copy number determination, Northern blot analysis and RT-PCR reactions were performed primarily on the litters derived from latter homozygous transgenic breeding pair ( $\mathrm{F} 3$ generation).

Table I depicts the morphometric findings of homozygous transgenic MLC- $2_{\mathrm{v}}$-sPLA $\mathrm{P}_{2}$ transgenic mice compared to their non-transgenic mice. No obvious differences in health, appearance and body weight were detected between transgenic and non-transgenic mice. Additionally, gross histological inspection of the heart 
following removal from the thorax demonstrated no obvious abnormalities in cardiac morphology of transgenic animals, nor significant differences in heart weight compared to wildtype hearts.

\section{Dot blot determination of copy number}

To determine the absolute amount of integrated transgene copies into the haploid genome of the MLC- $2_{\mathrm{y}}-\mathrm{SPLA}_{2}$ transgenic line, a standard curve of serial diluted plasmid pMLCSVOA-PLA ${ }_{2}$ containing the transgene was constructed following hybridization with a 300 bp probe directed against the coding region of type IIA sPLA $\mathrm{A}_{2}$ present in the heart (Xho I/Pst I fragment, see Materials and Methods). Taking into account that $100 \mathrm{pg}$ of a $4,000 \mathrm{bp}$ plasmid consists of $7.3 \times 10^{6}$ molecules (first dot) and $6.25 \mathrm{pg}$ contains $4.6 \times 10^{5}$ molecules of the plasmid (last dot), a standard curve was fitted by plotting the amount of transgene copies against the signals as quantitated by the PhosphorImager analysis (Figure 4). In Figure 4A the triplo serial diluted pMLCSVOA-PLA $A_{2}$ is depicted by numbers 1,2 and 3 . The genomic DNA derived from two PCR positive MLC- ${ }_{\mathrm{v}}$-SPLA $\mathrm{S}_{2}$ animals (one homozygous and one heterozygous transgenic mouse) and a wildtype littermate are also shown. Figure 4B depicts the standard curve obtained by plotting the absolute amount of arbitrary Phospholmager units against the absolute amount of plasmid molecules following hybridization with ${ }^{32} \mathrm{P}$-labeled PLA probe. Table II depicts all arbitrary PhosphoImager units calculated from the dot blot analysis as demonstrated in Figure 4A. Using the equation that follows from the standard curve in Figure 4B, the absolute amount of sPLA $\mathrm{A}_{2}$ copies in the serial diluted genomic DNA are given. By dividing the absolute transgene copies by the absolute amount of haploid genome copies spotted in each dot, an estimation of the transgene copy number is obtained (Table II). Following latter analysis it was found that the wildtype nontransgenic mouse haploid genome contains only one copy of type IIA sPLA (endogenous type IIA sPLA ${ }_{2}$ gene), while heterozygous transgenic MLC-2 ${ }_{\mathrm{v}}-\mathrm{SPLA}_{2}$ animals contain 9 copies and homozygous transgenic animals about the double number of heterozygous transgenic animals, i.e. about 20 copies per haploid genome (Figure 4A, Table II). 

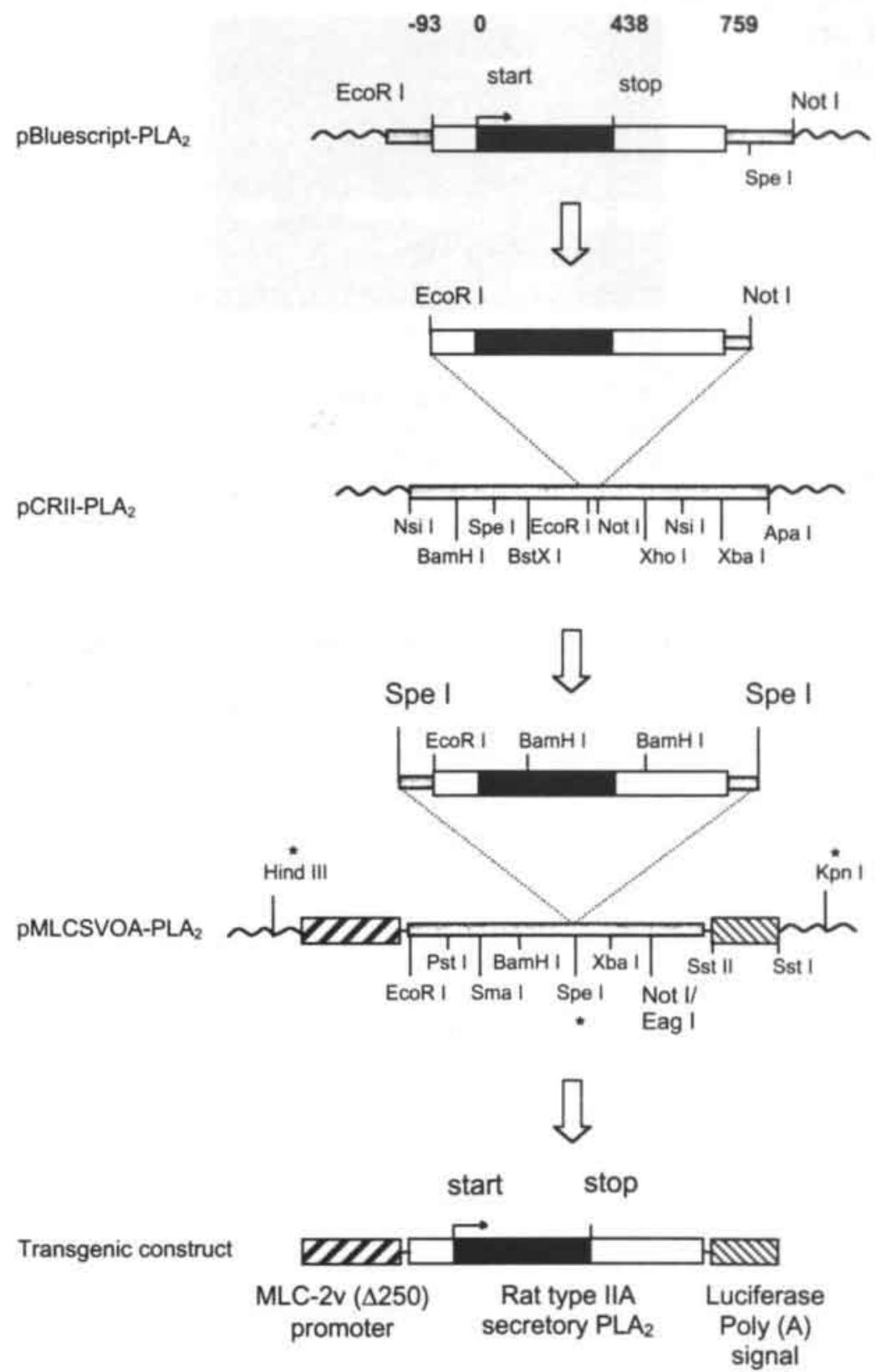

Figure 2. Cloning strategies to obtain a MLC-2v-sPLA $A_{2}$ transgene vector. To obtain a MLC-2v-sPLA $\mathrm{A}_{2}$ expression vector to drive type IIA sPLA $A_{2}$ specifically to the heart of mice, a 852 bp fragment containing the $5^{\circ}$ and $3^{\circ}$ UTF sequences and open reading frame of rat heart type IIA SPLA $A_{2}$ was excised from a parental pBluescript vector and subeloned into a linearized pCRII vector. To this end, sPLA 2 was excised from a parental pBluescript vector (De Windt et al., 1997) via an EcoRI/Notl double digest and ligated into an EcoRI/NotI linearized pCRII vector. Resulting pCRII-sPLA $A_{2}$ was digested with Spel to release a -900 bp fragment containing the open reading frame of $\mathrm{SPLA}_{2}$. Finally, this Spel fragment was ligated into the multiple cloning site of pMLCSVOA, a vector containing the $250 \mathrm{bp}$ truncated rat MLC-2v promoter upstream and the luciferase polyadenylation signal downstream of the multiple cloning site, respectively. A HindIII/Kpnl digest removed the vector sequences from the transgenic construct for injection into oocytes. " indicates unique restriction site in vector. 


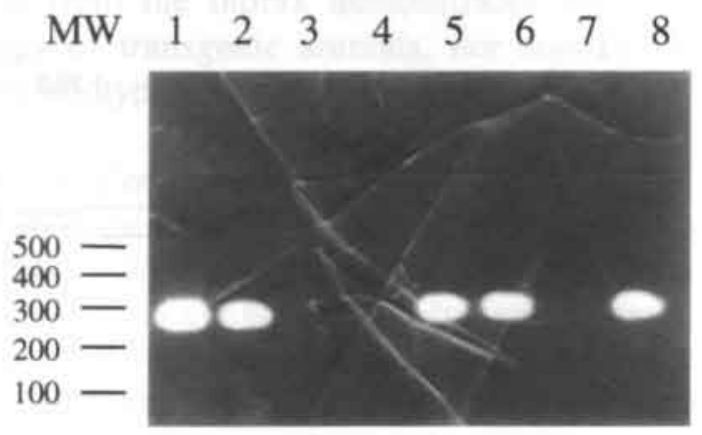

Figure 3. Example of MLC- $2 \mathrm{r}_{\mathrm{v}}$-sPLA $\mathrm{A}_{2}$ PCR genotyping. Lane 1 represents positive control as template (pMLCSVOA-sPLA ${ }_{2}$ plasmid). Lanes 2-8 represent genotyping of 7 individual mice from a litter of the original founder mouse with a wildtype mate. The molecular weights are indicated on the left in bp.

Northern blot analysis of cardiac type IIA sPLA levels Following confirmation of germline dependent transmission and copy number assessment of the transgene it was investigated by RNA blot analysis whether the MLC- $2_{\mathrm{v}}$-sPLA $\mathrm{S}_{2}$ transgenic line demonstrated increased cardiac mRNA levels for type IIA sPLA 2 . Figure 5 demonstrates a respresentative result of this analysis, demonstrating high levels of type IIA sPLA ${ }_{2}$ mRNA in rat ileum (positive control tissue). A very weak signal for $\mathrm{SPLA}_{2}$ mRNA was obtained in hearts derived from wildtype nontransgenic littermates (lane 1, 4 and 6; Figure 5). However, no difference was found in type IIA sPLA ${ }_{2}$ mRNA signals in hearts derived from transgenic MLC- ${ }_{\mathrm{v}}$-sPLA $\mathrm{PL}_{2}$ animals (lane 2, 3 and 5; Figure 5). This result demonstrated that the MLC-2 ${ }_{\mathrm{v}}-\mathrm{SPLA} \mathrm{A}_{2}$ transgenic line was not overexpressing type IIA sPLA ${ }_{2}$, despite the presence of multiple copies of the transgene.

\section{Table I}

Morphometric parameters of homozygous transgenic MLC- $2_{\mathrm{v}}$-SPLA $\mathrm{A}_{2}$ mice and wildtype mice.

\begin{tabular}{lll}
\hline & Wildtype & MLC-2 ${ }_{v}$-sPLA \\
\cline { 2 - 3 } & & \\
$B W(g)$ & $30.6 \pm 4.6$ & $29.9 \pm 4.1$ \\
$H W(m g)$ & $207 \pm 22$ & $217 \pm 12$ \\
$H W / B W\left(m g \cdot g^{-1}\right)$ & $6.87 \pm 1.16$ & $7.32 \pm 0.66$ \\
Age (weeks) & $28 \pm 5$ & $28 \pm 5$ \\
$N$ & 6 & 6 \\
\hline
\end{tabular}

Data are expressed as means $\pm \mathrm{SD}$. BW, body weight; $\mathrm{HW}$, heart weight; $\mathrm{HW} / \mathrm{BW}$, heart weight-to-body weight ratio. 


\section{$R T-P C R$}


performed on total RNA isolated from wildtype and transgenic hearts. To ascertain linearity of the PCR reaction, PCR products were analyzed following 15, 20, and 25 cycles and subjected to agarose gel electrophoresis. It was found that 20 RT-PCR cycles were sufficient to detect a weak signal for $\mathrm{SPLA}_{2} \mathrm{mRNA}$ and still remain in the linear phase of PCR product generation (data not shown). No notable upregulation of mRNA transcripts were observed between wildtype and MLC- $2 \mathrm{v}^{-}$ sPLA $_{2}$ hearts (data not shown). The latter result confirmed the observations obtained by using Northern blotting procedures that the MLC- $2_{\mathrm{v}}-\mathrm{SPLA}$ transgenic line did not overexpress type IIA sPLA 2 mRNA transcripts in the heart and, hence, was not suitable for studies to assess the role of $\mathrm{PLA}_{2}$-mediated phospholipid degradation during cardiac ischemia and reperfusion

\section{Cloning of $\alpha-M H C-s P L A_{2}$ construct}

Following the negative result of the $\mathrm{MLC}-2_{\mathrm{v}}-\mathrm{SPLA} \mathrm{A}_{2}$ transgenic line, experiments were undertaken to obtain several transgenic lines of mice with differing amounts of sPLA $_{2}$ overexpressed and driven to the heart by a $5.5 \mathrm{~kb} \alpha$-MHC promoter construct. To this end, the cDNA coding for rat heart type IIA sPLA 2 was excised from the PCRII-sPLA 2 vector (Figure 6) by an EcoR I/Xba I double digest and cloned into EcoR I/Xba I linearized pBluescript vector. This subcloning stategy

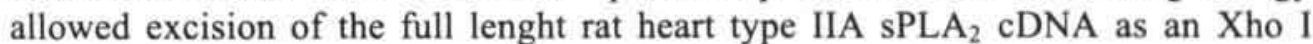
fragment, which allowed for cloning into clone 26 (generous gift from Prof. J Robbins, Children s Hospital Medical Center, Cincinnati OH, USA to Dr. PA Doevendans, Department of Cardiology, University Hospital Maastricht), a pBluescript based vector containing the mouse $5.5 \mathrm{~kb} \alpha$-MHC promoter upstream and the $0.6 \mathrm{~kb}$ human growth hormone poly adenylation site ( $\mathrm{HgH}$ poly $\mathrm{A}$ ) downstream of the multiple cloning site. Cloning of the Xho I sPLA $\mathrm{X}_{2}$ fragment into the Sal I site of clone 26 finally resulted in the vector pBluescript- $\alpha-\mathrm{MHC}-\mathrm{sPLA}$. Resulting transgenic vector (pBluescript- $\alpha-\mathrm{MHC}-\mathrm{sPLA} \mathrm{A}_{2}$ ) was subjected to extensive restriction digest and sequencing analysis to confirm correct orientation and integrity of the open reading frame of $\mathrm{PLA}_{2}$.

In a collaboration the transgenic vector was sent to Dr. Solito of the Institute Cochin de Genetique Moleculaire INSERM U-322, Paris, France, where the $\sim 7.0 \mathrm{~kb}$ fragment containing the $\alpha$-MHC promoter, $\mathrm{PLA}_{2}$ and the $\mathrm{HgH}$ poly $\mathrm{A}$ signal were released by Not I restriction digest. Subsequently, the transgenic construct was purified and injected into fertilized oocytes as described earlier (Hogan et al., 1986).

Following one round of injections, three litters with a total of 20 pups were obtained. Screening of transgenic pups by PCR analysis as described in the Materials and Methods section demonstrated the presence of 5 PCR positive pups. The presence of the transgene was further confirmed by Southern blot analysis of genomic DNA using a probe to detect the $\mathrm{HgH}$ poly (A) signal of the transgenic vector (data not shown). The PCR-positive founder with the highest signal at the Southern blot level soon became ill between 1-2 weeks after birth and died several days later. Gross examination of the major organs revealed no apparent 


\section{Chapter 9}

abnormalities or deviations in organ wet weight and, more importantly, the heart did not show any morphological abnormalities or signs of hypertrophy (Personal communications E Solito).

Following overnight fixation in $10 \%$ formalin, the heart of the animal was shipped to the Netherlands where total RNA was isolated in an attempt to establish whether transgenic type IIA sPLA ${ }_{2}$ expression could be detected via Northern blot analysis. Unfortunately, the quality of the RNA was of such poor quality, probably because the animal was deceased for some time after detection of the carcass, that the cardiac RNA had already been degraded upon fixation of the tissues.

\section{Discussion}

In the present study two approaches were undertaken to overexpress type IIA SPLA 2 levels selectively in the murine myocardium in vivo. The first approach involved the generation of transgenic mice where the cDNA of type IIA sPLA $\mathrm{P}_{2}$ was placed under control of the $250 \mathrm{bp} \mathrm{MLC-2}$ promoter. Early studies indicated that this $250 \mathrm{bp}$ fragment was sufficient to drive exogenous gene products specifically to both ventricles in the mouse (Lee et al., 1992, Lee et al., 1994, Hunter et al 1995). Following multiple rounds of oocyte injections, however, only one founder with 9 copies of the transgene incorporated into the haploid genome was obtained which, as indicated by Northern blot and RT-PCR analysis of myocardial RNA, did not show overexpression of the transgene. Hereafter experiments were initiated to overexpress type IIA sPLA $\mathrm{A}_{2}$ in a cardiac-restricted fashion under control of the $\alpha$ MyHC promoter. By using this approach, multiple $\alpha$-MHC-sPLA $\mathrm{A}_{2}$ transgenic founder mice were identified and await further characterization. Of interest, one founder with the highest transgene copy number died of unknown cause soon after birth, which might implicate that driving high type IIA sPLA $\mathrm{A}_{2}$ transgene levels in the heart is unfavorable for correct cardiac function in the adult mouse.

Although the promoter and cis-elements responsible for driving the cardiacrestricted expression patterns of MLC- $2 \mathrm{v}$ gene have been identified and characterized (Henderson et al., 1989, Lee et al., 1992, Lee et al., 1994, Navankasattusas et al., 1994, Hunter et al., 1995, Ross et al., 1996) only few reports have documented successful cardiac-restricted overexpression in vivo using the MLC-2 promoter and involved the oncogene $\mathrm{H}$-ras in the murine heart (Hunter $e t$ al., 1995), two reporter genes, luciferase and $\beta$-galactosidase, in the mouse heart (Lee et al., 1992, Lee et al., 1994, Ross et al., 1996) and the plasma membrane, calmodulin-dependent $\mathrm{Ca}^{2+}$ ATPase (PMCA) in the rat heart (Hammes et al., 1998). One specific advantage of the MLC-2 $\mathrm{v}$ promoter is based in the ventricular specificity of the MLC-2 2 gene in the animal in vivo with no detectable expression in the atria (Lee et al., 1992, Lee et al., 1994, Ross et al., 1996). However, major drawbacks of the promoter are related to the developmental expression pattern of the MLC -2 v gene which itself is one of the earliest markers of cardiac morphogenesis (O Brien et al., 1993). 
A

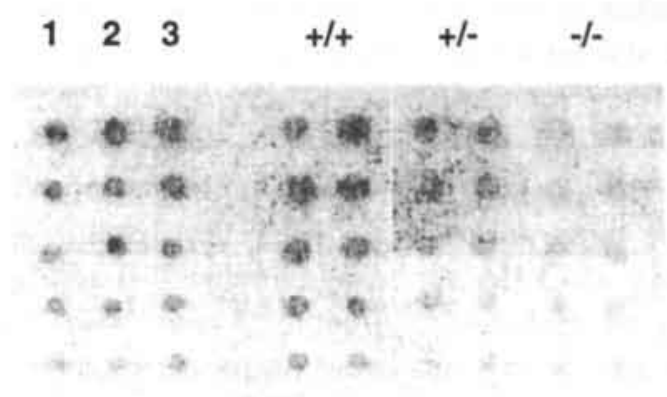

B

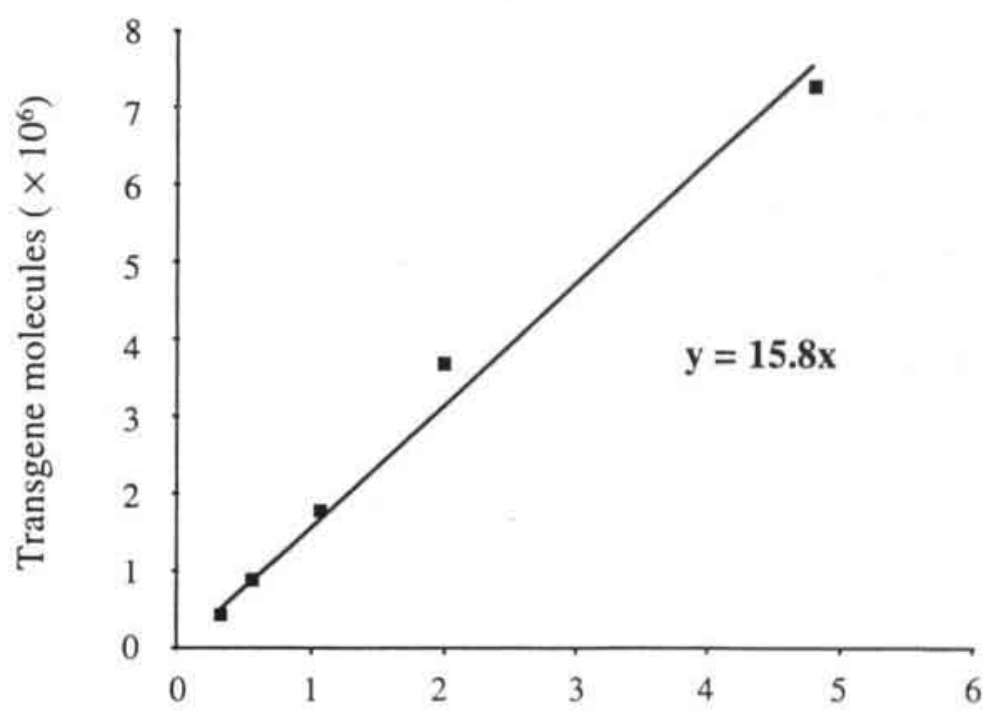

Arbitrary PhosphoImager units $\left(\times 10^{6}\right)$

Figure 4. Demonstration of copy number analysis in $\mathrm{MLC}^{2} 2_{\mathrm{y}}$-sPLA 2 transgenic mice. $\boldsymbol{A}$, Genomic DNA isolated from wildtype $(-/-)$, heterozygous $(+/-)$ and homozygous $(+/+)$ transgenic animals was two-fold serial diluted and spotted in duplicate next to two-fold serial dilutions of the plasmid containing the transgene (pMLCSVOA-sPLA $;$ Figure 2). As a radiolabeled probe a 275 bp fragment of the coding region of rat heart type IIA sPLA ${ }_{2}$ was used (De Windt et al., 1997). B, Taking into account that $100 \mathrm{pg}$ of a 4,000 bp plasmid consists of $7.3 \times 10^{6}$ molecules (first dot) and $6.25 \mathrm{pg}$ contains $4.6 \times 10^{6}$ molecules of the plasmid (last dot), a standard curve was fitted by plotting the number of transgene copies against the signals as quantitated by the PhosphorImager analysis using the arbitrary PhosphoImager units obtained with the serial diluted plasmid and the absolute number of nlasmid molecules. 
Table II

Dot blot procedure for determination of copy number in MLC-2,-sPLA transgenic mice.

DNA origin

Dot \#
$\mathbf{A}$

B

C

D Copy number

E

\begin{tabular}{|c|c|c|c|c|c|c|c|}
\hline \multirow[t]{5}{*}{ Plasmid } & 1 & 478880 & $7.3 .10^{6}$ & - & - & $\cdot$ & \\
\hline & 2 & 198025 & $3.7 .10^{6}$ & - & - & - & \\
\hline & 3 & 105167 & $1.8 .10^{6}$ & - & - & . & \\
\hline & 4 & 55329 & $0.9 .10^{6}$ & - & - & - & \\
\hline & 5 & 31830 & $0.45 .10^{6}$ & - & - & . & \\
\hline \multirow[t]{5}{*}{ MLC-2, $-5 P_{L} A_{2}(+/+)$} & 1 & 454915 & - & 7187657 & 340000 & 21 & \\
\hline & 2 & 264867 & - & 4184899 & 170000 & 25 & \\
\hline & 3 & 121522 & - & 1920048 & 85000 & 23 & \\
\hline & 4 & 43707 & - & 690571 & 42500 & 16 & \\
\hline & 5 & 23538 & - & 371900 & 21300 & 17 & 20 \\
\hline \multirow[t]{5}{*}{ MLC-2,-sPLA $(+/-)$} & 1 & 161740 & - & 2555492 & 340000 & 8 & \\
\hline & 2 & 80618 & - & 1273764 & 170000 & 7 & \\
\hline & 3 & 49564 & - & 783111 & 85000 & 9 & \\
\hline & 4 & 28798 & - & 455008 & 42500 & 11 & \\
\hline & 5 & 12944 & $\cdot$ & 204515 & 21300 & 10 & 9 \\
\hline \multirow[t]{5}{*}{ MLC-2,-sPLA $(-/-)$} & 1 & 19702 & - & 311292 & 340000 & 1 & \\
\hline & 2 & 9752 & - & 154082 & 170000 & 1 & \\
\hline & 3 & 4936 & - & 77989 & 85000 & 1 & \\
\hline & 4 & 2279 & - & 36008 & 42500 & 1 & \\
\hline & 5 & - & - & 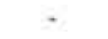 & 21300 & - & 1 \\
\hline
\end{tabular}

Depicted are the mean arbitrary Phosphoimager units (column A) following hybridization with a sPLA $\mathrm{A}_{2}$-specific probe.

Data are expressed as means from triplicate (plasmid) or duplicate (MLC-2,-sPLA 2 ) experiments. DNA was spotted in serial 2-fold dilutions starting with $100 \mathrm{pg}$ or $1 \mu \mathrm{g}$ (dot 1) and ending with $6.25 \mathrm{pg}$ or $62.5 \mathrm{ng}(\operatorname{dot} 5)$ for plasmid and genomic DN/ respectively. Corresponding number of plasmid molecules (B) or number of haploid genomes (D) are indicated. In C the unit obtained in A are multiplied using the correction factor from the standard curve of Figure 4, i.e. 15.8. Following division of $\mathrm{C}$ by $D$ the copy number of transgene integration into the haploid genome is obtained. Column (E) depicts the mean of the data presented in column (Copy number) and represents the mean copy number per haploid genome. 
As a consequence, the truncated 250 bp fragment of the MLC -2 v promoter drives not only high transgene expression levels prenatally, but also in a distinct anteriorposterior gradient, leading to robust expression in the right ventricle and less or no expression in the left ventricle. This distinct feature, although only once reported using a MLC-2 ${ }_{\mathrm{v}}-\beta$-galactosidase fusion gene (Ross et al., 1996), is highly undesirable for projects where left ventricular ischemic vulnerability is to be tested in the adult animal using an isolated left ventricular ejecting heart preparation (De Windt et al., 1999). An additional disadvantage of the MLC-2v promoter is that relatively large numbers of transgenic founder lines need to be generated and screened before ventricular overexpression, in the absence of ectopic expression, is truly achieved (personal communication KR Chien). Regarding latter difficulties, the MLC -2 v promoter is clearly a less apropiate device to generate animal models with a cardiac-specific gain-of-function. It should be noted that at the time of generating the MLC-2v-sPLA 2 transgenic mice in the present study, this information (Ross et al., 1996) had not been published about this particular promoter construct.

Although less restricted in its expression pattern than the MLC-2, promoter, the $\alpha$-MHC promoter has been used successfully to drive overexpression of a large number of transgenes to the myocardium. The $\alpha-$ and $\beta$-MHC genes are a group of muscle-specific genes which are expressed in both the cardiac and skeletal muscle compartments. In the mouse, $\beta$-MHC expression is first detected 8 days post-coitum in the primitive heart tube and as the heart undergoes looping and forms distinct atrial and ventricular chambers, the expression of $\beta$-MHC becomes restricted to the ventricular region, whereas $\alpha-\mathrm{MHC}$ is restricted to the atrial region. Subsequently, $\beta$-MHC expression is down-regulated in the ventricular compartment and within 1 week after birth $\alpha$-MHC transcripts accounts for $95 \%$ of the MHC transcripts in the heart (Lyons et al., 1990). Similar to the spatio-temporal expression pattern of the endogenous $\alpha$-MHC gene in rodents, transgenes under control of the $5.5 \mathrm{~kb}$ mouse $\alpha$-MHC promoter fragment are expressed atrial-specifically at very low levels during embryonic development. About one week after birth a copy number dependent overexpression pattern in both ventricles, both atria and the pulmonary myocardium is routinely observed (Subramanian et al., 1991). The $\alpha-\mathrm{MHC}$ promoter generally results in a large numbers of founder animals per injection, a relatively large number of which are likely to demonstrate germline-dependent overexpression of the transgene (about $35 \%$ of founders). Although the exact reason for the high successrate of the $\alpha$-MHC promoter remains to be established, the size of the transgene (generally over $7 \mathrm{~kb}$ ), which normally integrates into a chromosomal locus as a complex of concatemers, and the large number of cardiac muscle specific enhancers present within the promoter (Molkentin et al., 1996) probably contribute to the observed efficiency of this promoter. In line with this notion, it is of interest to note that recent efforts to reconstruct the original MLC-2 promoter by increasing the size of the construct (up to $5 \mathrm{~kb}$ ) have resulted in a high succesrate in obtaining transgenic founders expressing reporter enzymes at very 
high levels in a ventricular-specific fashion without the presence of an anteriorposterior gradient (personal communications J Robbins).

The observation that the one founder with the highest copy number died soon after activation of the $\alpha$-MHC promoter might indicate that high type IIA sPLA $_{2}$ expression levels specifically in the heart is incompatible with life, resulting in selection of transgenic animals with relatively lower levels of the enzyme. This might also be an alternative explanation for the low successrate of generating MLC$2 \mathrm{v}$-sPLA $\mathrm{S}_{2}$ founders. However, the above considerations are in contrast with the

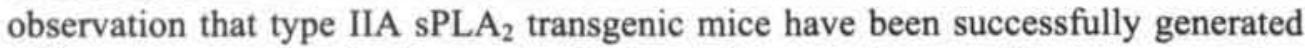
with overexpression in the heart, albeit not in a cardiac-specific overexpression pattern (Grass et al., 1996, Nevelainen et al., 1997, Fox et al., 1996).

In summary, it was attempted to create an animal model with a cardiacspecific overexpression of type IIA sPLA ${ }_{2}$ by generating mice with rat type IIA sPLA $_{2}$ under control of either of the MLC- 2 v or the $\alpha-\mathrm{MHC}$ promoter. Following multiple rounds of micro-injections, only one transgenic founder line of MLC- $2 v^{-}$ $\mathrm{PPLA}_{2}$ was obtained and propagated. Although germline transmission was observed, no overexpression of type IIA sPLA 2 could be detected in the heart. Subsequently, type IIA sPLA $\mathrm{A}_{2}$ was placed under control of the $\alpha$-MHC promoter and following one round of oocyte injections multiple transgenic mice were identified. The availability of an animal model with a gain-of-function for cardiac PLA $\mathrm{A}_{2}$ activity, in combination with an isolated perfused heart model to perform cardiac ischemia/reperfusion studies (De Windt et al, 1999), will provide more insight into the question whether membrane phospholipid degradation is a critical step during the transition from reversible to irreversible damage.

$$
\begin{array}{lllllll}
1 & 2 & 3 & 4 & 5 & 6 & 7
\end{array}
$$


Figure 5. Northern blot analysis of total RNA isolated from homozygous transgenic MLC- $2_{v}-$ sPLA $_{2}$ hearts (lane $2,3,5$ ) and wildtype non-transgenic littermates (lanes $1,4,6$ ) using a $\mathrm{P}^{32}$-labeled type IIA sPLA ${ }_{2}$ probe (De Windt et al., 1997). As a positive control and reference for size total RNA derived from rat ileum was included in the analysis (Lane 7). Arrow indicates size of type IIA sPLA 2 mRNA. To check for equality in loading, the RNA was visualized with methylene blue (data not shown). 
PCRII-PLA

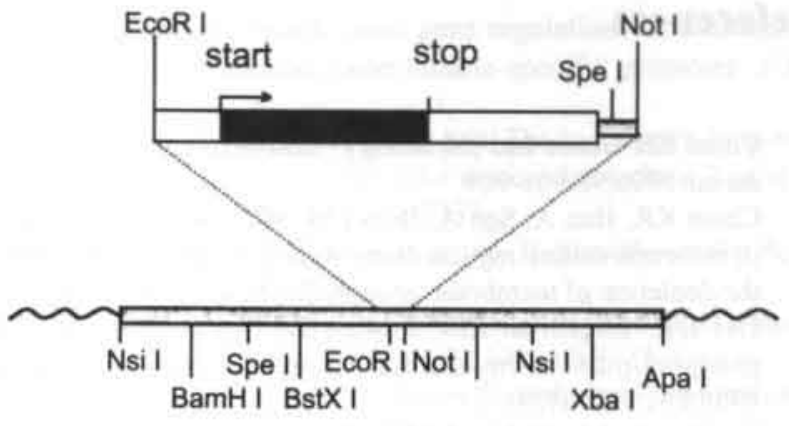

pBluescript-PLA $\mathrm{A}_{2}-\mathrm{II}$

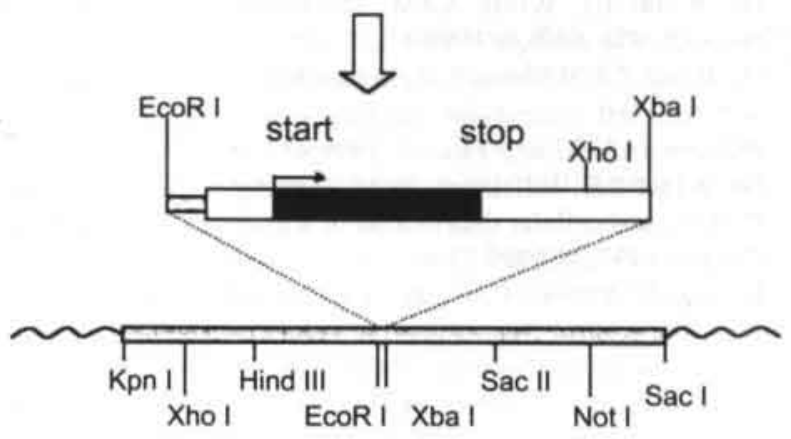

Clone 26-PLA
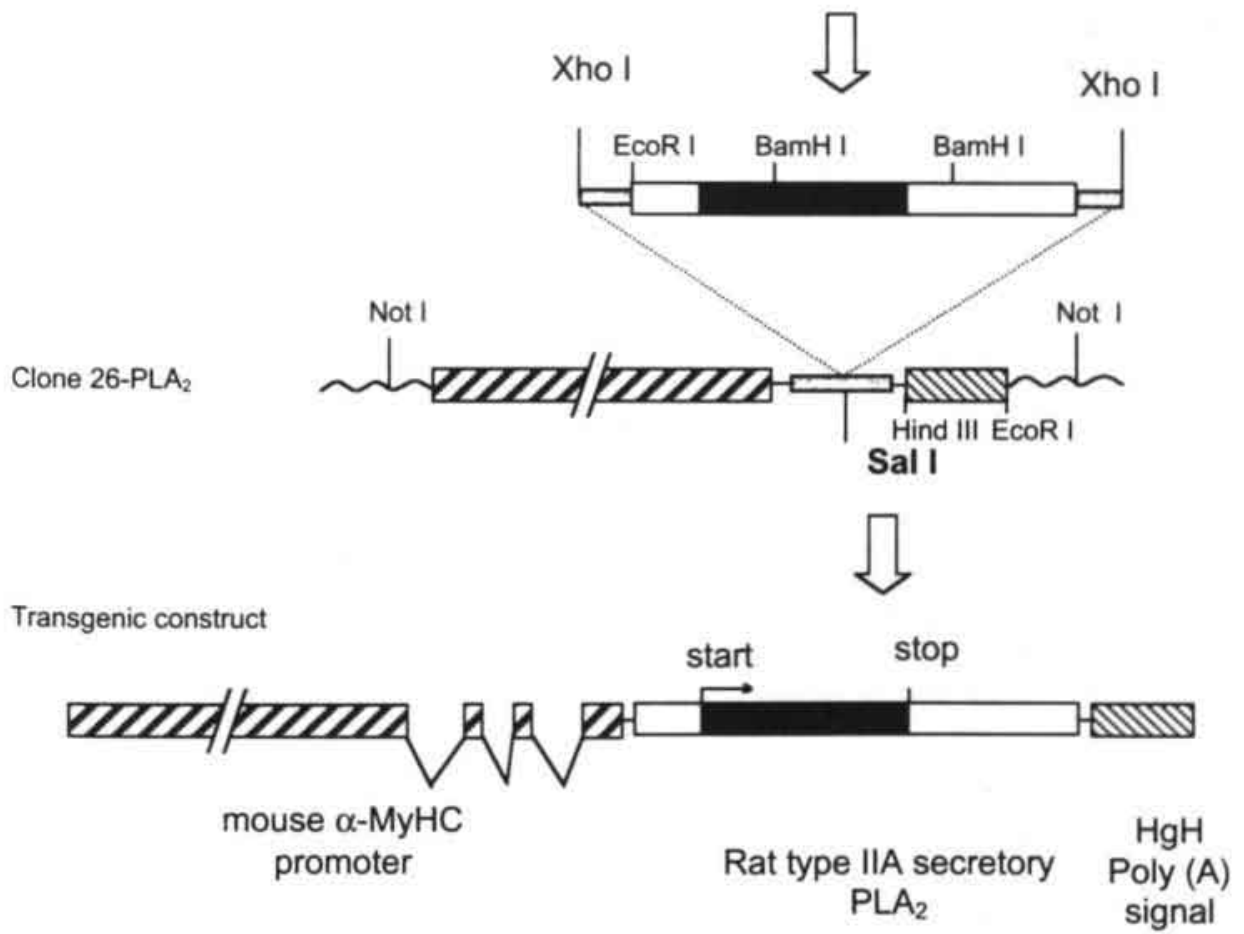

Figure 6. Cloning strategies followed to place the full length cDNA coding for rat heart type IIA sPLA 2 under control of the $5.5 \mathrm{~kb}$ murine $\alpha-\mathrm{MHC}$ promoter. The full length cDNA was excised from the pCRII-sPLA $\mathrm{A}_{2}$ vector (see Figure 2) by an EcoRI/Xbal double digest and subcloned into an EcoRI/Xbal linearized pBluescript vector. This subcloning strategy allowed excision of the full length rat heart type IIA sPLA 2 as an Xho I fragment, which allowed for ligation into the Sal I site of clone 26, a pBluescript based vector containing the murine $5.5 \mathrm{~kb} \alpha$-MHC pomoter upstream and the $0.6 \mathrm{~kb}$ human growth hormone polyadenylation signal downstream of the multiple cloning site. Cloning of the Xhol sPLA $\mathrm{A}_{2}$ fragment into the Sall site of clone 26 resulted in the vector pBluescript- $\alpha$ MHC-sPLA . A Notl digest susbsequently removed the vector sequences from the transgenic construct for injection into fertilized murine oocvtes. 


\section{References}

1. Chien KR Genes and physiology: molecular physiology in genetically engineered animals. J Clin Invest 1996;97:901-909.

2. Chien KR, Han A, Sen A, Buja LM, Willerson JT. Accumulation of unesterified arachidonic acid in ischemic canine myocardium. Relationship to a phosphatidyl deacylation-reacylation cycle and the depletion of membrane phospholipids. Circ Res 1984;54:313-322.

3. Das DK, Engelman RM, Rousou JA, Breyer RH, Otani H, Lemeshow S. Role of membrane phospholipids in myocardial injury induced by ischemia and reperfusion. Am J Physiol 1986;251:H71-H79.

4. De Windt LJ, Wilde AAM, Doevendans PA. Animal models in molecular cardiovascular research. Cardiologie 1998;4:132-141.

5. De Windt LJ, Willems J, Reneman RS, Van der Vusse GJ, Arts T, Van Bilsen M. An improved isolated, left ventricular ejecting murine heart model. Functional and metabolic evaluation. Pfl gers Archiv-Eur J Physiol 1999;437:182-190.

6. De Windt LJ, Willemsen PHM, P pping S, Van der Vusse GJ, Reneman RS, Van Bilsen M. Cloning and cellular distribution of a group II phospholipase $\mathrm{A}_{2}$ expressed in the heart. $\mathrm{J} \mathrm{Mol} \mathrm{Cell}$ Cardiol 1997;29:2095-2106.

7. Di Lisi R, Millino C, Calabria E, Altruda F, Schiaffino S, Ausoni S. Combinatorial cis-acting elements control tissue-specific activation of the cardiac troponin I gene in vitro and in vivo. $J$ Biol Chem 1998;273:25371-25380.

8. Doevendans PA. Cardiac specific gene expression of the regulatory myosin light chains. Thesis, Maastricht 1998.

9. Field LJ. Atrial natriuretic factor-SV40 $\mathrm{T}$ antigen transgenes produce tumors and cardiac arrhythmias in mice. Science 1988;2391029-33.

10. Fox N, Song M, Schrementi J, Sharp JD, White DL, Snyder DW, Hartley LW, Carlson DG, Bach NJ, Dillard RD, Draheim SE, Bobbitt JL, Fisher L, Mihelich ED. Transgenic model for the discovery of novel human secretory non-pancreatic phospholipase $\mathrm{A}_{2}$ inhibitors. Eur J Pharmacol 1996;308:195-203.

11. Grass DS, Felkner RH, Chiang MY, Wallace RE, Nevalainen TJ, Bennett CF, Swanson ME. Expression of human group II PLA $\mathrm{A}_{2}$ in transgenic mice results in epidermal hyperplasia in the absence of inflammatory infiltrate. J Clin Invest 1996;97:2233-2241.

12. Hammes A, Oberdorf-Maass S, Rother T, Nething K, Gollnick F, Linz KW, Meyer R, Hu K, Han $\mathrm{H}$, Gaudron P. Overexpression of the sarcolemmal calcium pump in the myocardium of transgenic rats. Circ Res 1998;83:877-88

13. Henderson SA, Spencer M, Sen A, Kumar C, Siddiqui MAQ, Chien KR. Structure, organization and expression of the rat cardiac myosin light chain-2 gene. J Biol Chem 1989;264:18142-18148.

14. Hunter JJ, Tanaka N, Rockman HA, Ross J Jr, Chien KR. Ventricular expression of a MLC-2vras fusion gene induces cardiac hypertrophy and selective diastolic dysfunction in transgenic mice. J Biol Chem 1995;270:23173-23178.

15. Kelly S, Alonso S, Tajbakhsh S, Cossu G, Buckingham M. Myosin light chain 3 F regulatory sequences confer regionalized cardiac and skeletal muscle expression in transgenic mice. $J$ Cell Biol 1995; 129:383-396.

16. Lee KJ, Hickey R, Zhu H, Chien KR. Positive regulatory elements (HF-la and HF-lb) and a novel negative regulatory element (HF-3) mediate ventricular muscle-specific expression of myosin light-chain 2-luciferase fusion genes in transgenic mice. Mol Cell Biol 1994;14:12201229.

17. Lee KJ, Ross RS, Rockman HA, Harris AN, O Brien TX, Van Bilsen M, Shubeita HE, Kandolf R, Brem G, Price J, Evans SM, Zhu H, Franz WM, Chien KR. Myosin light chain-2 luciferase transgenic mice reveal distinct regulatory programs for cardiac and skeletal muscle-specific expression of a single contractile protein gene. J Biol Chem 1992;267:15875-15885.

18. Lyons GE, Schiaffino S, Sassoon D, Barton P, Buckingham M. Developmental regulation of myosin gene expression in mouse cardiac muscle. J Cell Biol 1990;111:2427-2436. 
19. Molkentin JD, Jobe SM, Markham BE. $\alpha$-myosin heavy chain gene regulation: delineation and characterization of the cardiac muscle-specific enhancer and muscle-specific promoter. $J \mathrm{Mol}$ Cell Cardiol 1996;28:1211-1225.

20. Navankasattusas S, Sawadogo M, Van Bilsen M, Dang CV, Chien KR. The basic helix-loop-helix protein upstream stimulating factor regulates the cardiac ventricular myosin light-chain 2 gene via independent cis regulatory elements. Mol Cell Biol 1994;14:7331-7339.

21. Nevalainen TJ, Laine VJ, Grass DS. Expression of human group II phospholipase $A_{2}$ in transgenic mice. J Histochem Cytochem 1997;45:1109-1119.

22. O Brien TX, Lee KJ, Chien KR. Positional specification of ventricular myosin light chain 2 expression in the primitive murine heart tube. Proc Natl Acad Sci USA 1993;90:5157-5161.

23. Otani H, Prasad MR, Jones RM, Das DK. Mechanism of membrane phospholipid degradation in ischemic-reperfused rat hearts. Am J Physiol 1989;257:H252-H258.

24. Prasad MR, Lawrentiu MP, Moraru II, Liu X, Maity S, Engelman RM, Das DK. Role of phospholipase $A_{2}$ and $C$ in myocardial ischemic reperfusion injury. Am J Physiol 1991;260: H873-H877.

25. Ross RS, Navankasattusas S, Harvey RP, Chien KR. An HF-la/HF-1b/MEF-2 combinatorial element confers cardiac ventricular specificity and establishes an anterior-posterior gradient of expression. Development 1996;122:1799-1809.

26. Subramaniam A, Jones WK, Gulick J, Wert S, Neumann J, Robins J. Tissue-specific regulation of the $\alpha$-myosin heavy chain gene promoter in transgenic mice. J Biol Chem 1991;266:2461324620 .

27. Van der Vusse GJ, Reneman RS, Van Bilsen M. Accumulation of arachidonic acid in ischemic/reperfused cardiac tissue: possible causes and consequences. Prostaglandins Leukot Essent Fatty Acids 1997;57:85-93.

28. Van der Vusse GJ, Roemen THM, Prinzen FW, Coumans WA, Reneman RS. Uptake and tissue content of fatty acids in dog myocardium under normoxic and ischemic conditions. Circ Res 1982;50:538-546.

29. Van der Vusse GJ, Van Bilsen M, Reneman RS. Is phospholipid degradation a critical event in ischemia- and reperfusion-induced damage. NIPS 1989;4:49-53. 



\section{Chapter 10}

\section{General Discussion}


The central hypothesis of this study stated that type IIA secretory phospholipase $\mathrm{A}_{2}$ activity plays a role in ischemia and reperfusion-induced membrane phospholipid degradation, eventually leading to cardiac muscle cell injury and deterioration of cardiac function. To address this issue the presence and abundance of type IIA secretory phospholipase $A_{2}$ in the heart was established. Secondly, an ex vivo perfused, left ventricular ejecting mouse heart model was developed to specifically study ischemia/reperfusion related phenomena in this organ, puting placing emphasis on cardiac phospholipid metabolism. Thirdly, phospholipid homeostasis and cardiac ischemia tolerance were investigated in a mutant inbred mouse strain that lack type IIA secretory phospholipase $A_{2}$ to explore whether absence of this phospholipase isoform would attenuate ischemia and reperfusion-induced cardiac phospholipid degradation, cellular injury and functional deterioration. In addition, attempts were made to create transgenic mice overexpressing type IIA phospholipase $A_{2}$ in the heart to study the significance of increased phospholipase $\mathrm{A}_{2}$ activity on cardiac ischemia tolerance in this animal species.

\section{Ischemia/reperfusion-induced damage to the isolated mouse heart}

\section{Functional aspects}

To study ischemia/reperfusion-induced alterations in hemodynamic function, cardiac energy metabolism and lipid homeostasis in the isolated mouse heart, the assisted mode perfusion set-up, previously developed for the isolated rat heart, was downscaled to the level of the mouse heart. It was demonstrated in Chapter 5 that it is feasible to obtain hemodynamic values of the isolated working mouse heart that resemble findings of the anesthetized mouse heart in vivo (Lembo et al., 1996, Lorenz et al., 1997, Milano et al., 1994). The major improvement of the present model is that the impedance characteristics of the artificial outflow tract is matched with the in vivo outflow tract of the mouse heart so that physiologically relevent measurements are obtained. In this experimental model the hemodynamic function of the mouse heart is quite stable, as evidenced by minor changes in cardiac output over an extended period of time. The possibility to construct Frank-Starling curves (at different extracellular $\mathrm{Ca}^{2+}$ concentrations) makes this model suitable to properly evaluate cardiac function in transgenic or gene targeted models with deteriorated heart function or heart failure.

Isolated Swiss mouse hearts were found to be highly sensitive to an ischemic insult with a narrow time interval between almost complete hemodynamic recovery and severe impairment of functional recovery (Chapter 6). An ischemic period of $10 \mathrm{~min}$ resulted in hardly any impairment of function and only a limited degree of cellular injury following reperfusion. These findings indicate that this mouse heart preparation allows distinction between small differences in ischemia/reperfusion insults as far as functional and cell injury are concernes. This notion is substantiated by the finding that the myocardium of the IGF-1 heterozygous knockout mouse is more sensitive to ischemia and reperfusioninduced damage than the myocardium of wildtype mice following $15 \mathrm{~min}$ of global ischemia. When the ischemic period was extended by $5 \mathrm{~min}$ to $20 \mathrm{~min}$, however, the 
function of IGF-1 heterozygous knockout hearts were deteriorated to the same extent as those of wildtype littermates. Also, subtle differences in cardiac ischemia tolerance were observed between hearts derived from different mouse strains. Wildtype C57BL/6 hearts tolerated $15 \mathrm{~min}$ of ischemia substantially better (Chapter 8) than Swiss mouse hearts (Chapter 6). It is doubtful whether such subtle differences in ischemia tolerance would have been detected in the less physiological Langendorff perfused heart model, indicating the advantage of the present ejecting heart model. Collectively, these findings are in line with the notion of a relative susceptibility of the mouse heart to ischemia/reperfusion damage as compared to hearts derived from other species such as the rat (Headrick et al., 1998, De Groot et al., 1993).

As indicated by the observations in Chapter 8 , the model is also sufficiently sensitive to detect subtle differences in murine baseline systolic and diastolic cardiac function (i.e. before the ischemic insult) as a result of lowered levels of IGF-1 in a gene targeted mouse model and in different mouse strains. Hearts derived from Swiss mice (Chapter 5 and 6), C57BL/6 mice (Chapter 8) and 129/Sv mice (Chapter 7), mouse strains that are extensively used in cardiovascular studies, demonstrated some differences in baseline systolic function and contractility. More specifically, isolated C57BL/6 hearts displayed higher baseline values for systolic left ventricular pressure and contractility (Table II, Chapter 8 ) than hearts derived from Swiss (Table I, Chapter 5) and 129/Sv mice (Table II, Chapter 7). Using an isolated working mouse heart preparation, Hewett and colleagues demonstrated markedly elevated contractility in BALB/c and DBA mice, as compared to such strains as Swiss Webster, C57BL/6 and CD-1 (Hewett et al., 1994), resulting from higher levels of $\alpha$-skeletal actin in the BALB/c heart due to a duplication event in the promoter of the gene (Garner et al., 1986, Alonso et al., 1990). It can be concluded that the isolated ejecting mouse heart preparation may be of value in future studies to detect differences in cardiac hemodynamic function of various knockout and transgenic models.

\section{Lipid changes in the ischemic-reperfused mouse heart}

Disruption of the sarcolemma has been proposed as a critical event of ischemia/reperfusion-induced cellular injury (Jennings et al., 1986). The initial weakening of the plasma membrane may be related to several mechanisms. Impaired anchoring of the plasma membrane to the cytoskeleton and increased osmotic forces have been postulated to play a role in ischemia/reperfusion-induced weakening of the sarcolemma (Steenbergen et al., 1987). In addition, the $\mathrm{Ca}^{2+}$ induced loss of assymmetric bilayer behavior of phospholipid species, such as phosphatidylserine and phosphatidylethanolamine, leading to phase segregation and subsequent destabilization of the sarcolemma (Post et al., 1998, Musters et al., 1993, Post et al., 1995), and enhanced hydrolysis of membrane phospholipids due to activation of cardiac phospholipases $A_{2}$ (Van der Vusse et al., 1982, Chien et al., 1984, Prinzen et al., 1984, Das et al., 1986, Van Bilsen et al., 1989, Prasad et al., 1991) have also been proposed as alternative mechanisms. Irrespective of the mechanism, subsequent disruption of the sarcolemma, most probably caused by physical forces imposed on the cardiac myocyte (Jennings et al., 1986), leads to 
disruption of the weakened sarcolemma and release of cytoplasmic constituents, representing a hallmark of irreversible cell injury.

Exposure of Swiss mouse hearts to ischemia either or not followed by reperfusion did not lead to appreciable changes in the tissue content of phospholipids or triacylglycerols. However, an initial small but significant decrease in cardiac unesterified fatty acid content and shifts in the composition of the cardiac fatty acid pool relative to the pre-ischemic fatty acid pool were observed (Chapter 6). When the ischemic period was extended (i.e., $20 \mathrm{~min}$ ) the tissue fatty acid content started to rise. This increase in fatty acid content was accompanied by a significant increase in the amount of such (poly)-unsaturated fatty acids as arachidonic acid. Reperfusion was associated with a substantial rise in the cardiac fatty acid content, the absolute amount depending on the duration of the ischemic period. The relatively high contribution of poly-unsaturated fatty acid species, such as arachidonic acid and docosahexaenoic acid, to the (unesterified) fatty acid pool indicates a disbalance between the deacylation and reacylation rates of the cardiac membrane phospholipids during reperfusion. These findings are in line with earlier observations in the ischemic or reperfused canine heart (Van der Vusse et al., 1982, Prinzen et al., 1984, Chien et al., 1984) and rat heart (Van Bilsen et al., 1989) and support the notion that the underlying mechanisms of disturbances of cardiac membrane phospholipid homeostasis are similar in the mouse heart.

A linear correlation was found between post-ischemic tissue fatty acid accumulation on the one hand and the extent of irreversible cell injury, as assessed by the cumulative release of cytoplasmic enzymes or post-ischemic recovery of mechanical behavior as determined by the percentage recovery of cardiac output, on the other (Figure 8 in Chapter 6 and Figure 5 in Chapter 7). These findings suggest a close relation between membrane phospholipid degradation and loss of cellular integrity and, hence, mechanical recovery of the ischemic-reperfused myocardium. It should be noted that the elevation in post-ischemic fatty acid content, although substantial, still represents only about $2.5 \%$ of the total murine cardiac phospholipid content. At first glance this may be a discrepancy between the number of cells irreversibly damaged (about $10 \%$ following $20 \mathrm{~min}$ of global ischemia) and the amount of (unesterified) fatty acids accumulated. However, if the hydrolysis of membrane phospholipids is confined to a limited number of cells or only to phospholipids of the sarcolemma, which represent a small percentage of total phospholipids, cellular integrity might well be compromised by the observed extent of phospholipid degradation (Van der Vusse et al., 1989). It should be noted that the increased tissue arachidonic acid levels could also be a reflection of reduced reacylation activity of the post-ischemic heart (Van Bilsen et al., 1989). Collectively, these findings lend support to the notion that derangements in cardiac membrane phospholipid homeostasis, possibly mediated by the activation of cardiac phospholipases $\mathrm{A}_{2}$, is a causal factor in the transition from reversible to irreversible cellular damage following ischemia and reperfusion.

Since accumulation of polyunsaturated fatty acids in cardiac tissue reflects an imbalance between membrane phospholipid hydrolysis and resynthesis, it has been hypothesized that activation of phospholipase $A_{2}$ (relative to the activity of enzymes involved in phospholipid resynthesis) plays a major role in ischemia and 
reperfusion-induced net phospholipid degradation. Circumstantial evidence for the involvement of cardiac phopholipases $A_{2}$ in the loss of cellular integrity in the ischemic-reperfused myocardium is provided by the present findings in the more ischemia vulnerable, heterozygous IGF-1 knockout mouse. It was demonstrated that total post-ischemic cardiac arachidonic acid content correlated well with recovery of cardiac output and cellular viability in this mouse model, suggesting a relationship between ischemia tolerance and phospholipid homeostasis (Figure 5, Chapter 7). At present at least three different classes of phospholipase $A_{2}$ have been identified in cardiac tissue: (I) the small molecular mass type IIA and V secretory phospholipases $\mathrm{A}_{2}$; (II) the high molecular mass, type IV cytosolic phospholipase $\mathrm{A}_{2}$; and (III) the plasmalogen-specific type VI phospholipase $\mathrm{A}_{2}$ (Chen et al., 1994, De Windt et al., 1997, Larsson et al., 1998, Liu et al., 1998, Ma et al., 1999, Murakami et al., 1998, Pickard et al., 1999, Underwood et al., 1998).

\section{Type IIA secretory phospholipase $\mathbf{A}_{2}$}

Type IIA secretory phospholipase $\mathrm{A}_{2}$ was chosen as a likely candidate for cardiac ischemia and reperfusion-induced phospholipid degradation based on a number of earlier studies and its enzymatic characteristics. First, in the present study in mice it was demonstrated (Chapter 6) that like in the ischemic-reperfused rat heart (Van Bilsen et al., 1989b) not only arachidonic acid but also other (un)saturated fatty acid species accumulate during ischemia. This argues in favor of the aspecific type IIA secretory phospholipase $A_{2}$. Secondly, the observation that fatty acids continue to rise in the reperfusion phase points toward a role for type IIA secretory phospholipase $A_{2}$ in the process, since reperfusion is known to be accompanied by a substantial influx of calcium, potentially leading to the activation of the $\mathrm{Ca}^{2+}$ dependent type IIA secretory phospholipase $A_{2}$. Thirdly, pretreatment of isolated hearts with antibodies raised against a snake venom type II secretory phospholipase $\mathrm{A}_{2}$ effectively blocked the degradation of membrane phospholipids and mitigated the release of cytoplasmic proteins in the acute reperfusion phase (Prasad et al., 1991). Anti-type IIA secretory phospholipase $A_{2}$ antibodies were also found to decrease phospholipid degradation in homogenates of rat hearts that had been previously subjected to a period of hypoxia and reoxygenation (Kikuchi-Yanoshita et al., 1993). Fourthly, peroxidation of membrane phospholipids due to enhanced oxygen free radical production occurring during reperfusion (Myers et al., 1985), may also play a role, because peroxidation-damaged phospholipids are more vulnerable to type IIA secretory phospholipase $A_{2}$ attack (Dan et al., 1990). Finally, increased expression levels of type IIA secretory phospholipase $A_{2}$ have been found in rat brain after severe forebrain ischemia (Laurtizen et al., 1994) and in the rat small intestinal mucosa after ischemia and revascularization (Otamiri et al., 1987). On the basis of its $\mathrm{Ca}^{2+}$-sensitivity and the profile of fatty acids accumulating in ischemic/reperfused myocardium, it was proposed that type IIA secretory phospholipase $A_{2}$ is involved in phospholipid hydrolysis in the flow-deprived and reperfused heart. 
In this thesis the presence of type IIA secretory phospholipase $A_{2}$ in the myocardium was confirmed by cloning of its cDNA from a rat heart cDNA library and detection of its mRNA in cardiac tissue as well as isolated myocytes. The full length cDNA predicts a mature protein of 146 amino acids residues, including a typical $\mathrm{N}$-terminal stretch of 21 amino acid sequence representing a signal peptide for secretion. As such it resembles mammalian type IIA secretory phospholipases $\mathrm{A}_{2}$ present in other tissues. Analysis of the tissue distribution of type IIA secretory phospholipase $\mathrm{A}_{2}$ mRNA (Chapter 3 ) confirmed its ubiquitous presence (Ishizaki et al., 1989, Kennedy et al., 1995). The abundance of the transcript demonstrates large differences between the tissues examined, with the highest levels in rat ileum and relatively low levels in the myocardium, spleen and soleus muscle. Using primary cultures of rat neonatal ventricular cardiomyocytes it was further demonstrated that type IIA secretory phospholipase $A_{2}$ was stimulated at the level of gene transcription by pathophysiologically relevant stimuli such as TNF- $\alpha$ and phenylephrine. In this respect, it is of interest to note that in the infarcted human myocardium high levels of TNF- $\alpha$ have been reported (Maury et al., 1989), while $\alpha_{1}$-adrenergic stimulation of cardiomyocytes is associated with hypertrophic growth (Sadoshima and Izumo, 1997), suggesting a role for type IIA secretory phospholipase $A_{2}$ both in myocardial infarction and in the processes leading to cardiac hypertrophy and failure.

In the present study attempts were made to assess the protein levels of type IIA secretory phospholipase $A_{2}$ in various different tissues via Western blotting techniques. The enzyme was found to be below the detection level in cardiac tissue via regular immunoblotting techniques, in contrast to rat ileum and rat and human platelets in which the protein could be readily detected (Chapter 4 ). The presence of a $\mathrm{N}$-terminal signal peptide for secretion in the enzyme raises the possibility that type IIA secretory phospholipase $A_{2}$ exerts its (patho)physiological functions both intra- and extracellularly. Recent findings that components of the extracellular matrix bind to and influence type IIA secretory phospholipase $A_{2}$ activity are of interest and support the notion of an extracellular localization of this particular enzyme (Murakami et al., 1996, Romano et al., 1998). Whether type IIA secretory phospholipase $A_{2}$ is also secreted by cardiac myocytes and/or is localized on the extracellular side of the sarcolemma and what the physiological consequences might be of this observation remain to be determined.

\section{Ischemia and reperfusion-induced cardiac phospholipid degradation: involvement of type IIA secretory phospholipase $A_{2}$}

To address the issue whether (increased) phospholipase $\mathrm{A}_{2}$ activity in general is involved in the transition from reversible to irreversible cardiac cell injury and loss of cardiac function, attempts were made to create an animal model with a gain-offunction of type IIA secretory phospholipase $\mathrm{A}_{2}$ in the heart. Unfortunately, one transgenic line, in which type IIA secretory phospholipase was placed under control of the ventricular myosin light chain promoter, did not demonstrate transgene expression in the heart. In a follow-up approach to the latter attempt, a number of 
transgenic founders was produced by placing type IIA secretory phospholipase $A_{2}$ under control of the $\alpha$-myosin heavy chain promoter. Interestingly, one founder animal with a relatively high copy number died at young age, possibly indicating that high level cardiac overexpression of type IIA secretory phospholipase $\mathrm{A}_{2}$ might be lethal in the mouse. Future characterization of the remaining founders may result in transgenic lines with different levels of type IIA secretory phospholipase $A_{2}$ overexpression.

To more specifically investigate the role of type IIA secretory phospholipase $A_{2}$ in cardiac ischemia/reperfusion-induced damage, the ischemia tolerance of hearts from two closely related inbred mouse strains was investigated. No significant differences in post-ischemic tissue arachidonic acid or total fatty acid accumulation, ischemia/reperfusion-induced cellular injury or loss of cardiac function was observed between two $86 \%$ genetically identical inbred mouse strains, except for the fact that in one strain no functional type IIA secretory phospholipase $\mathrm{A}_{2}$ was present (Kennedy et al., 1997). These findings argue against a significant role for cardiac type IIA secretory phospholipase $A_{2}$ in sarcolemmal phospholipid degradation as observed during ischemia and reperfusion in the isolated heart. It should be noted that these findings do not exclude a role for e.g. circulating type IIA secretory phospholipase $A_{2}$ in sarcolemmal phospholipid degradation in the infarcted heart in vivo.

\section{Future directions}

It is becoming increasingly clear that ischemia and reperfusion-associated irreversible cell death is a multifactorial process including free radical generation, intracellular $\mathrm{Ca}^{2+}$ overload and alterations in the sarcolemmal composition. To more specifically define whether phospolipase $A_{2}$ mediated hydrolysis of (sarcolemmal) membrane phospholipids plays a crucial role in the sequence of events leading to ischemic cardiac cell death, a definition of the individual roles and interplay of the growing family of cardiac phospholipase $\mathrm{A}_{2}$ is needed. Knowledge about the significance of ischemia and reperfusion associated phospholipase $\mathrm{A}_{2}$-mediated cardiac cell damage could be of therapeutic significance, and might lead to application of specific pharmacological inhibition of ischemia and reperfusioninduced cellular injury. Regarding the finding that cellular type IIA secretory phospholipase $\mathrm{A}_{2}$ probably does not play a dominant, or rather a redundant, role in cardiac ischemia/reperfusion-induced cell death (Chapter 7), reconsideration of the pathophysiological roles of the other phospholipase $\mathrm{A}_{2}$ candidates is required.

A major future obstacle in defining the individual roles of cardiac phospholipases $\mathrm{A}_{2}$ is posed by the identification of novel members and isoforms of the (cardiac) phospholipase $A_{2}$ family in recent years. Currently several splice isoforms of type VI calcium-independent, plasmalogen-specific phospholipase $\mathrm{A}_{2}$ have been detected in cardiac muscle, human pancreatic islets and Chinese hamster ovary cells (Larsson et al., 1998, Liu et al., 1998, Ma et al., 1999). Calciumindependent phospholipases $\mathrm{A}_{2}$ have been reasoned to play dominant pathophysiological roles in cardiac muscle where contractions cause large 
fluctuations in calium concentrations, and, hence, the need exists to regulate phospholipase $\mathrm{A}_{2}$ activity via calcium-independent processes. Additionally, the family of calcium-dependent, arachidonoyl-specific type IV cytosolic phospholipase $A_{2}$ consists of at least three distinct members, one of which, type IV $\mathrm{CPLA}_{2}-\gamma$, was demonstrated to be abundantly present in heart and muscle in a membrane-bound state (Underwood et al., 1998, Pickard et al., 1999). Finally, the identification of the novel small molecular mass, $\mathrm{Ca}^{2+}$-dependent type $\mathrm{V}$ secretory phospholipase $\mathrm{A}_{2}$ with limited specificity towards fatty acids esterified at the $s n-2$ position of membrane phospholipids and functions redundant to type IIA secretory phospholipase $A_{2}$ remains an attractive candidate for ischemia/reperfusionassociated membrane phospholipid hydrolysis, especially as this type of phospholipase $A_{2}$ is abundantly present in the heart (Chen et al., 1994, Murakami et al., 1998). In this light, the recent findings of Murakami and colleagues demonstrating cross-talk between type IV cytosolic phospholipase $A_{2}$, on the one hand, and type IIA and type V secretory phospholipase $\mathrm{A}_{2}$, on the other, using cotransfection assays of several phospholipase $A_{2}$ families, are of interest. It was observed that $(I)$ type IV cytosolic phospholipase $\mathrm{A}_{2}$ was required for proper action of both type $\mathrm{V}$ and type IIA phospholipases $\mathrm{A}_{2}$, which act in a functionally redundant manner, and (II) that type IV cytosolic phospholipase $\mathrm{A}_{2}$ and type IIA and type $\mathrm{V}$ secretory phospholipases $\mathrm{A}_{2}$ cooperate in the generation of arachidonic acid metabolites (Murakami et al., 1998). Furthermore, studies in mice genetically deficient of type IV cytosolic phospholipase $\mathrm{A}_{2}$ demonstrated important roles for this enzyme in such processes as ischemia-induced cell death in the forebrain and asthmatic processes (Bonventre et al., 1997, Uozumi et al., 1997).

Future in vitro studies on cultured cardiomyocytes, using adenoviral overexpression and sense/antisense technologies of the various types of phospholipase $\mathrm{A}_{2}$ in combination with an in vitro hypoxia-reoxygenation model, should provide a means to investigate the individual role or potential cross-talk between the various phospholipase $A_{2}$ members. An advantage of adenoviral mediated gene transfer is that the low transfection efficiency of cultured cardiomyocytes can be circumvented. Such in vitro technologies provide a relatively less expensive and time consuming approach than the generation of genetically altered mouse models to obtain data in vitro regarding hypoxiareoxygenation-mediated irreversible cell injury. This model, however, would not provide relevant data on the hemodynamic consequences of ischemia and reperfusion-induced alterations in the whole organ. Future experimental efforts should also concentrate on testing the cardiac ischemic vulnerability of mice genetically engineered to overexpress type IIA or type V secretory phospholipase $\mathrm{A}_{2}$ in a cardiac-restricted manner (Chapter 9) using the ex vivo perfused mouse heart model as described in the present thesis. In addition, other transgenic mouse models of type IIA secretory phospholipase $A_{2}$ overexpression, albeit not in a cardiac-restricted manner (Grass et al., 1996, Nevelainen et al., 1997, Fox et al., 1996), and of the type IV cytosolic phospholipase $A_{2}$ deficient mouse model, could be tested in the isolated ejecting murine heart model to provide more insight into the significance of phospholipase $\mathrm{A}_{2}$-mediated membrane phospholipid hydrolysis during experimental ischemia and reperfusion and to determine the dominant 
phospholipase $A_{2}$ member(s) in this particular pathological process. The generation of mouse models with a gain-of-function and a loss-of-function of each of the cardiac phospholipase $A_{2}$ members and testing the ischemic tolerance of their hearts in e.g. an ex vivo perfusion setup as described in the present thesis will constitute an example of molecular physiological approaches that will give more insight into the pathophysiological processes in the heart. In either way, the mouse as a mammalian species, complex enough to give relevant information about human (patho)physiology but still allowing routine genetic manipulations, will be the future animal model of choice to obtain insight into role of the major players in ischemia/reperfusion-induced cardiac muscle injury.

\section{References}

1. Alonso S, Garner I, Vanderkerckhove J, Buckingham M. Genetic analysis of the interaction between cardiac and skeletal actin gene expression in striated muscle of the mouse. $J \mathrm{Mol}$ Biol 1990;211:727-738.

2. Berenbaum F, Thomas G, Poiraudeau S, Bereziat G, Corvol MT, Masliah J. Insulin-like growth factors counteract the effect of interleukin-1 beta on type II phospholipase $A_{2}$ expression and arachidonic acid release by rabbit articular chondrocytes. FEBS Lett 1994;340:51-55.

3. Bonventre JV, Huang Z, Taheri MR, O Leary E, Li E, Moskowitz MA, Sapirstein A. Reduced fertility and postischaemic brain injury in mice deficient in cytosolic phospholipase $\mathrm{A}_{2}$. Nature 1997;390:622-625.

4. Chen $\mathrm{Y}$ and Dennis EA. Expression and characterization of human group V phospholipase $\mathrm{A}_{2}$. Biochim Biophys Acta 1998;1394:57-64.

5. Chien KR, Han A, Sen A, Buja LM, Willerson JT: Accumulation of unesterified arachidonic acid in ischemic canine myocardium. Relationship to a phosphatidyl deacylation-reacylation cycle and the depletion of membrane phospholipids. Circ Res 1984;54:313-322.

6. Dan P, Ntzan DW, Dagan A, Ginsburg I, Yedgar S: $\mathrm{H}_{2} \mathrm{O}_{2}$ renders cells accesible to lysis by exogenous phospholipase $\mathrm{A}_{2}$ a novel mechanism for cell damage in inflammatory processes. FEBS Lett 1996;383:75-78,

7. Das DK, Engelman RM, Rousou JA, Breyer RH, Otani H, Lemeshow S. Role of membrane phospholipids in myocardial injury induced by ischemia and reperfusion. Am J Physiol 1986;251:H71-H79.

8. De Windt LJ, Willemsen PHM, P pping S, Van der Vusse GJ, Reneman RS, Van Bilsen M. Cloning and cellular distribution of a group II phospholipase $\mathrm{A}_{2}$ expressed in the heart. $\mathrm{J} \mathrm{Mol} \mathrm{Cell}$ Cardiol 1997;29:2093-2106.

9. Fox N, Song M, Schrementi J, Sharp JD, White DL, Snyder DW, Hartley LW, Carlson DG, Bach NJ, Dillard RD, Draheim SE, Bobbitt JL, Fisher L, Mihelich ED. Transgenic model for the discovery of novel human secretory non-pancreatic phospholipase $A_{2}$ inhibitors. Eur J Pharmacol 1996;308:195-203.

10. Garner I, Minty AJ, Alonso S, Barton PJ, Buckingham ME. A 5 duplication of the $\alpha$-cardiac actin gene in BALB/c mice is associated with abnormal levels of $\alpha$-cardiac and $\alpha$-skeletal actin mRNAs in adult cardiac tissue. EMBO $J$ 1986;5:2559-2567.

11. Grass DS, Felkner RH, Chiang MY, Wallace RE, Nevalainen TJ, Bennett CF, Swanson ME. Expression of human group II PLA 2 in transgenic mice results in epidermal hyperplasia in the absence of inflammatory infiltrate. J Clin Invest 1996;97:2233-2241.

12. Hewett TE, Grupp IL, Grupp G, Robbins J. $\alpha$-skeletal actin is associated with increased contractility in the mouse heart. Circ Res 1994;74:740-746.

13. Ishizaki J, Ohara O, Nakamura E, Tamaki M, Ono T, Yoshida N, Tereoka H, Tojo H, Okamoto M. cDNA cloning and sequence determination of rat membrane-associated phospholipase $\mathrm{A}_{2}$. Biochem Biophys Res Commun 1989;162:1030-1036. 
14. Jacques C, Bereziat G, Humbert L, Olivier J-L, Torvol M-T, Masliah J, Berenbaum F. Posttranscriptional effect of insulin-like growth factor- 1 on interleukin- $1 \beta$-induced type IIsecreted phospholipase $\mathrm{A}_{2}$ gene expression in rabbit articular chondrocytes. $J$ Clin Invest 1997; 99:1864-1872.

15. Jennings RB, Reimer KA, Steenbergen C. Myocardial ischemia revisited. The osmolar load, membrane damage and reperfusion. J Mol Cell Cardiol 1986;18:769-780.

16. Kennedy BP, Payette P, Mudgett J, Vadas P, Pruzanski W, Kwan M, Tang C, Rancourt DE, Cromlish W. A natural disruption of the secretory group II phospholipase $\mathrm{A}_{2}$ gene in inbred mouse strains. J Biol Chem 270;22378-22385, 1995.

17. Kennedy BP, Payette P, Mudgett J, Vadas P, Pruzanski W, Kwan M, Tang C, Rancourt DE, Cromlish W. A natural disruption of the secretory group II phospholipase $\mathrm{A}_{2}$ gene in inbred mouse strains. J Biol Chem 270;22378-22385, 1995.

18. Kennedy BP, Vadas P, Pruzanski W. Secretory PLA $\mathrm{A}_{2}$-deficient and transgenic mice in phospholipase $\mathrm{A}_{2}$ research. In: Phospholipase $\mathrm{A}_{2}$, basic and clinical aspects in inflammatory disease. Uhl W, Nevelainen TJ, Buchler MW, eds. Basel Karger 1997;24:65-71.

19. Kikuchi-Yanoshita R, Yanoshita R, Kudo I, Arai, H, Takamura T, Nokomoto K, Inoue K. Preferential hydrolysis of phosphatidylethanolamine in rat ischemic heart homogenates during in vitro incubation. J Biochem 1993;114:33-38.

20. Komada M, Kudo I, Inoue K. Structure of the gene coding for rat group II phospholipase $A_{2}$. Biochem Biophys Res Commun 1990;168:1059-1065.

21. Larsson PKA, Claesson H-E, Kennedy BP. Multiple splice variants of the human calciumindependent phospholipase $A_{2}$ and their effect on enzyme activity. $J$ Biol Chem 1998;273:207214.

22. Lauritzen I, Heurtaux C, Lazdunski M: Expression of group II PLA $A_{2}$ in rat brain after severe forebrain ischemia and in endotoxin shock. Brain Res 1994;651:353-356.

23. Lembo G, Rockman HA, Hunter JJ, Steinmetz H, Koch WJ, Ma L, Prinz MP, Ross J Jr, Chien KR, Powell-Braxton L. Elevated blood pressure and enhanced contractility in mice with severe IGF-1 deficiency. J Clin Invest 1996;98:2648-2655.

24. Li Q, Li, B, Wang X, Leri A, Jana KP, Liu Y, Kajstura J, Baserga R, Anversa P. Overexpression of insulin-like growth factor-1 in mice protects from myocyte death after infarction, attenuating ventricular dilatation, wall stress, and cardiac hypertrophy. J Clin Invest 1997;100:1991-1999.

25. Liu SJ, McHowat J. Stimulation of different phospholipase $A_{2}$ isoforms by TNF- $\alpha$ and IL-Ib in adult rat ventricular myocytes. Am J Physiol 1998;275:H1462-H1472.

26. Lorenz JN, Robbins J. Measurement of intraventricular pressure and cardiac performance in the intact closed-chest anesthetized mouse. Am J Physiol 1997;272:H1137-H1146.

27. Ma Z, Wang X, Nowatzke W, Ramanadham S, Turk J. Human pancreatic islets express mRNA species encoding two distinct catalytically active isoforms of group VI phospholipase $\mathrm{A}_{2}$ (iPLA $\mathrm{A}_{2}$ ) that arise from an exon-skipping mechanism of alternative splicing of the transcript from the iPLA $_{2}$ gene on chromosome 22q13.1. J Biol Chem 1999;274:9607-9616.

28. Maury CPJ, Teppo AM: Circulating tumor necrosis factor alpha (cachetin) in myocardial infarction. J Intern Med 1989;225:333-336.

29. Milano CA, Allen LF, Rockman HA, Dolber PC, McMinn TR, Chien KR, Johnson TD, Bond RA, Lefkowitz RJ. Enhanced myocardial function in transgenic mice overexpressing the b2adrenergic receptor. Science 1994;264:582-586.

30. Murakami M, Nakatani Y, Kudo I. Type II secretory phospholipase $\mathbf{A}_{2}$ associated with cell surfaces via C-terminal heparin-binding lysine residues augments stimulus-initiated delayed prostaglandin generation. J Biol Chem 1996;271:30041-30051.

31. Murakami M, Shimbara S, Kambe T, Kuwata H, Winstead MV, Tischfield JA, Kudo I. The function of five distinct mammalian phospholipase $\mathrm{A}_{2} \mathrm{~S}$ in regulating arachidonic acid release. $J$ Biol Chem 1998;273:14411-14423.

32. Musters RJP, Otten E, Biegelmann E, Bijvelt J, Keizer JJH, Post JA, Op den Kamp JAF, Verkleij AJ. Loss of phosphatidylethanolamine transbilayer assymmetry in the sarcolemma of the isolated neonatal rat cardiomyocyte during simulated ischemia. Circ Res 1993;73:514-523.

33. Myers ML, Bolli R, Lekich RF, Hartley CJ, Roberts R. Enhancement of recovery of myocardial function by oxygen free-radical scavengers after reversible regional ischemia. Circulation 1985;72:915-921. 
34. Nevalainen TJ, Laine VJ, Grass DS. Expression of human group II phospholipase $A_{2}$ in transgenic mice. J Histochem Cytochem 1997;45:1109-1119.

35. Otamiri T, Franzen L, Lindmark D, Tageson C: Increased phospholipase $A_{2}$ and decreased lysophospholipase activity in the small intestinal mucosa after ischemia and revasculariation. Gut 1987;28:1445-1453.

36. Pickard RT, Strifler BA, Kramer RM, Sharp JD. Molecular cloning of two new human paralogs of 85-kDa cytosolic phospholipase $A_{2}$. J Biol Chem 1999;274:8823-8831.

37. Post JA, Bijvelt JJM, Verkleij AJ. The role of phosphatidylethanolamine in sarcolemmal damage of cultured heart myocytes during simulated ischemia and metabolic inhibition. Am J Physiol 1995;268:H773-H780.

38. Post JA, Clague JR, Langer GA. Changes in sarcolemmal phospholipid assymmetry and Cafluxes upon metabolic inhibition of neonatal rat heart cells. Am J Physiol 1993;265:H461-H468.

39. Prasad MR, Lawrentiu MP, Moraru II, Liu X, Maity S, Engelman RM, Das DK: Role of phospholipase $\mathrm{A}_{2}$ and $\mathrm{C}$ in myocardial ischemic reperfusion injury. Am $\mathrm{J}$ Physiol 1991;260:H873-H877.

40. Prinzen FW, Van der Vusse GJ, Willemsen PHM, Coumans WA, Roemen THM, Reneman RS. Accumulation of nonesterified fatty acids in ischemic canine myocardium. Am J Physiol 1983;247: $\mathrm{H} 264-\mathrm{H} 272$.

41. Pruzanski W, Stefanski E, Vadas P, Kennedy BP, van den Bosch H. Regulation of the cellular expression of secretory and cytosolic phospholipases $A_{2}$, and cyclooxygenase- 2 by peptide growth factors. Biochim Biophys Acta 1998;1403:47-56.

42. Redealli G, Malhotra A, Li B, Li P, Sonnenblick EH, Hofmann PA, Anversa P. Effects of constitutive overexpression of insulin-like growth factor-1 on the mechanical characteristics and molecular properties of ventricular myocytes. Circ Res 1998;82:594-603.

43. Romano M, Romano E, Bjorkerud S, Hrt-Camejo E. Ultrastructural localization of secretory type II phospholipase $A_{2}$ in atherosclerotic and nonatherosclerotic regions of human arteries. Arterioscler Thromb Vasc Biol 1998; 18:519-525.

44. Sadoshima J, Izumo S. The cellular and molecular response of cardiac myocytes to mechanical stress. Anmu Rev Physiol 1997;59:551-571.

45. Steenbergen $\mathrm{C}$, Hill ML, Jennings RB. Cytoskeletal damage during myocardial ischemia: changes in vinculin immunofluorescence staining during total in vitro ischemia in canine heart. Circ Res 1987;60:476-486.

46. Underwood KW, Song C, Kriz RW, Chang XJ, Knopf JL, Lin L-L. A novel calcium-independent phospholipase $\mathrm{A}_{2}, \mathrm{cPLA}_{2}-\gamma$, that is prenylated and contains homology to $\mathrm{CPLA}_{2} . J$ Biol Chem 1998;273:21926-21932.

47. Uozumi N, Kume K, Nagase T, Nakatani N, Ishii S, Tashiro F, Komagata Y, Maki K, Ikuta K, Ouchi Y, Miyazaki J, Shimizu T. Role of cytosolic phospholipase $A_{2}$ in allergic response and parturition. Nature 1997;390:618-622.

48. Van Bilsen M, Van der Vusse GJ, Coumans WA, De Groot MJ, Willemsen PH, Reneman RS. Degradation of adenine nucleotides in ischemic and reperfused rat heart. Am J Physiol 1989a;257:H47-H54.

49. Van Bilsen M, Van der Vusse GJ, Willemsen PH, Coumans WA, Roemen TH, Reneman RS. Lipid alterations in isolated, working rat hearts during ischemia and reperfusion: its relation to myocardial damage. Circ Res 1989b;64:304-314.

50. Van Bilsen $M$, Van der Vusse GJ. Phospholipase $A_{2}$-dependent signalling in the heart. Cardiovasc Res 1995;30:518-529.

51. Van der Vusse GJ, Glatz JFC, Stam HCG, Reneman RS: Fatty acid homeostasis in the normoxic and ischemic heart. Physiol Rev 1992;72:881-940.

52. Van der Vusse GJ, Reneman RS, Van Bilsen M. Accumulation of arachidonic acid in ischemic/reperfused cardiac tissue: possible causes and consequences. Prostaglandins Leukot Essent Fatty Acids 1997; 57:85-93.

53. Van der Vusse GJ, Van Bilsen M, Reneman RS. Is phopholipid degradation a critical event in ischemia- and reperfusion-induced damage. NIPS 1989;4:49-53.

54. Van Schaick RHN, Verhoeven NM, Neijs FW, Aarsman AJ, Van den Bosch H. Cloning of the cDNA coding for $14 \mathrm{kDa}$ group II phospholipase $\mathrm{A}_{2}$ from rat liver. Biochem Biophys Res Commun 1991;1169:1-11. 


\section{Samenvatting}

In Hoofdstuk 1 worden de achtergrond en het doel van de huidige studie beschreven. Het hart is een holle spier die circa 70 mal per minuut samentrekt en daarmee het lichaam van bloed voorziet. Tijdens iedere contractie voorziet het hart zichzelf van zuurstof en voedingstoffen via de kransslagaderen. Tijdens een hartinfarct als gevolg van een vernauwing van een kransslagader of tijdens een kransslagader bypass operatie lijdt de hartspier onder een periode van zuurstoftekort (ischemie), wat kan leiden tot afsterving van de hartspiercellen. Herstel van de bloedtoevoer (reperfusie) kan slechts ten dele de afsterving van hartspiercellen voorkomen en in sommige gevallen zelfs het proces versterken. Dit fenomeen van ischemie en reperfusie geïnduceerde hartspiercelschade wordt ten dele veroorzaakt door veranderingen in de celmembraan, de natuurlijke barriëre van de hartspiercel. Uit experimentele studies is gebleken dat enzymatische afbraak van de belangrijkste componenten van de celmembraan, namelijk de fosfolipiden, mogelijk een belangrijke factor speelt in ischemie en reperfusie geïnduceerde celschade. Het lichaam bevat een familie van enzymen, fosfolipases $\mathrm{A}_{2}$ genaamd, die gespecialiseerd zijn in de afbraak van fosfolipiden en die verschillen in werking en lokalisatie. In het huidige proefschrift werd de rol van het type IIA secretoire fosfolipase $\mathrm{A}_{2}$ enzym (type IIA sPLA $\mathrm{A}_{2}$ ) nader onderzocht. In hoofdstuk 2 wordt ingegaan op de theoretische overwegingen voor de keuze van dit lid van de fosfolipase $\mathrm{A}_{2}$ familie. Het type IIA sPLA $\mathrm{A}_{2}$ werd gekozen op basis van zijn werkingsprofiel en omdat dit bepaalde enzym gevoelig is voor calcium, een mineraal dat in verhoogde concentratie voorkomt in het hart tijdens ischemie en reperfusie.

In hoofdstuk 3 werd via moleculair biologische technieken onderzocht of het type IIA sPLA $\mathrm{A}_{2}$ in het hart voorkomt. Daartoe werd het hart van de rat onderzocht op de aanwezigheid van de moleculaire voorloper van het enzym, het messenger RNA. Onderzoek wees uit dat het hart inderdaad het type IIA sPLA $\mathrm{A}_{2}$ messenger RNA bevat en dat de genetische code zeer sterk geconserveerd is vergeleken met diverse andere celtypen en diersoorten. Tevens bleek dat de hoeveelheid van het type IIA sPLA messenger RNA in het hart zeer gering zijn.

In hoofdstuk 4 werd de genetische code van het enzym zodanig aangepast dat het enzym in grote hoeveelheden in de $E$. Coli bacterie geproduceerd kon worden. Tegen dit recombinante type IIA PLA $_{2}$ enzym werden vervolgens in de konijn polyclonale antistoffen opgewekt. De mogelijkheid van deze antilichaam fractie om het type IIA sPLA 2 enzym aan te tonen werd getest naast andere antilichamen die waren opgewekt tegen andere typen fosfolipase $\mathrm{A}_{2}$. Al de geteste antilichamen bleken in meer of minder mate het type IIA sPLA ${ }_{2}$ enzym te herkennen in diverse celtypen en organen. Geen van de geteste antilichamen konden het type IIA sPLA $\mathrm{A}_{2}$ enzym in het hart echter aantonen, waaruit geconcludeerd kon worden dat dat dit enzym in geringe hoeveelheden in het hart voorkomt, aangezien de onderste detectiegrens van het meetsysteem niet overschreden werd.

Hoofdstuk 5 beschrijft de ontwikkeling van een geïsoleerd, met buffer geperfundeerd muizenhart model om de hemodynamische functie van het intacte hart in detail te bestuderen. Door speciale aandacht te besteden aan de aorta cannule, de temperatuur van het geïsoleerde hart en de samenstelling van de perfusiebuffer, bleek het mogelijk te zijn hemodynamische metingen te verrichten die vergelijkbare waarden opleverden met hartfunctiemetingen in de intacte, levende muis.

Dit model werd verder gebruikt in hoofdstuk 6 om de ischemie tolerantie van het muizenhart te testen. Door metingen te verichten aan de hoeveelheid intracellulaire eiwitten die verschijnen in de perfusiebuffer na een periode van ischemie, kon een schatting gemaakt worden van het percentage hartspiercellen dat onherstelbaar beschadigd was door de voorafgaande periode van ischemie. Ook werd na afloop van 
het experiment in het hart de stapeling gemeten van o.a. arachidonzuur, een meervoudig onverzadigd vetzuur dat vrijkomt bij de afbraak van membraanfosfolipiden tengevolge van fosfolipase $\mathrm{A}_{2}$ activiteit. Het bleek dat de afname in hemodynamische hartfunctie na een periode van ischemie gecorreleerd kon worden aan enerzijds het percentage beschadigde hartspiercellen en anderzijds aan de afbraak van membraan fosfolipiden. Ook wees deze studie uit dat al na een relatief korte periode van zuurstoftekort (circa 15 minuten) het muizenhart een sterke afname in hemodynamische functie vertoont, hetgeen duidt op een grote ischemie gevoeligheid van dit orgaan.

Verder werd in hoofdstuk 7 de ischemie tolerantie gemeten van harten die afkomstig waren van muizen die zodanig genetische gemodificeerd waren dat ze verminderde hoeveelheden van de groeifactor insulin-like growth factor-1 (IGF-1) bevatten. Eerdere experimentele studies hebben uitgewzen dat IGF-1 een protectief effect heeft op het hart na een periode van zuurstoftekort. De verwachting is dat harten met een verminderde hoeveelheid IGF-1 gevoeliger zouden zijn voor een periode van zuurstoftekort. De harten van IGF-1 deficiënte muizen bleken inderdaad na een periode van ischemie en reperfusie slechter hemodynamisch te herstellen, en verhoogde celschade en grotere stapeling van vrij arachidonzuur in het hart te vertonen. Deze bevindingen tonen aan dat het model ontwikkeld en beschreven in hoofdstuk 5 en 6 inderdaad gevoelig genoeg is om subtiele verschillen in ischemie tolerantie aan te tonen van het geïsoleerde, intacte hart. Verder toont deze studie aan dat fosfolipase $\mathrm{A}_{2}$ gemedieerde afbraak van celmembranen van de hartspiercel mogelijk een rol kan spelen in ischemie en reperfusie geïnduceerde harspiercelschade in de IGF-1 deficiente muis.

Om de mogelijke rol van het type IIA sPLA te testen in ischemie en reperfusie geïnduceerde afbraak van celmembranen, werd in hoofdstuk 8 de ischemie tolerantie getest van muizen die een chromosomale mutatie bevatten in de genetische code voor het type IIA sPLA . Deze muizenstam bevat als gevolg van deze mutatie geen type IIA sPLA $A_{2}$ in het hart. De ischemie tolerantie van harten van deze mutante muizenstam werd vergeleken met die van een nauw verwante muizenstam die normale hoeveelheden type IIA sPLA ${ }_{2}$ in het hart bevat. Interessant genoeg werden geen verschillen gevonden in arachidonzuur stapeling in het hart, de hoeveelheid celschade of de afname in hemodynamische functie na een periode van ischemie gevolgd door reperfusie. Deze bevindingen tonen aan dat het type IIA sPLA $\mathrm{A}_{2}$ in het geïsoleerde muizenhart zeer waarschijnlijk geen dominante rol speelt in ischemie en reperfusie gemedieerde afbraak van celmembranen en dat andere leden van de fosfolipase $A_{2}$ familie mogelijk een belangrijkere rol in dit fenomeen vervullen.

Om meer inzicht te verkrijgen in de rol van fosfolipase $A_{2}$ aktiviteit op zich in ischemie en reperfusie geassociëerde membraanafbraak in het hart, werden in hoofdstuk 9 pogingen ondernomen om een transgeen muismodel te crëeren, dat zodanig genetisch gemodificeerd was dat het hart meer fosfolipase $A_{2}$ bevat. Dit resulteerde in een transgene muizenstam die weliswaar meer kopiën van het gen voor fosfolipase $A_{2}$, maar geen aantoonbare hogere hoeveelheden fosfolipase $A_{2}$ in het hart bevatte. Een vervolgpoging werd gedaan met andere DNA konstrukten en verscheidene transgene muizen werden gecrëerd die meerdere kopiëen van het fosfolipase $A_{2}$ gen bevatten. Eén van de transgene muizen die een groot aantal kopiën bevatte stierf snel na geboorte, wat mogelijk inhoudt dat grote hoeveelheden fosfolipase $\mathrm{A}_{2}$ niet verenigbaar zijn met normale hartfunctie. De beschikbaarheid van muismodellen met grotere of verminderde hoeveelheden fosfolipase $\mathrm{A}_{2}$ in het hart, in combinatie met een geïsoleerd muizenhartmodel om de ischemie tolerantie van het hart van genetisch gemodificeerde muizen te testen, kan in toekomstige studies uitwijzen welk lid van de fosfolipase $A_{2}$ familie een dominante rol speelt in ischemie en reperfusie geïnduceerde hartspierschade. 


\section{Summary}

In chapter 1 the background to the present thesis and the general aim of our study are presented. The heart is a muscle that contracts approximately 70 times per minute and supplies the body with blood. During each contraction the heart supplies itself with oxygen and nutrients through the coronary arteries. During a myocardial infarction as a result of an occlusion of coronary arteries or during aorta-coronary bypass surgery, the heart is temporarily devoid of oxygen (ischemia), what eventually leads to cardiac muscle cell death. Restoration of the cardiac blood supply (reperfusion) is only partially able to reduce cardiac cell death and may even exacerbate the injuring process. This phenomenon of ischemia and reperfusion induced cardiac muscle cell death is partially caused by a disruption of the cellular membrane, which forms the natural barier of the cardiac cell. Experimental studies have indicated that enzymatic breakdown of the major components of the cellular membrane, the phospholipids, might play an important role in the transition from ischemia and reperfusion induced reversible to ireversible cell damage, eventually leading to cardiac dysfunction. Our body contains a family of enzymes, phospholipases $\mathrm{A}_{2}$, which are specialized in hydrolyzing membrane phopholipids and differ amongst each other in their activation profile and subcellular localization. In the present thesis the role of one particular member of this family, type IIA secretory phospholipase $\mathrm{A}_{2}$ (type IIA sPLA $\mathrm{A}_{2}$ ) in ischemia and reperfusion induced cell damage was investigated in more detail. Chapter 2 presents a review of literature and theoretical background of the rationale behind the choice for this particular enzyme. In brief, type IIA sPLA ${ }_{2}$ was chosen on the basis of its activation profile and its dependency on calcium, a mineral the intracellular level of which is increased during cardiac ischemia and reperfusion.

In chapter 3 it was investigated whether type IIA sPLA $\mathrm{A}_{2}$ is present in the heart using molecular biological techniques. To this end, the rat heart was investigated for the presence of the messenger RNA of type IIA sPLA $\mathrm{A}_{2}$, the molecular precursor of the protein itself. It was demonstrated that the heart indeed contains this messenger RNA and that the genetic code of cardiac type IIA sPLA $\mathrm{A}_{2}$ was highly conserved amongst different species and cell types. It was also demonstrated that the amount of type IIA sPLA messenger RNA is very low in the heart.

In chapter 4 high amounts of recombinant type IIA sPLA 2 were produced and purified from the $E$. Coli bacteria. Against this purified enzyme polyclonal antibodies were produced in the rabbit and used to detect type IIA sPLA protein in different tissues. The ability of the latter antibody to detect type IIA sPLA $\mathrm{P}_{2}$ was compared with four other antiphospholipase $A_{2}$ antibodies. It was found that all antibodies were able to detect the enzyme with different sensitivity. None of the antibodies, however, were able to detect the enzyme in cardiac tissue, providing further indication that the protein level of type IIA sPLA $\mathrm{A}_{2}$ is very low in cardiac muscle.

Chapter $\mathbf{5}$ describes the development and characterization of an isolated, buffer perfused mouse heart model to measure hemodynamic cardiac function devoid of neurohumoral stimulation. By paying special attention to the artificial aortic outflow tract, the temperature of the isolated heart and the composition of the perfusion buffer, it was found that this model was able to sensitively monitor hemodynamic function, that resembled cardiac function of the mouse heart in vivo.

This model was subsequently used in chapter 6 to study ischemia and reperfusion phenomena in the mouse heart. By measuring the leakage of intracellular enzymes into the coronary outflow an estimate could be obtained of the percentage cells irreversibly damaged during the preceding ischemic period. Biochemical analysis of cardiac tissue after experimentation allowed measurements of the accumulation of unesterified fatty acids such as arachidonic acid, which is a sensitive marker for phospholipase $A_{2}$ activity. A strong 
correlation was found between the tissue accumulation of arachidonic acid on the one hand and the percentage irreversibly damaged cardiac cells or the post-ischemic recovery of hemodynamic function on the other. In addition, it was found that the mouse heart shows a relatively high sensitivity towards global ischemia and reperfusion.

This model was subsequently used in chapter 7 to measure the ischemia tolerance of hearts derived from mice that were genetically engineered to contain less insulin-like growth factor-1 (IGF-1) in their bodies. Previous studies provide evidence that IGF-1 has a potent protective effect on the cardiac muscle during ischemia and reperfusion. As such, IGF-1 deficient hearts would be expected to be more vulnerable towards ischemia and reperfusion induced damage. IGF-1 deficient hearts subjected to a period of ischemia followed by reperfusion indeed demonstrated a significant increase in cellular damage, lower hemodynamic recovery and increased accumulation of unesterified fatty acids, such as arachidonic acid. These findings provided further indications that the model described in chapter 5 and 6 was sensitive enough to detect subtle differences in ischemia tolerance of isolated mouse hearts. In addition, these observations further point toward a possible role of phospholipase $\mathrm{A}_{2}$-mediated hydrolysis of membrane phospholipids in the suequela of events leading to cardiac ischemia and reperfusion induced cell death.

To study the possible role of type IIA sPLA $\mathrm{S}_{2}$ in cardiac ischemia and reperfusioninduced membrane damage and cell death, in chapter $\mathbf{8}$ the ischemia tolerance was tested of hearts derived from mice with a chromosomal mutation in the gene of type IIA sPLA 2 . As a result of the mutation this mouse strain is unable to produce the type IIA sPLA 2 enzyme in the heart. The ischemia tolerance of mutant mouse hearts was compared with hearts derived from a mouse strain that was closely related but did not contain the mutation, and, hence,

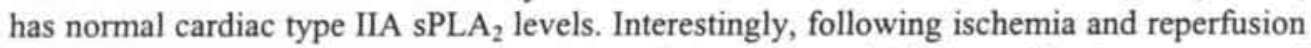
no differences were found in the accumulation of arachidonic acid, the amount of irreversible cell damage or recovery of hemodynamic function. These findings indicate that type IIA sPLA 2 activity most probably is not a major factor in cardiac ischemia and reperfusion-induced membrane damage in the isolated mouse heart and that other members of the phospholipase $A_{2}$ family may have more dominant roles in this phenomenon.

To gain more insight in the role of phospholipase $A_{2}$ activity during cardiac ischemia and reperfusion, attempts were made in chapter 9 to create a transgenic mouse model that was genetically modified to contain increased type IIA secretory phospholipase $\mathrm{A}_{2}$ activity in the heart. This resulted in a transgenic mouse strain that contained more copies of the phospholipase $\mathrm{A}_{2}$ gene in its chromosomes, but did not demonstrate a detectable increase in the amount of the enzym. In a follow up experiment other DNA constructs were used and multiple transgenic mice were obtained. Interestingly, one mouse that contained a high number of copies of the phospholipase $\mathrm{A}_{2}$ gene died soon after birth, possibly indicating that large quantities of phospholipase $\mathrm{A}_{2}$ may not be compatible with normal cardiac function. The availability of genetically engineered mice containing either more or less of the different members of the phospholipase $A_{2}$ in the heart, in combination with an isolated mouse heart model to test the cardiac ischemia tolerance, may indicate in the future whether or not phospholipase $\mathrm{A}_{2}$ mediated membrane hydrolysis plays a role in the transition of reversible to irreversible cardiac myocyte injury and which of the members of the phospholipase $\mathrm{A}_{2}$ family plays a dominant role in this process. 


\section{Dankwoord}

Op de allereerste plaats wil ik mijn co-promotor en dagelijkse begeleider Marc van Bilsen bedanken voor zijn geduld, steun en enthusiaste begeleiding in de afgelopen vijf jaar. Marc heeft mij de beginselen geleerd van het correct en nauwkeurig uitvoeren van de wetenschap, vanaf de planning van een experiment aan de labtafel tot aan het correct verwoorden van de resultaten op papier. Verder heeft Marc mij doen inzien dat de toekomstige wetenschapper beter gebaat is bij een opleiding in de breedte dan in de diepte en op deze wijze fungeert Marc nog altijd als een voorbeeld wetenschapper voor mij. Marc, bedankt voor alles!

Ger van der Vusse speelde gedurende het verloop van het promotie onderzoek een steeds prominenter rol in mijn opleiding en ik kan met plezier terugkijken op de vrolijke en persoonlijke omgang met Ger. Ger's inzicht in de fysiologie en vetzuurhomeostase van het hart is ronduit fenomenaal te noemen en ik denk dat nog vele aio's na mij daar profijt van zullen hebben. Ger, bedankt voor een gedegen opleiding en een fijne tijd.

De korte momenten in het gezelschap van Rob Reneman waren altijd gezellig en leerzaam en in retrospect besef ik dat de invloed van Rob altijd van doorslaggevend belang was, van de laatste correcties van manuscripten tot aan de belangrijke telefoontjes en brieven. Ik denk dan ook dat wetenschappelijk Nederland zich mag koesteren in een persoon als Rob. Ook u (ik kan nog altijd geen "jij" zeggen), heel hartelijk bedankt voor alles!

Jodil Willems heeft een groot deel van de experimentele kant van dit proefschrift mogelijk gemaakt en in die zin hoop ik, Jodil, dat je dit proefschrift een klein beetje beschouwt als het het jouwe! Jodil's behendigheid met de levende en de computermuis is bewonderingswaardig en doet me nog altijd afvragen of hier een genetische component achter zit.

Peter Willemsen, Will Coumans en Theo Roemen hebben een belangrijke experimentele bijgedrage geleverd aan het tot stand komen van dit "boekje". Ook jullie, heel hartelijk bedankt! De intellectuele en experimentele inbreng van Michaël(is) "Menten" Vork waren zeer behulpzaam en zijn grappen maakten van elke dag een vrolijke. Speciale dank verdienen natuurlijk mijn vriend en mede-Tilbo "Ome Adje" van Gorp, Richard Cornelussen en Ronnie Bronsaer. Het feit dat laatste twee geboren en getogen Maastrichtenaren zijn vind ik nu niet (zo) erg meer. Pieter Doevendans zorgden voor een gezellige sfeer op het lab en benadrukte dat ik de klinische relevantie van wetenschappelijk onderzoek niet uit het oog mag verliezen. Verder wilde ik mijn ex-collega's van de afdeling Fysiologie bedanken voor de prettige sfeer en vrolijke omgang.

De mensen die een speciale dank verdien in mij persoonlijke leven zijn mijn zusjes Jacqueline en Eveline de Windt en mijn vriend Mohammed Lazaar. Het feit dat laatste twee als paranimf wilden fungeren kan als symbolisch gezien worden. Ook wilde ik hier mijn automonteur Eric Gommers hier speciaal bedanken voor het rijdend houden van mijn "vieze ouwe auto's".

En aan mijn vrouw Diana: Dushi, sorry ku mi a traha asina duru durante e lastu dos aña y masha danki pa bo pasenshi ku mi i mi trabou. Mi stimabo pa bo apoyo i pasenshi. Mi ta spera un dia nos yu muhe Aïsha lo kompronde ku mi tambe a traha asina duru pe i ku bosonan ta orguyoso ku bosonan tata i kasá.

En tot slot wilde ik eindigen met waar alles begon: mijn ouders. $\mathrm{Pa}$ en $\mathrm{Ma}$, jullie steun, liefde en "duwtjes in de rug" hebben dit werk en mijn opleiding werkelijk mogelijk gemaakt en daarom is dit werk dan ook aan jullie opgedragen. Ik hoop dat jullie er trots op zijn! 


\section{Curriculum vitae}

September 1988 - April 1994

April 1994 - August 1998

August 1998 - current
Undergraduate studies Biology,

University of Utrecht.

Graduate studies

Department of Physiology,

Cardiovascular Research Institute Maastricht, University of Maastricht.

Sponsored by grant from the Netherlands Foundation of Scientific Research (NWO)

Postdoctoral Fellowship,

Division of Molecular Cardiovascular Biology,

Department of Pediatrics,

Children's Hospital Medical Center, Cincinnati,

USA.

Sponsored by American Heart Association

postdoctoral grant.

\section{List of Publications}

\section{Papers}

1. De Windt LJ, Pöpping S, Willemsen PHM, Reneman RS, Van der Vusse GJ, Van Bilsen M. Cloning and cellular distribution of a group II phospholipase $\mathrm{A}_{2}$ expressed in the heart. J Mol Cell Cardiol 1997;29:2095-2106.

2. De Windt LJ, Reneman RS, Van der Vusse GJ, Van Bilsen M. Phospholipase $\mathbf{A}_{2}$ mediated hydrolysis of cardiac phospholipids: the use of molecular and transgenic techniques. Mol Cell Biochem 1998;180:65-73.

3. De Windt LJ, Wilde AAM, Doevendans PA. Animal models in molecular cardiovascular research. Cardiologie 1998;4:132-141.

4. Bronsaer RJP, De Windt LJ, Doevendans PA. Calcium in het hart. Hartbulletin 1998;29:62-65.

5. Van der Vusse GJ, De Windt LJ, Jans SWS, Reneman RS, Van Bilsen M. Potential role of phospholipase $\mathrm{A}_{2}$ in the normoxic, ischemic and reperfused heart. In: Protection against ischemia/reperfusion damage of the heart. Eds: Abiko Y and Karmazyn M. Springer, Berlin 1998 (Bookchapter).

6. De Windt LJ, Willems J, Arts T, Reneman RS, Van der Vusse GJ, Van Bilsen M. An improved isolated, left ventricular ejecting, murine heart model. Functional and metabolic evaluation. Eur J Physiol (Pflügers Archiv) 1999;437:182-190.

7. De Windt LJ, Lim HW, Wencker D, Kitsis RN, Condorelli G, Dorn GW II, Molkentin JD. Calcineurin mediated hypertrophy protects against apoptosis in vitro and in vivo: an apoptosis independent model of dilated cardiomyopathy. Accepted Circ Res. 
8. Lim HW, De Windt LJ, Steinberg L, Taigen T, Witt SA, Kimball TR, Molkentin J. Calcineurin expression, activation, and function in cardiac pressure overload hypertrophy. Accepted Circulation.

9. Taigen T, De Windt LJ, Lim HW, Molkentin JD. Targeted inhibition of calcineurin prevents agonist induced cardiomyocyte hypertrophy. Accepted Proc Natl Acad Sci USA.

10. Lim HW, Mante J, Kimball TR, Witt SA, De Windt LJ, Sussman MA, Molkentin JD. Reversal of cardiac hypertrophy in transgenic disease models by calcineurin inhibition. Accepted J Mol Cell Cardiol.

11. De Windt LJ, Lim HW, JD Molkentin. Calcineurin activates PKC and c-Jun $\mathrm{NH}_{2}$ terminal kinase in the heart. Evidence for crosstalk between intracellular hypertrophic signaling pathways. Submitted J Biol Chem.

12. De Windt LJ, Willems J, Coumans WA, Roemen THM, Reneman RS, Van der Vusse GJ, Van Bilsen M. Assesment of ischemia tolerance of the isolated left ventricular ejecting mouse heart: Functional and biochemical correlates. Submitted Am J Physiol.

13. De Windt LJ, Willems J, Coumans WA, Roemen THM, Reneman RS, Van der Vusse GJ, Van Bilsen M. Type IIA secretory phospholipase $A_{2}$ deficiency fails to attenuate cardiomyocyte damage in the ischemic-reperfused mouse heart. Submitted Am J Physiol.

14. De Windt LJ, Molkentin JD, Doevendans PA. Mouse models of human heart disease: potential for gene discovery arrays. Submitted Eur Heart J.

\section{Abstracts}

1. De Windt LJ, Van Bilsen M, Van der Vusse GJ, Reneman RS. Cloning and sequence determination of rat heart membrane associated low molecular weight phospholipase A2. Eur J Physiol (Pflügers Archiv) 1996;430:R21 (Abstract).

2. De Windt LJ, Van Bilsen Van der Vusse GJ, Reneman RS. Cloning and cellular distribution of a group II phospholipase $\mathrm{A}_{2}$ expressed in the heart. $\mathrm{J} \mathrm{Mol} \mathrm{Cell}$ Cardiol 1996;28:A193 (Abstract).

3. De Windt LJ, Willems J, Van der Vusse GJ, Reneman RS, Van Bilsen M. Ischemia-reperfusion induced damage in the isolated left ventricular ejecting mouse heart. Faseb J 1998;12:A75 (Abstract).

4. Lim HW, De Windt LJ, Molkentin JD. Calcineurin and cardiac hypertrophy. J Mol Cell Cardiol 1999;43:A73 (Abstract).

5. De Windt LJ, Lim HW, Wencker D, Kitsis RN, Condorelli G, Molkentin JD. Calcineurin mediated hypertrophy protects against apoptosis in vitro and in vivo. Presented at AHA conference of Molecular and Physiological Aspects of the Failing Heart (Salt Lake City 1999). 




